\title{
SET TIME CONTROL STUDIES OF POLYMER CONCRETE
}

Robert G. Mathey* James M. Pommersheim**

* U.S. DEPARTMENT OF COMMERCE National Institute of Standards and Technology Natlonal Engineering Laboratory Center for Bullding Technology Galthersburg, MD 20899

* *Bucknell Universlty Department of Chemical Engineering Lewlsburg, PA 17837
U.S. DEPARTMENT OF COMMERCE Robert A. Mosbacher, Secretary NATIONAL INSTITUTE OF STANDARDS AND TECHNOLOGY

Raymond G. Kammer, Acting Director

QQC 


\section{NATIONAL INSTITUTE OF STANDARDS \& TECHNOLOGY Research Information Center Gaithersburg, MD 20899}

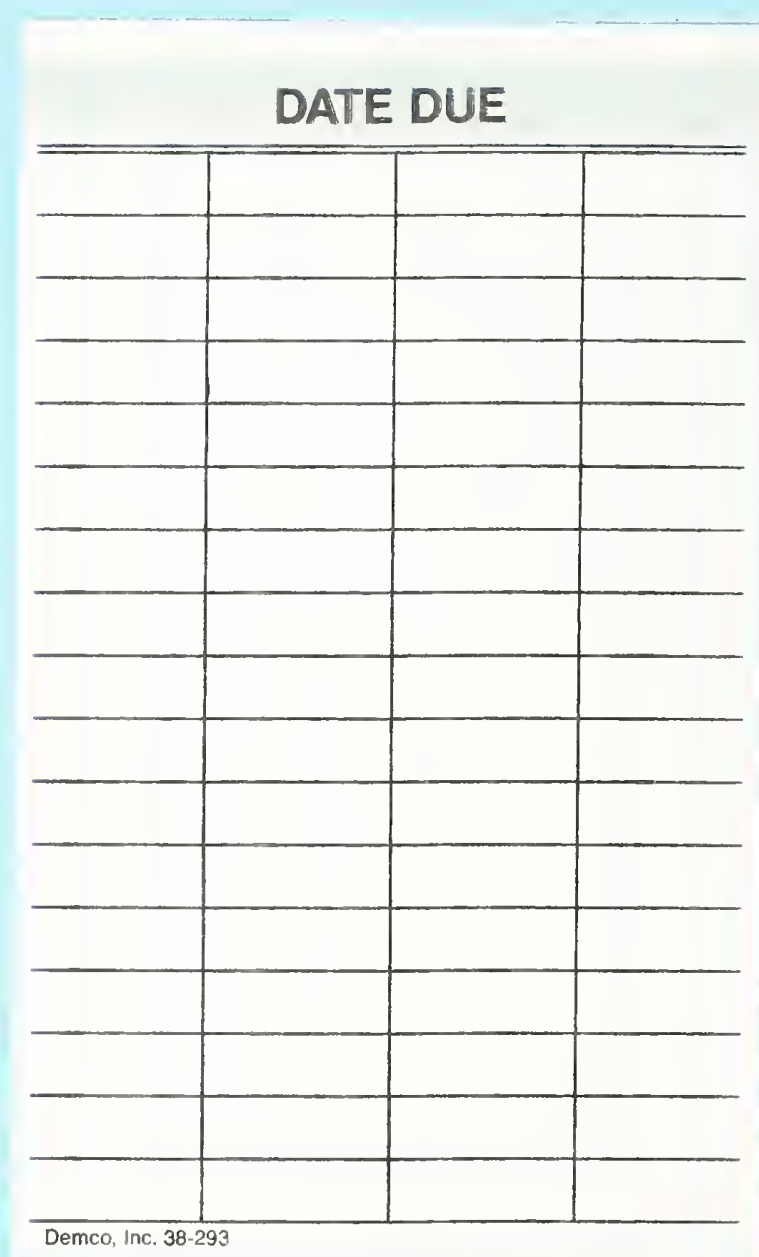


NISTC

QC100

- U56

no. 89-4026

1989

C. 2

\section{STUDIES OF}

POLYMER

CONCRETE

\section{Robert G. Mathey*}

James M. Pommersheim**

* U.S. DEPARTMENT OF COMMERCE Natlonal Instltute of Standards and Tochnology Natlonal Engineoring Laboratory Conter for Bullding Technology

Galthersburg, MD 20899

* * Bucknell Unlversity Department of Chemlcal Englneerlng Lowlsburg, PA 17837

Prepared for:

Alr Force Englneerlng and Servlces Center Tyndall Alr Force Base, FL 32403-8001

September 1989

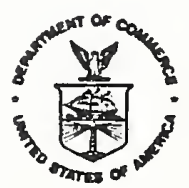

U.S. DEPARTMENT OF COMMERCE Robert A. Mosbacher, Secretary NATIONAL INSTITUTE OF STANDARDS AND TECHNOLOQY

Raymond O. Kammer, Acting Director 


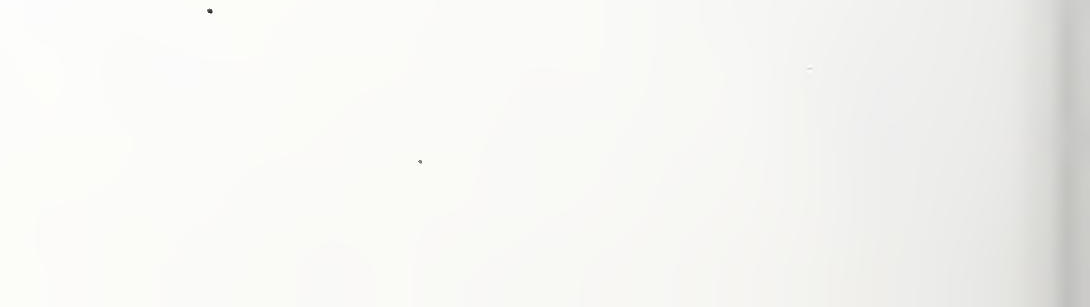




\begin{abstract}
Set time data were obtained for polymer concrete made with a proprietary polyurethane resin for a wide range of aggregate and resin temperatures. Catalyst concentrations were adjusted so that setting occurred within a required time range. The effects of the presence of water and ice on set time were also studied. Set time data were also obtained from pilot tests using another polyurethane and catalyst for various aggregate and resin temperatures and moisture conditions. Considerably more catalyst was required in the pilot tests to obtain comparable set times. The impact of temperature variations on flexural strength was investigated. The flexural strength and failure mechanism at early ages depended on the temperature of aggregate and resin at the time of casting the polymer concrete.
\end{abstract}

A model for the prediction of set time of polymer concrete was developed based upon thermodynamic and kinetic principles. The model parameters were determined experimentally from auxiliary laboratory tests conducted separately from the set time tests. Reasonable agreement was found between the model and the data from the set time tests since observed set times and resin temperatures generally agreed with those predicted by the model. Using the model, a series of design charts were prepared which can be used to predict set time when catalyst concentration and initial aggregate and resin temperatures are given, or to 
determine the catalyst concentration needed to assure set time corresponding to specified aggregate and resin temperatures.

Key Words: aggregate; flexural strength; heat transfer;model;peak exotherm; polymer concrete;polyurethane;rapid repair;set time;set time prediction model. 


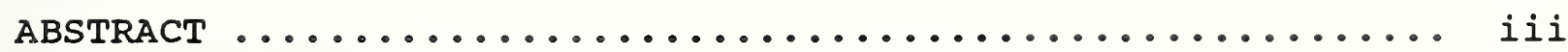

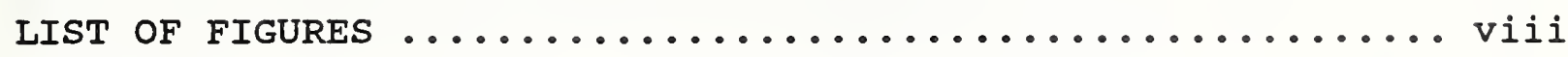

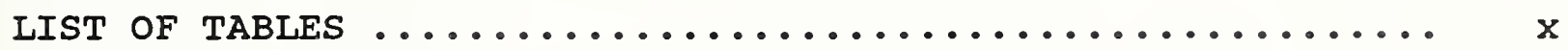

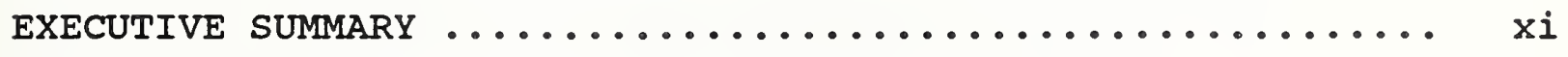

1. INTRODUCTION ................................ 1

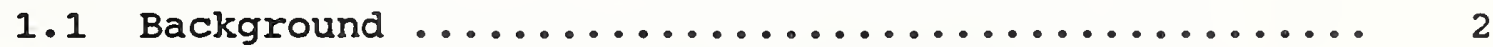

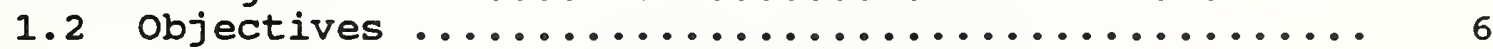

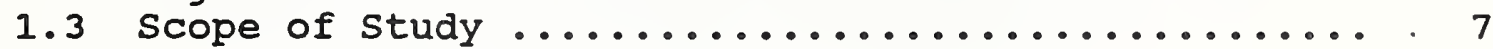

2. LABORATORY TESTS ............................... 9

2.1 Materials .............................. 10

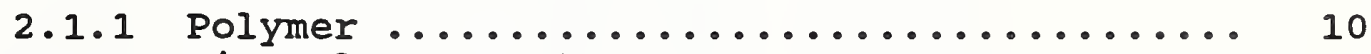

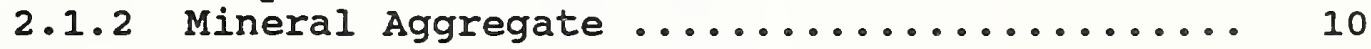

2.2 Test Procedures ......................... 11

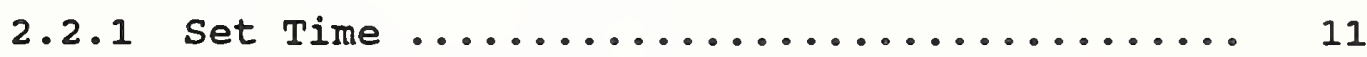

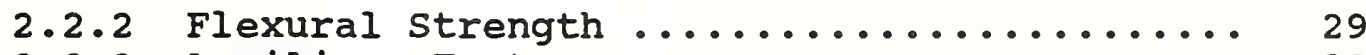

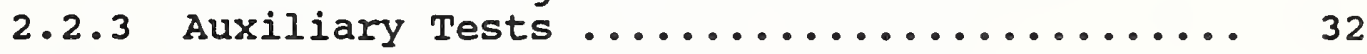

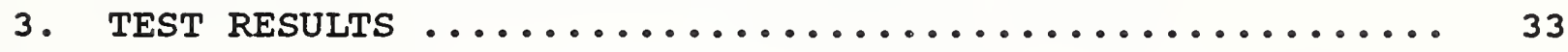

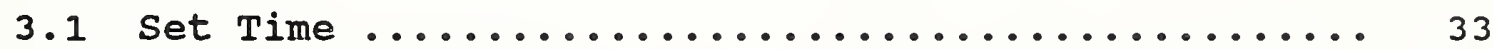

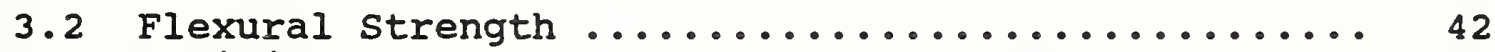

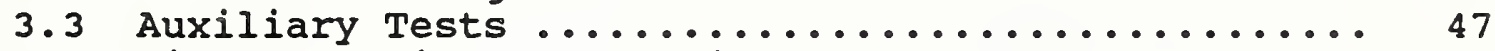

3.4 Pilot Set Time Tests Using Another Polyurethane

Resin ................................ 48

4. SET TIME PREDICTION MODEL FOR POLYMER CONCRETE ....... 52

4.1 Conceptual Model ........................ 55

4.1.1 Heat Transfer Mechanisms .............. 55

4.1 .2 Reaction Mechanisms ................. 57

4.2 Mathematical Model ....................... 61

4.2.1 Energy Balance: Dry Aggregate .......... 61

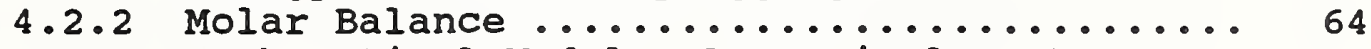

4.2.3 Mathematical Model: Demensionless Form ... 65

4.3 Modeling Effects of Moisture and Ice .......... 68 
4.3.1 Wet Aggregate (Saturated Surface Dry) .... 68

4.3 .2 Ice Inclusions ..................... 69

4.4 Model Parameters ........................ 73

4.4.1 Determination of Model Parameters ........ 73

4.4 .2 Discussion of Results ................ 76

4.5 Model Validation ....................... 77

4.5.1 Comparison of Model Predictions with

Experimental Data ................ 78

4.5.1.1 Comparison with set Times ......... 78

4.5.1.2 Empirical Modeling of Set Time ..... 79

4.5.1.3 Mathematical Modeling of Set Time

4.5.1.4 Comparison of Model Predictions with

Resin Temperature - Time Data ..... 86

4.5.1.5 Determination of Aggregate Time

Constant, $t_{a} \ldots \ldots . . . . . . . . . .89$

4.5.2 Model Application ................... 90

4.5.2.1 Model Implementation ............. 90

4.5.2.2 Discussion and Illustration of Model

Predictions .................... 91

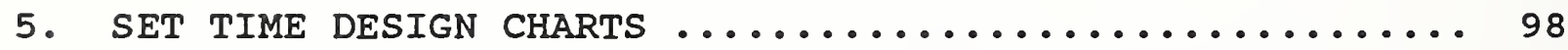

5.1 Development of Design Charts ................. 99

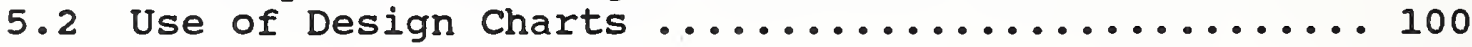

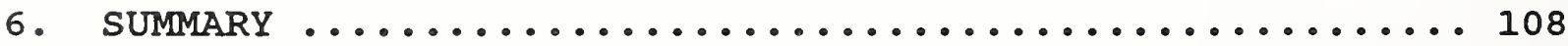

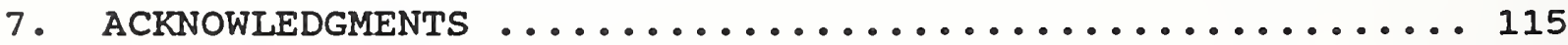

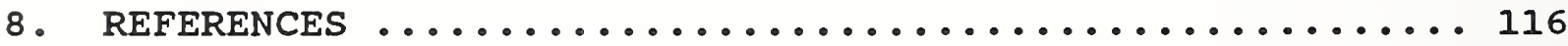

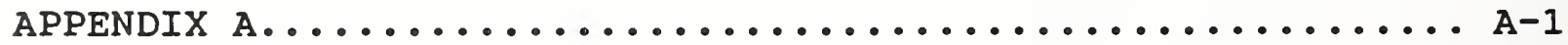

A.1 Resin Warming Auxiliary Test Results .............. A-1

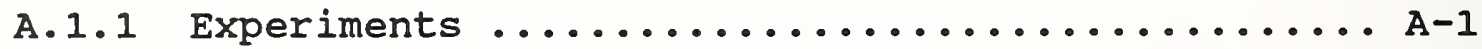

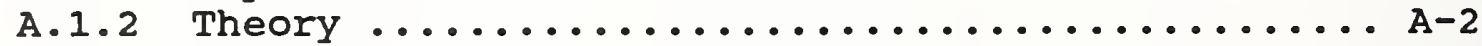

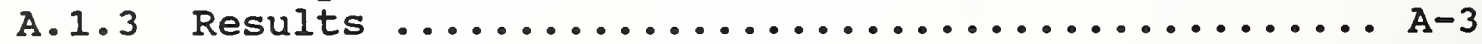


Table of contents (Continued)

Page

A.2 Water Immersion Auxiliary Test Results .......... A-5

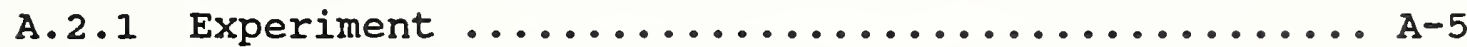

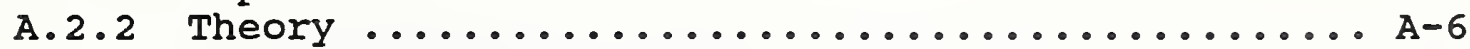

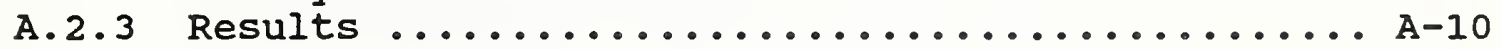

A.3 Kinetic Auxiliary Test Results ................ A-11

A.3.1 Experiments ......................... A

A.3.2 Results .............................

A.3.2.1 Thermodynamic Parameters $(\Delta H)^{\prime} \ldots \ldots \ldots$ A-13

A.3.2.2 Kinetic Parameters-Analysis of Results .. A-15 
Figure 1. Plastic Buckets Containing Aggregate

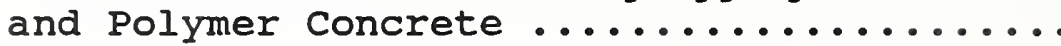

Figure 2. Plot of set Time Data for Polymer Concrete Cast with Dry Aggregate and Saturated Surface Dry Aggregate ...... 35

Figure 3. Sawed Sections of Polymer concrete Specimens Cast Using Dry Aggregate at About

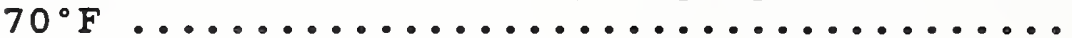

Figure 4. Sawed sections of Polymer Concrete Specimens Cast Using Dry Aggregate and Saturated Surface Dry Aggregate at Cold

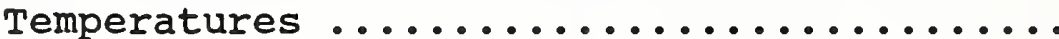

Figure 5. Polymer concrete specimens Cast with Ice Inclusions (Tests No. 144, 149,150 , and 152

Figure 6. Polymer Concrete Specimens Cast with Ice Inclusions (Tests No. 154, $157,160$, and 162$) \ldots \ldots \ldots \ldots \ldots \ldots \ldots \ldots$

Figure 7. Typical Polymer Concrete Flexural Beam

specimen ........................

Figure 8. Fractured Sections of Flexural Beam

specimens Cast at High (Test No. 4) and

Low (Test No. 23) Temperatures ...........

Figure 9. Effects of Temperature Variations of Aggregate and Resin on the Flexural strength of Polymer

Concrete Beam specimens .............. 46

Figure 10. Sawed Sections of Polymer Concrete specimens from Pilot set Time Tests

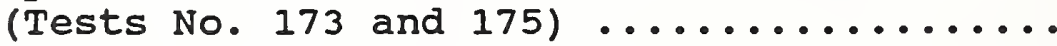

Figure 11. Heat Transfer within the Polymer Concrete system ...................

Figure 12 .

Plot of Catalyst concentration Versus Adiabatic Mix Temperature, $\mathrm{T}_{\mathrm{m}}$, for set

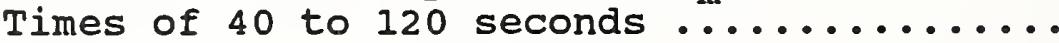


Page

Figure 13. Predicted Versus Experimental set Times Corresponding to $x_{s}=0.58 \ldots \ldots . . . \ldots . . . . .85$

Figure 14. Comparison of Experimental and Predicted Average Resin Temperatures for A Typical

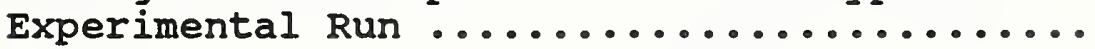

Figure 15. Effect of Parameter m on Predicted Resin

Temperature ..................... 93

Figure 16. Effect of Parameter $m$ on Resin Conversion ... 94

Figure 17. Effect of Initial Resin Temperature on Resin

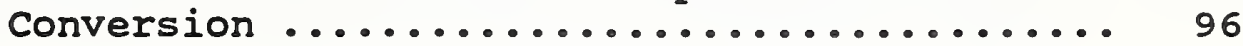

Figure 18. Effect of Catalyst Concentration on Resin

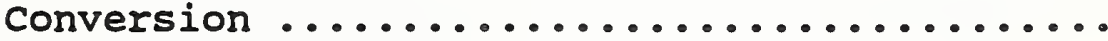

Figure 19. Set Time Design Chart for Aggregate

Temperature $\left(\mathrm{T}_{\mathrm{a} o}\right)=-25^{\circ} \mathrm{F} \ldots \ldots . . . . . . .101$

Figure 20. Set Time Design Chart for Aggregate

Temperature $\left(\mathrm{T}_{\mathrm{ao}}\right)=0^{\circ} \mathrm{F} \ldots \ldots . . \ldots \ldots . . . . . . .102$

Figure 21. Set Time Design Chart for Aggregate

Temperature $\left(\mathrm{T}_{\mathrm{ao}}\right)=25^{\circ} \mathrm{F} \ldots \ldots . . . \ldots . . . . .103$

Figure 22. Set Time Design Chart for Aggregate

Temperature $\left(\mathrm{T}_{\mathrm{ao}}\right)=50^{\circ} \mathrm{F} \ldots \ldots . \ldots . \ldots . . . . .104$

Figure 23. Set Time Design Chart for Aggregate

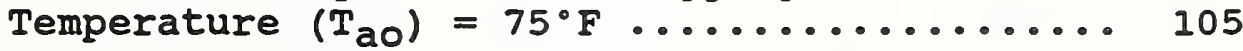

Figure 24. Set Time Design Chart for Aggregate

Temperature $\left(\mathrm{T}_{\mathrm{ao}}\right)=100^{\circ} \mathrm{F} \ldots \ldots . \ldots . \ldots 106$

Figure Al. Determination of Resin Heat Capacities

(In $Y$ versus $t$ ) from Resin Warming Auxiliary

Tests ........................ A $A-4$

Figure A2. Determination of Model Heat Transfer and Time constants from Water Immersion Auxiliary Tests A-8

Figure A3. Determination of Conversion from Adiabatic Temperature - Time Profiles ............. A-14

Figure A4. Kinetic submodel Fit ( $T$ versus $t$ ) for $\mathrm{C}=1.25 \times 10^{-3}$ and $\mathrm{T}=71^{\circ} \mathrm{F} \ldots \ldots \ldots \ldots . . . . . . .17$ 
Table 1. AFESC Requirements for Aggregate ............ 11

Table 2. AFESC Requirements for Combinations of Aggregate and Resin Temperatures Used in Set Time Tests ..

Table 3. Set Time Data for Polymer Concrete Specimens

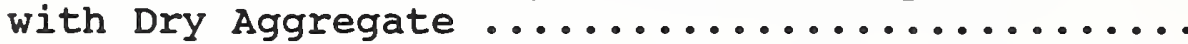

Table 4. Set Time Data for Polymer Concrete Specimens with Saturated Surface Dry Aggregate

(Wet Aggregate) $\ldots \ldots \ldots \ldots \ldots \ldots \ldots \ldots \ldots \ldots$

Table 5. Set Time Data for Polymer Concrete Specimens with Saturated Surface Dry Aggregate Containing

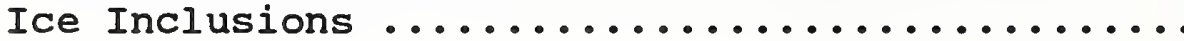

Table 6. Information Pertaining to the Time of set for Specimens Cast with Saturated Surface Dry Aggregate Containing Ice Inclusions .......... 25

Table 7. Flexural Beam Test Data ................ 30

Table 8. Pilot Set Time Tests Using Another Polyurethane

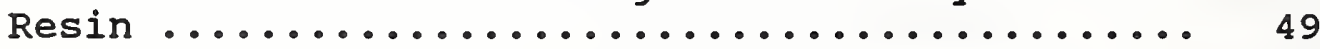

Table 9. Set Time Model Parameters ................ 74

Table 10. Observed set Time $\left(t_{s}\right)$ and Calculated Resin Conversion at set $\left(x_{S}\right)$ Determined from Auxiliary

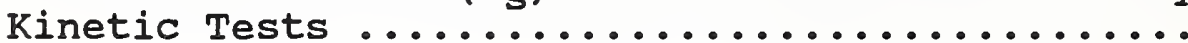

Table A1. Data for Resin Warming Auxiliary Tests ........ A-22

Table A2. Data for Water Immersion Auxiliary Tests ....... A-7

Table A3. Experimental Design for Determination of Kinetic

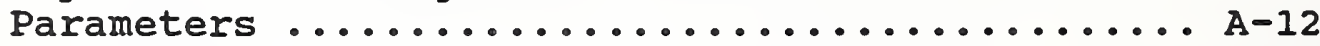

Table A4. Resin Temperature Versus Time Data for Kinetic Auxiliary Tests ...........................

Table A5. Calculated Activation Energies, E (cal/g mol) .. A-18 Table A6. Calculated Modified Pre-Exponential Factors,

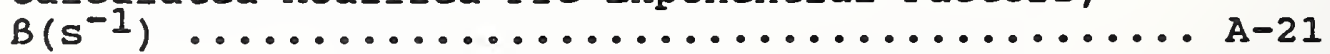


EXECUTIVE SUMMARY

I. BACKGROUND, OBJECTIVES, AND SCOPE

The Air Force Engineering and Services center (AFESC) has conducted testing of materials for bomb damage repair since 1980. Polyurethane resins have been considered for possible use as a binder with preplaced open-graded aggregate for a rapid setting polymer concrete to form a structural cap to repair areas of bomb-damaged runways. The present study was conducted to characterize the performance of a polymer concrete made using a particular proprietary polyurethane resin.

The objectives of this study were to conduct laboratory tests to (1) obtain set time data for polymer concrete made with a particular proprietary resin under various resin and aggregate temperatures and moisture conditions: (2) to develop a set time prediction model for the polymer concrete based on reaction kinetics and thermodynamics of reaction and heat transfer which predicts set time as a function of system variables: (3) to obtain data from auxiliary tests on the properties of the hardened resins and aggregate and on the rate and heat of reaction of the two-part resin system corresponding to various catalyst levels for input into the set time prediction model; (4) to investigate the effect of temperature variations on the flexural strength of the polymer concrete at an early age, and (5) to obtain set time data from pilot tests of polymer concrete 
made using another proprietary polyurethane resin and catalyst, and mineral aggregate cast under various temperature and moisture conditions.

The AFESC provided the proprietary polyurethane resins used in the polymer concrete tests. They also assisted in the development of the experimental design, including selecting aggregates and test temperatures.

\section{SET TIME TESTS}

The set time tests were conducted in a temperature - controlled environmental chamber. The polymer concrete was cast using equal amounts of a two-component resin, a catalyst, and a round mineral aggregate. The aggregate temperature ranged from -25 to $110^{\circ} \mathrm{F}$ and the resin temperature ranged from 5 to $110^{\circ} \mathrm{F}$. A catalyst was mixed with Resin B (diamine-polyglycol) and then mixed with Resin A (isocyanate). The resulting mixture was quickly poured over aggregate in a plastic bucket. In both air dried and saturated surface dry aggregate tests, the mixed resin percolated through the aggregate and filled the voids. The amount of catalyst was adjusted to provide a set time of about 55 to 75 seconds. The set time was sensitive to the amount of catalyst used, more catalyst gave shorter set time. Set time was determined as the time from the start of mixing of the two resins to the time that set of the mixed resin occurred. The temperature of the polymer 
concrete was continuously recorded from thermocouples placed in the aggregate. The set time and temperatures at the time of set and the peak exotherm were reported for 88 tests using dry aggregate, 38 tests using saturated surface dry aggregate, and 40 tests using saturated surface dry aggregate containing ice inclusions.

As expected, the data showed that more catalyst was needed when the resin was cold; it also showed the equally important effect of initial aggregate temperature on set time. There was a consistent trend in the data from the air dried and saturated surface dry aggregate tests which indicated an increase in catalyst amount for a decrease in aggregate and resin temperatures when considering those tests where the set time was in the 55 to 75 second range. A linear relationship between catalyst concentration and resin temperature was suggested for adiabatic mix temperatures above $20^{\circ} \mathrm{F}$. This mix temperature is a weighted value of aggregate and resin temperature.

Little difference in set time was observed for polymer concretes cast using air dried aggregate and saturated surface dry aggregate for comparable combinations of aggregate and resin temperatures. The moisture content of the saturated surface dry aggregate ranged from 0.4 to 0.9 percent. The small amount of moisture in the saturated surface dry aggregate did not appreciably affect the set time or the filling of the aggregate voids with resin. 
Considerably more catalyst was needed in the set time tests with ice inclusions. The amount of ice ranged from 5 to 15 percent of the mass of aggregate. It was difficult to control set time in these tests. Poor bond between aggregate and resin was observed over the lower part of these test specimens. The results from set time tests with ice inclusions were inconclusive because set time could not generally be accurately determined and in many cases could not be reproduced when comparable amounts of catalyst were used.

III. SET TIME PREDICTION MODEL AND AUXILIARY TESTS FOR MODEL PARAMETERS

The set time prediction model consists of energy balances, one for the resin matrix (continuous phase) and the other for the aggregate particles (dispersed phase), as well as molar balance on the reacting species (resins). It accounts for heat exchange between resin and aggregate and the heat of reaction, as well as heat losses to the surroundings. Model input includes initial temperatures (resin, aggregate, and surroundings), catalyst concentration, moisture and ice content (if present), and mass of aggregate and resin. Model parameters include heat transfer coefficients and time constants, specific heats of the phases, chemical reaction order, reaction activation energies, and parameters measuring the effect catalyst concentration has on the reaction rate constant. Model output predicts set time, resin 
conversion, and the temperature of the resin and aggregate as functions of time. For tests with ice inclusions, the model also predicts the fraction of ice which has melted at any time.

In order to independently determine the parameters for the model, separate auxiliary tests were conducted. Resin heat capacities were found in experiments where the resins were allowed to warm in a temperature controlled environment. Heat transfer coefficients and model time constants were determined from tests conducted with water used in place of resin, while reaction parameters were determined from separate tests conducted in insulated containers which did not contain aggregate. These latter tests established a reaction order of 1.5 and a set time which occurred near 60 percent conversion regardless of experimental conditions. The reaction activation energy was found to decrease with increasing catalyst concentration, as would be expected based on kinetic theory. The data collected were fitted to models developed and solved specifically for the auxiliary tests. Because of constraints, the time constant for aggregate heat transfer could not be found independently using this method. Instead its value was determined by matching experimental data of resin temperature for each run directly to the set time model and then using an overall average. Results showed that heat transfer into the aggregate was much faster than into the air. 
Reasonable agreement was found between the set time prediction model and the experimental data since observed set time and resin temperatures generally agreed with those predicted by the model. Larger deviations between predicted and experimental results were noted at higher catalyst concentrations and lower initial resin and aggregate temperatures.

\section{SET TIME DESIGN CHARTS}

The set time prediction model was used to develop a series of design charts which can be used to predict set time given the catalyst concentration and initial temperatures of the resin and aggregate. The design charts can also be used to determine the catalyst concentration to assure set of the resin within a given time at a specified temperature.

The set time prediction model does not determine catalyst concentration directly, it must be run repeatedly at different catalyst concentrations until one is found that matches the desired set time. Using this method, six design charts were generated from the model. Initial aggregate temperatures selected were $-25,0,25,50,75$, and $100^{\circ} \mathrm{F}$ while initial resin temperatures were varied between 0 and $120^{\circ} \mathrm{F}$ in increments of $10^{\circ} \mathrm{F}$. This gave a total of 308 combinations of set time and initial temperature. The model was run iteratively for each combination in order to find the amount of catalyst to be used to 
achieve the desired set time. These data were plotted on the six charts. Each chart is a plot of the catalyst concentration versus the initial resin temperature. The four curves on each chart correspond to set times of $45,60,90$, and 120 seconds.

In summary, the charts are a graphical representation of the model encoded in the four variables, initial resin temperature, initial aggregate temperature, catalyst concentration, and set time. With any three of the variables known, the fourth can be found using the charts. Use of the charts is illustrated.

\section{FLEXURAL STRENGTH}

The flexural strength of the polymer concrete was determined using beam specimens tested at an age of 30 minutes. The average value of the flexural strength ranged from 1050 to 425 psi for beam specimens cast at warm temperatures (air and aggregate at $119^{\circ} \mathrm{F}$ and resin at $91^{\circ} \mathrm{F}$ ) and cold temperatures (air and aggregate at $-27^{\circ} \mathrm{F}$ and resin at $39^{\circ} \mathrm{F}$ ), respectively. Set times for the beam specimens ranged from 30 to 45 seconds. Beams cast with aggregate and resin at the higher temperatures had the highest values of flexural strength. There were eight combinations of aggregate and resin temperatures. The aggregate fractured along the failure surface of beam specimens cast at higher temperatures of aggregate and resin, while for beam specimens cast with lower temperatures, bond failure between aggregate and hardened resin 
was discernable. The flexural strength or modulus of rupture data were compared with the adiabatic mix temperature, $\mathrm{T}_{\mathrm{m}}$, which was a weighted value of aggregate and resin tempeature at the time of casting a beam specimen. The flexural strength was essentially constant for values of $T_{m}$ of $70^{\circ} \mathrm{F}$ or greater. For lower values of $\mathrm{T}_{\mathrm{m}}$, the flexural strength decreased nearly linearly as $\mathrm{T}_{\mathrm{m}}$ decreased. It was observed at age 30 minutes that the hardened resin was softer in the five beams cast with lower values of $\mathrm{T}_{\mathrm{m}}$ than those cast at the higher temperatures.

VI. PILOT SET TIME TESTS USING ANOTHER POLYURETHANE RESIN

In the 18 pilot tests using equal volumes of another two-component polyurethane resin, considerably more catalyst was needed to obtain comparable set times as compared to the main series of set time tests. There were five combinations of aggregate and resin temperatures in these tests which also included air dry aggregate, saturated surface dry aggregate, and saturated surface dry aggregate with ice inclusions. As the tempeature at the time of casting these pilot test specimens decreased, the catalyst concentration needed for equal set time increased considerably. As an example, for specimens cast with an aggregate temperature about $-2^{\circ} \mathrm{F}$ and a resin temperature of $5^{\circ} \mathrm{F}$ or less, the catalyst volume ratio (volume of catalyst to volume of one polyurethane resin component) was in the range of 0.5 to 1.0 and the set time ranged from 95 to 220 seconds. For comparable specimens in the 
main series of set time tests, the catalyst ratio was 0.007 for set time between 67 and 72 seconds. Specimens cast in the pilot tests with resin temperatures of $5^{\circ} \mathrm{F}$ or lower and those specimens with ice inclusions present exhibited poor bond over their lower half. 

1. INTRODUCTION

Polymer concrete made with proprietary polyurethane resins are among several materials being considered by the Air Force Engineering and Services center (AFESC) for use in rapid repair of runways. In using polymer concrete, a resin may be used as a binder with preplaced open-graded aggregate for a rapid-setting polymer concrete which could be used to form a structural cap to repair areas of bomb-damaged airfield runways. Relatively large bomb craters could be backfilled with pavement debris, rock, or. other suitable material. Over this weak backfill, a layer of select aggregate could be placed and leveled even with the surrounding pavement. Polymer resin components mixed with appropriate amounts of catalyst could be applied to the aggregate layer. The mixed resin would flow into the voids in the aggregate and harden to form a polymer concrete structural cap in about a minute. If possible, the structural cap of polymer concrete should support needed aircraft traffic within a half hour after resin application.

The AFESC requested that the National Institute of Standards and Technology (NIST), formerly the National Bureau of standards (NBS), conduct a study to obtain set time data for polymer concrete made with a particular proprietary polyurethane resin. The polymer concrete was to be made using a wide range of resin and aggregate temperatures. In addition, the impact of the presence of water and ice on set time was to be examined. This 
study was required by the AFESC to better characterize the performance of the proprietary resin and the polymer concrete made with it.

\subsection{Background}

The AFESC has initiated, supported and conducted research on materials for rapid repair of runways for many years [1-13] ${ }^{1}$. Many different materials have been investigated for this application, they include polyurethane, methyl methacrylate and other acrylic, polyester, epoxy, and furfuryl alcohol resins and asphalt products, magnesium phosphate cement, high alumina cement, and mono-ammonium phosphate - modified polyphosphate cement composites. Many of the polymer concrete candidate materials investigated involved pouring or applying a mixed two-component polymer, with a catalyst, over open-graded aggregate. Some materials foamed and swelled above the pavement surface [1]. This reaction was attributed to moisture on the surface of the aggregate.

There have been many studies on methyl methacrylate polymer concrete $[2,6,9]$. In one of the studies, polymer concrete made from a mixture of dry aggregate and methyl methacrylate was reported to be very strong, durable, and to have excellent bond between the polymer and aggregate [2]. In making this type of polymer concrete, polymerization of the monomer in the aggregate is promoted by heat. The resulting composite is a strong,

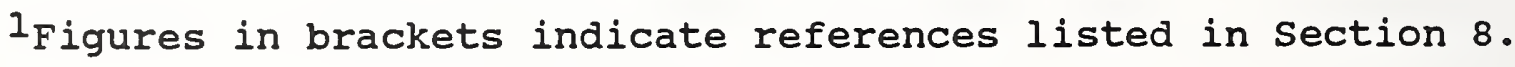


durable material which uses the polymer to bond the aggregate together without using water or portland cement. In another study, several resin systems were evaluated for use with microwave curing. Included among these resin systems were polyesters, urea/formaldehyde, phenolics, and epoxies [5]. The urea/formaldehyde, phenolic and epoxy resins were immediately abandoned either because of extreme foaming or incomplete cure.

An unsaturated polyester - styrene formulation was reported to provide for excellent placement and property characteristics above $32^{\circ} \mathrm{F}$ [4]. At lower temperatures, it was not possible to increase the curing rate enough to meet a one-hour strength criterion while maintaining an acceptable set time [4].

In the early $1980^{\prime}$ s, a program was conducted to identify and develop potential advanced materials to speed repair of bomb damaged airfield pavements [5]. The program recommended polyurethane resin and modified acrylic resin concretes for structural caps; polyurethane-bonded sand and furan-bonded expanded polystyrene beads for crater fills; and polyurethane resin and modified acrylic resin for soil stabilization. Some apparent deficiencies of polyurethane were reported. They included variations required in catalyst levels and the loss in strength and bond when water was present. The wet flexural strength of the polymer concrete dropped to $500 \mathrm{psi}$ while the bond strength fell to about 70 psi [5]. It was reported that both of these problems could probably 
be solved with coupling agents. Moisture can impact the anticipated repair methods and materials in the following three general ways: (1) preventing or degrading the bonding of the polymeric materials to aggregate or pavement, (2) diluting the polymeric material or inhibiting polymerization, and (3) degrading subgrade bearing capacities [5].

In the late $1970^{\prime}$ s, Rollings [7] reviewed the technical literature and identified seven potential capping materials for expedient repair of small craters in airfield pavements. These materials were tested in the laboratory to develop information on their strengths and curing requirements. Accelerated high alumina cement, magnesium phosphate cement, three commercial asphalt products, and unsurfaced, well-compacted aggregate were recommended for field testing as the most promising small crater repair materials.

Several research programs in the late $1970^{\prime} \mathrm{s}$ investigating the use of organic resin binders reported promising results. Even though there were shortcomings such as limited shelf life, complexity of application, moisture sensitivity, and insufficient adhesion, the most promising candidates included acrylics, polyesters, and epoxy resins [8]. In a study of these candidate materials, the focus was on three technical problems that had to be overcome to develop a satisfactory repair system. These technical problems were adhesion to wet aggregates, cure rate 
control for low temperature service, and control of resin viscosity $[8]$

Silane-modified furfuryl alcohol polymer concrete and monoammonium phosphate-modified polyphosphate cement composites were reported to have great potential for use as all-weather rapid repair materials for bomb-damaged runways [10]. It was demonstrated that both of these materials can be mixed and placed on a continuous basis using conventional portland cement concrete equipment and techniques.

Studies were conducted to achieve new materials and equipment required to field an advanced material bomb-damage repair system [11-13]. The two primary types of materials investigated were polyurethanes and acrylics. Screening criteria were based on high early strength in wet and dry environments, with ambient temperatures ranging from $-25^{\circ} \mathrm{F}$ to $125^{\circ} \mathrm{F}$ and material (aggregates and resin) temperatures varying from 5 to $110^{\circ} \mathrm{F}$. The final selected material was polyurethane, modified to improve its wet performance and strength characteristics. The selected placement method was percolation of the polyurethane resin into aggregate, placed in a crater, to form a polymer concrete structural cap [11].

The brief review of literature on rapid runway repair materials presented above is to acquaint the reader with some of the 
research conducted over the last 15 years. Some of the concerns about these materials are their cost, early strength development, effect of moisture and temperature on their bond and mechanical strength, variations in the amounts of catalyst needed, complexity of application, changes in viscosity due to environment, and incomplete filling of voids in open graded aggregate by down percolation of a polymer. The overall need is to provide rapid repair materials for bomb-damaged runways which are applicable to a wide range of weather and environmental conditions.

\subsection{Objectives}

The objectives of this study are:

(1) to obtain set time data for polymer concrete made with a particular proprietary polyurethane resin and catalyst, and a mineral aggregate under various resin and aggregate temperatures and moisture conditions,

(2) to develop a set time prediction model for the polymer concrete based on reaction kinetics and the thermodynamics of reaction and heat transfer which predicts set time as a function of system variables,

(3) to obtain data from auxiliary tests on the properties of the hardened resin and aggregate and on the rate and heat of reaction of the two-part resin system corresponding 
to various catalyst levels for input into the set time prediction model,

(4) to investigate the effect of temperature at the time of casting on the flexural strength of beam specimens of polymer concrete, and

(5) to obtain set time data from pilot tests of polymer concrete made using another proprietary polyurethane resin and catalyst, and mineral aggregate cast under various temperature and moisture conditions.

\subsection{Scope of the study}

Information is needed by the Air Force to better characterize the performance of the polymer concrete material included in this study prior to its use in the field for rapid repair of runways and pavements. The AFESC provided the proprietary polyurethane resins used in the polymer concrete tests.

The AFESC required many specific combinations of aggregate and resin temperatures to be included in the set time tests. Catalyst concentrations were adjusted so that set time occurred within a required time range. Requirements were also established by AFESC with regard to moisture conditions of the aggregate (air dry or saturated surface dry) at the time of testing, and 
specific quantities of ice inclusions to be included in the aggregate prior to adding the resin.

With regard to the effect of temperature on the flexural strength of polymer concrete, the AFESC provided requirements for aggregate and resin temperatures, set time range, size of flexural specimens, and age of specimens at the time of test.

Requirements were also provided by AFESC for conducting the pilot set time tests using another proprietary resin (also a polyurethane). These requirements included temperatures of aggregate and resin and moisture conditions of the aggregate at the time of casting the polymer concrete.

In developing the set time prediction model for the polymer concrete, information on the properties of the hardened resin and the aggregate and on the rate and heat of reaction of the twopart resin system for various amounts of catalyst was needed as input to the model. Auxiliary tests were devised and conducted to provide these data. Most model parameters were determined independently of the polymer concrete set time tests. Model set time predictions were compared with the experimental results. Using the model, design charts were prepared which can be used to predict set time or to select catalyst concentration for a specific set time. 


\section{IABORATORY TESTS}

Laboratory tests were conducted to obtain set time data for polymer concrete made with a proprietary polyurethane resin and catalyst and a mineral aggregate. These tests were carried out over an extensive range of resin and aggregate temperatures. The effects of water and ice inclusions in the aggregate on the set time of the polymer concrete were also investigated.

A model for the prediction of set time of the polymer concrete was developed. The model parameters were determined experimentally from laboratory tests conducted separately from the set time tests. The set time model was developed based on data from the separate or auxiliary small scale tests and was tested using the data from the set time tests.

Laboratory tests were also conducted to determine the flexural strength of the polymer concrete. Beams were cast over an extensive range of resin and aggregate temperatures and were tested at age 30 minutes.

The following sections (2.1 and 2.2) describe the materials and test procedures used in the set time, auxiliary small scale, and flexural tests. 
The AFESC also requested that pilot set time tests of polymer concrete be conducted using another polyurethane resin. The results of these pilot tests are presented in section 3.4 .

\subsection{Materials}

The materials used in the polymer concrete tests were a two-part polyurethane resin including a catalyst and mineral aggregate.

\subsubsection{Polymer}

The proprietary two-component resin and catalyst was supplied by AFESC. One component, component $A$, was a blend of aromatic isocyanates and hydrocarbons and the other component, Component B, was a blend of diamine, polyglycol, and halogenated hydrocarbons. Information regarding the contents of the catalyst was not available. The AFESC requested that the proprietary resin and catalyst not be analyzed for its composition.

\subsubsection{Mineral Aggregate}

The smooth surfaced and rounded mineral aggregate, a river run quartz gravel, was from White Marsh, Maryland. It was required to meet the AFESC requirements given in Table 1. 
Table 1. AFESC Requirements for Aggregate

Property

Gradation

Void volume

Abrasion resistance

Soundness

\section{Limit}

No. 57 per ASTM D 488

(< 1\% passing No. 8 sieve)

$$
\begin{array}{ll}
35-40 \% & \text { ASTM C } 29 \\
<42 \% & \text { ASTM C } 131 \\
<12 \% \mathrm{Na}_{2} \mathrm{SO}_{4} & \text { ASTM C } 88 \\
<18 \% \mathrm{MgSO}_{4} &
\end{array}
$$

Test Method

ASTM C 136

Gradation and void volume test results, as determined by NIST, met the AFESC requirements. The void volume ratio ranged from 36 to 38 percent. Data from tests conducted over a period of about 20 years by the National Aggregates Association on aggregate from the same source as that supplied to NIST indicated that the aggregate met the AFESC requirements for abrasion resistance and soundness.

\subsection{Test Procedures}

Descriptions of the test procedures for the set time, flexural, and auxiliary tests are given in sections $2.2 .1,2.2 .2$, and 2.2 .3 , respectively.

\subsubsection{Set Time}

Polymer concrete set time tests were conducted in an exhaust hood located in an environmental chamber or room. The hood was 56 in. high, 45-1/2 in. wide, and 32 in. deep. It was fabricated from plywood and painted. The hood had two transparent plastic doors, each about 22-3/4 in. $x 56$ in. The hood had a high volume of air 
flow which exited outside of the building. In addition to providing a safe place to conduct the set time tests, the hood also provided for safe storage of the Part A and Part B resins.

The set time tests were performed over a temperature range of $0^{\circ} \mathrm{F}$ to $125^{\circ} \mathrm{F}$. The AFESC requested that specific combinations of aggregate and resin temperatures be used in the tests. They are given in Table 2. Three conditions of aggregate were included in the tests -- they were air dried (also referred to as dry aggregate), saturated and surface dried (also referred to as wet aggregate), and saturated surface dried with ice inclusions. The saturated surface dry aggregate was kept in water for four or more days at the scheduled set time test temperature, and then prior to testing, towel dried to a saturated surface dry condition. For freezing set time test temperatures, saturated surface dry aggregate was stored at schedule test temperature until testing. For tests where the aggregate temperature was $-25^{\circ} \mathrm{F}$, the aggregate was kept in a freezer maintained at this temperature. The aggregate was taken from the freezer and the set time tests were conducted as soon as possible in the hood in the environmental chamber at $0^{\circ} \mathrm{F}$. For all the other tests, the aggregate was conditioned to test temperature in the environmental chamber which had a temperature range of $0^{\circ}$ to $150^{\circ} \mathrm{F}$. The test temperature of the aggregate was the same as the environmental chamber, while 
Table 2. AFESC Requirements for Combinations of Aggregate and Resin Temperatures Used in Set Time Tests

Set Time Test Conditions - Dry Aggregate

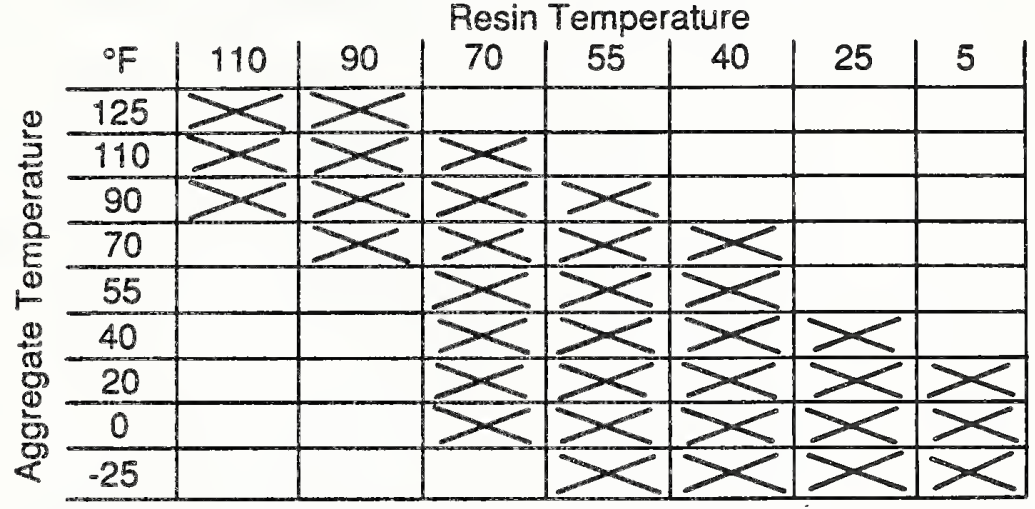

Set Time Test Conditions - Saturated Surface Dry Aggregate

(Wet Aggregate)

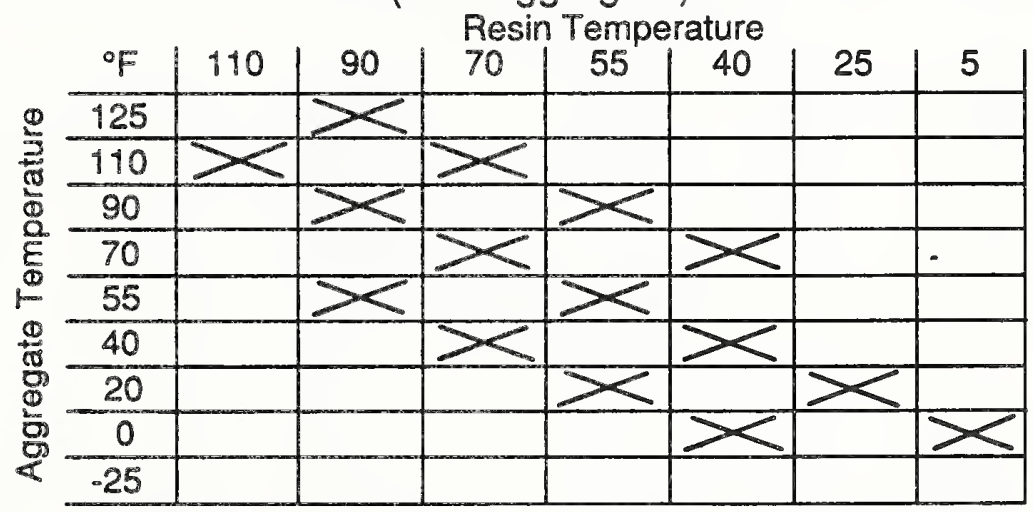

Set Time Test Conditions - Saturated Surface Dry Aggregate

(Wet Aggregate) Containing Ice Inclusions

\begin{tabular}{|c|c|c|c|c|c|c|c|}
\hline${ }^{\circ} \mathrm{F}$ & 110 & 90 & 70 & 55 & 40 & 25 & 5 \\
\hline 125 & & & & & & & \\
\hline 110 & & & & & & & \\
\hline 90 & & & & & & & \\
\hline 70 & & & & & & & \\
\hline 55 & & & & & & & \\
\hline 40 & & & & & & & \\
\hline 20 & & & $>$ & 2 & 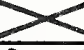 & $\geq<$ & \\
\hline 0 & & & & & $\geq$ & & $\leq$ \\
\hline-25 & & & & & & $\Sigma$ & 7 \\
\hline
\end{tabular}

Adjust catalyst concentrations so set time falls between 15 and 120 seconds 
the resins usually had to be stored in a refrigerator, freezer, or oven, to attain the required test temperatures.

The set time tests were performed by pouring the mixed resin (Components $A$ and $B$ ), including catalyst, into a 5-gallon plastic bucket containing $0.44 \mathrm{ft}^{3}$ of a smooth surface, rounded mineral aggregate (gravel). The weight of the aggregate was $42 \mathrm{lbm}$ $(19,230 \mathrm{~g})$ and its depth in the bucket was $8 \mathrm{in}$. The diameter of the bucket at the bottom was about 10-1/4 in. and at a depth of 8 in. the diameter was about $10-3 / 4$ in. The aggregate was air dried for at least 7 days before placing it in buckets and weighing the test specimens. During air drying, the gravel was spread out to a depth of about 4 in. The moisture content of the air dried gravel was determined to be about 0.08 percent by mass. The void volume ratio of the gravel ranged from 36 to 38 percent.

Equal parts by volume of Part $A$ and Part B resin were used in the set time tests. For each specimen of polymer concrete, $2220 \mathrm{ml}$ $(2453 \mathrm{~g})$ of Part A resin and $2220 \mathrm{ml}(3048 \mathrm{~g})$ of Part B resin were used. Each of the resins were poured into separate 5 gallon plastic buckets. Immediately prior to casting the polymer concrete, a measured amount of catalyst, at room temperature, was added to the Part $B$ resin and stirred using a wood paddle. The amount of catalyst used for each of the tests with air dried and saturated surface dry aggregate ranged from 0.1 to $17 \mathrm{ml}$ (see Tables 3 and 4 ). The Part $B$ resin, with catalyst, was poured 
Table 3. Set Time Data for Polymer concrete Specimens with Dry Aggregate

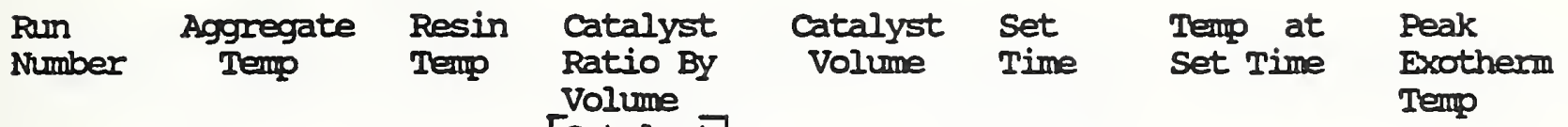

$\left({ }^{\circ} \mathrm{F}\right)$

('F) [ $\left[\frac{\text { Catal B }}{\text { Part }}\right]$

(mI)

(s)

$\left({ }^{\circ} \mathrm{F}\right)$

$\left({ }^{\circ} \mathrm{F}\right)$

\begin{tabular}{|c|c|c|c|c|c|c|c|}
\hline $\begin{array}{l}1 \\
2\end{array}$ & $\begin{array}{l}75 \\
73\end{array}$ & $\begin{array}{l}75 \\
72\end{array}$ & $\begin{array}{l}0.00125 \\
0.00125\end{array}$ & $\begin{array}{l}2.775 \\
2.775\end{array}$ & $\begin{array}{l}72 \\
67\end{array}$ & $\frac{-}{173}$ & $\begin{array}{r}177 \\
.173\end{array}$ \\
\hline $\begin{array}{l}3 \\
4 \\
5\end{array}$ & $\begin{array}{l}74 \\
74 \\
75\end{array}$ & $\begin{array}{l}40 \\
40 \\
40\end{array}$ & $\begin{array}{l}0.00170 \\
0.00190 \\
0.00200\end{array}$ & $\begin{array}{l}3.774 \\
4.218 \\
4.440\end{array}$ & $\begin{array}{r}110 \\
93 \\
86\end{array}$ & $\begin{array}{l}128 \\
124 \\
127\end{array}$ & $\begin{array}{l}129 \\
132 \\
129\end{array}$ \\
\hline $\begin{array}{l}6 \\
7\end{array}$ & $\begin{array}{l}75 \\
75\end{array}$ & $\begin{array}{l}90 \\
90\end{array}$ & $\begin{array}{l}0.00090 \\
0.00090\end{array}$ & $\begin{array}{l}1.998 \\
1.998\end{array}$ & $\begin{array}{l}65 \\
60\end{array}$ & $\begin{array}{l}178 \\
192\end{array}$ & $\begin{array}{l}178 \\
196\end{array}$ \\
\hline $\begin{array}{l}8 \\
9\end{array}$ & $\begin{array}{l}75 \\
76\end{array}$ & $\begin{array}{l}55 \\
55\end{array}$ & $\begin{array}{l}0.00170 \\
0.00170\end{array}$ & $\begin{array}{l}3.774 \\
3.774\end{array}$ & $\begin{array}{l}81 \\
74\end{array}$ & $\begin{array}{l}144 \\
132\end{array}$ & $\begin{array}{l}144 \\
137\end{array}$ \\
\hline $\begin{array}{l}10 \\
11 \\
17 \\
18 \\
12 \\
13 \\
14\end{array}$ & $\begin{array}{l}56 \\
56 \\
57 \\
58 \\
56 \\
56 \\
57\end{array}$ & $\begin{array}{l}70 \\
70 \\
70 \\
71 \\
57 \\
57 \\
56\end{array}$ & $\begin{array}{l}0.00210 \\
0.00170 \\
0.00215 \\
0.00170 \\
0.00210 \\
0.00190 \\
0.00190\end{array}$ & $\begin{array}{l}4.662 \\
3.774 \\
4.780 \\
3.774 \\
4.662 \\
4.218 \\
4.218\end{array}$ & $\begin{array}{l}48 \\
76 \\
49 \\
56 \\
54 \\
55 \\
63\end{array}$ & $\begin{array}{l}143 \\
158 \\
152 \\
147 \\
138 \\
160 \\
128\end{array}$ & $\begin{array}{l}144 \\
162 \\
153 \\
149 \\
141 \\
168 \\
131\end{array}$ \\
\hline $\begin{array}{l}15 \\
16\end{array}$ & $\begin{array}{l}57 \\
58\end{array}$ & $\begin{array}{l}42 \\
40\end{array}$ & $\begin{array}{l}0.00220 \\
0.00220\end{array}$ & $\begin{array}{l}4.884 \\
4.884\end{array}$ & $\begin{array}{l}83 \\
92\end{array}$ & $\begin{array}{c}118 \\
-\end{array}$ & $\begin{array}{c}118 \\
-\end{array}$ \\
\hline $\begin{array}{l}19 \\
20\end{array}$ & $\begin{array}{l}89 \\
89\end{array}$ & $\begin{array}{l}88 \\
89\end{array}$ & $\begin{array}{l}0.00070 \\
0.00070\end{array}$ & $\begin{array}{l}1.554 \\
1.554\end{array}$ & $\begin{array}{l}64 \\
71\end{array}$ & $\begin{array}{l}164 \\
160\end{array}$ & $\begin{array}{l}168 \\
160\end{array}$ \\
\hline $\begin{array}{l}21 \\
22\end{array}$ & $\begin{array}{l}90 \\
90\end{array}$ & $\begin{array}{l}71 \\
71\end{array}$ & $\begin{array}{l}0.00100 \\
0.00100\end{array}$ & $\begin{array}{l}2.220 \\
2.220\end{array}$ & $\begin{array}{l}74 \\
72\end{array}$ & $\begin{array}{l}162 \\
142\end{array}$ & $\begin{array}{l}164 \\
148\end{array}$ \\
\hline $\begin{array}{l}23 \\
24\end{array}$ & $\begin{array}{l}90 \\
90\end{array}$ & $\begin{array}{l}54 \\
54\end{array}$ & $\begin{array}{l}0.00130 \\
0.00130\end{array}$ & $\begin{array}{l}2.886 \\
2.886\end{array}$ & $\begin{array}{l}76 \\
70\end{array}$ & $\begin{array}{l}143 \\
140\end{array}$ & $\begin{array}{l}145 \\
144\end{array}$ \\
\hline $\begin{array}{l}25 \\
26\end{array}$ & $\begin{array}{l}91 \\
91\end{array}$ & $\begin{array}{l}109 \\
110\end{array}$ & $\begin{array}{l}0.00035 \\
0.00035\end{array}$ & $\begin{array}{l}0.777 \\
0.777\end{array}$ & $\begin{array}{l}70 \\
72\end{array}$ & $\begin{array}{l}182 \\
162\end{array}$ & $\begin{array}{c}182 \\
175\end{array}$ \\
\hline $\begin{array}{l}27 \\
28\end{array}$ & $\begin{array}{l}44 \\
43\end{array}$ & $\begin{array}{l}41 \\
41\end{array}$ & $\begin{array}{l}0.00260 \\
0.00260\end{array}$ & $\begin{array}{l}5.772 \\
5.772\end{array}$ & $\begin{array}{l}76 \\
72\end{array}$ & $\frac{119}{113}$ & $\begin{array}{l}120 \\
113\end{array}$ \\
\hline
\end{tabular}


Table 3. Set Time Data for Polymer Cancrete Specimens with Dry Aggregate (Continued)

$\begin{array}{llllll}\text { Rum } & \text { Aggregate } \\ \text { Number } & \begin{array}{c}\text { Resin } \\ \text { Temp }\end{array} & \text { Catalyst } & \text { Catalyst set } & \text { Temp at } & \text { Peak } \\ \text { Ratio By } & \text { Volume Time } & \text { Set Time Exotherm } \\ \text { Volume } & & & & \text { Termp }\end{array}$

$\left({ }^{\circ} \mathrm{F}\right)$

$(\cdot F) \quad\left[\frac{\text { Catalyst }}{\text { Part B }}\right]$

(ml)

(s)

$\left({ }^{\circ} \mathrm{F}\right)$

$\left(^{\circ} \mathrm{F}\right)$

\begin{tabular}{|c|c|c|c|c|c|c|c|}
\hline 29 & 42 & 23 & 0.00290 & 6.438 & 94 & 94 & 97 \\
\hline 30 & 43 & 27 & 0.00310 & 6.882 & 66 & 112 & 116 \\
\hline 31 & 42 & 23 & 0.00310 & 6.882 & 71 & 91 & 101 \\
\hline 32 & 42 & 70 & 0.00200 & 4.440 & 41 & 146 & 146 \\
\hline 33 & 44 & 71 & 0.00180 & 3.996 & 47 & 128 & 129 \\
\hline 34 & 44 & 69 & 0.00150 & 3.330 & 76 & 131 & 132 \\
\hline 35 & 43 & 71 & 0.00150 & 3.330 & 66 & 136 & 137 \\
\hline 36 & 43 & 55 & 0.00205 & 4.551 & 67 & 119 & 121 \\
\hline 37 & 43 & 55 & 0.00205 & 4.551 & 73 & 122 & 123 \\
\hline 38 & 110 & 109 & 0.00010 & 0.222 & 70 & 167 & 176 \\
\hline 39 & 110 & 109 & 0.00010 & 0.222 & 106 & 168 & 179 \\
\hline 40 & 110 & 109 & 0.00010 & 0.222 & 92 & 155 & 174 \\
\hline 41 & 110 & 72 & 0.00600 & 1.332 & 72 & 156 & 170 \\
\hline 42 & 110 & 74 & 0.00060 & 1.332 & 80 & 157 & 166 \\
\hline 43 & 111 & 89 & 0.00038 & 0.833 & 81 & 156 & 168 \\
\hline 44 & 110 & 90 & 0.00038 & 0.833 & 89 & 167 & 181 \\
\hline 45 & 21 & 70 & 0.00195 & 4.329 & 68 & 124 & 127 \\
\hline 46 & 21 & 71 & 0.00195 & 4.329 & 66 & 142 & 143 \\
\hline 47 & 21 & 24 & 0.00335 & 7.881 & 74 & 91 & 93 \\
\hline 48 & 23 & 25 & 0.00355 & 7.881 & 73 & 86 & 86 \\
\hline 49 & 23 & 5 & 0.00425 & 9.435 & 96 & 74 & 76 \\
\hline 50 & 22 & 5 & 0.00450 & 9.990 & 126 & 79 & 80 \\
\hline 55 & 22 & 4 & 0.00540 & 11.998 & 104 & 76 & 80 \\
\hline 56 & 23 & 4 & 0.00630 & 13.986 & 79 & 77 & 79 \\
\hline 57 & 22 & 5 & 0.00630 & 13.986 & 71 & 97 & 100 \\
\hline 51 & 23 & 40 & 0.00300 & 6.660 & 67 & 86 & 88 \\
\hline 52 & 22 & 40 & 0.00300 & 6.660 & 67 & 84 & 89 \\
\hline 53 & 23 & 54 & 0.00245 & 5.439 & 53 & 117 & 117 \\
\hline 54 & 25 & 54 & 0.00230 & 5.106 & 61 & 118 & 119 \\
\hline
\end{tabular}


Table 3. Set Time Data for Polymer Cancrete Specimens with Dry Aggregate (Continued)

Rum Number
Aggregate Temp

$\left({ }^{\circ} \mathrm{F}\right)$

$\begin{array}{ll}123 & 110 \\ 123 & 110 \\ 123 & 90 \\ 123 & 90 \\ 122 & 90\end{array}$

63

64

65

66

67

69

68

70

71

72

73

74

75

76

82

77

78

79

80

81

83

84

\section{1}

2

3

\section{3}

4

5

6

7

4

4

5
7

7

2

0

$-22$

$-26$

$-24$

$-32$

$-32$

$-26$

$-29$
10

$90 \quad 0.00020$

$90 \quad 0.00025$

$90 \quad 0.00023$

\section{5}

0.00285

0.00260

0.00260

\subsection{7}

5.772

54

25

24

0.00395

0.00395

0.00395

8.769

8.769

8.769

40

40

0.00340

0.00340

7.548

7.548

70

0.00235

0.00210

5.217

4.662

70

70

0.00180

3.996

0.00160

3.552

0.00150

3.330

5

0.00675

0.00675

14.985

14.985

50.00720

15.984

$0.00720 \quad 15.984$

25

0.00440

0.00495

9.768

0.00480

10.989

10.656

$39 \quad 0.00385$

$41 \quad 0.00375$

8.547
8.325

57

59
Temp at Peak

Set Time Exotherm

Termp

$\left({ }^{\circ} \mathrm{F}\right)$

$\left({ }^{\circ} \mathrm{F}\right)$

192

186

181

193

183

125

98

99

73

78

91

104

118

140

127

160

114

107

71

65

57

63

49

57

68

85

90 
Table 3. Set Time Data for Polymer concrete Specimens with Dry Aggregate (Contimued)

\begin{tabular}{|c|c|c|c|c|c|c|c|}
\hline $\begin{array}{l}\text { Rum } \\
\text { Number }\end{array}$ & $\begin{array}{l}\text { Aggregate } \\
\text { Temp }\end{array}$ & $\begin{array}{l}\text { Resin } \\
\text { Temp }\end{array}$ & $\begin{array}{l}\text { Catalyst } \\
\text { Ratio By } \\
\text { Volume } \\
{\left[\frac{\text { Catalyst }}{\text { Part B }}\right]}\end{array}$ & $\begin{array}{l}\text { Catalyst } \\
\text { Volume }\end{array}$ & $\begin{array}{l}\text { Set } \\
\text { Time }\end{array}$ & $\begin{array}{l}\text { Temp at } \\
\text { Set Time }\end{array}$ & $\begin{array}{l}\text { Peak } \\
\text { Exotherm } \\
\text { Tent! } \\
\left({ }^{\circ} \mathrm{F}\right)\end{array}$ \\
\hline $\begin{array}{l}85 \\
86 \\
87 \\
88\end{array}$ & $\begin{array}{l}-33 \\
-26 \\
-47 \\
-25\end{array}$ & $\begin{array}{l}55 \\
54 \\
55 \\
55\end{array}$ & $\begin{array}{l}0.00290 \\
0.00270 \\
0.00240 \\
0.00240\end{array}$ & $\begin{array}{l}6.438 \\
5.994 \\
5.328 \\
5.328\end{array}$ & $\begin{array}{l}52 \\
53 \\
60 \\
59\end{array}$ & $\begin{array}{l}75 \\
75 \\
91 \\
54\end{array}$ & $\begin{array}{r}85 \\
109 \\
91 \\
77\end{array}$ \\
\hline
\end{tabular}


Table 4. Set Time Data for Polymer Concrete Specimens with Saturated Surface Dry Aggregate (Wet Aggregate)

\begin{tabular}{|c|c|c|c|c|c|c|c|c|}
\hline $\begin{array}{l}\text { Run } \\
\text { Number }\end{array}$ & $\begin{array}{l}\text { Aggregate } \\
\text { Tenp } \\
\left({ }^{\circ} \mathrm{F}\right)\end{array}$ & $\begin{array}{l}\text { Resin } \\
\text { Tentp } \\
\left({ }^{\circ} \mathrm{F}\right)\end{array}$ & $\begin{array}{l}\text { Catalyst } \\
\text { Ratio } \\
\text { By } \\
\text { Volume } \\
{\left[\frac{\text { Catalyst }}{\text { Part B }}\right]}\end{array}$ & $\begin{array}{l}\text { Catalyst } \\
\text { Volume } \\
\text { (ml) }\end{array}$ & $\begin{array}{l}\text { Set } \\
\text { Time } \\
\text { (s) }\end{array}$ & $\begin{array}{l}\text { Temp at } \\
\text { Set Time } \\
\left({ }^{\circ} \mathrm{F}\right)\end{array}$ & $\begin{array}{l}\text { Peak } \\
\text { Exotherm } \\
\text { Temp } \\
\left({ }^{\circ} \mathrm{F}\right)\end{array}$ & $\begin{array}{l}\text { Moisture } \\
\text { Content of } \\
\text { Aggregate } \\
\left(\frac{\%}{\%}\right)\end{array}$ \\
\hline $\begin{array}{l}89 \\
90\end{array}$ & $\begin{array}{l}70 \\
71\end{array}$ & $\begin{array}{l}71 \\
71\end{array}$ & $\begin{array}{l}0.00125 \\
0.00125\end{array}$ & $\begin{array}{l}2.775 \\
2.775\end{array}$ & $\begin{array}{l}68 \\
59\end{array}$ & $\begin{array}{l}122 \\
145\end{array}$ & $\begin{array}{l}140 \\
148\end{array}$ & $\begin{array}{l}0.5 \\
0.5\end{array}$ \\
\hline $\begin{array}{l}91 \\
92\end{array}$ & $\begin{array}{l}70 \\
71\end{array}$ & $\begin{array}{l}40 \\
40\end{array}$ & $\begin{array}{l}0.00220 \\
0.00220\end{array}$ & $\begin{array}{l}4.884 \\
4.884\end{array}$ & $\begin{array}{l}68 \\
72\end{array}$ & $\begin{array}{l}115 \\
123\end{array}$ & $\begin{array}{l}122 \\
123\end{array}$ & $\begin{array}{l}0.5 \\
0.5\end{array}$ \\
\hline $\begin{array}{l}93 \\
94\end{array}$ & $\begin{array}{l}55 \\
55\end{array}$ & $\begin{array}{l}55 \\
55\end{array}$ & $\begin{array}{l}0.00185 \\
0.00175\end{array}$ & $\begin{array}{l}4.107 \\
3.885\end{array}$ & $\begin{array}{l}58 \\
70\end{array}$ & $\begin{array}{l}110 \\
106\end{array}$ & $\begin{array}{l}119 \\
121\end{array}$ & $\begin{array}{l}0.9 \\
0.9\end{array}$ \\
\hline $\begin{array}{l}95 \\
96 \\
97\end{array}$ & $\begin{array}{l}56 \\
56 \\
56\end{array}$ & $\begin{array}{l}90 \\
90 \\
90\end{array}$ & $\begin{array}{l}0.00120 \\
0.00100 \\
0.00100\end{array}$ & $\begin{array}{l}2.664 \\
2.220 \\
2.220\end{array}$ & $\begin{array}{l}50 \\
73 \\
76\end{array}$ & $\begin{array}{l}188 \\
146 \\
144\end{array}$ & $\begin{array}{l}195 \\
147 \\
148\end{array}$ & $\begin{array}{l}0.9 \\
0.9 \\
0.9\end{array}$ \\
\hline $\begin{array}{r}99 \\
100\end{array}$ & $\begin{array}{l}86 \\
86\end{array}$ & $\begin{array}{l}90 \\
90\end{array}$ & $\begin{array}{l}0.00070 \\
0.00060\end{array}$ & $\begin{array}{l}1.554 \\
1.332\end{array}$ & $\begin{array}{l}58 \\
67\end{array}$ & $\begin{array}{l}172 \\
141\end{array}$ & $\begin{array}{l}174 \\
162\end{array}$ & $\begin{array}{l}0.4 \\
0.4\end{array}$ \\
\hline $\begin{array}{l}101 \\
102\end{array}$ & $\begin{array}{l}86 \\
85\end{array}$ & $\begin{array}{l}55 \\
54\end{array}$ & $\begin{array}{l}0.00130 \\
0.00130\end{array}$ & $\begin{array}{l}2.886 \\
2.886\end{array}$ & $\begin{array}{l}69 \\
67\end{array}$ & $\begin{array}{l}143 \\
127\end{array}$ & $\begin{array}{l}147 \\
139\end{array}$ & $\begin{array}{l}0.4 \\
0.4\end{array}$ \\
\hline $\begin{array}{l}103 \\
104\end{array}$ & $\begin{array}{l}44 \\
44\end{array}$ & $\begin{array}{l}41 \\
42\end{array}$ & $\begin{array}{l}0.00260 \\
0.00250\end{array}$ & $\begin{array}{l}5.772 \\
5.550\end{array}$ & $\begin{array}{l}61 \\
70\end{array}$ & $\begin{array}{l}102 \\
103\end{array}$ & $\begin{array}{l}106 \\
108\end{array}$ & $\begin{array}{l}0.6 \\
0.6\end{array}$ \\
\hline $\begin{array}{l}105 \\
106\end{array}$ & $\begin{array}{l}44 \\
44\end{array}$ & $\begin{array}{l}69 \\
69\end{array}$ & $\begin{array}{l}0.00150 \\
0.00140\end{array}$ & $\begin{array}{l}3.330 \\
3.108\end{array}$ & $\begin{array}{l}64 \\
61\end{array}$ & $\begin{array}{l}128 \\
129\end{array}$ & $\begin{array}{l}129 \\
130\end{array}$ & $\begin{array}{l}0.6 \\
0.6\end{array}$ \\
\hline $\begin{array}{l}107 \\
108 \\
109 \\
110\end{array}$ & $\begin{array}{l}101 \\
103 \\
103 \\
102\end{array}$ & $\begin{array}{l}106 \\
111 \\
109 \\
108\end{array}$ & $\begin{array}{l}0.00010 \\
0.00015 \\
0.00015 \\
0.00015\end{array}$ & $\begin{array}{l}0.222 \\
0.333 \\
0.333 \\
0.333\end{array}$ & $\begin{array}{r}108 \\
58 \\
104 \\
104\end{array}$ & $\begin{array}{l}155 \\
157 \\
162 \\
159\end{array}$ & $\begin{array}{l}171 \\
176 \\
173 \\
177\end{array}$ & $\begin{array}{l}0.5 \\
0.5 \\
0.5\end{array}$ \\
\hline $\begin{array}{l}111 \\
112 \\
115\end{array}$ & $\begin{array}{l}105 \\
101 \\
118\end{array}$ & $\begin{array}{l}70 \\
70 \\
70\end{array}$ & $\begin{array}{l}0.00070 \\
0.00070 \\
0.00070\end{array}$ & $\begin{array}{l}1.554 \\
1.554 \\
1.554\end{array}$ & $\begin{array}{l}68 \\
75 \\
67\end{array}$ & $\begin{array}{l}143 \\
146 \\
169\end{array}$ & $\begin{array}{l}159 \\
157 \\
184\end{array}$ & $\begin{array}{c}0.5 \\
0.5 \\
-\end{array}$ \\
\hline $\begin{array}{l}113 \\
114\end{array}$ & $\begin{array}{l}131 \\
129\end{array}$ & $\begin{array}{l}89 \\
90\end{array}$ & $\begin{array}{l}0.00023 \\
0.00025\end{array}$ & $\begin{array}{l}0.500 \\
0.555\end{array}$ & $\begin{array}{l}86 \\
77\end{array}$ & $\begin{array}{l}186 \\
164\end{array}$ & $\begin{array}{l}200 \\
182\end{array}$ & - \\
\hline $\begin{array}{l}116 \\
117 \\
118\end{array}$ & $\begin{array}{l}7 \\
4 \\
9\end{array}$ & $\begin{array}{l}5 \\
5 \\
5\end{array}$ & $\begin{array}{l}0.00690 \\
0.00770 \\
0.00740\end{array}$ & $\begin{array}{l}15.318 \\
17.094 \\
16.428\end{array}$ & $\begin{array}{r}104 \\
59 \\
58\end{array}$ & $\begin{array}{l}70 \\
52 \\
74\end{array}$ & $\begin{array}{l}73 \\
55 \\
76\end{array}$ & $\begin{array}{l}0.4 \\
0.4 \\
0.4\end{array}$ \\
\hline
\end{tabular}


Table 4. Set Time Data for Polymer concrete Specimens with Saturated surface Dry Aggregate (Wet Aggregate) (Continued)

\begin{tabular}{|c|c|c|c|c|c|c|c|c|}
\hline $\begin{array}{l}\text { Rum } \\
\text { Number }\end{array}$ & $\begin{array}{l}\text { Aggregate } \\
\text { Tenly } \\
\left({ }^{\circ} \mathrm{F}\right)\end{array}$ & $\begin{array}{l}\text { Resin } \\
\text { Temp } \\
\left({ }^{\circ} \mathrm{F}\right)\end{array}$ & $\begin{array}{c}\text { Catalyst } \\
\text { Ratio } \\
\text { By } \\
\text { Volume } \\
{\left[\begin{array}{c}\text { Catalyst } \\
\text { Part B }\end{array}\right]}\end{array}$ & $\begin{array}{l}\text { Catalyst } \\
\text { Volume } \\
\text { (ml) }\end{array}$ & $\begin{array}{l}\text { Set } \\
\text { Time } \\
\text { (s) }\end{array}$ & $\begin{array}{l}\text { Temp at } \\
\text { Set Time } \\
\left({ }^{\circ} \mathrm{F}\right)\end{array}$ & $\begin{array}{l}\text { Peak } \\
\text { Exotherm } \\
\text { Temp } \\
\left({ }^{\circ} \mathrm{F}\right)\end{array}$ & $\begin{array}{l}\text { Moisture } \\
\text { Content of } \\
\text { Aggregate } \\
(\%)\end{array}$ \\
\hline $\begin{array}{l}119 \\
120 \\
121\end{array}$ & $\begin{array}{l}5 \\
4 \\
5\end{array}$ & $\begin{array}{l}40 \\
40 \\
40\end{array}$ & $\begin{array}{l}0.00380 \\
0.00360 \\
0.00330\end{array}$ & $\begin{array}{l}8.436 \\
7.992 \\
7.326\end{array}$ & $\begin{array}{l}51 \\
48 \\
54\end{array}$ & $\begin{array}{r}72 \\
113 \\
69\end{array}$ & $\begin{array}{r}78 \\
124 \\
73\end{array}$ & $\begin{array}{l}0.4 \\
0.4 \\
0.4\end{array}$ \\
\hline $\begin{array}{l}122 \\
123 \\
124\end{array}$ & $\begin{array}{l}19 \\
19 \\
19\end{array}$ & $\begin{array}{l}55 \\
54 \\
54\end{array}$ & $\begin{array}{l}0.00220 \\
0.00200 \\
0.00200\end{array}$ & $\begin{array}{l}4.884 \\
4.440 \\
4.440\end{array}$ & $\begin{array}{l}50 \\
67 \\
66\end{array}$ & $\begin{array}{l}89 \\
89 \\
95\end{array}$ & $\begin{array}{l}96 \\
95 \\
95\end{array}$ & $\begin{array}{l}0.8 \\
0.8 \\
0.8\end{array}$ \\
\hline $\begin{array}{l}125 \\
126 \\
127\end{array}$ & $\begin{array}{l}20 \\
19 \\
21\end{array}$ & $\begin{array}{l}25 \\
25 \\
26\end{array}$ & $\begin{array}{l}0.00330 \\
0.00350 \\
0.00345\end{array}$ & $\begin{array}{l}7.326 \\
7.770 \\
7.659\end{array}$ & $\begin{array}{l}85 \\
65 \\
76\end{array}$ & $\begin{array}{l}64 \\
68 \\
69\end{array}$ & $\begin{array}{l}74 \\
78 \\
78\end{array}$ & $\begin{array}{l}0.8 \\
0.8 \\
0.8\end{array}$ \\
\hline
\end{tabular}

a percent by mass 
into the Part A resin within 8 to 10 seconds. While pouring, the mixed resins were stirred with a wood paddle. Immediately following this step, the mixed resins were poured into the aggregate within 5 seconds. Photographs of the 5 gallon plastic buckets containing aggregate and polymer concrete are shown in Figure 1. In the set time tests using air dried aggregate and saturated surface dry aggregate, the mixed resins, when poured into the aggregate, filled the voids up to the top surface of aggregate. This was in general the case for all the combinations of aggregate (air dried and saturated surface dried) and resin temperatures included in the 127 set time tests (see Tables 3 and 4). However, this was not the case for tests where ice inclusions were included in the saturated surface dried aggregate. Data from the set time tests using saturated surface dry aggregate containing ice inclusions are listed in Table 5. Information pertaining to the time of set for specimens cast with saturated surface dry aggregate containing ice inclusions is given in Table 6. In this table, the portion of the area of the surface of the test specimen for which the resin appeared to be set or hardened was estimated. Large voids and poor bond of aggregate to hardened resin were observed in these polymer concrete specimens that contained ice inclusions. Some of the hardened polymer concrete specimens were sawed in half to observe the extent to which the resin had filled the voids in the aggregate. 


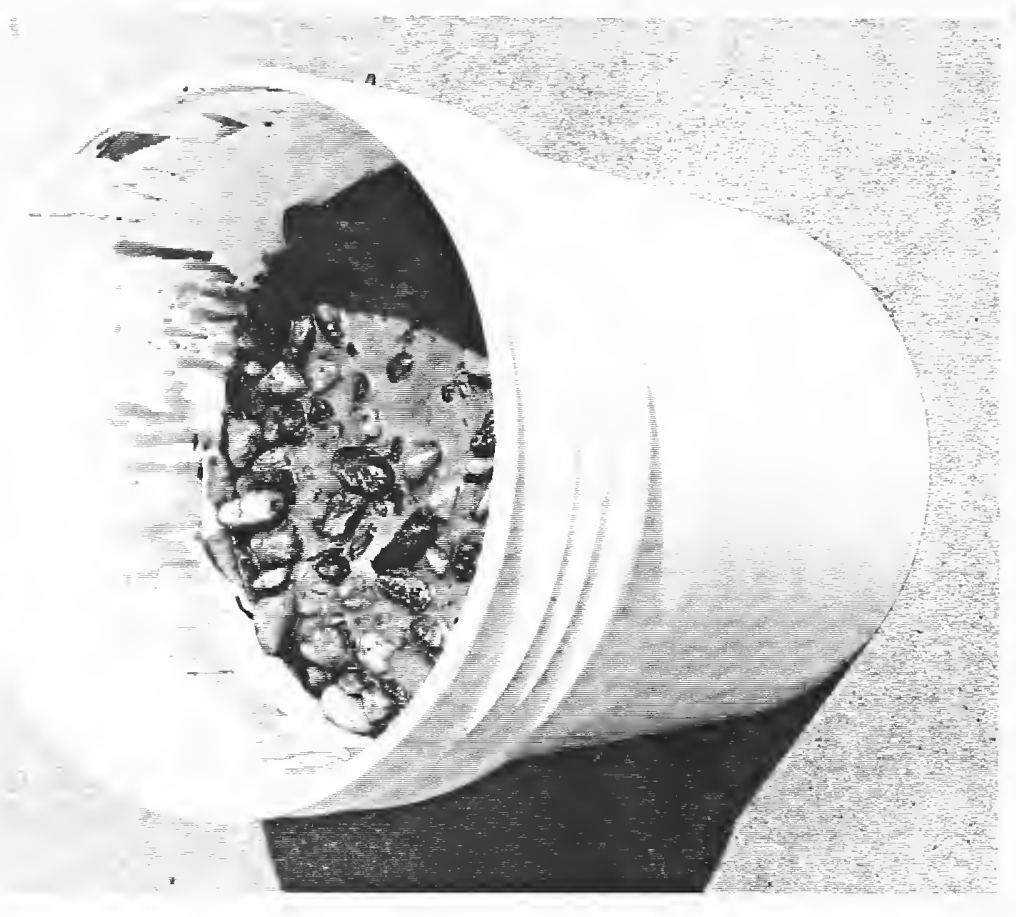

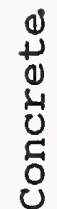

告

ฮั

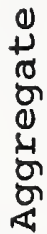

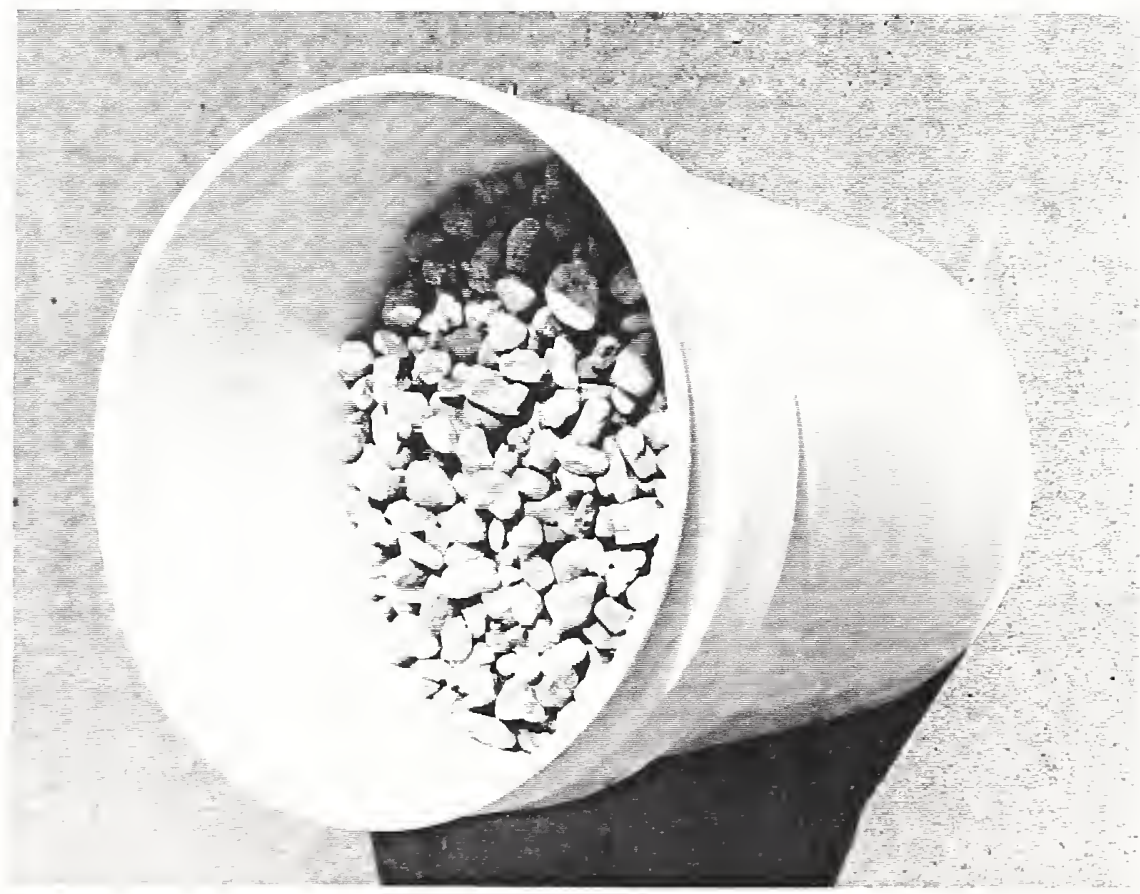

U

岌

.

in

a

ํ-1 
Table 5. Set Time Data for Polymer Concrete Specimens with Saturated surface Dry Aggregate containing Ice Inclusions

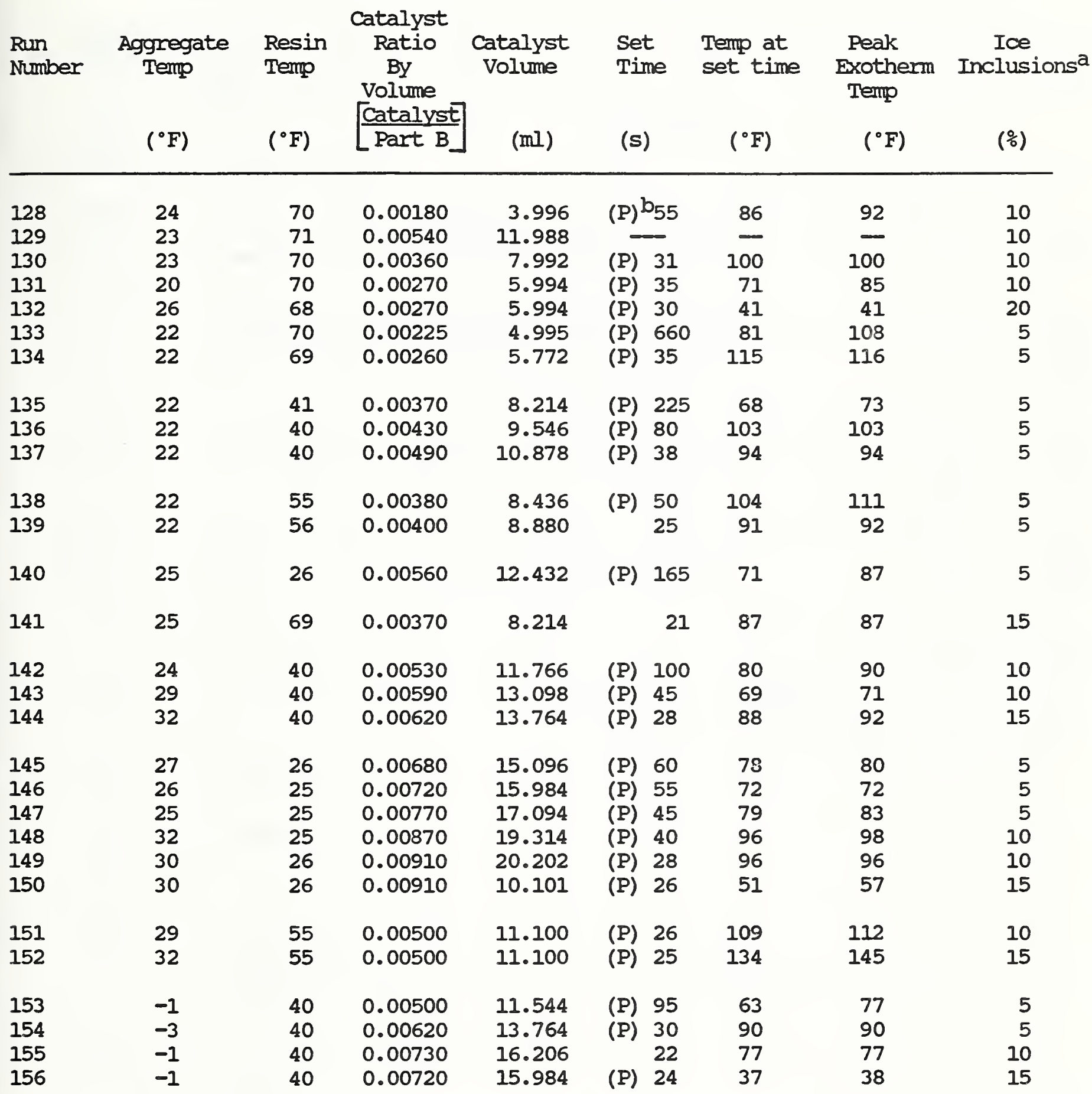


Table 5. Set Time Data for Polymer concrete Specimens with Saturated surface Dry Aggregate Containing Ice Inclusions (Continued)

\begin{tabular}{|c|c|c|c|c|c|c|c|c|c|}
\hline $\begin{array}{l}\text { Rum } \\
\text { Number }\end{array}$ & $\begin{array}{c}\text { Aggregate } \\
\text { Temp } \\
\text { ('F) }\end{array}$ & $\begin{array}{l}\text { Resin } \\
\text { Temp } \\
\left({ }^{\circ} \mathrm{F}\right)\end{array}$ & $\begin{array}{l}\text { Catalyst } \\
\text { Ratio } \\
\text { By } \\
\text { Volume } \\
{\left[\begin{array}{l}\text { Catalyst } \\
\text { Part B }\end{array}\right.}\end{array}$ & $\begin{array}{l}\text { atalyst } \\
\text { Volume }\end{array}$ & $\begin{array}{l}\text { Set } \\
\text { Tin }\end{array}$ & & $\begin{array}{l}\text { Termp at } \\
\text { set time } \\
\left({ }^{\circ} \mathrm{F}\right)\end{array}$ & $\begin{array}{l}\text { Peak } \\
\text { Exotherm } \\
\text { Temp } \\
\left({ }^{\circ} \mathrm{F}\right)\end{array}$ & $\begin{array}{l}\text { Ice } \\
\text { Inclusions }\end{array}$ \\
\hline 157 & 0 & 25 & 0.01020 & 22.644 & (P) & 27 & 49 & 49 & 5 \\
\hline 158 & 0 & 25 & 0.01130 & 25.086 & (P) & 26 & 67 & 67 & 10 \\
\hline 159 & 4 & 26 & 0.01130 & 25.086 & (P) & 23 & 68 & 68 & 15 \\
\hline 160 & 4 & 5 & 0.01220 & 27.084 & (P) & 80 & 44 & 50 & 5 \\
\hline 161 & 4 & 6 & 0.01290 & 28.638 & (P) & 45 & 67 & 70 & $\cdot 5$ \\
\hline 162 & 4 & 5 & 0.01430 & 31.745 & (P) & 30 & 52 & 52 & 10 \\
\hline 163 & 0 & 6 & 0.01440 & 31.968 & (P) & 25 & 43 & 45 & 15 \\
\hline 164 & -36 & 26 & 0.01250 & 27.750 & (P) & 19 & 51 & 53 & 5 \\
\hline 165 & -34 & 26 & 0.01340 & 29.748 & (P) & 20 & 36 & 59 & 10 \\
\hline 169 & -39 & 25 & 0.01330 & 29.526 & (P) & 22 & 37 & 37 & 15 \\
\hline 166 & -35 & 5 & 0.01530 & 33.966 & (P) & 26 & 100 & 180 & 5 \\
\hline 167 & -44 & 6 & 0.01640 & 36.408 & (P) & 26 & 42 & 42 & 10 \\
\hline 168 & -43 & 5 & 0.01640 & 36.408 & (P) & 29 & 33 & 36 & 15 \\
\hline
\end{tabular}

\footnotetext{
a Percent by mass of aggregate

b Partial set, see Table 6 for information pertaining to time of set
} 
Table 6. Information Pertaining to the Time of set for specimens Cast with Saturated Surface Dry Aggregate containing Ice Inclusions

Test No.

128

129

130

131

141

142

Partial set, 55 seconds; total set, 22 minutes. No data, resin set up before it could be poured into gravel.

Set time, 31 seconds (about 90\% of surface area); steam emmitted from between hardened concrete and side of bucket shortly after set.

Set time, 35 seconds (about $80 \%$ of surface area); polymer concrete was soft or there were voids around the edge of the specimen.

set time, 30 seconds (about $85 \%$ of surface area).

$40 \%$ set at $2-1 / 2 \mathrm{~min}$ : gummy at $3-1 / 2 \mathrm{~min}$ : about $75 \%$ set at $11 \mathrm{~min}$.

Set time, 35 seconds (about $90 \%$ of surface area).

$50 \%$ set at $3-3 / 4 \mathrm{~min}$.

$25 \%$ set at 80 sec.: $60 \%$ set at $105 \mathrm{sec}$; $75 \%$ set at $225 \mathrm{sec}$; $95 \%$ set at $285 \mathrm{sec}$.

Set time, 38 seconds (about $85 \%$ of surface area); $90 \%$ set at $90 \mathrm{sec}$.

$50 \%$ set at 50 sec.; $75 \%$ set at 75 sec.; $80 \%$ set at 95 sec.

$100 \%$ set at $25 \mathrm{sec}$.

$50 \%$ set at 165 seconds: $90 \%$ set at 225 sec.

Set time, 21 seconds ( $100 \%$ of area).

Note: Small amount of resin (5\%) set up before it entered gravel, most of mixed resin (95\%) entered gravel; a lot of steam was released from bucket.

$30 \%$ set at 100 sec.; $50 \%$ set at 160 sec.; $60 \%$ set at 225 sec.; $75 \%$ set at $270 \mathrm{sec}$; $100 \%$ set at 300 sec. 
Table 6. Information Pertaining to the Time of set for Specimens Cast with Saturated Surface Dry Aggregate Containing Ice Inclusions (Continued)

Test No.

143

144

145

146

147

148

149

150

151

152

153

154

155

156

157

158

159

160

161

162
$70 \%$ set at 45 sec.; $90 \%$ set at $65 \mathrm{sec}$.

Set time, 28 seconds (about 95\% of area).

$20 \%$ set at 60 sec.; $40 \%$ set at 75 sec.; $60 \%$ set at 90 sec.; $80 \%$ set at 110 sec.; $90 \%$ set at 135 sec.

$40 \%$ set at 55 sec. i $50 \%$ set at 80 sec.; $75 \%$ set at 90 sec.; $90 \%$ set at 110 sec.; $95 \%$ set at 135 sec.

$50 \%$ set at 45 sec.; $70 \%$ set at $60 \mathrm{sec} ; 90 \%$ set at 80 sec.; 95\% set at $95 \mathrm{sec}$.

$40 \%$ set at $40 \mathrm{sec}$; $50 \%$ set at $70 \mathrm{sec}$; $75 \%$ set at 105 sec.: $90 \%$ set at 120 sec.

Set time, 28 sec.; (about 95\% of area).

set time, 26 sec.; (about $95 \%$ of area).

Set time, 26 sec.; (about $95 \%$ of area).

Set time, 25 sec.: (about 95\% of area).

$30 \%$ set at 95 sec.; $75 \%$ set at 165 sec.:

$90 \%$ set at $190 \mathrm{sec}$.

Set time, 30 sec.: (about $90 \%$ of area).

Set time, $22 \mathrm{sec}$; (about 100\% of area).

set time, 24 sec.; (about $98 \%$ of area).

Set time, 27 sec.: (about 98\% of area).

set time, 26 sec.; (about $98 \%$ of area).

set time, 23 sec.; (about $98 \%$ of area).

$50 \%$ set at 80 sec.; $90 \%$ set at $60 \mathrm{sec}$.

$75 \%$ set at $45 \mathrm{sec}$; $95 \%$ set at $60 \mathrm{sec}$.

Set time, 30 seconds (about 95\% of area). 
Table 6. Information Pertaining to the Time of set for Specimens Cast with Saturated Surface Dry Aggregate Containing Ice Inclusions (Continued)

Test No.

163

164

165

166

167

168

169
Set time, 25 seconds (about 95\% of area).

set time, 19 sec., (about $98 \%$ of area).

Set time, 20 sec., (about $98 \%$ of area).

Set time, $26 \mathrm{sec}$, (about $95 \%$ of area).

set time, 26 sec., (about 98\% of area).

set time, 29 sec., (about $98 \%$ of area).

set time, 22 sec., (about $95 \%$ of area). 
Personnel handling the resins were required to wear respirators, protective gloves, and eye protection. Resins were stored in containers in hoods in the laboratories or in containers in a particular building designated as a storage area. The resins were weighed to the amount required in the tests in one gallon metal cans. Prior to testing, the metal cans containing the measured amount of resin were placed in refrigerators, freezers, or ovens to provide the required test temperature of the resin.

Temperature data from the cast polymer concrete were continuously recorded on data-logger tape and on a computer disc. The temperatures were recorded from three thermocouples located at mid-depth in the gravel at the center, at the edge, and half way between the center and edge of the bucket. As previously noted, the depth of gravel in the bucket was $8 \mathrm{in.}$. In this series of tests, the intended set time of the mixed resin in the aggregate was 55-75 seconds. The AFESC requirement for set time was between 15 and 120 seconds. Set time was determined by using a $1 / 8$ in. diameter steel rod to tap the liquid phase of the resin and recording when it became solid. A stopwatch was used to measure, to the nearest second, the time from when the resins were mixed to when set occurred. It was observed at set that the color of the mixed resin in the gravel changed from a dark to light green. In almost all tests where air dried and saturated surface dried aggregate were used, the set of the resin occurred rapidly. 
The temperatures of the gravel and resins were measured immediately prior to the set time tests using thermocouples or thermometers. The catalyst was at room temperature when added to the resin, since very small amounts were used.

\subsubsection{Flexural strength}

The $4 \times 4 \times 14$ in. polymer concrete beams were cast in a temperature controlled environmental chamber. The temperatures of the aggregate and resin used in casting the beam specimens are given in Table 7. The resin temperatures were different from the aggregate temperatures. The aggregate temperature was the same as the air temperature in the environmental chamber except for the aggregate temperature of $-25^{\circ} \mathrm{F}$. For this case, the air temperature was $0^{\circ} \mathrm{F}$. The catalyst ratios were selected in an attempt to produce set time of the resin in the range of 30 to 45 seconds. Catalyst ratios and amounts are given in Table 7 along with set times.

In casting a beam specimen, the gravel was placed in the form and leveled off even with the top surface of the form. The bottom and ends of the forms were $1 / 2$ in.-thick Teflon ${ }^{2}$. The sides of the form were $3 / 8$ in.-thick aluminum, with $1 / 8$ in.-thick Teflon ${ }^{2}$

2 Certain manufacturer names and proprietary materials are included in this report in order to identify and describe some of the materials used in this study. Such identification does not imply recommendation or endorsement by the National Institute of Standards and Technology, nor does it imply that the materials identified are necessarily the best available for the purpose used in this study. 
Table 7. Flexural Beam Test Data

\begin{tabular}{|c|c|c|c|c|c|c|c|c|}
\hline $\begin{array}{l}\text { Run } \\
\text { Number }\end{array}$ & $\begin{array}{l}\text { Aggregate } \\
\text { Temp } \\
\text { ('F) }\end{array}$ & $\begin{array}{l}\text { Resin } \\
\text { Temp } \\
\left({ }^{\circ} \mathrm{F}\right)\end{array}$ & $\begin{array}{l}\text { Catalyst } \\
\text { Ratio } \\
\text { By } \\
\text { Volume } \\
{\left[\begin{array}{c}\text { Catalyst } \\
\text { Part B }\end{array}\right]}\end{array}$ & $\begin{array}{l}\text { Catalyst } \\
\text { Volume }\end{array}$ & $\begin{array}{l}\text { Set } \\
\text { Time } \\
\text { (s) }\end{array}$ & $\begin{array}{l}\text { Max } \\
\text { Load }\end{array}$ & $\begin{array}{l}\text { Moculus } \\
\text { of } \\
\text { Rupture }\end{array}$ & $\begin{array}{l}\text { Avg. Value } \\
\text { of Modulus } \\
\text { of Rupture } \\
\text { (psi) }\end{array}$ \\
\hline $\begin{array}{l}1 \\
2 \\
3\end{array}$ & $\begin{array}{l}72 \\
72 \\
72\end{array}$ & $\begin{array}{l}40 \\
43 \\
40\end{array}$ & $\begin{array}{l}0.00240 \\
0.00250 \\
0.00260\end{array}$ & $\begin{array}{l}2.40 \\
2.50 \\
2.60\end{array}$ & $\begin{array}{l}42 \\
43 \\
40\end{array}$ & $\begin{array}{l}4930 \\
5260 \\
5340\end{array}$ & $\begin{array}{r}924 \\
986 \\
1001\end{array}$ & 970 \\
\hline $\begin{array}{l}4 \\
5 \\
6\end{array}$ & $\begin{array}{l}110 \\
110 \\
110\end{array}$ & $\begin{array}{l}71 \\
72 \\
73\end{array}$ & $\begin{array}{l}0.00800 \\
0.00085 \\
0.00085\end{array}$ & $\begin{array}{l}0.80 \\
0.85 \\
0.85\end{array}$ & $\begin{array}{l}47 \\
40 \\
41\end{array}$ & $\begin{array}{l}5840 \\
5410 \\
5540\end{array}$ & $\begin{array}{l}1095 \\
1014 \\
1039\end{array}$ & 1049 \\
\hline $\begin{array}{l}7 \\
8 \\
9\end{array}$ & $\begin{array}{l}90 \\
90 \\
90\end{array}$ & $\begin{array}{l}55 \\
55 \\
55\end{array}$ & $\begin{array}{l}0.00170 \\
0.00170 \\
0.00170\end{array}$ & $\begin{array}{l}1.70 \\
1.70 \\
1.70\end{array}$ & $\begin{array}{l}37 \\
42 \\
37\end{array}$ & $\begin{array}{l}5700 \\
5490 \\
5350\end{array}$ & $\begin{array}{l}1069 \\
1029 \\
1003\end{array}$ & 1034 \\
\hline $\begin{array}{l}10 \\
11 \\
12\end{array}$ & $\begin{array}{l}119 \\
119 \\
118\end{array}$ & $\begin{array}{l}92 \\
91 \\
90\end{array}$ & $\begin{array}{l}0.00033 \\
0.00037 \\
0.00420\end{array}$ & $\begin{array}{l}0.33 \\
0.37 \\
0.42\end{array}$ & $\begin{array}{l}52 \\
53 \\
54\end{array}$ & $\begin{array}{l}5430 \\
5740 \\
5610\end{array}$ & $\begin{array}{l}1012 \\
1076 \\
1052\end{array}$ & 1047 \\
\hline $\begin{array}{l}13 \\
14 \\
15 \\
16\end{array}$ & $\begin{array}{l}23 \\
21 \\
21 \\
22\end{array}$ & $\begin{array}{l}91 \\
89 \\
90 \\
90\end{array}$ & $\begin{array}{l}0.00100 \\
0.00060 \\
0.00070 \\
0.00070\end{array}$ & $\begin{array}{l}1.00 \\
0.60 \\
0.70 \\
0.70\end{array}$ & $\begin{array}{l}27 \\
59 \\
39 \\
37\end{array}$ & $\begin{array}{l}4970 \\
4920 \\
4050 \\
4450\end{array}$ & $\begin{array}{l}932 \\
922 \\
759 * \\
834\end{array}$ & $\begin{array}{l}862 * * \\
896\end{array}$ \\
\hline $\begin{array}{l}17 \\
18 \\
19\end{array}$ & $\begin{array}{l}22 \\
20 \\
20\end{array}$ & $\begin{array}{l}69 \\
70 \\
70\end{array}$ & $\begin{array}{l}0.00190 \\
0.00180 \\
0.00160\end{array}$ & $\begin{array}{l}1.90 \\
1.80 \\
1.60\end{array}$ & $\begin{array}{l}30 \\
27 \\
36\end{array}$ & $\begin{array}{l}4430 \\
4390 \\
4530\end{array}$ & $\begin{array}{l}831 \\
823 \\
849\end{array}$ & 834 \\
\hline $\begin{array}{l}20 \\
21 \\
22 \\
23\end{array}$ & $\begin{array}{l}1 \\
1 \\
0 \\
0\end{array}$ & $\begin{array}{l}56 \\
54 \\
55 \\
55\end{array}$ & $\begin{array}{l}0.00280 \\
0.00250 \\
0.00250 \\
0.00250\end{array}$ & $\begin{array}{l}2.80 \\
2.50 \\
2.50 \\
2.50\end{array}$ & $\begin{array}{l}23 \\
37 \\
30 \\
38\end{array}$ & $\begin{array}{l}4930 \\
3840 \\
3240 \\
3040\end{array}$ & $\begin{array}{l}924 * \\
720 \\
607 \\
570\end{array}$ & $\begin{array}{l}705 * * \\
632\end{array}$ \\
\hline $\begin{array}{l}24 \\
25 \\
26 \\
27\end{array}$ & $\begin{array}{l}-25 \\
-35 \\
-27 \\
-26\end{array}$ & $\begin{array}{l}39 \\
39 \\
38 \\
40\end{array}$ & $\begin{array}{l}0.00390 \\
0.00380 \\
0.00370 \\
0.00380\end{array}$ & $\begin{array}{l}3.90 \\
3.80 \\
3.70 \\
3.80\end{array}$ & $\begin{array}{l}30 \\
32 \\
68 \\
28\end{array}$ & $\begin{array}{l}3240 \\
2160 \\
2130 \\
2500\end{array}$ & $\begin{array}{l}608 * \\
405 \\
399 \\
469\end{array}$ & $\begin{array}{l}470 * * \\
424\end{array}$ \\
\hline
\end{tabular}

* Data considered as outlier

** Average value includes outlier 
on the inside surfaces of the sides of the form. The forms were assembled with screws which enabled rapid disassembly to remove the beam specimens from the forms about 10 minutes after casting.

About $12.3 \mathrm{lbm}(5580 \mathrm{~g})$ of gravel was placed in the forms. Catalyst at room temperature was added to the $1000 \mathrm{ml}$ of Part B resin and mixed using a wood paddle. The Part $B$ resin with catalyst was then quickly poured into the $1000 \mathrm{ml}$ of Part A resin and the mixed resin was stirred during pouring. The mixed resin was immediately poured into the form containing the aggregate. From the time resin mixing started, the resin mixture was poured into the form containing the gravel within 15 seconds.

The beam specimens were tested in flexure at age 30 minutes by third point loading as described by ASTM C 78. They were removed from the forms about 10 minutes after casting and kept in the environmental chamber until age 25 minutes. The beams were then placed in an insulated container and moved from the environmental chamber to the testing machine. The air temperature at the time of flexural test was about $70^{\circ} \mathrm{F}$. The beams were removed from the insulated container and positioned in a flexural testing apparatus and the load was applied using a testing machine. An initial load of 2000 to 3000 lbf (about 50 percent of breaking load) was applied to the beams and the rate of loading thereafter was 800 lbf/min. The beams were loaded until failure occurred. 


\subsubsection{Auxiliary Tests}

Small-scale auxiliary tests were conducted to determine parameters for a set time prediction model. As previously noted, most model parameters were determined independently of the polymer concrete set time tests. The auxiliary tests denoted as resin warming, water immersion, and kinetic are described in Appendix A. 


\section{TEST RESULTS}

The results of the set time, flexural strength, and auxiliary tests using the proprietary two-component resin are given in Sections $3.1,3.2$, and 3.3 , respectively. The auxiliary small scale tests were conducted to determine the parameters for a set time prediction model. Section 3.4 provides set time data from pilot tests of casting polymer concrete using another proprietary resin and catalyst.

\subsection{Set Time}

The set time, temperature of mixed resin in the aggregate at set time, and peak exotherm for each of the tests are given in Tables 3, 4, and 5. These tables include data from tests using dry aggregate, saturated surface dry aggregate (wet aggregate), and aggregate with ice inclusions, respectively. Values of initial aggregate and resin temperature, cataiyst ratio, and catalyst amount for each test are also given in the tables. It is noted that the ambient temperature and aggregate temperature were essentially the same except for the case where aggregate temperatures were about $-25^{\circ} \mathrm{F}$. For this case the ambient temperature was about $0^{\circ} \mathrm{F}$.

The set time was very sensitive to the amount of catalyst used. slight changes in the amount of catalyst appreciably affected the 
set time. Since very small amounts of catalyst were used, it was at room temperature, $70^{\circ} \mathrm{F}$, when added to the Part $\mathrm{B}$ resin. In conducting the set time tests, it was intended to narrow the set time to a range of about 55 to 75 seconds. This range was about midway between the AFESC requirement of between 15 to 120 seconds. Therefore, the set time data presented in Tables 3, 4, and 5 are in most cases in the range of 55 to 75 seconds. From the data plotted in Figure 2 for polymer concrete cast with air dry aggregate and with saturated surface dry aggregate, it can be seen that there is a consistent trend in the data when considering those points having set times in the 55 to 75 second range. In Figure 2, the set time(s) are the numbers associated with each data point. The lines drawn in this figure are for different initial aggregate temperatures, $\mathrm{T}_{\mathrm{a} o}$. These data are briefly discussed in Section 4.5.1.2. and are compared to data for which a weighted value of aggregate temperature and resin temperature is used instead of the initial resin temperature.

In comparing set times for comparable combinations of aggregate and resin temperatures for polymer concrete cast using air dry aggregate and those cast using saturated surface dry aggregate, little difference was observed. Comparing average temperatures of the polymer concrete at set time and at peak exotherm for specimens cast using air dry aggregate and those cast using saturated surface dry aggregate, the temperature at set time was about 11 percent greater when dry aggregate was used. The peak 


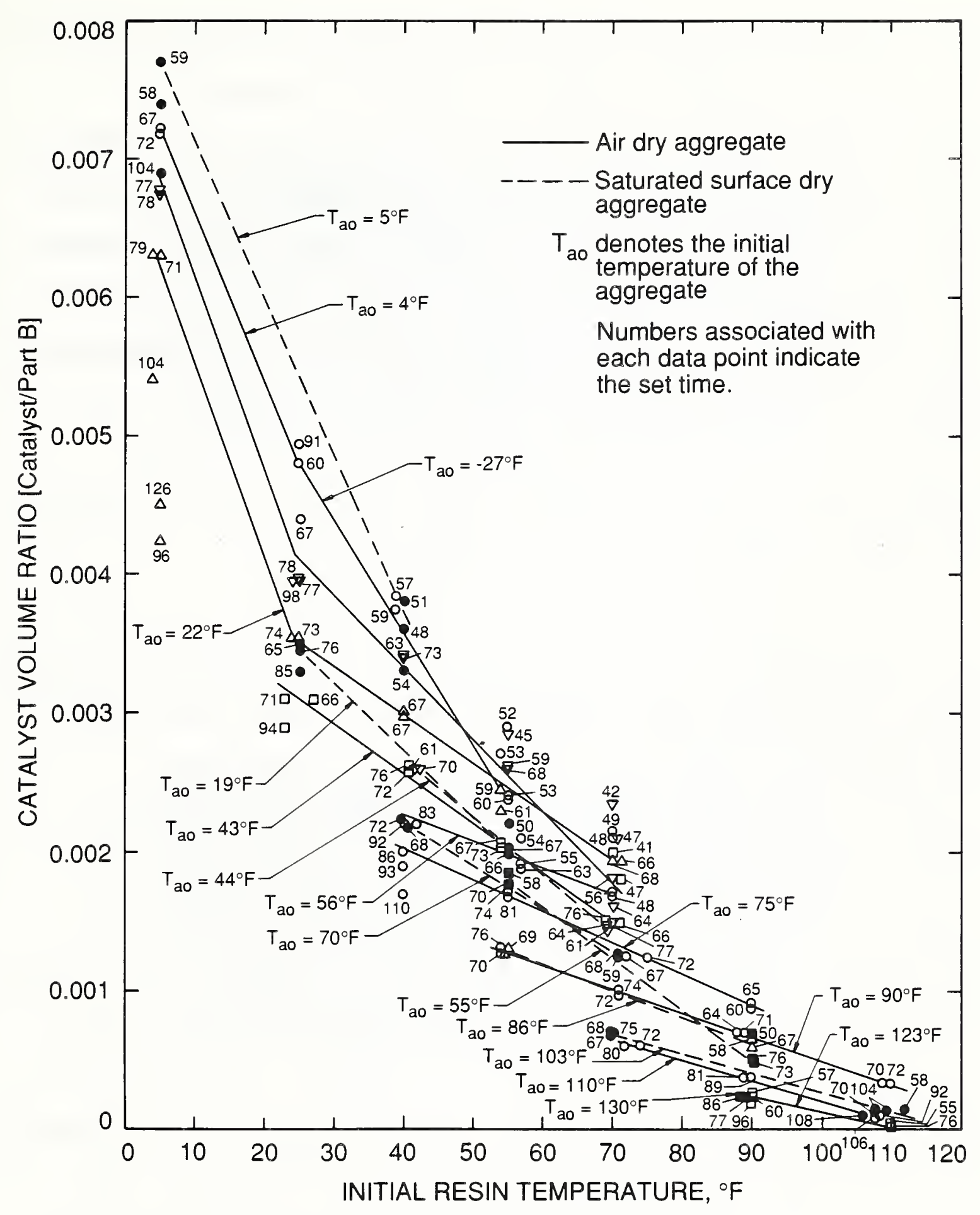

Figure 2. Plot of Set Time Data for Polymer Concrete Cast with Dry Aggregate and Saturated surface Dry Aggregate. 
exotherm for specimens cast with dry aggregate was about 5 percent greater than for specimens cast with saturated surface dry aggregate. The catalyst ratios were about the same for comparable specimens cast with saturated surface dry aggregate as compared to specimens cast using air dry aggregate. The moisture content of the saturated surface dry aggregate used to cast the polymer concrete ranged from 0.4 to 0.9 percent by weight (see Table 4 ). As compared to polymer concrete cast using dry aggregate, this small amount of moisture in the aggregate appeared to have relatively little effect on the set time, temperature of concrete at set time, and peak exotherm (see Tables 3 and 4 ).

Some of the polymer concrete specimens (dry aggregate or saturated surface dry aggregate) were sawed in half to observe the extent to which the resin had filled the voids in the aggregate. From Figures 3 and 4 it can be seen that the resin completely filled the voids in the aggregate. This was the case for the wide range of aggregate and resin temperatures included in the set time tests. Samples denoted as A and B in Figure 3 were from test runs where the aggregate and resin temperatures were about $70^{\circ} \mathrm{F}$. In Figure 4, polymer concrete for Test No. 78 and Test No. 118 are shown. In Test No. 78, the room dry aggregate temperature was $-26^{\circ} \mathrm{F}$ and the resin temperature was $5^{\circ} \mathrm{F}$. In Test No. 118, the saturated surface dry aggregate temperature was $9^{\circ} \mathrm{F}$ and the resin temperature was $5^{\circ} \mathrm{F}$. 


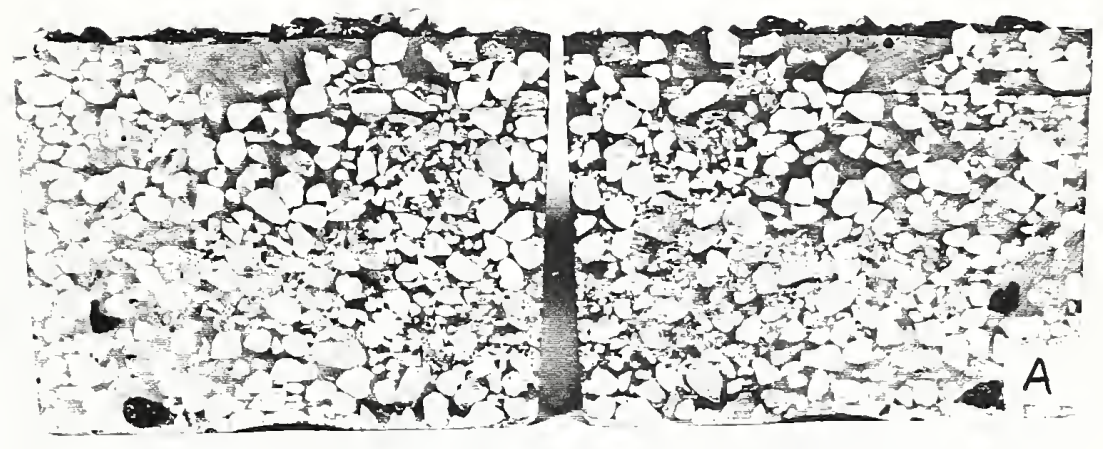

Test No. 1 (Sample A)

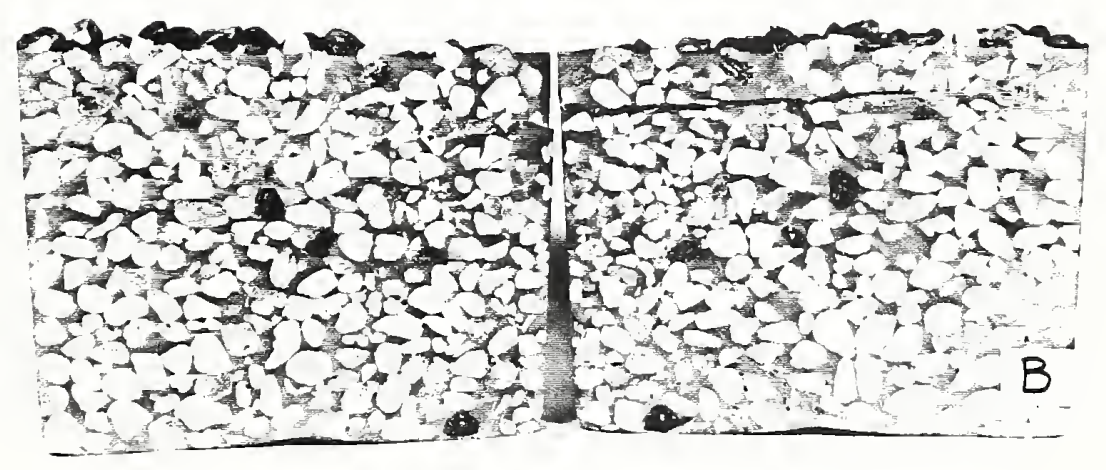

Test No. 2 (Sample B)

Figure 3. Sawed Sections of Polymer Concrete Specimens Cast Using Dry Aggregate at About $70^{\circ} \mathrm{F}$. 


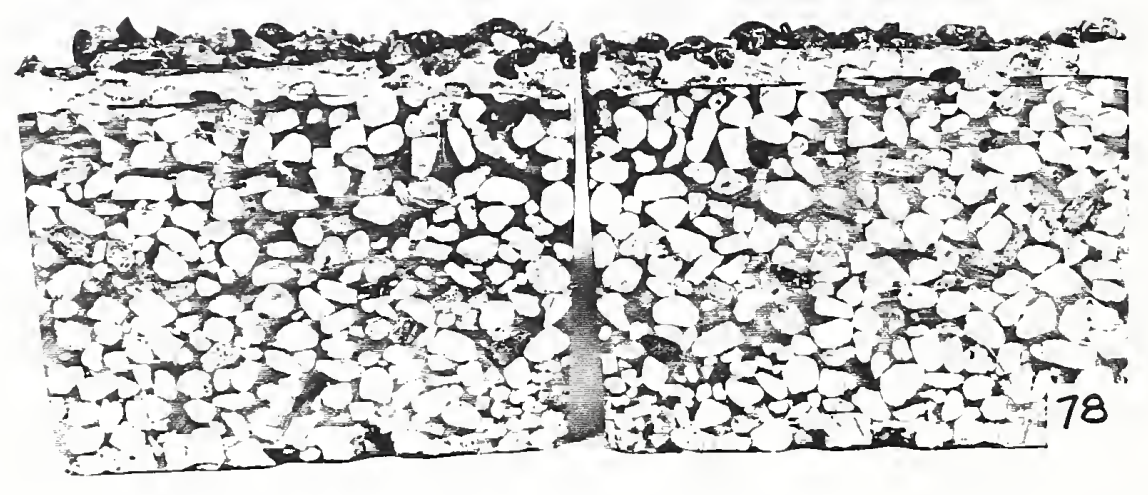

Test No. 78

Dry Aggregate at $-26^{\circ} \mathrm{F}$, Resin at $5^{\circ} \mathrm{F}$

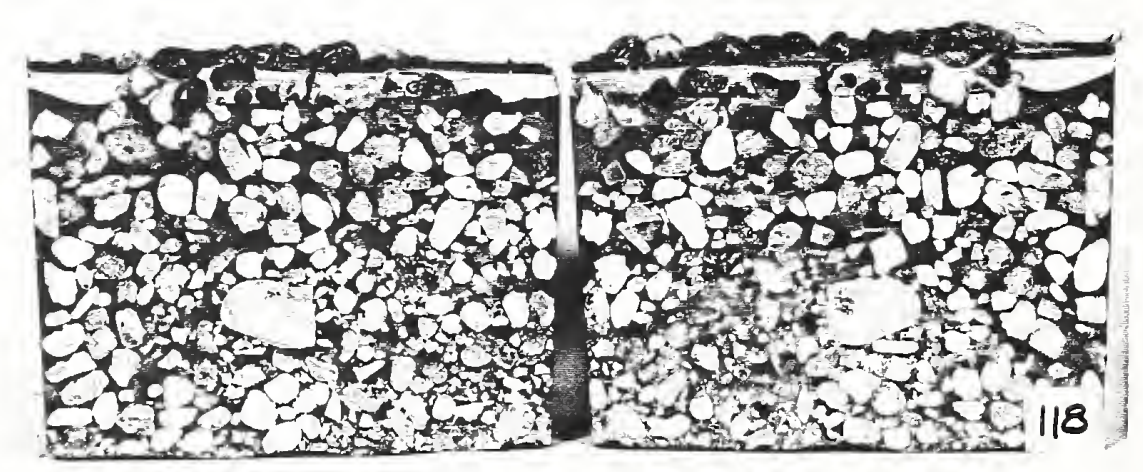

Test No. 118

Wet Aggregate at $9^{\circ} \mathrm{F}$, Resin at $5^{\circ} \mathrm{F}$

Figure 4. Sawed sections of Polymer concrete specimens Cast Using Dry Aggregate and saturated surface Dry Aggregate at cold Temperatures. 
The results of set time tests using saturated surface dry aggregate containing ice inclusions are reported in Tables 5 and 6. These tables give information about the time of set for this sexies of tests. In comparing catalyst ratios for set time tests using dry aggregate and saturated surface dry aggregate with aggregate containing ice inclusions, considerably more catalyst was used in the tests with the ice inclusions. It was difficult to control the set time when ice inclusions were in the aggregate. As these tests progressed, apparent short set times $(20-30$ seconds) were achieved. However, when the polymer concrete samples were examined after the tests, it was observed that only the top portion of the sample, a depth of about 3 to 5 inches, had resin and aggregate bonded together. The bond of the aggregate and resin in the lower parts of the specimens was poor or did not exist. Therefore, since the bond between aggregate and resin in the hardened polymer concrete was poor, the set time data from the specimens cast with saturated surface dry aggregate containing ice inclusions are not applicable for field use. Also, results for test runs with ice inclusions were inconclusive because set times were not reproducible (see Tables 5 and 6).

Photographs of polymer concrete made with ice inclusions are shown in Figures 5 and 6 . The poor bond between aggregate and resin is illustrated for Tests No. $144,149,150$, and 152 in Figure 5 and for Tests No. 154, 157, 160, and 162 in Figure 6 . 


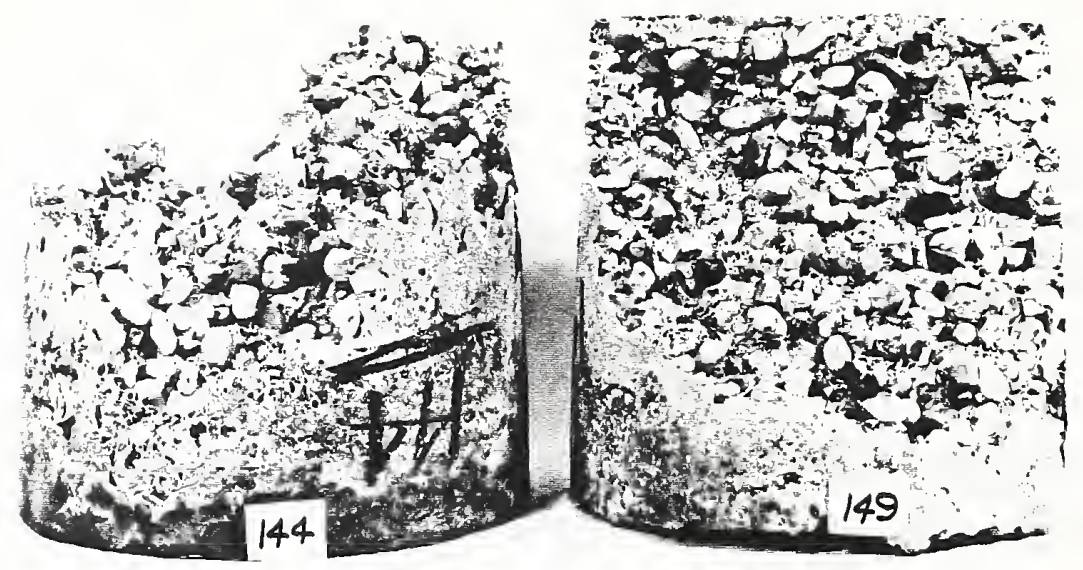

Test No. 144

Test No. 149

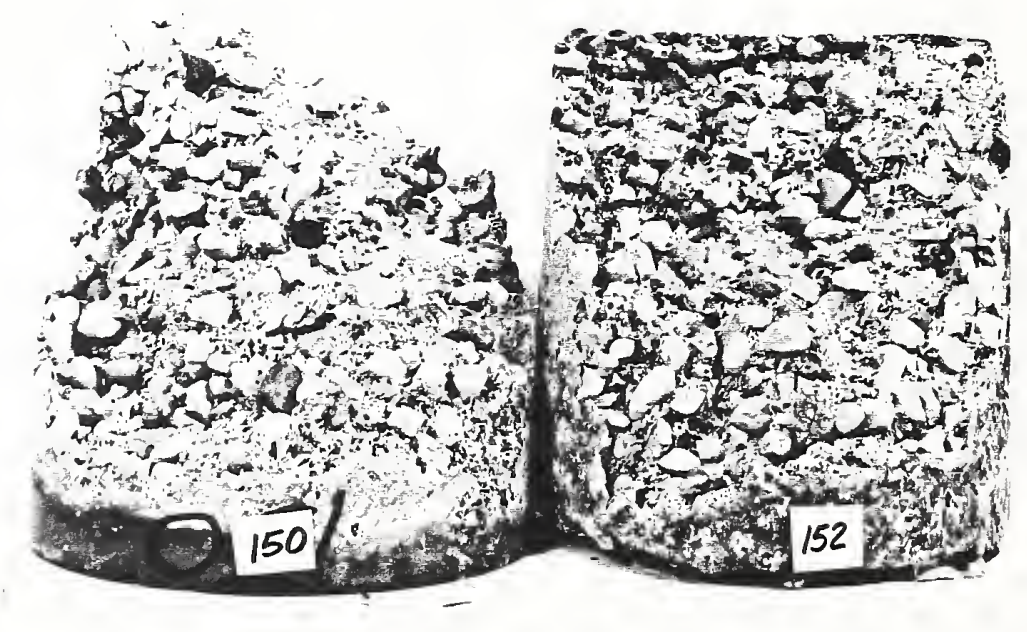

Test No. 150

Test No. 152

Figure 5. Polymer Concrete Specimens Cast with Ice Inclusions (Tests No. 144, 149, 150, and 152). 

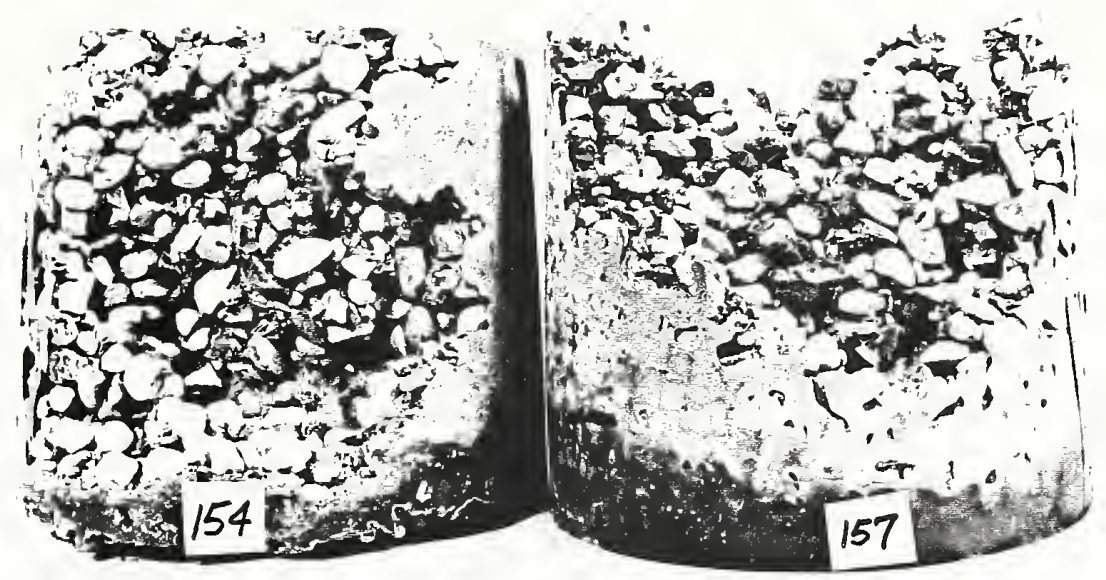

Test No. 154

Test No. 157

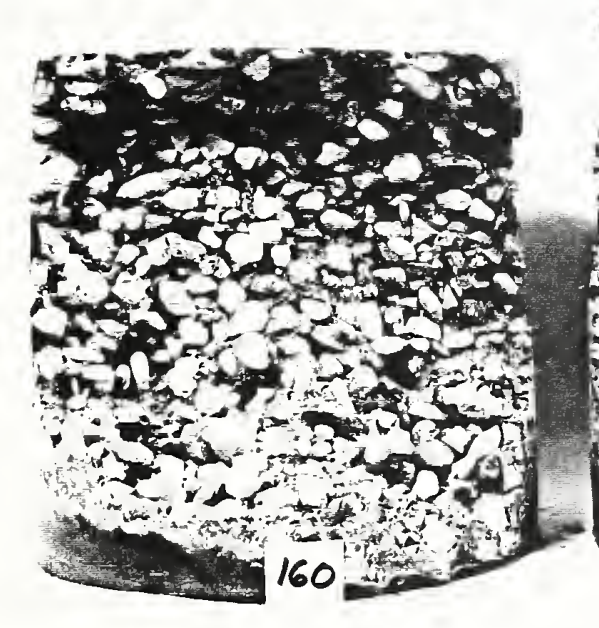

Test No. 160

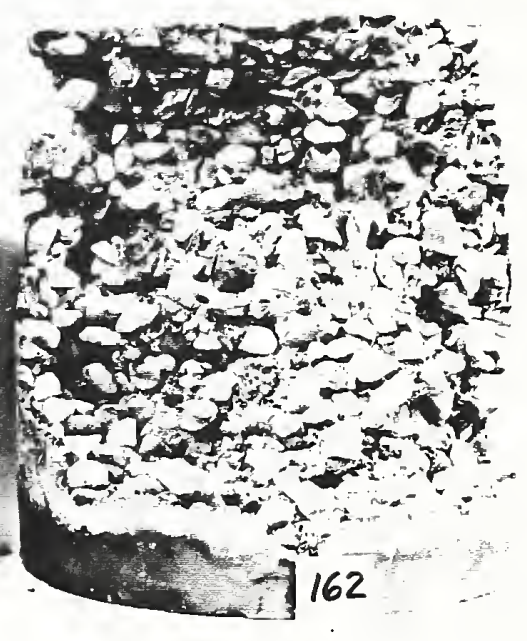

Test No. 162

Figure 6. Polymer concrete specimens cast with Ice Inclusions (Tests No. 154, 157, 160, and 162). 
The aggregate and resin temperatures and the percent ice inclusions for these tests are given in Table 5 .

Water is known to affect the rates of many chemical reactions. In this study, only the set time tests using saturated surface dry aggregate with ice inclusions involved appreciable amounts of moisture. As previously noted, considerably more catalyst was required in these tests as compared to tests where air dried or saturated surface dry aggregate was used. Furthermore, the tests which had ice inclusions were inconclusive with regard to set time because set times were not reproducible. Also, for those specimens containing ice-inclusions, the bond between aggregate and hardened resin was poor or did not exist over a large part of the hardened polymer concrete specimens. These differences in test results for polymer concrete specimens containing ice inclusions can also be attributed to the effect of moisture on the chemical reaction during hardening of the polyurethane resins. It is emphasized that very little moisture was present in the saturated surface dry aggregate and that the surface of the aggregate was dry. Since little moisture was present in the saturated surface dry aggregate, it apparently had little effect on the set time compared to tests where air dried aggregate was used.

\subsection{Flexural Strength}

Data from the flexural tests are presented in Table 7. A photograph of a flexural beam specimen is shown in Figure 7 . 


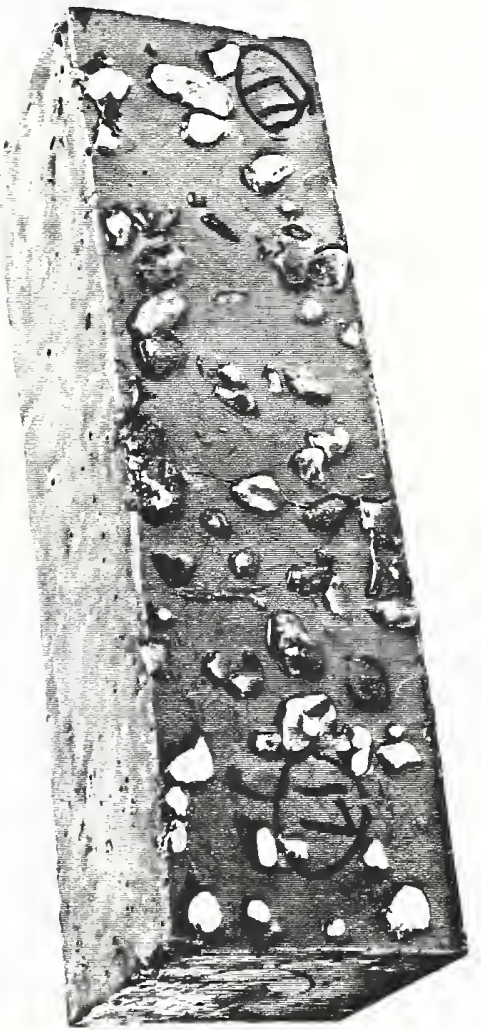

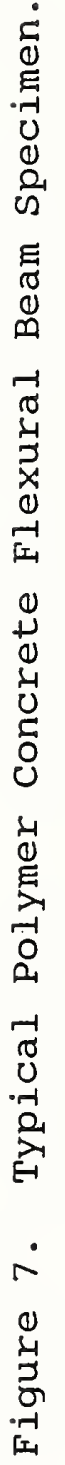


The modulus of rupture or flexural strength was determined from beams at age 30 minutes and was calculated as described in ASTM C 78. In this test, flexural strength of the polymer concrete is determined by use of a simple beam with third-point loading. Failure of the beams occurred in the middle third of their span length. The aggregate fractured along the failure line of beams cast at the higher temperatures. Bond failure between the aggregate and resin became more discernible as the casting temperature of the beams decreased. Figure 8 shows the fractured sections of polymer concrete beams from Tests No. 4 and 23 . Fractured aggregate can be seen along the failed surfaces of Beam No. 4, whereas pulled out aggregate can be seen along the failed surfaces of Beam No. 23. Beam No. 4 was cast at a high temperature $\left(110^{\circ} \mathrm{F}\right)$ and Beam No. 23 was cast at a low temperature $\left(0^{\circ} \mathrm{F}\right)$. See Table 7 for aggregate and resin temperatures.

Figure 9 shows the effects of temperature variations of the aggregate and resin on the flexural strength at the time of casting the beams. In this figure, the modulus of rupture is plotted versus $T_{m} \cdot T_{m}$ is a weighted value of aggregate temperature and resin temperature at the time of casting a beam specimen. See section 4.5.1.2 for an explanation of $T_{m}$. Temperatures of the aggregate and resin for each flexural test are given in Table 7. 


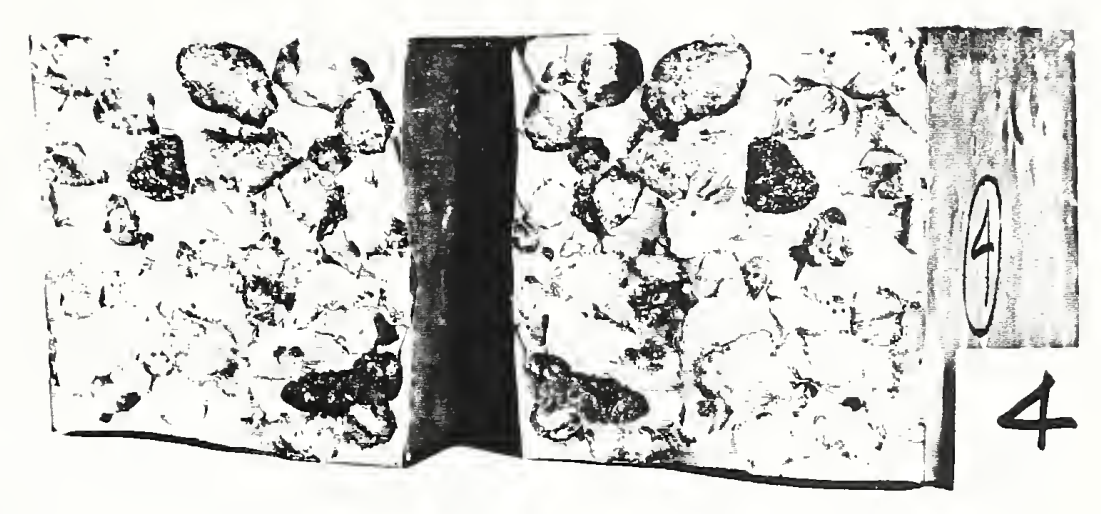

Test No. 4

Aggregate at $110^{\circ} \mathrm{F}$, Resin at $71^{\circ} \mathrm{F}$

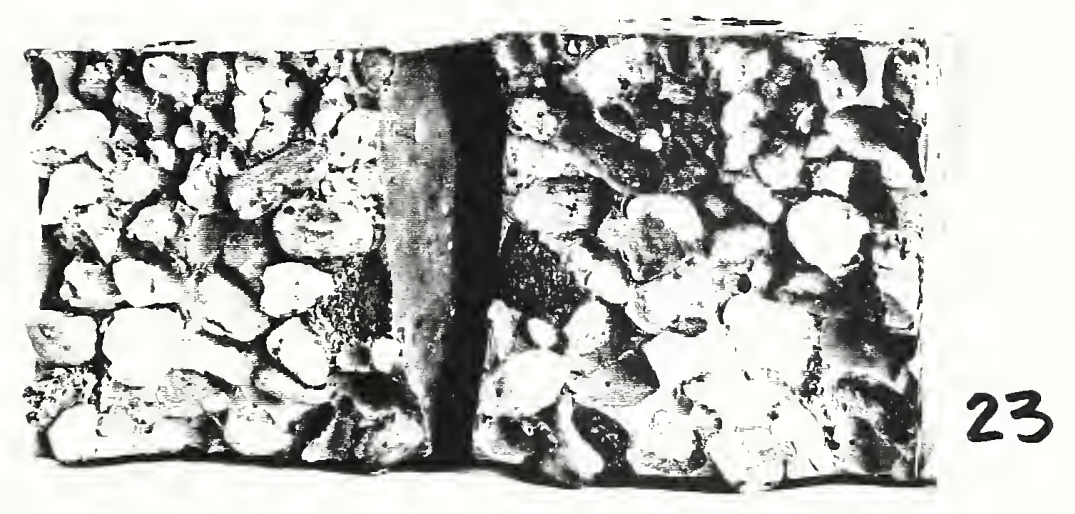

Test No. 23

Aggregate at $0^{\circ} \mathrm{F}$, Resin at $55^{\circ} \mathrm{F}$

Figure 8. Fractured sections of Flexural Beam specimens cast at High (Test No. 4) and Low (Test No. 23) Temperatures. 


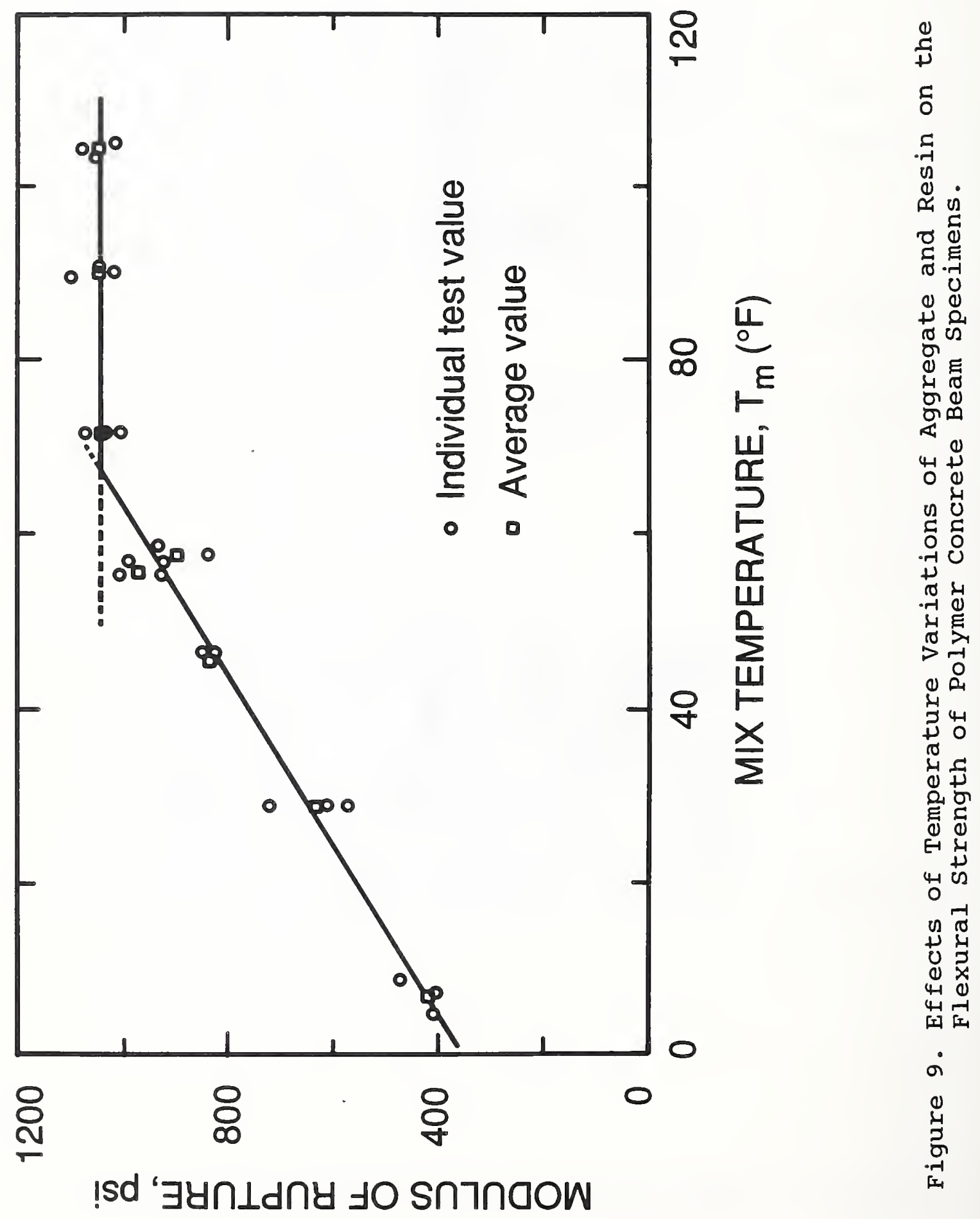


The modulus of rupture was essentially constant for values of $\mathrm{T}_{\mathrm{m}}$ above $70^{\circ} \mathrm{F}$. For lower values of $\mathrm{T}_{\mathrm{m}}$, the modulus of rupture decreased roughly linearly as $\mathrm{T}_{\mathrm{m}}$ decreased. It was observed at a beam age of 30 minutes that the hardened resin in five of the beam specimens was softer than in the other beams. Three of these beams were cast with the aggregate at temperatures between -26 and $-33^{\circ} \mathrm{F}$, one beam was cast with the aggregate at a temperature of $0^{\circ} \mathrm{F}$, and another beam was cast with the aggregate at a temperature of $21^{\circ} \mathrm{F}$.

The set times of the resin in casting the $4 \times 4 \times 14$ in. flexural beam specimens were in the range of 30 to 45 seconds. At least three beams were cast for each of the eight different combinations of aggregate and resin temperature as requested by AFESC.

During casting of the beam specimens, the resin flowed through the aggregate and completely filled the voids.

\subsection{Auxiliary Tests}

set time prediction model parameters were determined independently in separate tests. Resin heat capacities were found in experiments (denoted as resin warming) where the resins were allowed to warm together with an equivalent amount of water. The heat capacity of the aggregate was taken from the literature. Heat transfer coefficients were determined from tests (denoted as water immersion) conducted with water instead of resin, while reaction 
parameters were found from tests (denoted as kinetic) conducted in an insulated container which did not contain aggregate. The results of the auxiliary tests to determine set time model parameters are given in Appendix A.

\subsection{Pilot Set Time Tests Using Another Polyurethane Resin}

Set time data were obtained from pilot tests by casting a polymer concrete using a different resin (polyurethane) and catalyst than in the main series of tests and using the same mineral aggregate under various temperature and moisture conditions. The pilot set time tests were carried out using the same test procedure as reported in section 2.2.1. The proprietary resin used in the pilot tests was also a two part polyurethane. The important difference in the pilot tests and the main series of tests, reported in sections 2.2 .1 and 3.1, was that considerably more catalyst was needed in the pilot tests for comparable set times. This was more pronounced for the colder resin and aggregate temperatures. The intent, as in the previous tests, was to have set time between 55 and 75 seconds. Data for the pilot set time tests are reported in Table 8 . It is noted that in most of the pilot tests the catalyst was at room temperature $\left(70^{\circ} \mathrm{F}\right)$ when added to the Part I resin (phenol formaldehyde). The Part II resin was mostly methylene phenylene isocyanate oligomers. The Part I resin with catalyst was poured into and mixed with the Part II resin. The catalyst was phenylpropylpyridine. Information about 
Table 8. Pilot Set Time Tests Using Another Polyrurethane Resin

\begin{tabular}{|c|c|c|c|c|c|c|c|c|}
\hline $\begin{array}{l}\text { Run } \\
\text { Number }\end{array}$ & $\begin{array}{c}\text { Aggregate } \\
\text { Temp } \\
\left({ }^{\circ} \mathrm{F}\right)\end{array}$ & $\begin{array}{l}\text { Resin } \\
\text { Temp } \\
\left({ }^{\circ} \mathrm{F}\right)\end{array}$ & $\begin{array}{l}\text { Catalyst } \\
\text { Ratio by } \\
\text { Volume } \\
{\left[\frac{\text { Catalyst }}{\text { Part 1 }}\right]}\end{array}$ & $\begin{array}{l}\text { Catalysta } \\
\text { Volume } \\
\text { (ml) }\end{array}$ & $\begin{array}{l}\text { Set } \\
\text { Time } \\
\text { (s) }\end{array}$ & $\begin{array}{c}\text { Temp at } \\
\text { Set Time } \\
\left({ }^{\circ} \mathrm{F}\right)\end{array}$ & $\begin{array}{l}\text { Peak } \\
\text { Exotherm } \\
\text { Termp } \\
\left({ }^{\circ} \mathrm{F}\right)\end{array}$ & $\begin{array}{l}\text { Ice } \\
\text { Inclusions } \\
\text { (q) }\end{array}$ \\
\hline $\begin{array}{l}170 \\
171\end{array}$ & $\begin{array}{l}43 \\
44\end{array}$ & $\begin{array}{l}70 \\
70\end{array}$ & $\begin{array}{l}0.1410 \\
0.1320\end{array}$ & $\begin{array}{l}315 \\
290\end{array}$ & $\begin{array}{l}45 \\
53\end{array}$ & $\begin{array}{r}91 \\
103\end{array}$ & $\begin{array}{l}118 \\
118\end{array}$ & - \\
\hline $\begin{array}{l}172 \\
173\end{array}$ & $\begin{array}{l}45 \\
43\end{array}$ & $\begin{array}{l}55 \\
55\end{array}$ & $\begin{array}{l}0.1344 \\
0.1500\end{array}$ & $\begin{array}{l}300 \\
333\end{array}$ & $\begin{array}{l}75 \\
70\end{array}$ & $\begin{array}{l}102 \\
133\end{array}$ & $\begin{array}{l}114 \\
147\end{array}$ & - \\
\hline $\begin{array}{l}174 \\
175\end{array}$ & $\begin{array}{l}45^{C} \\
44^{C}\end{array}$ & $\begin{array}{l}55 \\
55\end{array}$ & $\begin{array}{l}0.1550 \\
0.1600\end{array}$ & $\begin{array}{l}344 \\
355\end{array}$ & $\begin{array}{l}77 \\
66\end{array}$ & $\begin{array}{r}118 \\
98\end{array}$ & $\begin{array}{l}130 \\
120\end{array}$ & - \\
\hline $\begin{array}{l}176 \\
177\end{array}$ & $\begin{array}{l}109 \\
108\end{array}$ & $\begin{array}{l}107 \\
108\end{array}$ & $\begin{array}{l}0,0099 \\
0.0113\end{array}$ & $\begin{array}{l}22 \\
25\end{array}$ & $\begin{array}{r}104 \\
98\end{array}$ & $\begin{array}{l}147 \\
152\end{array}$ & $\begin{array}{l}175 \\
174\end{array}$ & - \\
\hline $\begin{array}{l}178 \\
179\end{array}$ & $\begin{array}{l}103^{C} \\
103^{C}\end{array}$ & $\begin{array}{l}108 \\
109\end{array}$ & $\begin{array}{l}0.0135 \\
0.0158\end{array}$ & $\begin{array}{l}30 \\
35\end{array}$ & $\begin{array}{r}100 \\
93\end{array}$ & $\begin{array}{l}153 \\
158\end{array}$ & $\begin{array}{l}166 \\
180\end{array}$ & - \\
\hline $\begin{array}{l}180 \\
181 \\
182\end{array}$ & $\begin{array}{l}23^{C} \\
23^{C} \\
24^{C}\end{array}$ & $\begin{array}{l}55 \\
55 \\
55\end{array}$ & $\begin{array}{l}0.2496 \\
0.2815 \\
0.3041\end{array}$ & $\begin{array}{l}550 \\
625 \\
675\end{array}$ & $\begin{array}{c}140^{d} \\
90^{e} \\
64\end{array}$ & $\begin{array}{r}120 \\
76 \\
101\end{array}$ & $\begin{array}{r}127 \\
80 \\
103\end{array}$ & $\begin{array}{l}5 \\
5 \\
5\end{array}$ \\
\hline 183 & $24^{C}$ & 55 & 0.3604 & 800 & 48 & 118 & 125 & 10 \\
\hline $\begin{array}{l}184 \\
185 \\
186\end{array}$ & $\begin{array}{l}-27 \\
-26 \\
-27\end{array}$ & $\begin{array}{l}5 \\
5 \\
5\end{array}$ & $\begin{array}{l}0.4617 \\
0.6306 \\
0.7658\end{array}$ & $\begin{array}{l}1025 \\
1400 \\
1700\end{array}$ & $\begin{array}{c}130^{f} \\
95 \\
2209\end{array}$ & $\begin{array}{l}36 \\
15 \\
17\end{array}$ & $\begin{array}{l}52 \\
50 \\
38\end{array}$ & - \\
\hline 188 & $-22^{C}$ & 1 & 1.0000 & 2200 & $195^{h}$ & 24 & 53 & - \\
\hline
\end{tabular}

\footnotetext{
a Catalyst at room temperature $\left(70^{\circ} \mathrm{F}\right)$ was added to resin except for Test No. 186 and 188

b Percent by mass of aggregate

c Saturated surface dry aggregate

d $40 \%$ set at $110 \mathrm{~s} ; 80 \%$ set at $140 \mathrm{~s} ; 90 \%$ set at $195 \mathrm{~s}$

e $90 \%$ set at $90 \mathrm{~s}$

f $90 \%$ set at $130 \mathrm{~s}$; $100 \%$ set at $140 \mathrm{~s}$

g $85 \%$ set at $220 \mathrm{~s}$

h $75 \%$ set at $195 \mathrm{~s}$
} 
the components of the resins and catalyst were provided by the producer of the material. The AFESC requested that this proprietary resin should not be analyzed for its composition.

The polymer concrete specimens made using air dry aggregate and saturated surface dry aggregate and resin temperatures of $55^{\circ} \mathrm{F}$ or higher had the voids in the aggregate completely filled with resin. Specimens cast with resin temperatures $5^{\circ} \mathrm{F}$ or lower and those with ice inclusions present exhibited poor bond over their lower half. Figure 10 shows sawed sections of polymer concrete (Specimens No. 173 and 175) from pilot set time tests. It can be seen that the resin completely filled the voids in the aggregate in these two tests. See Table 8 for aggregate and resin temperatures for these pilot test specimens.

The viscosity of the resin at $5^{\circ} \mathrm{F}$ was like that of corn syrup. Because of the higher viscosity at this low temperature, the thick resin slowly settled to the bottom of the aggregate. When the low temperature resin set it appeared to be of rubbery consistency. 


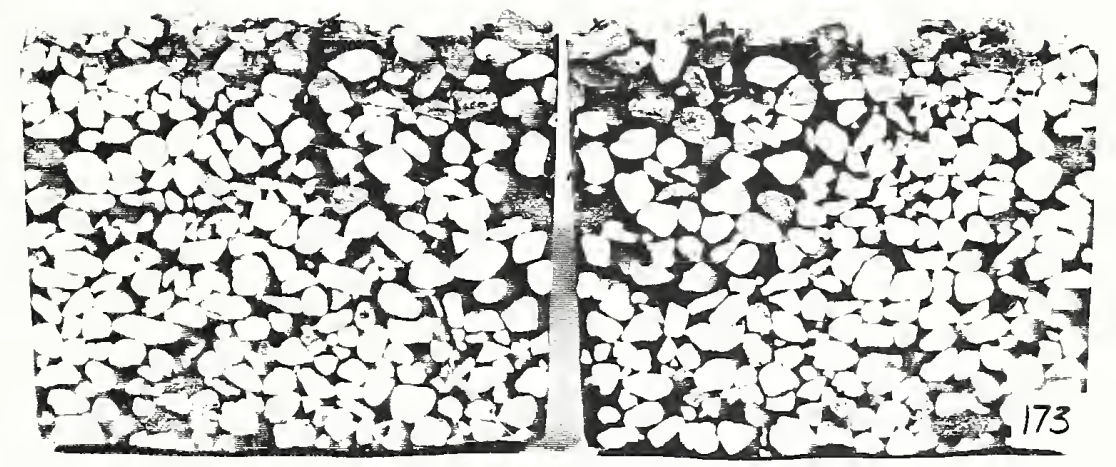

Test No. 173

Aggregate at $43^{\circ} \mathrm{F}$, Resin at $55^{\circ} \mathrm{F}$

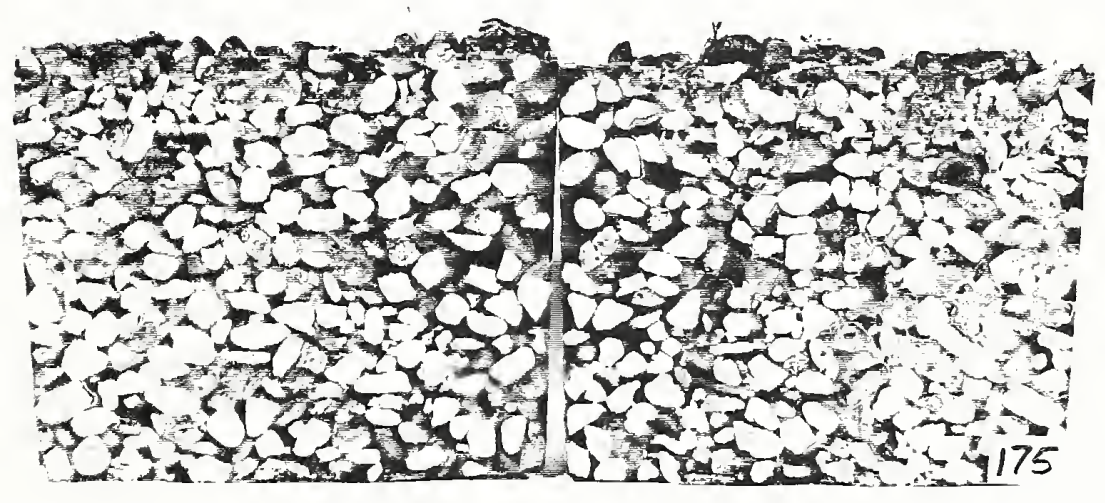

Test No. 175

Aggregate at $44^{\circ} \mathrm{F}$, Resin at $55^{\circ} \mathrm{F}$ Figure 10. Sawed Sections of Polymer Concrete Specimens from
Pilot set Time Tests (Tests No. 173 and 175). 
4. SET TIME PREDICTION MODEL FOR POLYMER CONCRETE

A mathematical model for the prediction of the set time of polymer concrete was developed based upon thermodynamic and kinetic principles. The model consists of energy balances, one for the resin matrix (continuous phase) and the other for the aggregate particles (dispersed phase), as well as a molar balance on the reacting species (resins). The energy balance is composed of two simultaneous coupled non-linear differential equations, one governing temperatures in the resin and the other temperatures in the aggregate. It accounts for heat exchange between resin and aggregate and the heat of reaction as well as heat losses to the surroundings. The molar balance consists of a single nonlinear differential equation governing the conversion of the resins into a polymer product. Because of the heat of reaction, the energy and molar balances are mathematically coupled.

Model input includes initial temperatures (resin, aggregate and surroundings), catalyst concentration, moisture and ice content (if present) and weights of aggregate and resin. Model parameters include heat transfer coefficients and time constants, specific heats of the phases, chemical reaction order, reaction activation energies and parameters measuring the effect catalyst concentration has on the reaction rate constant. Model output predicts set time, resin conversion, and the temperature of the resin and aggregate as functions of time. For runs with ice inclusions the model also predicts the fraction of ice which has melted. 
In order to independently determine the parameters of the model, separate auxiliary tests were made. Resin heat capacities were found in experiments where the resins were allowed to warm in a temperature controlled environment. Heat transfer coefficients and model time constants were found from tests conducted with water used in place of resin, while reaction parameters were found from separate runs conducted in insulated containers which contained no aggregate. These latter tests established a reaction order of 1.5 and a set time which occurred near 60 percent conversion of the resin regardless of experimental conditions. These results suggest for the system examined that reaction proceeds by a free radical mechanism which leads to a critical degree of chain branching where set rapidly insues. The reaction activation energy was found to decrease with increasing catalyst concentration, as would be expected based on kinetic theory. The data collected were fitted to models developed and solved specifically for the auxiliary tests. Use of independently determined parameters increased model credibility. Because of constraints, the time constant for aggregate heat transfer could not be independently found in this way. Instead, its value was determined by matching experimental data of resin temperature for each run directly to the set time prediction model and then using an overall average. Results showed that heat transfer into the aggregate was much faster than heat loss to the air. 
Values of the parameters obtained were used in the set time prediction model to compare to experimental data of set time and average resin temperature vs. time. Reasonable agreement was found between the model and the data since observed set times and resin temperatures were generally in accord with those predicted by the model. Larger deviations between predicted and experimental results were noted at higher catalyst concentrations and lower initial resin and aggregate temperatures.

The model was run in a simulation mode to produce generic plots which illustrated the effects of model parameters on resin temperature, conversion and predicted set times. Each parameter in turn was varied about its base value with the other parameters fixed at theirs. The relative importance of the governing phenomena was shown to be consistent with expected trends and results from the auxiliary tests.

Methods were also developed to extend this treatment to the simulation of field conditions for rapid runway repair using polymer concrete. By running the model repeatedly a series of design charts was prepared. The design charts can be used to predict set time given the catalyst concentration and initial temperatures of the aggregate and resin, or to determine the catalyst concentration to use to assure set within a given time at specified temperature levels. 


\section{1 Conceptual Model}

The conceptual basis for the mathematical model is discussed in terms of the mechanisms of heat transfer and reaction.

\subsubsection{Heat Transfer Mechanisms}

In the laboratory set time tests of polymer concrete, both the resins and aggregate were contained in a plastic bucket located in a temperature controlled environmental chamber. The catalyst was first premixed with Resin B (diamine-polyglycol) and then added and mixed with Resin A (isocyanate). The resulting mixture was then rapidly poured over the aggregate. Although the temperature of the chamber remained constant the temperature of the resin rose because the heat of reaction did not have enough time to escape to the surroundings. In the laboratory tests, the temperature of the resin rose rapidly at the start of the tests, sometimes to a maximum or peak exotherm, and then slowly fell to a pseudo-constant value much above ambient. set generally occurred while the temperature was increasing rapidly but before the peak exotherm. The temperature at set was generally slightly less than the peak exotherm.

Figure 11 depicts the heat flow occurring within the system. The energy of reaction can go into heating the resin and aggregate or be lost to the surroundings through the walls of the bucket. In 


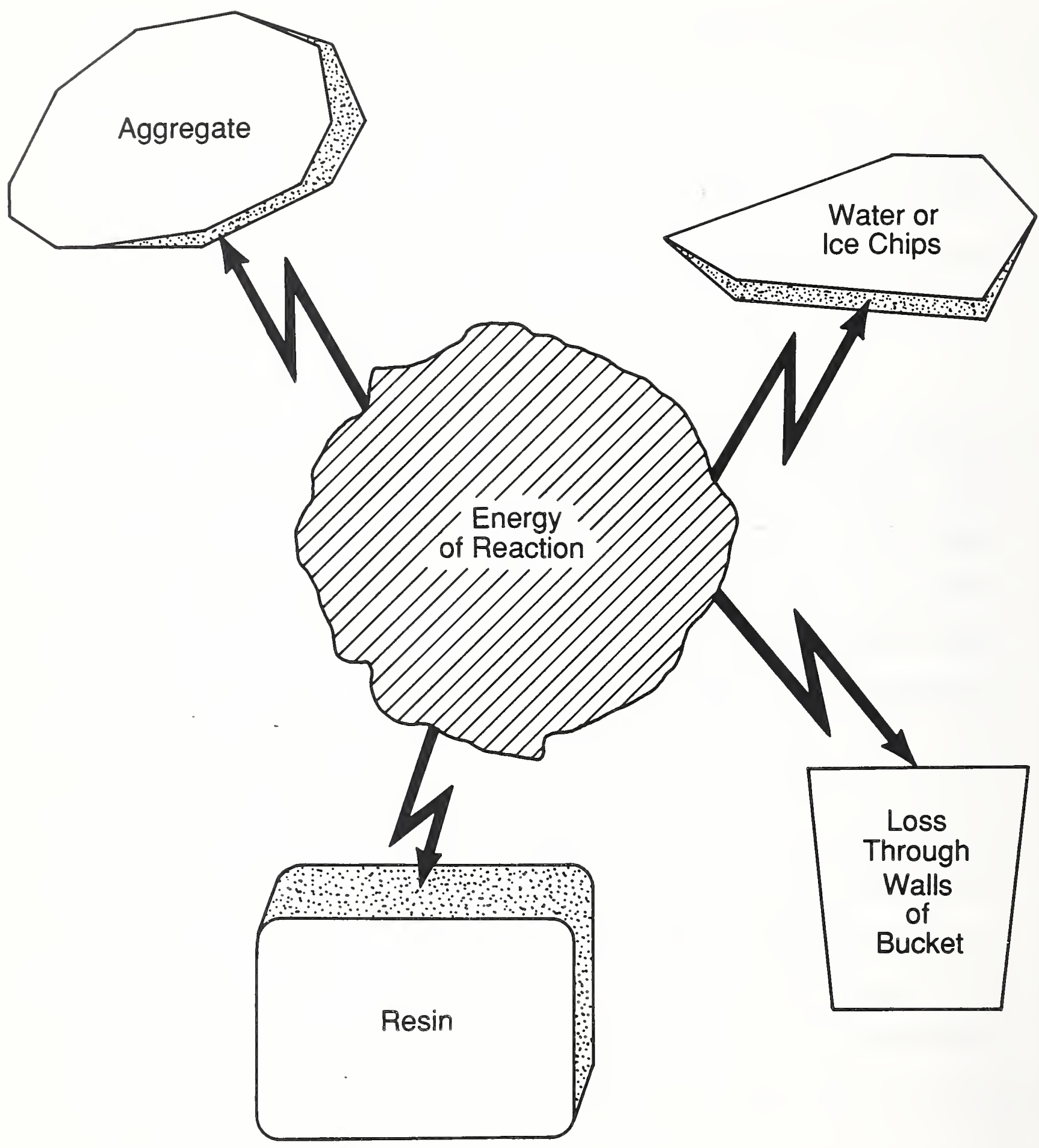

Figure 11. Heat Transfer witihin the Polymer Concrete System. 
runs conducted with moisture or ice inclusions, some of the energy of reaction can be transferred to heat the water and/or melt the ice. In those cases where the aggregate temperature is greater than that of the resin, heat flows the other way, i.e., from aggregate to resin.

It is the relative rate of heat transfer by different mechanisms which determines temperatures within the system, the conversion of the resins and set time. Heat transfer between phases is presumed to be dependent on convection across heat transfer films. Convection occurs between resin and aggregate, between resin and surroundings, and, with moisture or ice inclusions, between resin and water or ice. The less energy consumed in heating the resin, because of losses to the aggregate, moisture, ice or surroundings, the lower will be the temperature of the resin and the longer it will take set to occur. This effect feeds on itself since lowering the resin temperature will result in lower reaction rates leading to longer set times.

\subsubsection{Reaction Mechanisms}

With polymer reactions, the kinetic equations are normally formulated in terms of reactive groups rather than the actual concentrations of the resins. In this study, the composition and structure of the resins were proprietary and at the request of AFESC were not determined. Thus, it was not possible to determine 
the exact amount or nature of reactive groups present in the resin molecules. Reactions can involve chain initiation, propagation, and termination each of which can control reaction during a different period, and one of which may be rate controlling. It is also generally assumed that reaction rates are independent of the degree of polymerization. As molecular weights become larger, at higher degrees of polymerization, this assumption is less likely to be true.

The reaction between the two resins ( $A$ and $B$ ) is irreversible and is represented by

$$
\mathrm{a} A+\mathrm{b} B \stackrel{k}{\longrightarrow} \mathrm{PP}
$$

where $a, b$ and $p$ are the respective stoichiometric coefficients for Resin A, Resin B, and the polymer product $P$.

From the stoichiometry it follows that:

$$
\frac{\left[A_{0}\right]-[A]}{a}=\frac{\left[B_{0}\right]-[B]}{b}=\frac{[P]}{p}
$$

Here [A] and [B] are the molar concentrations of the reacting components in the Resins A and B after reaction has started, [P] is the concentration of polymer product $P$, and $\left[A_{O}\right]$ and $\left[B_{O}\right]$ are the initial concentrations. In the present analysis it is assumed that neither reacting ingredient is present in molar excess. Any other feed ratio would produce a residual amount of 
one of the resins whose excess would act as a diluent and contaminant, potentially lowering attainable strengths and increasing set times.

with neither reactant present in molar excess $\left[B_{0}\right]=\frac{b}{a}\left[A_{0}\right]$, so that:

$$
[B]=\frac{b}{a}[A]
$$

In general, for a power law rate equation, the rate of chemical reaction can be written as:

$$
-r_{A}=k^{\prime}[A]^{r}[B]^{q}
$$

where

- $I_{A}$ is the chemical reaction rate of $\operatorname{Resin} A\left(\operatorname{mol} \mathrm{A} / \mathrm{m}^{3}, \mathrm{~s}\right)$ $k^{\prime}$ is the reaction rate constant $r$ is the reaction order for Resin A $q$ is the reaction order for Resin B

The reaction rate is based on the amount of Resin A reacting per unit volume of solution obtained by mixing both resins together. The minus sign indicates that Resin $A$ is being consumed. 
Under condition that neither resin is present in molar excess it follows that:

$$
-r_{A}=k[A]^{r+q}=k[A]^{n}
$$

where $k=\left(\frac{b}{a}\right) q k^{\prime}$ is a modified reaction rate constant

Equation (5) results when (3) is substituted into equation (4). The overall reaction order is $n=r+q$. If the reaction was molecular (occurring as written in equation (1)) then the order would in general correspond to the stoichiometry (i.e., r=a, and $q=b)$ and the overall order would be $(a+b)$, an integer. However, many polymerization reactions are not molecular having nonintegral order characteristic of free-radical type reactions [14]. Thus $\mathrm{n}$ is unlikely to be an integer.

It is possible to obtain reaction orders and rate constants by analyzing kinetic data in terms of changes of concentrations of reactants (or products) with time. As shown in the next section, thermal data (temperature vs. time) can also be used to obtain information on the kinetics. However, in either case, it is not possible to obtain individual reaction orders, $r$ and $q$, unless experiments are conducted in which the relative amounts of Resins $A$ and $B$ used are changed from run to run. In the experiments conducted in this study, the amounts of Resins $A$ and $B$ were not varied. Only the amount of catalyst used and the initial 
temperature were varied. Thus, only the overall reaction order, $n$, was obtained.

\subsection{Mathematical Model}

The mathematical model for set time prediction was developed based on the conceptual model.

\subsubsection{Energy Balance: Dry Aggregate}

In this section, the aggregate is presumed to be dry so that there is no moisture nor ice inclusions present.

The temperature of the resin $(T)$ and the aggregate $\left(T_{a}\right)$ in the bucket are assumed to vary with time, but not with position within the system. This was observed from data from the three thermocouples in the aggregate in the bucket. The measured temperatures were usually within several degrees from one another after the mixed resins were poured into the aggregate. Accounting for the different modes of heat transfer (refer to Figure 11), a macroscopic energy balance can be written for both the resin and the aggregate. The energy balance has the form:

Rate of Accumulation of Energy

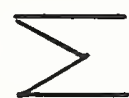

Rate of Input of Energy

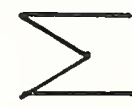
Rate of output of Energy

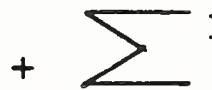

Rate of Appearance of Energy by Chemical Reaction 
For the resin the energy balance becomes:

$$
\begin{aligned}
& \frac{d E_{t}}{d t}=M C_{v} \frac{d T}{d t}=-U_{0} A\left(T-T_{a i r}\right)-h A_{a}\left(T-T_{a}\right)+\left(-r_{A}\right)\left(-\Delta H_{A}\right) V \\
& \frac{\text { accumulation }}{\text { of energy }} \frac{\text { loss of energy }}{\underline{\text { to air }}} \frac{\text { loss of energy }}{\text { to aggregate }} \frac{\text { generation of }}{\frac{\text { energy by }}{\text { ghenical }}}
\end{aligned}
$$

where

$E_{t}$

$\mathrm{U}_{\mathrm{O}}$

h

A

Aa is the total energy of the resin mixture (J)

is the overall heat transfer coefficient between the resin and the $\operatorname{air}\left(\mathrm{W} / \mathrm{m}^{2} \cdot \mathrm{K}\right)$

is the heat transfer coefficient between the resin and the aggregate $\left(\mathrm{W} / \mathrm{m}^{2}\right.$. K)

is the surface area of the resin exposed to the $\operatorname{air} m^{2}$ )

is the total surface area of the aggregate particles $\left(\mathrm{m}^{2}\right)$

$\mathrm{T}, \mathrm{T}_{\mathrm{a}}, \mathrm{T}_{\mathrm{air}}$ are the temperatures of the resin, aggregate

and air respectively (K)

M is the mass of resin (kg)

$\mathrm{C}_{\mathrm{V}} \quad$ heat capacity of $\operatorname{resin}(\mathrm{J} / \mathrm{kg} \cdot \mathrm{K})$

$-r_{A} \quad$ is the rate of chemical reaction (mol $\mathrm{A} / \mathrm{m}^{3}$. s)

$\left(-\Delta H_{A}\right)$ is the enthalpy of reaction $(\mathrm{J} / \mathrm{mol} A)$

$\mathrm{V} \quad$ is the volume of resin $\left(\mathrm{m}^{3}\right)$

$t \quad$ is time(s)

Assuming that potential and kinetic energy changes are negligible, the total energy, $E$, of the system will be equal to the internal energy $U$.

$$
\frac{d E_{t}}{d T}=d U=M C_{v} d T
$$


The overall heat transfer coefficient $U_{0}$ can be found from a knowledge of the dimensions of the bucket, individual inside (resin to bucket) and outside (bucket to air) heat transfer coefficients, and the thermal conductivity of the bucket walls. An expression can be developed for $U_{0}$ by considering that heat transfer occurs through the bucket walls in series with convection through inside and outside heat transfer films, but in parallel when considering that heat can simultaneously be lost from the sides, top and bottom of the bucket.

An energy balance (equation (7)) can also be written for the aggregate particles. It takes the form:

$$
M_{a} c_{v a} \frac{d T_{a}}{d t}=h A_{a}\left(T-T_{a}\right)
$$

where

$\mathrm{M}_{\mathrm{a}}$ is the mass of aggregate $(\mathrm{kg})$

$C_{v a}$ is the heat capacity of the aggregate $(\mathrm{J} / \mathrm{kg} \cdot \mathrm{k})$

Equation (9) equates the aggregate's rate of gain of internal energy to the heat flowing into the aggregate particles from the resin. When the aggregate is colder than the resin $\left(T_{a}<T\right)$, heat will flow the other way. Under these conditions, equation (9) will still be valid. 
Considering the Resin A contained in the bucket as the system and applying the molar conservation equation:

$$
-\frac{d N_{A}}{d t}=\left(-r_{A}\right) V
$$

where $\mathrm{N}_{\mathrm{A}}$ is the mols of Resin A contained in the system.

Unlike energy flow, there is no flow of $A$ in or out of the system, so that the depletion of A matches its disappearance by reaction. Since $\mathrm{N}_{\mathrm{A}}=[\mathrm{A}] \mathrm{V}$ and $\mathrm{V}$ is constant, it follows from equation (10) that,

$$
-\frac{d[A]}{d t}=\left(-r_{A}\right)
$$

a result which is true in general for any compound in a batch system. Substituting equation (5), the kinetic rate expression, into equation (11):

$$
-\frac{d[A]}{d t}=k[A]^{n}=k_{0} e^{-E / R T}[A]^{n}
$$

In general, as shown by equation (12), the rate constant $k$ will vary with temperature according to the widely used Arrhenius form:

$$
k=k_{0} e^{-E / R T}
$$


where $k_{0}$, the pre-exponential factor, is often presumed constant, but can be a function of temperature or activation energy, $E$, depending on the theory employed [15]

Equations (7), (9) and (12) comprise a set of three simultaneous non-linear ordinary differential equations governing the temperatures and concentration within the system. Together with their initial conditions, $T_{O}, T_{a O}$ and $\left[A_{O}\right]$, they can be solved simultaneously to predict resin and aggregate temperatures as a function of time as well as the concentration of resin remaining at any time.

Knowing the concentration, the conversion of resin (x) can be obtained:

$$
x=\frac{\left[A_{0}\right]-[A]}{\left[A_{0}\right]}
$$

The conversion will vary from 0 to 1 as reaction proceeds and the resin concentration changes from its initial to final value.

\subsubsection{Mathematical Model: Dimensionless Form}

The model can also be expressed in dimensionless form in order to facilitate computation. In the dimensionless form, equations (7), (9) and (12) become, respectively, equations (14), (15) and (16): 


$$
\begin{aligned}
& -\frac{d T^{\prime}}{d t^{\prime}}=\frac{T^{\prime}-T_{\text {air }}^{\prime}}{r}+m\left(T^{\prime}-T^{\prime} a\right)-(-\Delta H)^{\prime} \frac{d x}{d t^{\prime}} \\
& -\frac{\mathrm{dT}_{\mathrm{a}}^{\prime}}{\mathrm{dt^{ \prime }}}=\left(\mathrm{T}_{\mathrm{a}}^{\prime}-\mathrm{T}^{\prime}\right) \\
& \frac{d x}{d t^{\prime}}=t_{a} B e^{-E / R T}(1-x)^{n}
\end{aligned}
$$

where

$$
\begin{aligned}
& \mathrm{T}^{\prime}=\mathrm{T} / \mathrm{T}_{\mathrm{o}}, \quad \mathrm{T}^{\prime} \operatorname{air}=\mathrm{T}_{\mathrm{air}} / \mathrm{T}_{\mathrm{O}}, \quad \mathrm{T}_{\mathrm{a}}{ }^{\prime}=\mathrm{T}_{\mathrm{a}} / \mathrm{T}_{\mathrm{O}} \\
& \text { (dimensionless temperatures) } \\
& t^{\prime}=t / t_{a}, \text { dimensionless time } \\
& t_{a}=\frac{M_{a} C_{v a}}{h A_{a}} \text {, aggregate time constant } \\
& t_{\text {air }}=\frac{M C_{v}}{U A} \text {, air time constant } \\
& \text { Ma } \mathrm{C}_{\mathrm{va}} \\
& m=\frac{}{M C_{V}} \text {, aggregate-to-resin heat capacity ratio } \\
& \frac{t_{\text {air }}}{t_{a}} \text {, time constant ratio } \\
& (-\Delta H)^{\prime}=\frac{\left(-\Delta H_{A}\right) V^{\left[A_{0}\right]}}{M C_{V} T_{0}} \text {, dimensionless heat of reaction } \\
& B=\left[A_{0}\right] k_{0}^{n} \text {, modified pre-exponential factor }
\end{aligned}
$$

The primed notation denotes dimensionless quantities. The dimensionless initial conditions are that at time zero, 
$\mathrm{T}_{0}^{\prime}=1, \mathrm{~T}_{\mathrm{a} o}^{\prime}=\mathrm{T}_{\mathrm{a} o} / \mathrm{T}_{0}$ and $\mathrm{x}_{0}=0$. In the model the dimensionless time $t^{\prime}$ is based on the aggregate time constant $t_{a}, i . e ., t^{\prime}=t^{\prime} t_{a}$.

$t_{a i r}$ and $t_{a}$ are time constants for the transfer of heat from the resin to the air and aggregate, respectively. They have physical significance because they are a measure of the time taken for the resin to lose a certain amount of energy in the absence of other modes of heat transfer. The ratio of the time constants $t_{a i r} / t_{a}$ (denoted by $r$ ), which appears in the dimensionless resin energy balance, is the ratio of the rates at which energy produced by the chemical reaction goes into air and the aggregate, respectively. High values of $r$ indicate that heat is transferred much more rapidly to the aggregate than it is to the air. In this situation, the temperatures of the resin and aggregate will rapidly approach each other because heat is only slowly lost to the outside.

Subsequent heat transfer would then occur to the surrounding air with the system cooling as a unit.

Casting the model in dimensionless form has a number of advantages. The number of variables are greatly reduced, the physical significance of model parameters is more apparent and the use of a dimensionless model facilitates comparison with experimental data. 
The effects of moisture in aggregate (saturated surface dry) on setting time was also investigated. Between 0.5 and 0.9 percent by mass of moisture was added to the aggregate prior to the tests. In other tests, ice inclusions were added as granulated ice. The model was modified to treat these conditions.

\subsubsection{Wet Aggregate (Saturated Surface Dry)}

The quartz aggregate was relatively impermeable. Little water was observed on the surface of the saturated surface dry aggregate after towel drying. The aggregate absorbed 0.4 to 0.9 percent water by mass. At temperatures below freezing, small ice crystals were present on the aggregate surfaces. When the reaction began this ice melted. An energy balance on the iceaggregate system gives an estimate of $\mathrm{T}_{\mathrm{a}}$, the temperature of aggregate reached when ice of mass $M_{i}$ has melted:

$$
T_{\text {aio }}=T_{\text {ao }}-\frac{M_{i} \lambda_{m}}{M_{a} C_{\text {va }}}
$$

where $\lambda_{\mathrm{m}}$ is the latent energy of melting.

For runs made using wet aggregate, $\mathrm{T}_{\mathrm{a}}$ io is a more representative measure of the initial aggregate temperature than $T_{a o}$. However, since $\mathrm{M}_{i} / \mathrm{M}_{\mathrm{a}}$ is only about 0.003 , the value of the second term will be less than a fraction of a degree. Therefore, little 
error is introduced in analyzing the wet aggregate runs using the model previously developed for dry aggregate.

\subsubsection{Ice Inclusions}

In runs made with the addition of granulated ice, the amount of ice employed was sufficiently large (5 to 10 percent by mass of the aggregate) that a significant amount of the reaction energy went into heating the ice to $0^{\circ} \mathrm{C}$, melting it, and then warming the water formed above $0^{\circ} \mathrm{C}$. In this case, the model had be modified to account for these phenomena. The effect is to split the resin energy balance into three regions or periods, one corresponding to times before the ice begins to melt $\left(t<t_{A}\right)$, one while the ice is melting $\left(t_{A}<t<t_{B}\right)$ and the last after all the ice has melted $\left(t>t_{B}\right)$. In addition, predictions need to be made of the ice temperature, $T_{i}$, the water temperature, $T_{W}$, and the fraction, $f$, of the ice which has melted at any given time. Model development is similar to that for the dry aggregate runs. The dimensionless model is presented below as equations (18) through (23). For ease in interpretation, the equations have been multiplied by $T_{0}$, the initial resin temperature. The time of applicability of each equation is underlined below the equation. Initial conditions are also presented below each equation.

Equations 18,19 and 20 give the resin energy balance during the three periods. 


$$
\begin{aligned}
& \frac{d T}{d t^{\prime}}=\frac{T_{a i r}}{r}+m\left(T-T_{a}\right)+\frac{m_{i}}{r_{i}}\left(T-T_{i}\right)-(-\Delta H)^{\prime} T_{0} \frac{d x}{d t^{\prime}} \\
& \left(T=T_{0} \text { at } t=0\right) \quad\left(t<t_{A}\right) \\
& -\frac{d T}{d t^{\prime}}=\frac{T-T_{a i r}}{r}+m\left(T-T_{a}\right)-(-\Delta H)^{\prime} T_{0} \frac{d x}{d t^{\prime}}+\frac{m_{i w}}{r_{i w}}(T-273.2) \\
& T=T_{A O} \text { at } t=t_{A} \quad\left(t_{A}<t<t_{B}\right) \\
& -\frac{d T}{d t^{\prime}}=\frac{T-T_{a i r}}{r}+m\left(T-T_{a}\right)-(-\Delta H)^{\prime} T_{0} \frac{d x}{d t^{\prime}}+\frac{m_{w}}{r_{W}}\left(T-T_{W}\right) \\
& T=T_{B O} \text { at } t=t_{B} \quad\left(t>t_{B}\right)
\end{aligned}
$$

Equations 21, 22 and 23 give the ice-water energy balance during the three periods.

$$
\frac{d T_{i}}{d t^{\prime}}=\frac{\left(T-T_{i}\right)}{r_{i}} \quad \text { ice only }
$$

$T_{i}=T_{i 0}$ at $t=0$

$\underline{\left(t<t_{A}\right)}$

$$
\frac{d f}{d t^{\prime}}=T_{0} \frac{(T-273.2)}{r_{i W}}
$$$$
\text { ice and water }
$$

$$
f=0 \text { at } t=t_{A}
$$$$
\left(t_{A}<t<t_{B}\right)
$$

$$
\begin{aligned}
& \frac{d T_{W}}{d t^{\prime}}=\frac{\left(T-T_{W}\right)}{r_{W}} \\
& \frac{T_{W}=T_{W O}=273.2 \mathrm{~K} \text { at } t=t_{B}}{70} \frac{\left(t>t_{B}\right)}{(10}
\end{aligned}
$$$$
\text { water only }
$$ 
where

$$
\begin{gathered}
r_{i}=\frac{t_{i}}{t_{a}} \text {, ice time constant ratio } \\
\text { with } t_{i}=\frac{M_{i} c_{v i}}{h_{i}{ }^{A}} \text {, ice time constant }
\end{gathered}
$$

and

$$
\begin{aligned}
& \mathrm{M}_{\mathrm{i}}=\text { mass of ice }(\mathrm{kg}) \\
& C_{\mathrm{vi}}=\text { specific heat of ice }(\mathrm{J} / \mathrm{kg} \cdot \mathrm{K}) \\
& \mathrm{h}_{\mathrm{i}}=\text { heat transfer coefficient between resin and ice } \\
& \left(W / m^{2} \cdot K\right) \\
& A_{i}=\text { surface area of ice }\left(m^{2}\right) \\
& m_{i}=\frac{M_{i} C_{v i}}{M C_{v}} \text {, ice to resin heat capacity ratio }
\end{aligned}
$$

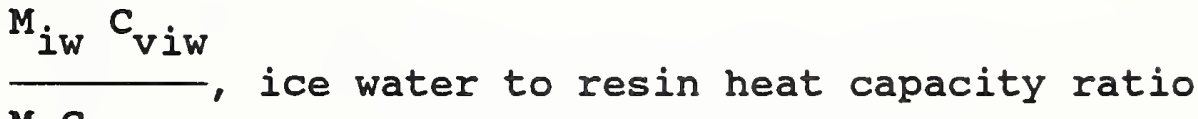

$$
\begin{aligned}
& \mathrm{m}_{\mathrm{iw}}=\frac{}{\mathrm{MC} \mathrm{C}_{\mathrm{v}}} \text {, ice water to resin heat capacity ratio } \\
& m_{w}=\frac{M_{W} C_{V w}}{M C_{v}} \text {, water to resin heat capacity ratio }
\end{aligned}
$$

and

$$
\begin{aligned}
& \mathrm{C}_{\mathrm{Vw}}=\text { specific heat of water }(\mathrm{J} / \mathrm{kg} \cdot \mathrm{K}) \\
& h_{W}=\text { heat transfer coefficient between the resin and the water } \\
& \left(w / m^{2} \cdot K\right) \\
& r_{i w}=\frac{t_{i w}}{t_{a}} \text {, ice-water time constant ratio }
\end{aligned}
$$


with

$$
t_{i w}=\frac{M_{i} C_{v i w}}{h_{i w} A_{i}} \text {, ice-water constant }
$$

and

$$
\begin{aligned}
& \mathrm{C}_{\mathrm{viw}}=\text { specific heat of ice-water mixture }(\mathrm{J} / \mathrm{kg} \cdot \mathrm{K}) \\
& \mathrm{h}_{\mathrm{iw}}=\text { heat transfer coefficient between the resin and the }
\end{aligned}
$$
ice-water $\left(\mathrm{W} / \mathrm{m}^{2} \cdot \mathrm{K}\right)$

$$
r_{w}=\frac{t_{w}}{t_{a}} \text {, water time constant ratio }
$$

with

$$
t_{w}=\frac{M_{i} C_{v w}}{h_{w} A_{i}} \text {, water time constant }
$$

The differential equations for the aggregate energy balance, equation (15), and the reaction kinetics, equation (16), are the same as when the aggregate is dry. $T_{A O}$ is the resin temperature when the ice first melts $\left(t=t_{A}\right)$, while $T_{B O}$ is the resin temperature when all the ice has melted $\left(t=t_{B}\right)$. $T_{\text {io }}$ is the initial ice temperature. All the ice will have melted (at $t=t_{B}$ ) when $f=1$. Considering that water and ice have similar specific heats and heat transfer coefficients, it is reasonable to assume that $\mathrm{m}_{\mathrm{i}}=\mathrm{m}_{\mathrm{iw}}=\mathrm{m}_{\mathrm{w}}$. The differential equations governing the model for the system with ice inclusions [equations (15), (16), and (18) through (23)] can be programmed and solved to predict 
resin, aggregate, ice and water temperatures as well as the conversion and fraction of ice melted at any time.

\subsection{Model Parameters}

In developing the set time prediction model for polymer concrete, information on the properties of the resins and aggregate, on the rate of internal and external heat transfer, and on the rate and heat of reaction of the two-part resin system using various amounts of catalyst was needed as input to the set time prediction model. This section summarizes model parameters, the methods used to find them and discusses their significance.

\subsubsection{Determination of Model Parameters}

Table 9 presents a summary of the values of the model parameters. These were determined from auxiliary tests, from accepted literature values, from model equations and from the simulation tests themselves. The mathematical model contains geometric parameters like mass and density, thermal parameters like specific heats and heat transfer coefficients, and kinetic parameters like activation energy and reaction order. Although geometric parameters can be measured directly and others like specific heat can be obtained from the literature, the other model parameters are unknown. Separate auxiliary tests were devised and conducted to provide these data so that most model 
Table 9. Set Time Model Parameters

\begin{tabular}{|c|c|c|}
\hline Parameter & Value & Test Method or Citation \\
\hline$c_{V A}$ & $1.846 \mathrm{~kJ} / \mathrm{kg} \cdot \mathrm{K}$ & auxiliary - resin warming \\
\hline$c_{v B}$ & $1.788 \mathrm{~kJ} / \mathrm{kg} \cdot \mathrm{K}$ & auxiliary - resin warming \\
\hline$c_{v}$ & $1.748 \mathrm{~kJ} / \mathrm{kg} \cdot \mathrm{K}$ & calculated - weighted average \\
\hline$c_{\text {va }}$ & $1.088 \mathrm{~kJ} / \mathrm{kg} \cdot \mathrm{K}$ & literature [16] \\
\hline $\mathrm{m}$ & 2.176 & equation (14) \\
\hline$U_{0}$ & $9.56 \times 10^{-2} \mathrm{~kJ} / \mathrm{kg} \mathrm{m} \mathrm{m}^{2} \mathrm{~s}$ & equation (AI) \\
\hline $\mathrm{r}$ & $>100$ & auxiliary - water immersion \\
\hline$t_{\text {air }}$ & $2.38 \times 10^{4} \mathrm{~s}$ & auxiliary - water immersion \\
\hline$t_{a}$ & $95.2 \mathrm{~s}$ & $\begin{array}{l}\text { simulation fit, weighted } \\
\text { average }\end{array}$ \\
\hline$\Delta \mathrm{H}^{\prime}$ & 0.3626 & $\begin{array}{l}\text { auxiliary - kinetic, } \\
\text { equation ( } \mathrm{A} 12)\end{array}$ \\
\hline $\mathrm{n}$ & 1.5 & auxiliary - kinetic \\
\hline$E_{0}$ & $6800 \mathrm{cal} / \mathrm{g} \mathrm{mol}$ & auxiliary - kinetic \\
\hline$E_{\mathrm{m}}$ & $9230 \mathrm{cal} / \mathrm{g} \mathrm{mol}$ & auxiliary - kinetic \\
\hline $\mathrm{m}_{0}$ & $1540 \mathrm{~g} \mathrm{~mol} / \mathrm{cal}$ & auxiliary - kinetic \\
\hline$B_{0}$ & $4.09 \times 10^{2} \mathrm{~s}^{-1}$ & auxiliary - kinetic \\
\hline$\alpha$ & $5.6 \times 10^{-4} \mathrm{~g} \mathrm{~mol} / \mathrm{cal}$ & auxiliary - kinetic \\
\hline
\end{tabular}


parameters were determined independently of the polymer concrete set time experiments. The experimental procedure for the auxiliary tests is explained in Appendix A. Along with the best values obtained for the model parameters, Table 9 also provides the test method used in the auxiliary tests to determine the parameters. Appendix A provides the model development that was used to obtain these parameters.

In its dimensionless form the overall mathematical model contains eight unknown model constants, the air and aggregate time constants, $t_{a i r}$ and $t_{a}$; the heat capacity ratio, $m$, the time constant ratio $r$; the dimensionless heat of reaction, $\Delta H^{\prime} ;$ the reaction order, $\mathrm{n}$; and the kinetic factor, $\mathrm{B}$. Additional kinetic parameters are involved in finding the temperature dependence of B. The three auxiliary test methods used to find model parameters have been designated as resin warming tests (used to determine heat capacity parameters and thermal parameters, $m$ and $U_{0}, C_{V A}$, $c_{v B}, C_{v}$ and $m$ ), water immersion tests (used to determine, or attempt to determine, time constant and thermal parameters, $r$, $t_{a i r}, t_{a}$, and $U_{0}$ ), and kinetic tests (used to determine kinetic parameters $\Delta H^{\prime}, n, E_{O}, E_{m}, m^{\prime}, B_{0}$ and $\left.\alpha\right)$. In Appendix $A$, theory and procedures for determining these parameters are presented for each test method. The parameter, $t_{a}$, was an average value, found by fitting test data for individual simulation runs directly to the mathematical model. The determination of $t_{a}$ is discussed in Section 4.4.2. 
The heat capacities found from the resin warming tests and overall heat transfer coefficients are consistent with generally accepted literature values [17]. The parameter $\mathrm{m}$, defined as $\mathrm{MaC}_{\mathrm{Va}} / \mathrm{MC}_{\mathrm{v}}$, is a measure of the thermal inertia of the aggregate as compared to that of the mixed resin. A value of $m \approx 2$ (Table 9) indicates that the aggregate has about twice the ability to absorb thermal energy. The values of the time constants give a measure of how fast energy goes from the resin to the air ( $t_{\text {air }}$ ) or to the aggregate $\left(t_{a}\right)$. Since it was found that $t_{a i r}>t_{a}$, the energy of reaction is predicted to go rapidly into the aggregate and only slowly into the air. This is confirmed by the parameter, $r$, the ratio of $t_{a i r}$ to $t_{a}$. In the auxiliary resin warming tests, this parameter was established to be large. The value calculated from $t_{a i r} / t_{a}$ is 250 , which indicates that energy goes into the aggregate 250 times faster than it is lost to the air. These results are consistent with the fact that the resin and aggregate are in direct physical contact while the air is external to the buckets used in the experiments. Since air also has a relatively low thermal conductivity, reaction energy is channeled into heating the resin and aggregate rather than being lost to the surroundings. In addition, the total surface area of the aggregate $\left(A_{a}\right)$ is much greater than that of the bucket exposed to air (A), so that the energy of reaction more easily flows into the aggregate. 
The kinetic parameters listed in Table 9 were all obtained in separate auxiliary tests. The procedures used to find the kinetic parameters are summarized in Appendix A (Section A.3.2.2). The reaction order of 1.5 is non-integral. Its value suggests that the polymerization process proceeds by a non-elementary reaction mechanism, perhaps involving chain branching [18]. The activation energies, $E_{o}$ and $E_{m}$, are also in the range typical of many polymerization reactions [19]. The fact that the activation energy for polymerization (E) decreases with catalyst concentration is also consistent with kinetic theory [19]. It would be expected that an increased concentration of catalyst would provide more sites for reaction, thereby lowering the energy barrier for reaction. This is also consistent with the concept that more catalyst lowers set time since, with a lower activation energy, the critical degree of chain branching for setting would occur sooner.

\subsection{Model Validation}

To validate the mathematical model, its predictions were compared with experimental data, and the consistency of its predictions was investigated when model parameters were varied around base or average values. In this section, the model predictions are compared to experimental set times and to data of resin temperature vs. time. Model predictions are illustrated and discussed and methods are reported for determining the best value of the 
aggregate time constant, $t_{a}$. Also, model implementation and predictions are presented.

4.5.1 Comparison of Model Predictions with Experimental Data 4.5.1.1 Comparison with Set Times

Set time data were collected for both the auxiliary kinetic tests and the set time simulation experiments. In this section these tests and experiments are discussed and the results compared to one another.

To predict the set time of polymer concrete, it is necessary to establish the conditions which influence set. The experiments conducted both with and without the addition of aggregate show that set occurs most rapidly when initial resin temperature, initial aggregate temperature and catalyst concentration are all high. Conversely, when the resin and aggregate are cold and the catalyst concentration is low, set is retarded. Since temperature is a measure of the degree of reaction, these facts are consistent with the expectation that set is correlated with the amount of reaction which has occurred. 


\subsubsection{Empirical Modeling of Set Time}

Preliminary modeling of set time predictions was empirical. It was based on the concept that, since both temperature and catalyst influence set time, there might be a correlation between them. Two approaches were taken. In the first, catalyst concentration was plotted against initial resin temperature (Figure 2). As expected, the data showed that more catalyst was needed when the resin was cold; it also showed the equally important effect of initial aggregate temperature on set time. In the second approach, which did account for aggregate temperature, the catalyst concentration was plotted against the adiabatic mix temperature, $T_{\mathrm{m}}$ (Figure 12). $\mathrm{T}_{\mathrm{m}}$ is defined as:

$$
T_{m}=\frac{M C_{v} T_{o}+M_{a} C_{v a} T_{a o}}{M C_{v}+M_{a} C_{v a}}
$$

$\mathrm{T}_{\mathrm{m}}$ is the temperature which would be achieved if the aggregate and resin were mixed in the absence of reaction and heat transfer to the surroundings. A similar mixture temperature has been recommended by ACI for use in calculations involving cold weather concreting systems [20].

Although there are a number of outlying points in Figure 12 , especially for the runs made with ice inclusions, where set was ill-defined, a single curve could be drawn through the data. 


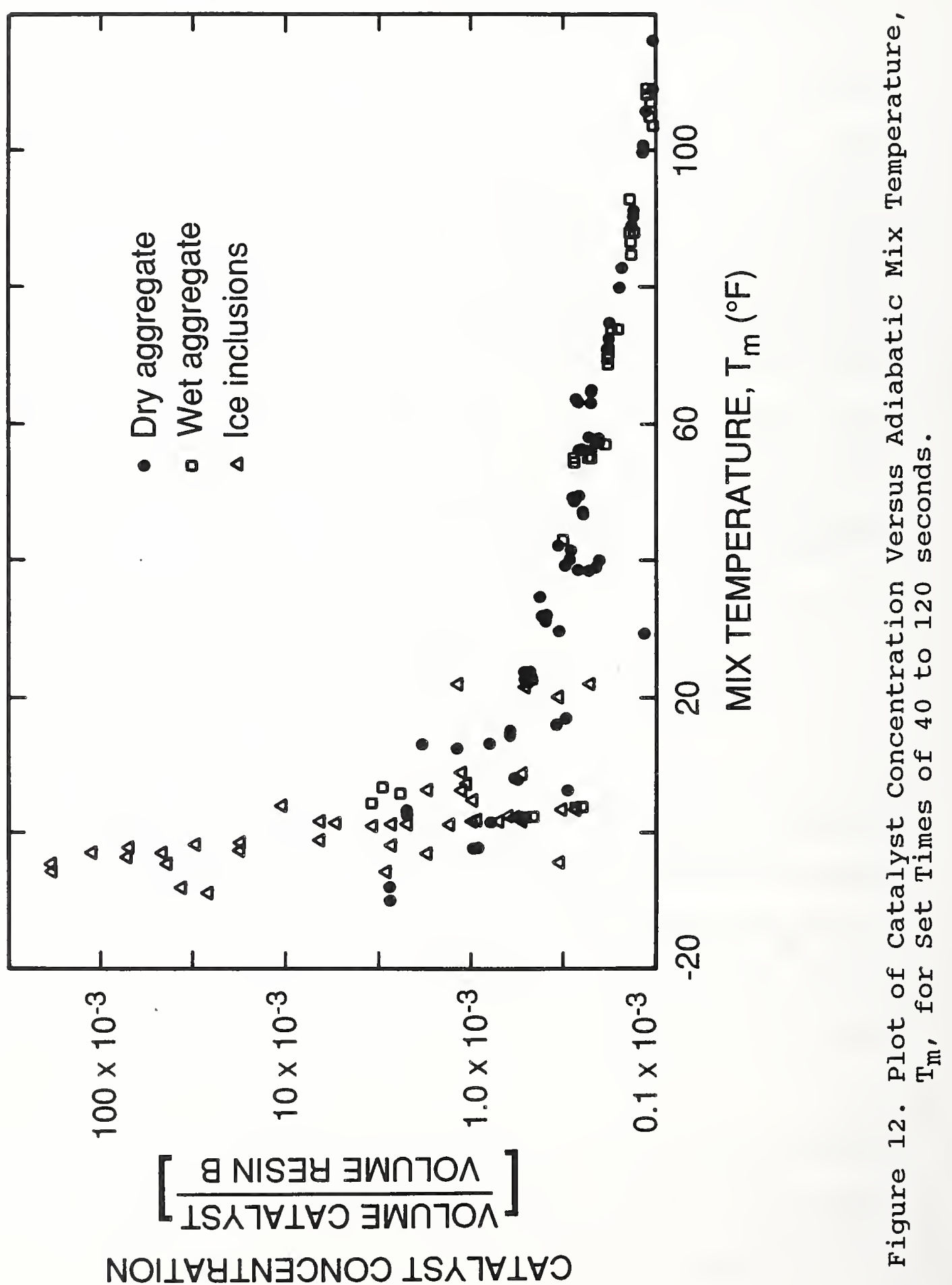


This is unlike the first approach (Figure 2) where the correlation between catalyst concentration and resin temperature levels was not as discernible. A linear relationship is suggested for adiabatic mix temperatures, $\mathrm{T}_{\mathrm{m}}$ above $20^{\circ} \mathrm{F}$. Figure 12 can not be used to predict set sufficiently precisely because experimental set times varied over a fairly wide range (40-120 s).

This wide range of experimental set times explains some of the scatter in Figure 12. Although the correlation shown in Figure 12 is not based on first principles, it is nevertheless useful since it shows that as temperatures increase much less catalyst is required for approximately equal set times.

\subsubsection{Mathematical Modeling of Set Time Prediction}

Mathematical modeling of the prediction of set time is based on the mathematical model developed to predict temperatures and resin conversions, and the concept, previously discussed, that set occurs at or near a specific value of resin conversion. Although plausible, this hypothesis is rather sweeping in scope and needs experimental verification.

For the experiments conducted in small insulated beakers with no aggregate (auxiliary kinetic tests), set time was accurately recorded for each test. At each resin temperature and catalyst level employed. Table 10 lists the observed set time $\left(t_{s}\right)$ and 
conversion at set $\left(x_{s}\right)$. The three replicate runs gave reproducible values of resin conversion but not of set $t$ ime, which for two of these runs differed by a factor of two. In general, the results show that higher catalyst concentrations and initial resin temperatures do indeed lower set time. This is consistent with an interpretation based on the principles of chemical reaction and heat transfer. The higher the catalyst concentration (C) and initial resin temperature ( $\left.T_{0}\right)$, the faster the reaction and the more heat is liberated at any given time. This effect is autothermal since as the temperature rises the reaction accelerates. Results from the auxiliary kinetic tests show that resin temperature only approaches a constant value when most of the energy of reaction has been expended, well beyond set.

The critical value of resin conversion where set occurs $\left(\mathrm{x}_{\mathrm{S}}\right)$ could depend on both $C$ and $T_{0}$. However, Table 10 shows no clear correlation with either variable. At $40^{\circ}, 71^{\circ}$ and $90^{\circ} \mathrm{F}$ the average values of conversion at set are $0.59,0.61$, and 0.53 , respectively. As catalyst concentration increases at a given initial resin temperature, Table 10 shows that the set time conversion also remains relatively constant, with slightly larger values at $c=0$. It appears, then, that within experimental error, $x_{S}$ is independent of $\mathrm{C}$ and $T_{0}$. The average value of $x_{S}$ for all of the 21 tests is $x_{S}=0.589 \pm 0.152$. With 
Table 10. Observed set Time $\left(t_{s}\right)$ and calculated Resin Conversion at set $\left(x_{s}\right)$ Determined from Auxiliary Kinetic Tests

Catalyst concentration (c) $1000 \times \frac{\text { vol catalyst }}{\text { volume Resin B }}$
Initial Resin Temperature $\left({ }^{\circ} \mathrm{F}\right)$

$\underline{40}$

$\underline{71}$

$\underline{90}$

\begin{tabular}{|c|c|c|c|c|c|c|}
\hline 0 & 0.656 & $(291)^{+}$ & 0.735 & (255) & 0.573 & $(88)$ \\
\hline 0.3 & $\begin{array}{l}0.669 \\
0.643\end{array}$ & $\begin{array}{l}(194) \\
(205)\end{array}$ & 0.619 & $(105)$ & 0.571 & $(57)$ \\
\hline 0.4 & 0.620 & (172) & 0.607 & $(78)$ & 0.540 & $(45)$ \\
\hline 0.7 & 0.622 & (108) & $\begin{array}{l}0.573 \\
0.472\end{array}$ & $\begin{array}{l}(55) \\
(13)\end{array}$ & 0.475 & (27) \\
\hline 1.3 & $\begin{array}{l}0.528 \\
0.692\end{array}$ & $\begin{array}{l}(60) \\
(64) \text { * }\end{array}$ & 0.487 & $(32)$ & 0.563 & (21) \\
\hline 2.6 & 0.544 & $(44)$ & - & & - & \\
\hline 5.0 & -- & & 0.586 & (17) & $=$ & \\
\hline 7.8 & 0.429 & (15) & -- & & - & \\
\hline
\end{tabular}

F numbers in parenthesis are the observed set times, $t_{\mathbf{s}}$, in $s$. * $c=1.25 \times 10^{-3}$ for this test. 
the runs at $c=0$ omitted, this becomes $x_{S}=0.576 \pm 0.152$. Accordingly, the criterion that set occurs when $x_{S}=0.58$ was adopted.

For the main simulation experiments, the experimental set times were also measured. These can be compared to the predictions of the model by running the mathematical model until the conversion reaches 58 percent. This criterion is applied to all of the runs made with dry and saturated surface dry aggregate. The time when this occurs is the predicted set time. A bias plot can then be prepared of predicted vs. experimental set times. Figure 13 presents such a plot with $x_{s}=0.58$ for the dry and saturated surface dry aggregate runs. Dry aggregate runs are marked by closed circles and saturated surface dry aggregate by open circles. The bias line shown represents perfect correlation (no error). Although there is a good deal of scatter, the data are essentially evenly distributed about the bias line which indicates a fair correlation between theory and experiment. When the analysis was redone, postulating that set occurred at conversions of 50 and 65 percent, the correlations exhibited more scatter then when $x_{S}=0.58$. In addition, most of the data points lay below the bias line when a 50 percent conversion measure of set was used, and above the bias line when a 65 percent measure was adopted. Further, points on the 58 percent bias plot matching simulation experiments with similar catalyst and temperature levels did not always lie on one side of the bias line as opposed 


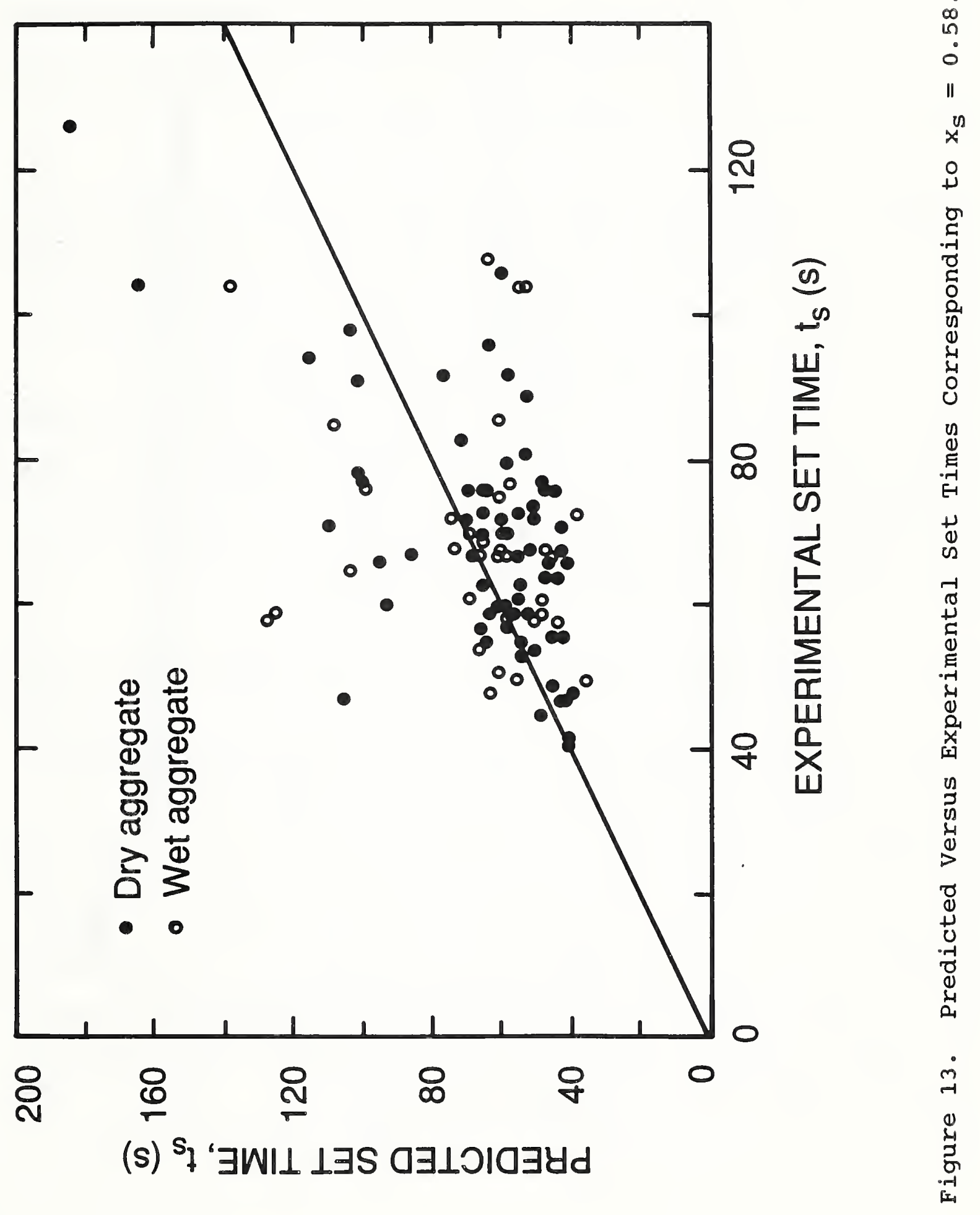


to the other; but were scattered around the line in a random way irrespective of experimental conditions. In conclusion, the hypothesis that set occurred near 60 percent conversion regardless of conditions was confirmed by results from both the auxiliary kinetic tests and the polymer concrete set time tests.

In summary, results from both the auxiliary kinetic tests and the set time tests were consistent with the concept that set occurs when the polyurethane product has achieved a critical amount of cross-linking or chain branching and is no longer able to maintain a liquid state. In this interpretation, set is delayed at low temperatures because the resin molecules are not sufficiently activated to have reached the critical degree of cross-linking where solidification (polymerization) occurs.

4.5.1.4 Comparison of Model Predictions with Resin Temperature Time Data

In this section, resin temperatures for a typical experimental run are compared to the predictions of the model. Figure 14 shows such a prediction for a typical experimental run, with $T_{0}=$ $70^{\circ} \mathrm{F}, \mathrm{T}_{\mathrm{aO}}=56^{\circ} \mathrm{F}$ and $\mathrm{C}=2.1 \times 10^{-3}$. The data points shown are the average of the three thermocouple readings at the corresponding times. The predictions of the model, shown as the solid curve, are in good agreement with the data. Agreement is even better before set occurs ( $t_{s}=48 \mathrm{~s}$ for this run). 


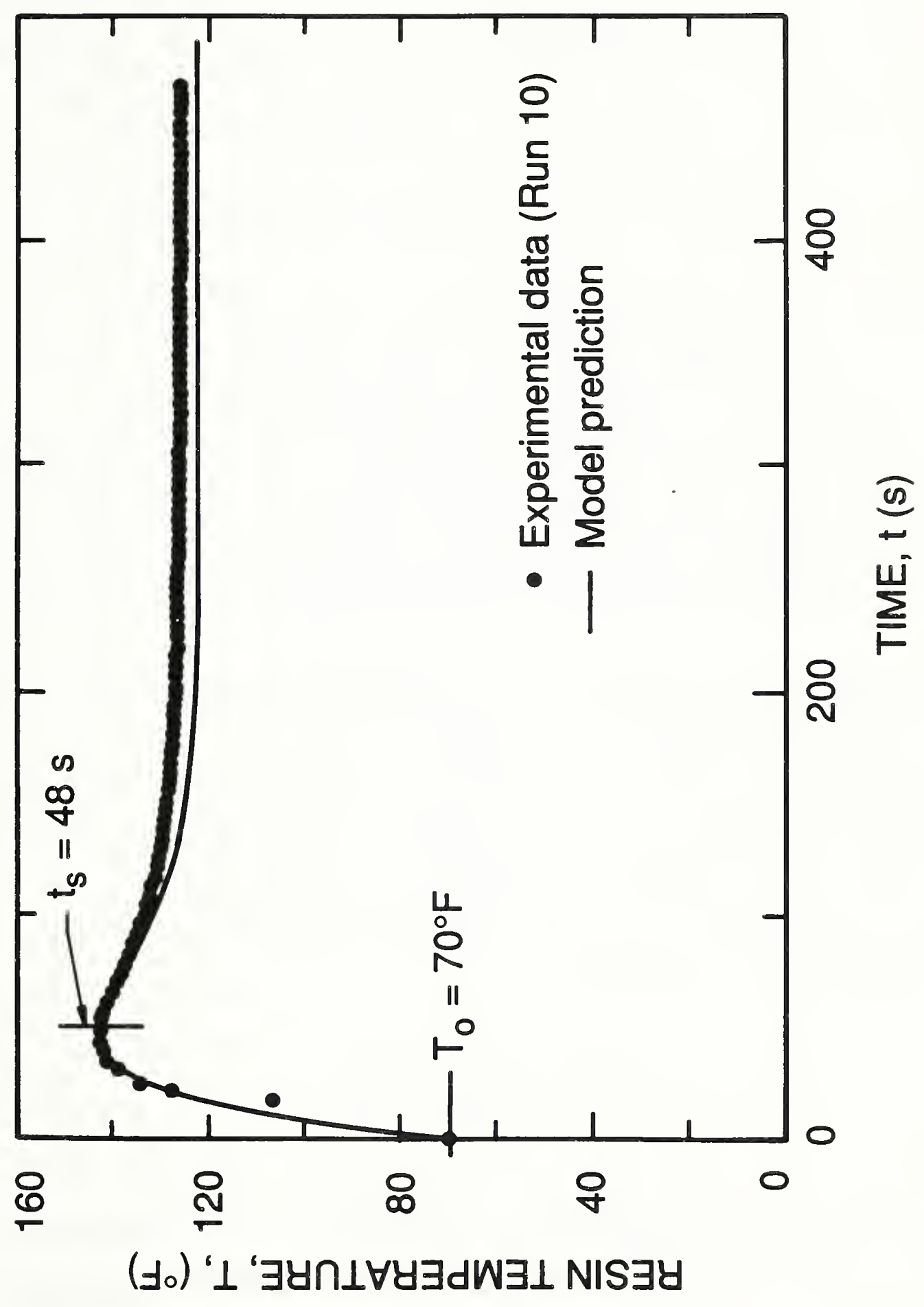

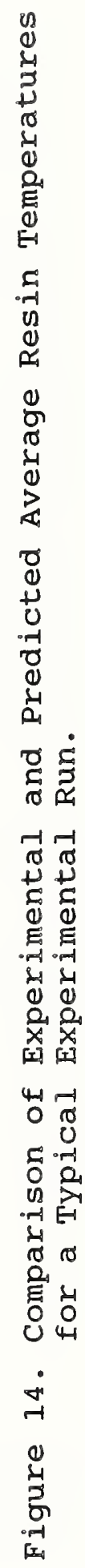


In general, the mathematical model predicted resin temperature vs. time traces which gave reasonable agreement with experimental data. This was further confirmed by the relatively low standard deviations between experimental and predicted values found for most runs. However, some runs at low temperature had high standard deviations and showed data which deviated considerably from the predicted curve. Better agreement could be reached if model parameters were further adjusted. For the test shown, an almost exact match between theory and data results if $t_{a}=86 \mathrm{~s}$ and $m=2.0$ (not shown). However such parameter adjustment sacrifices model credibility for fittability. In this study all the parameter of the model except $t_{a}$ were kept at the values determined independently (Table 9) when assessing model validity.

For all of the runs, the value of the parameter $m$ was fixed at its value of 2.176 , as determined from auxiliary tests. It is also possible to determine $\mathrm{m}$ from the simulation experiments. Using the model at steady state, with the parameter $r$ large (e.g., $r>$ 100), the aggregate and resin can be shown to reach a common final temperature $\left(T_{f}\right)$ given by:

$$
T_{f}=\frac{m T_{a o}+T_{o}\left[1+\Delta H^{\prime}\right]}{1+m}
$$

This was confirmed by examining the resin temperature-time traces for each run, almost all of which approach a horizontal asymptote at long times. Using values of $\mathrm{T}_{\mathrm{f}}$, equation (25) can be solved 
for $m$ for each run. The average $m$ for the dry aggregate runs was 2.167 which agrees quite well with the value of 2.176 determined independently in the auxiliary resin warming tests (refer to Appendix A, Section A.1). This prediction provides further confirmation of the model.

4.5.1.5 Determination of Aggregate Time Constant, $t_{a}$

In this study, the time constant for heat transfer into the aggregate, $t_{a}$, could not be established independently because sufficient auxiliary test data (water immersion) were not available during the short time period when most of the heat was going into the aggregate. In effect, this makes $t_{a}$ an adjustable constant which can only be found by fitting test data from the simulation runs themselves.

With the other parameters fixed at the values independently established (Table 9), $t_{a}$ was found for each run by finding the value which minimized the variance or error sum of squares between the model and the data points. For example, the value of $t_{a}$ found for the run illustrated in Figure 14 is $102 \mathrm{~s}$. In general, values of the aggregate time constant found by this method did not vary with experimental conditions, although greater variances were noted at high levels of catalyst concentration and temperature. To determine an average value of $t_{a}$ for all runs, the individual time constants were summed using 
the reciprocal of the variance as a weighting factor. For the dry aggregate runs, the average value was $66.4 \mathrm{~s}$, while for the wet aggregate runs it was $122.2 \mathrm{~s}$, to yield a composite average of $t_{a}=95.2 \mathrm{~s}$. This average value is the one used in subsequent analyses and it is the one reported in Table 9. Because of the variability in the data, no such analysis was performed on data for the experimental runs made with ice inclusions.

\subsubsection{Model Application}

Model validation can be provided not only by comparing observed set times and resin temperatures to theory but by the predictions it makes in untested regions. In this section the implementation of the model and the predictions that it makes are discussed and illustrated.

4.5.2.1 Model Implementation

In implementation, the differential equations of the model were solved on the computer in their dimensionless form. A standard differential equations solver was used which employed a variable step size and a choice of several generally accepted integration routines. Solutions were checked for numerical accuracy by running the computer program with smaller and smaller step sizes until no change in output was detected and by comparing model output to analytical solutions, where available. From a knowledge 
of model parameters and experimental conditions, the dimensionless output was translated to predictions of actual temperatures and conversion as a function of time.

In implementation, the program was modified to account for the mixing and pouring process. In the experiments, during the first ten seconds, the resins and catalyst were being mixed, after which it took about five additional seconds to fill the buckets containing the aggregate with the mixed resins. In the model, the term corresponding to heat loss of the aggregate was not added until 12.5 seconds into the computer program. In effect this split the model into two submodels, one before this time and one after. At this time, the values of the dependent variables ( $T^{\prime}, T_{a}^{\prime}$ and $x$ ) were set equal to one another so that the final conditions for the first submodel became the initial conditions for the second. The models ran sequentially on the computer.

4.5.2.2 Discussion and Illustration of Model Predictions

In this section, the results of model calculations simulating the setting performance of polymer concrete for anticipated ranges of experimental conditions, are presented. For the calculations, the parameters of the model were fixed at the base values given in Table 9. With the other parameters fixed, the parameter of interest was then varied about its base value in order to assess its effect on model performance. Results are most conveniently 
shown graphically. Unless otherwise noted, the illustrations shown in this section are based on the model parameters given in Table 9 and with experimental conditions: $\mathrm{T}_{0}=70^{\circ} \mathrm{F}, \mathrm{T}_{\mathrm{aO}}=56^{\circ} \mathrm{F}$ and $c=2.1 \times 10^{-3}$.

Figure 15 shows the effect of the parameter $m$ on predicted resin temperature. The temperature first rises rapidly towards a maximum (peak exotherm) and then falls slowly to a horizontal asymptote. At early times, there is little effect of $m$ on predicted resin temperatures. At later times, for higher values of $\mathrm{m}$, corresponding to a higher loading of cold aggregate, the temperature drops more rapidly and sooner from its maximum. With less aggregate, the temperature continues to rise longer and then drops slowly from its maximum value. All these results are consistent with expectations. The more aggregate, the more energy will be removed from the resin and the lower will be the final temperature. Thermal lag prevents this effect from being important for this system until about 30 seconds have elapsed.

For the conditions investigated, Figure 16 shows that the parameter $m$ has only a small effect on resin conversion, smaller values of m producing only marginally higher conversions at a given time. As shown in the figure, the predicted set times $\left(t_{s}\right.$ at $\mathrm{x}_{\mathrm{s}}=0.58$ ) are almost identical; quadrupling the relative amount of aggregate only delays set for a few seconds. For the conditions examined, it can be concluded that the reaction is 


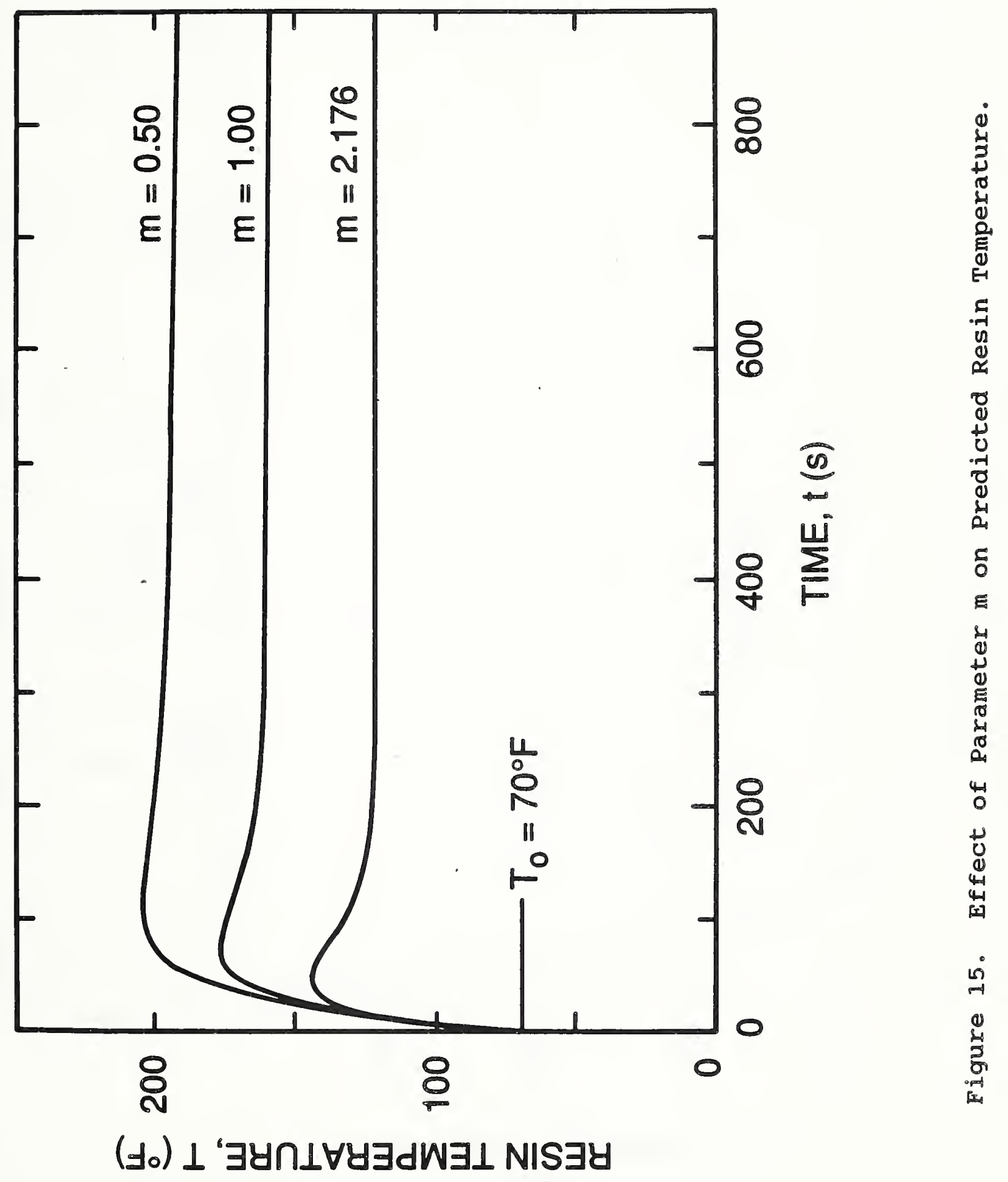




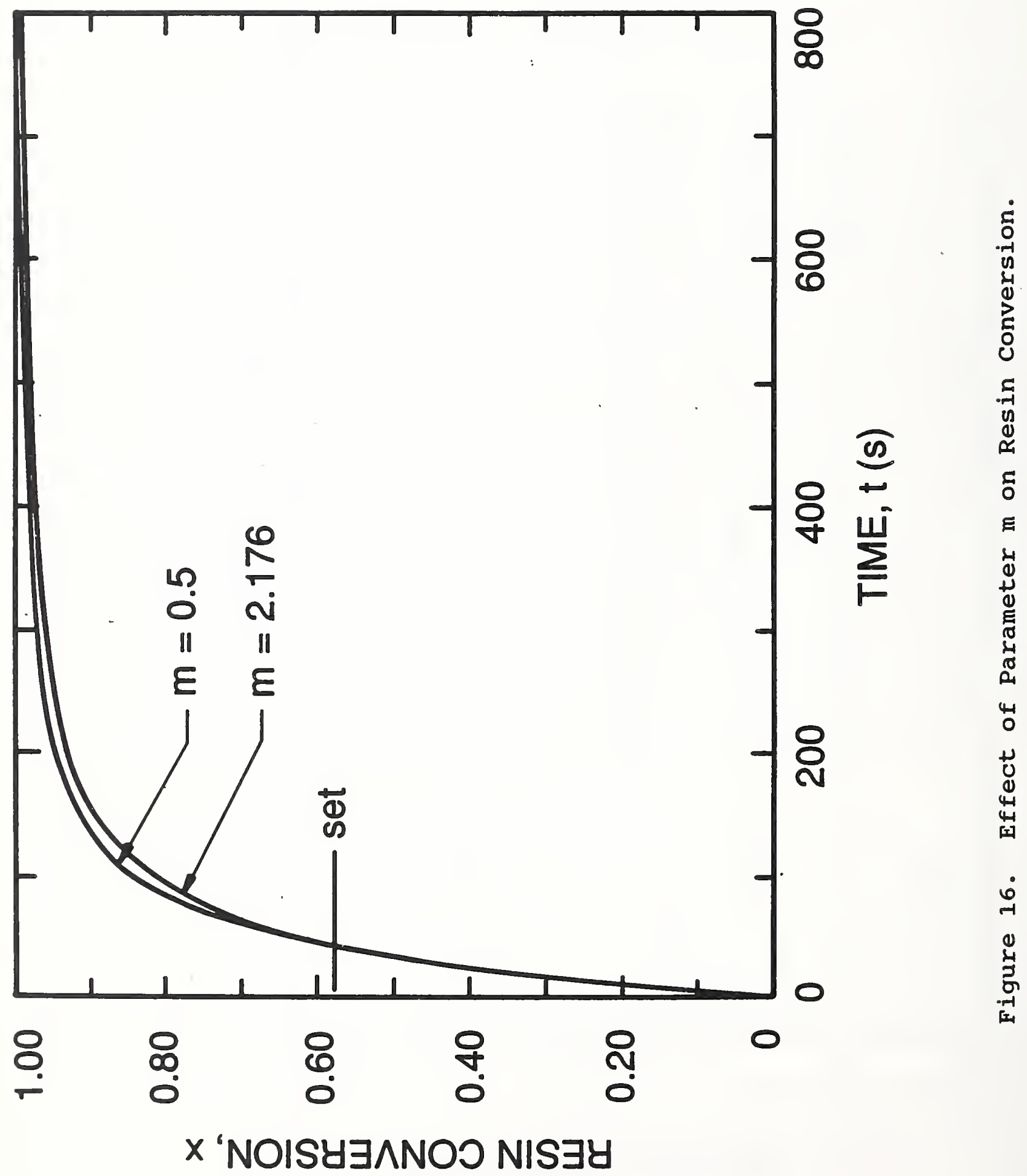


sufficiently exothermic so that most of the energy of reaction goes into heating the resin, rather than the aggregate, a conclusion which is also confirmed by Figure 15. When the aggregate is considerably colder than the resin, this is less likely to be true.

Figure 17 predicts how the resin conversion varies with time with the initial temperature of the resin shown as a parameter. For each curve, the catalyst concentration was 0.0021 (volume catalyst/volume Resin B). As expected, lowering the initial temperature of the resin lowers conversion at a given time, especially at the colder temperature $\left(4^{\circ} \mathrm{F}\right)$, where set is predicted to occur in 240s. Set this late would probably be unacceptable under field conditions. These model predictions show that more catalyst needs to be added to the resin in order to accelerate set.

Figure 18 predicts the way resin conversion varies with time at different levels of catalyst concentration. Raising the catalyst concentration is shown to raise the resin conversion at a given time and to accelerate set. The lower curve gives the prediction when no catalyst is added. This confirms the experimental results found in the auxiliary tests that reaction and set, although much delayed, do occur in the absence of catalyst. 


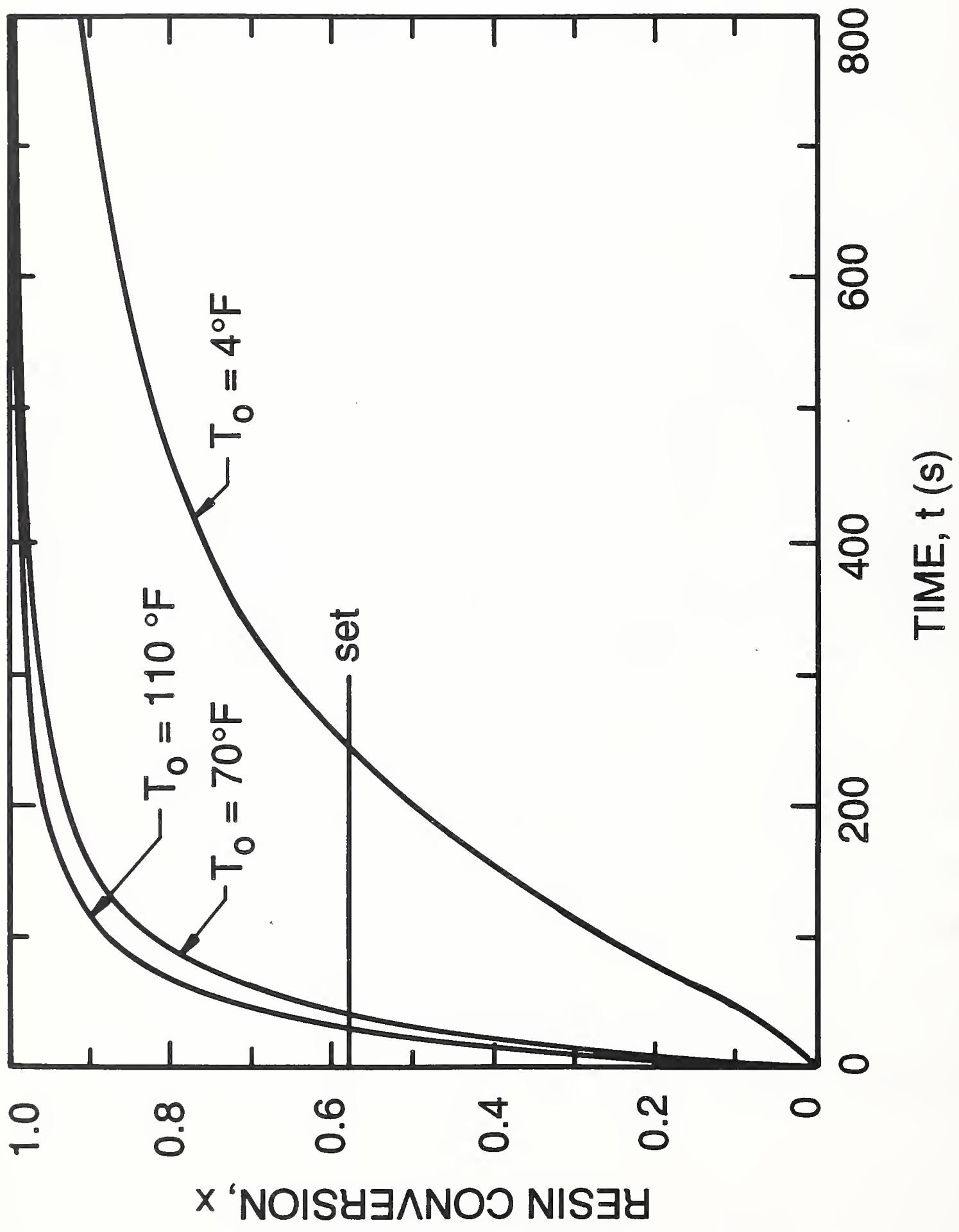

¿.5

.

ธ

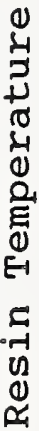



i

岂 


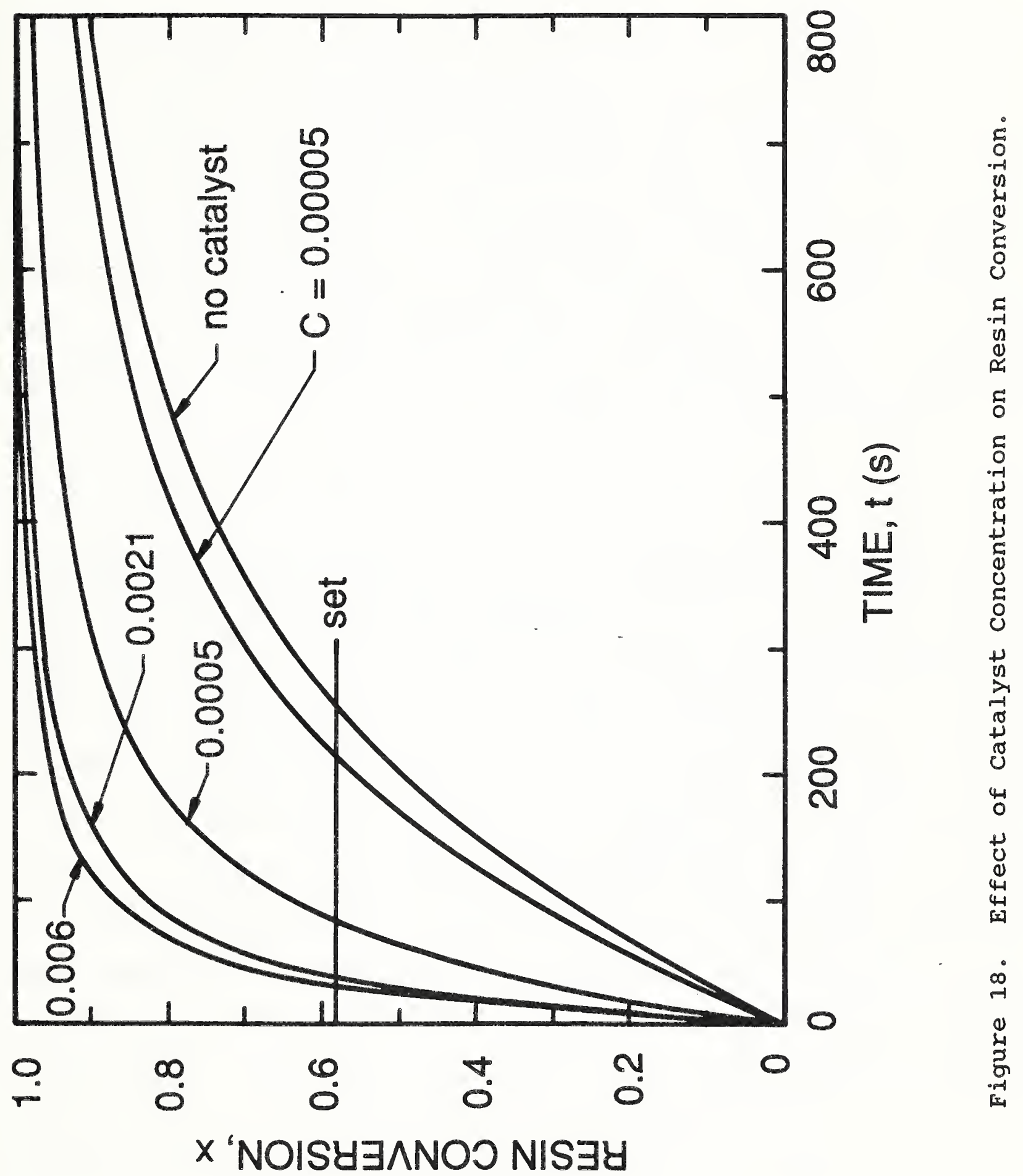




\section{SET TIME DESIGN CHARTS}

With the validity of the model established and its parameters estimated, the model can be used to predict set time under a wide range of conditions. Given the initial temperatures of the resin and aggregate and the temperature of the surroundings, the model will predict the catalyst concentration to use to achieve a desired set time. By running the model under a variety of conditions, design charts can be prepared which enable set time to be predicted under field conditions.

It is important to mention that since all experiments were made using the same concentration of the two resins (those corresponding to equal volumes), it is not possible to make predictions for resin concentrations different from those used in the set time tests nor for other resins. However, if the catalyst employed in the tests is diluted or strengthened in the amount of its unknown active ingredient, predictions can still be made by adjusting, in proportion, the catalyst concentrations used in the model. Additional experimental tests would need to be conducted over a range of concentrations in order to ascertain more fully the effect of resin concentration on the kinetics and heat transfer of the setting reaction. 


\subsection{Development of Design Charts}

The model predicts the set time directly. Thus, for given values of initial resin and aggregate temperature, fixing the catalyst concentration will predict the set time. The model calculations are carried forward in time until the critical conversion is reached and set occurs. A more practical problem is determining what catalyst concentration to use to achieve a prescribed set time under specific conditions. Since the model does not determine catalyst concentration directly it must be run repeatedly at different concentrations until one is found which matches the desired set time. This is inconvenient in practice.

To eliminate this problem the model was used to generate design charts. Set times of $45,60,90$ and $120 \mathrm{~s}$ were used. Initial aggregate temperatures, $T_{a 0}$, chosen were $-25,0,25,50,75$ and $100^{\circ} \mathrm{F}$, while initial resin temperature was varied between 0 and $120^{\circ} \mathrm{F}$ in increments of $10^{\circ} \mathrm{F}$. This gave a total of 308 combinations of set time and initial temperature. The model was run iteratively for each combination in order to find the amount of catalyst to be used to achieve the desired set time. Convergence was taken when the set time was matched to within $\pm 2 \mathrm{~s}$. The points shown in the charts are the result. A smooth curve was drawn through these points. As in the experimental tests, the temperature of the air used in the calculations was considered equal to the initial temperature of the aggregate. other air temperatures 
should not affect the prediction appreciably, since the calculations show that set usually occurs before much energy has had a chance to be transferred to the environment.

\subsection{Use of Design Charts}

There are six design charts designated C-1 through C-6 (Figures 19-24), one for each initial aggregate temperature: $\mathrm{T}_{\mathrm{a} o}=-25$, $0,25,50,75$ and $100^{\circ} \mathrm{F}$. Each chart is a plot of the catalyst concentration, $C$, vs. the initial resin temperature, $T_{0}$, in ${ }^{\circ} \mathrm{F}$. With the ordinate plotted on a log scale, the curves on the charts are quasi-linear. Each curve corresponds to a different set time $\left(t_{s}=45,60,90\right.$ or 120s). The charts are a graphical representation of the model encoded in four variables ( $T_{0}, T_{a o}, C$ and $\left.t_{s}\right)$. With any three of the variables specified, the fourth can be found using the charts.

As an example, their use is shown in Chart C-1 (Figure 19), with $\mathrm{T}_{\text {ao }}=-25^{\circ} \mathrm{F}$. As illustrated, to find the amount of catalyst to use if the desired set time is $45 \mathrm{~s}$ and the aggregate is at $-25^{\circ} \mathrm{F}$ with the resin supplied at $60^{\circ} \mathrm{F}$, enter the $\mathrm{T}_{\mathrm{a}}=-25^{\circ} \mathrm{F}$ chart on the abscissa at $60^{\circ} \mathrm{F}$, draw a vertical line to the ordinate and read off the catalyst concentration, $c=3.0 \times 10^{-3}$. This translates into using 0.3 percent by volume of catalyst per volume of Resin B employed. 


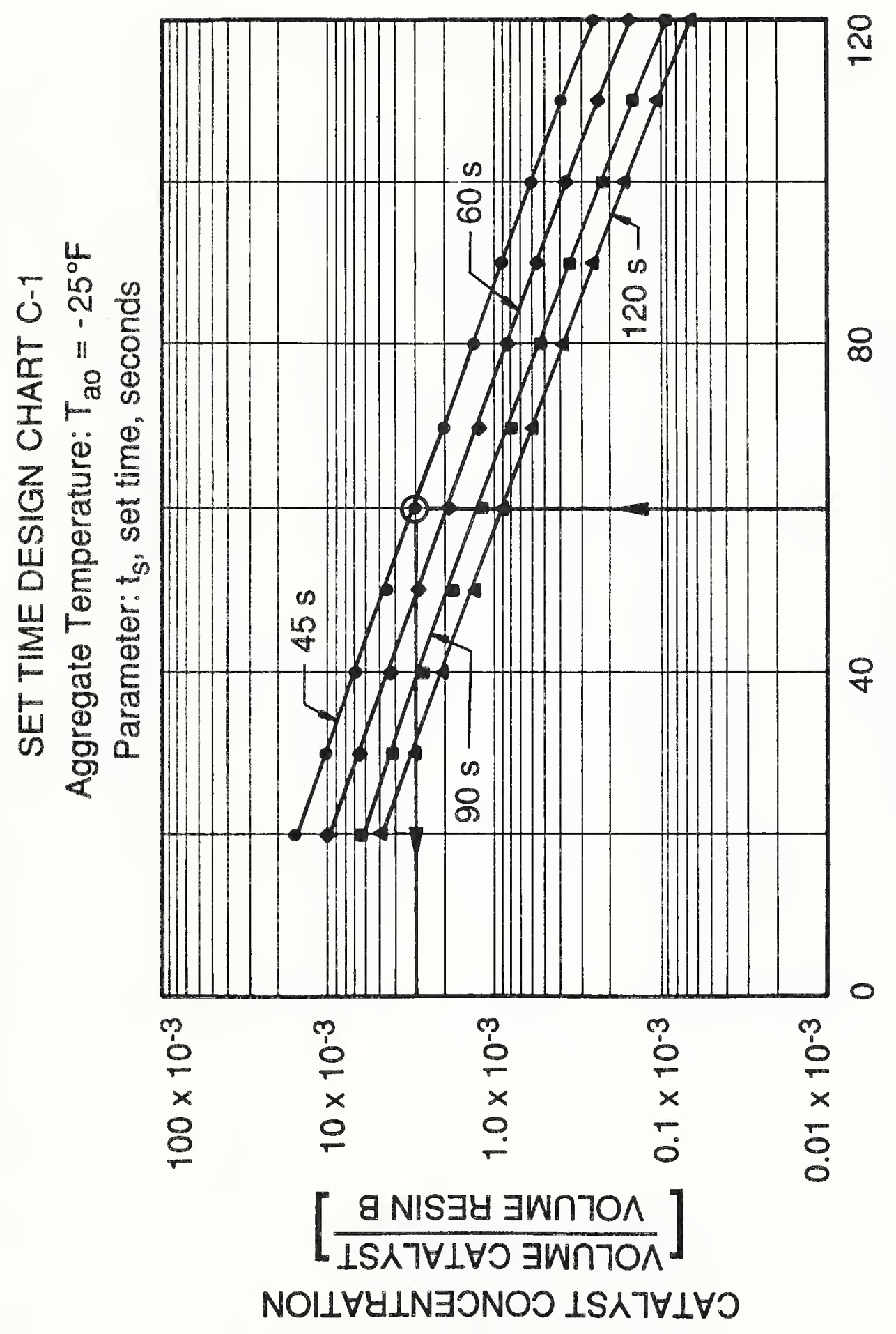

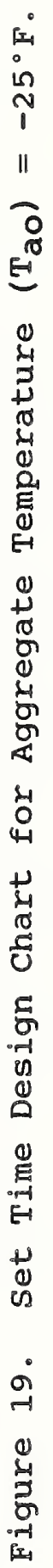




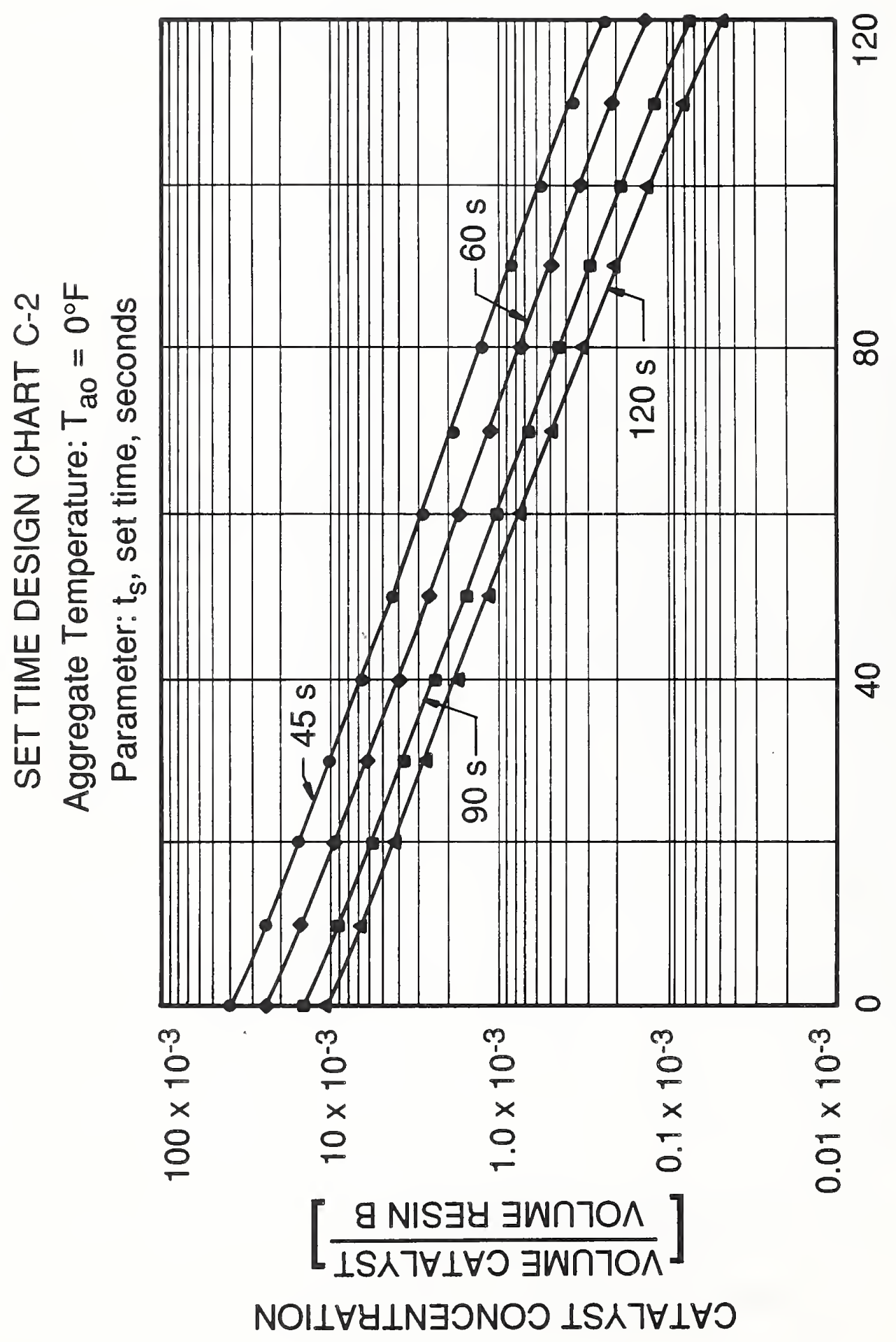

:

$\overbrace{0}^{0}$

1

崩范

$\frac{\sum_{w}}{\frac{2}{5}}$

山

$\stackrel{\frac{1}{E}}{E}$

8

亗

0
\[ -1 \]
0
0
0
0

$\stackrel{Ð}{.7}$

i

i

岂 


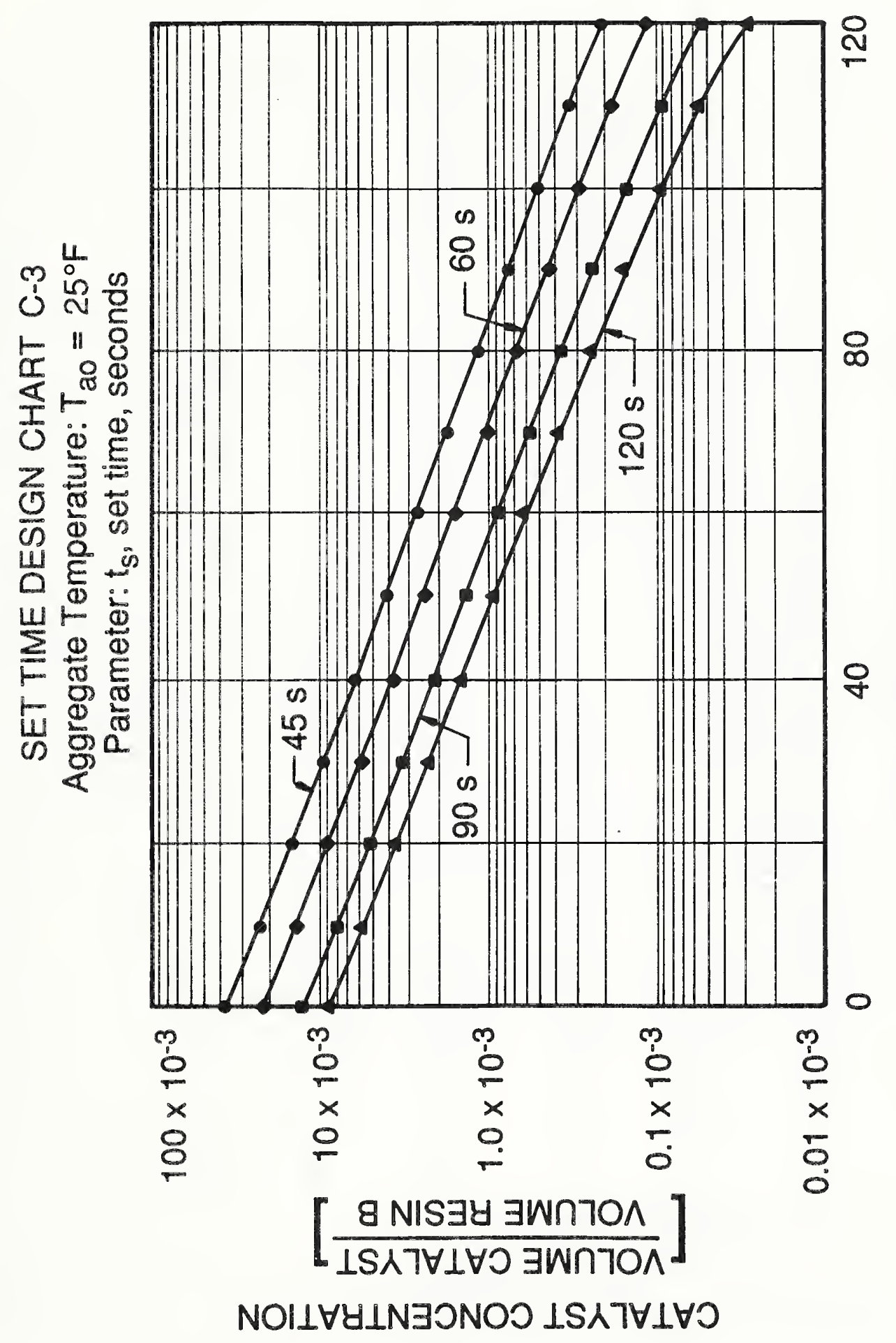

| 


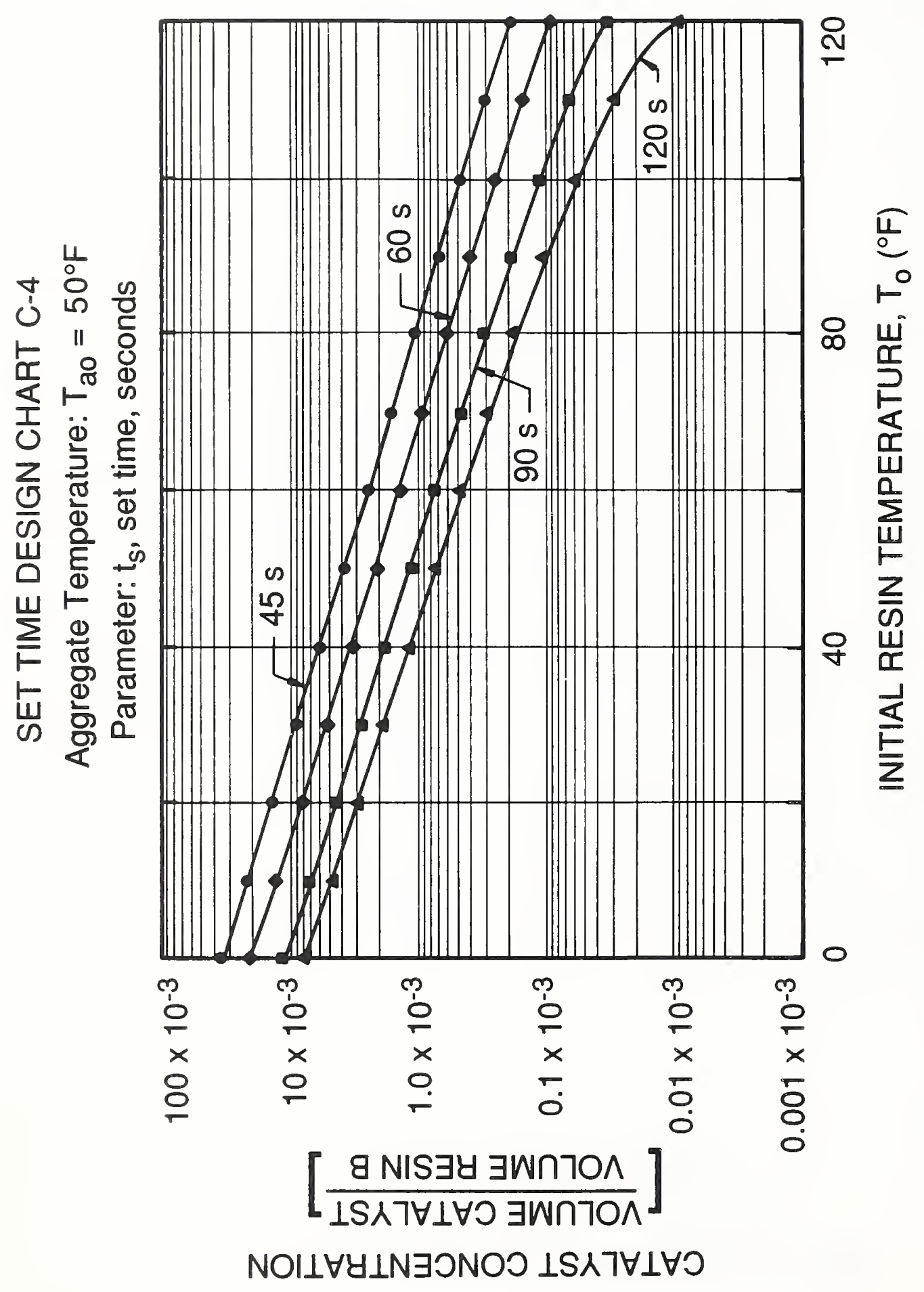

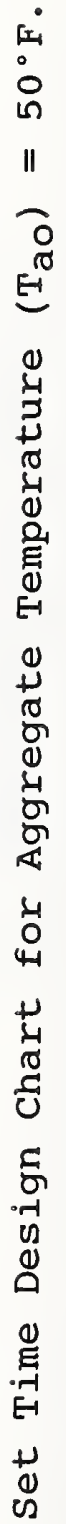

N 


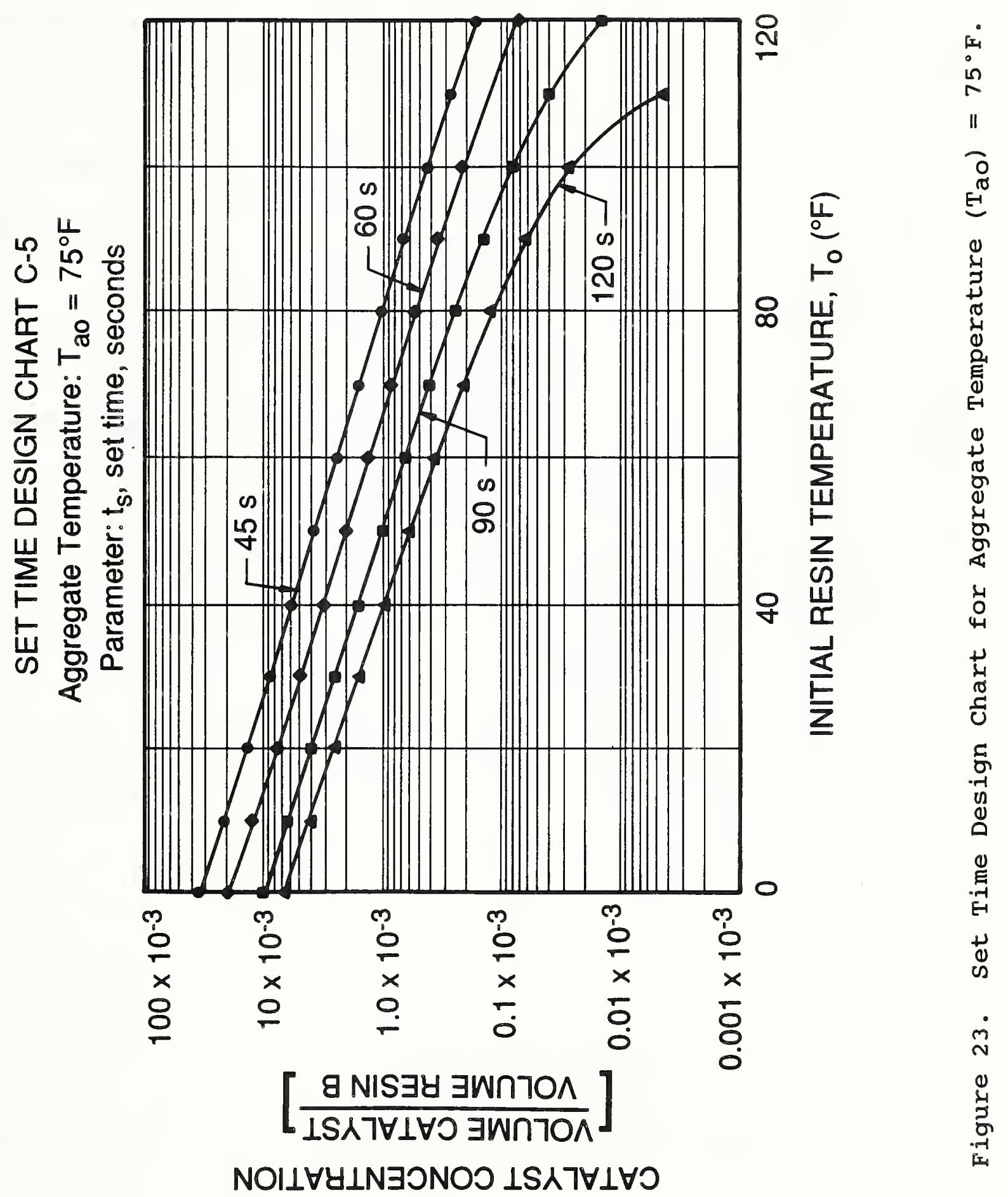




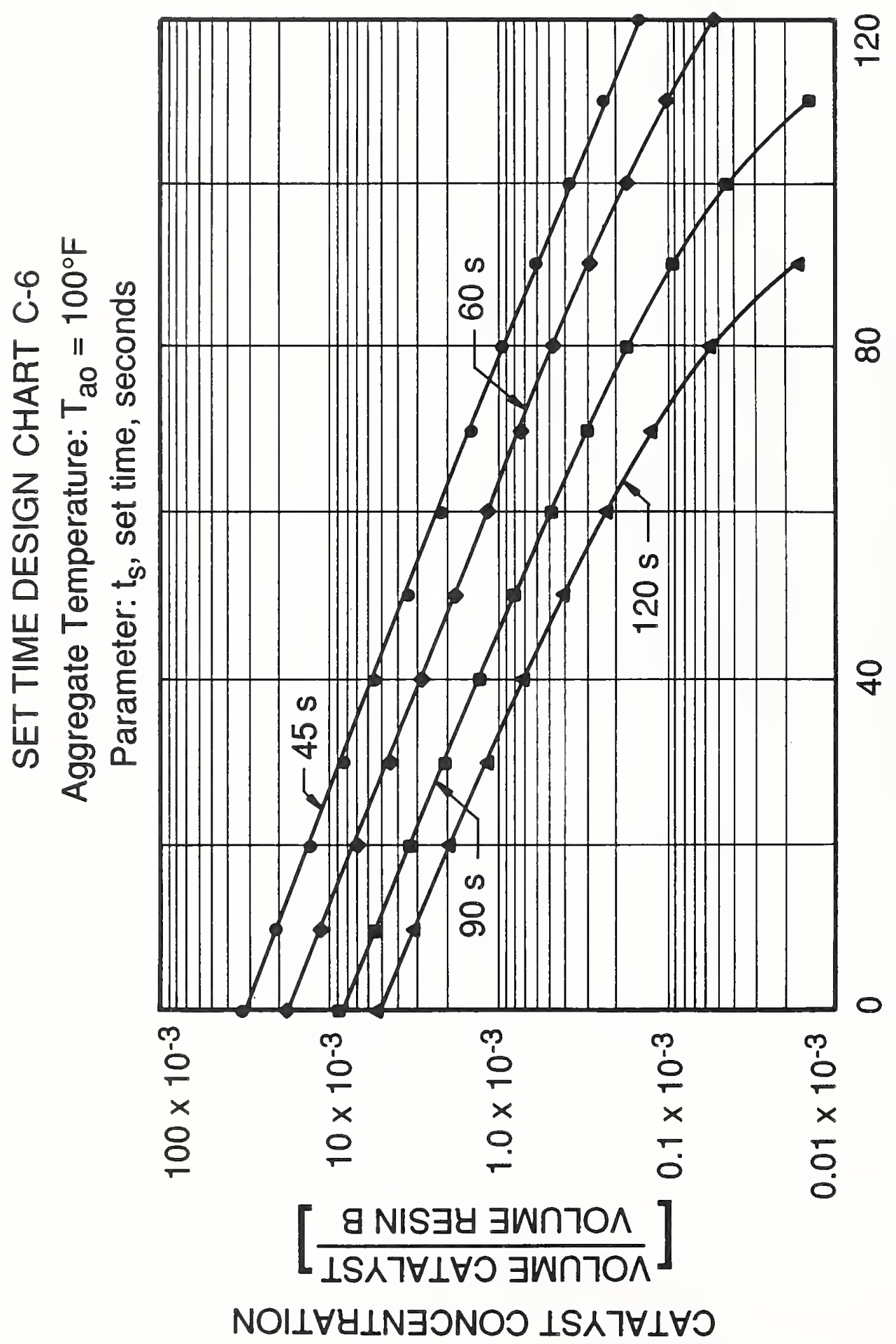

19

눙

1

苟

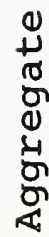

I

$\underline{E}$

㫕

5
E
o-
o
0
0

ڤ్.

$\stackrel{\dot{\sim}}{\sim}$

岂 
The problem of determining what set time will be achieved for a given catalyst concentration is worked similarly. The appropriate chart at the aggregate temperature $\mathrm{T}_{\mathrm{ao}}$ is first selected. On this chart a horizontal line is drawn from the given $C$ and a vertical line from the resin temperature $T_{0}$. The intersection of these lines will determine the predicted set time $t_{s}$, which can be read from the curves on the figure. In cases where the intersection point lies between two set time curves, linear interpolation can provide an estimate of $t_{s}$ other problems of interest include finding how hot the resin must be to insure, for a given catalyst concentration and aggregate temperature, that set will occur within a specified period. This is the inverse of the first problem. A horizontal line is drawn from the given catalyst concentration to the set time curve. At the intersection, a vertical line is drawn to the abscissa and the resin temperature is found. Temperatures lower than this will not cause set within the desired time unless more catalyst is used. Interpolation can also be used for set times other than those provided on the charts. 
6. SUMMARY

Proprietary polyurethane resins are among several materials considered by the Air Force Engineering and Services Center (AFESC) for use in rapid repair of runways. In this application, the resin is used as a binder with preplaced open-graded aggregate for a rapid setting polymer concrete. The AFESC requested that the National Institute of standards and Technology (NIST) conduct a study to obtain set time data for polymer concrete made with a particular two-component proprietary polyurethane resin and catalyst. The polymer concrete was to be made using a wide range of aggregate and resin temperatures. In addition, the impact of the presence of water and ice on set time was to be examined. This study was required by AFESC to better characterize the performance of the proprietary resin and the polymer concrete made using the resin.

The major portion of this study was devoted to obtaining set time data for the polymer concrete for a wide range of aggregate and resin temperatures and in developing and solving a set time prediction model. The effect of the presence of water and ice inclusions on set time was also included in the study. The model parameters were determined experimentally from auxiliary tests conducted separately from the set time tests. The effect of temperature variations of aggregate and resin on the flexural strength of polymer concrete at early ages was also investigated. 
Finally, some pilot tests were conducted to obtain set time data for polymer concrete cast using another proprietary polyurethane resin and catalyst. Various aggregate and resin temperatures and moisture conditions were also used in casting the polymer concrete in the pilot tests.

The set time tests were carried out in a temperature-controlled environmental chamber. The polymer concrete was cast using equal amounts of a two-component resin, a catalyst, and $0.44 \mathrm{ft}^{3}$ of a smooth surface, rounded mineral aggregate (quartz). The aggregate temperature ranged from -25 to $110^{\circ} \mathrm{F}$. A catalyst was mixed with Resin B (diamine - polyglycol) and then mixed with Resin A (isocyanate). The resulting mixture was quickly poured over aggregate in a plastic bucket. The mixed resin percolated through the air dried and the saturated surface dry aggregate and filled the voids. The amount of catalyst was adjusted to provide for a set time of about 55 to 75 seconds. Set time was determined as the time from the start of mixing of the two resins to the time that set of the mixed resin occurred. The set time was very sensitive to the amount of catalyst used. The temperature of the polymer concrete was continuously recorded from thermocouples placed in the aggregate. The temperatures at the time of set of the resin and the peak exotherm were reported. Set was observed by a rapid change of color of the mixed resin in the gravel and by tapping the top surface of the polymer concrete with a steel rod and noting when the resin became solid. 
Little difference in set time was observed for polymer concretes cast using air dry aggregate and saturated surface dry aggregate (wet aggregate) for comparable combinations of aggregate and resin temperatures. The moisture content of the saturated surface dry aggregate ranged from 0.4 to 0.9 percent by mass. In section 1 of this report, some concerns involved with rapid runway materials were noted, including the effect of moisture on the properties of the polymer concrete. It appears that the small amount of moisture in the saturated surface dry aggregate did not appreciably affect the set time or the filling of the aggregate voids with resin.

Considerably more catalyst was used in the set time tests with ice inclusions. It was difficult to control set time in these tests. In examining the polymer concrete specimens which contained ice inclusions, the bond between aggregate and hardened resin over the lower half of the specimens was poor or did not exist. This was particularly obvious for specimens with short set times because the resin set before it could completely percolate through the aggregate. Since the bond between aggregate and hardened resin was poor, it was recommended that data from the set time tests which included ice should not be used for field application. In addition, results from set time tests with ice inclusions were inconclusive because set times could not in general be accurately determined and in many cases could not be reproduced when comparable amounts of catalyst were used. 
The set time prediction model consists of energy balances, one for the resin matrix (continuous phase) and the other for the aggregate particles (dispersed phase), as well as a molar balance on the reacting species (resins). It accounts for heat exchange between resin and aggregate and the heat of reaction as well as heat losses to the surroundings. Model input includes initial temperatures (resin, aggregate, and surroundings), catalyst concentration, moisture and ice content (if present), and mass of aggregate and resin. Model parameters include heat transfer coefficients and time constants, specific heats of the phases, chemical reaction order, reaction activation energies, and parameters measuring the effect catalyst concentration has on the reaction rate constant. Model output predicts set time, resin conversion, and the temperature of the resin and aggregate as functions of time. For tests with ice inclusions, the model also predicts the fraction of ice which has melted.

In order to independently determine the parameters for the model, separate auxiliary tests were conducted. Resin heat capacities were found in experiments where the resins were allowed to warm in a temperature controlled environment. Heat transfer coefficients and model time constants were determined from tests conducted with water used in place of resin, while reaction parameters were determined from separate tests conducted in insulated containers which did not contain aggregate. These latter tests established a reaction order of 1.5 and a set time which occurred near 60 
percent conversion regardless of experimental conditions. The reaction activation energy was found to decrease with increasing catalyst concentation, as would be expected based on kinetic theory. The data collected were fitted to models developed and solved specifically for the auxiliary tests. Because of constraints, the time constant for aggregate heat transfer could not be found independently using this method. Instead its value was determined by matching experimental data of resin temperature for each run directly to the set time model and then using an overall average. Results showed that heat transfer into the aggregate was much faster than into the air.

Reasonable agreement was found between the set time prediction model and the experimental data since observed set time and resin temperatures were generally in accord with those predicted by the model. Larger deviations between predicted and experimental results were noted at higher catalyst concentrations and lower initial resin and aggregate temperatures.

The set time prediction model was used to develop a series of design charts which can be used to predict set time given the catalyst concentration and initial temperatures of the aggregate and resin. The design charts can also be used to determine the catalyst concentration to use to assure set of the resin within a given time and at specified temperature. 
The flexural strength of the polymer concrete was determined using beam specimens tested at an age of 30 minutes. Set times for the beam specimens were in the range of 30 to 45 seconds. Beams cast with aggregate and resin at the higher temperatures had the highest values of flexural strength. Along the failure surface of these beam specimens, the aggregate fractured while, for beam specimens cast with lower temperatures of aggregate and resin, bond failure between aggregate and hardened resin was discernable. The flexural strength or modulus of rupture data were compared with the adiabatic mix temperature, $\mathbf{T}_{\mathrm{m}}$, which was a weighted value of aggregate and resin temperature at the time of casting a beam specimen. The flexural strength was essentially constant for values of $\mathrm{T}_{\mathrm{m}}$ of $70^{\circ} \mathrm{F}$ or greater. For lower values of $\mathbf{T}_{\mathrm{m}}$, the flexural strength decreased nearly linearly as $\mathrm{T}_{\mathrm{m}}$ decreased. It was observed at age 30 minutes that the hardened resin was softer in the five beams cast with lower values of $T_{m}$ than those cast at the higher temperatures.

In pilot tests using another polyurethane resin, considerably more catalyst was needed to obtain comparable set times as compared to the other set time tests. As the temperature at the time of casting these pilot test specimens decreased, the catalyst concentration needed for equal set time increased considerably. As an example, for specimens cast with an aggregate temperature about $-2^{\circ} \mathrm{F}$ and a resin temperature of $5^{\circ} \mathrm{F}$ or less, the catalyst volume ratio was in the range of 0.5 to 1.0 and the 
set time ranged from 95 to 220 seconds. For comparable specimens in the main series of set time tests, the catalyst ratio was 0.007 for set time between 67 and 72 seconds. Specimens cast in the pilot tests with resin temperatures of $5^{\circ} \mathrm{F}$ or lower and those with ice inclusions present exhibited poor bond over their lower half. 


\section{ACKNOWLEDGMENTS}

This study was sponsored by the U.S. Air Force, Air Force Engineering and Services Center (AFESC). The authors appreciate the support and assistance of Patricia C. Suggs (AFESC) who provided information for this study and liaison between AFESC and NIST. The authors also thank their NIST colleagues, James Clifton, Geoffrey Frohnsdorff and Donald Hunston, who gave important review comments on this report. The authors gratefully acknowledge the contributions of Karen Knapp, John Kenner, and Li Voon Ng, Bucknell University, for their extensive help provided in computer programming and data analysis. The assistance of the Computer center at Bucknell University is also acknowledged. The authors also appreciate the excellent support of Denise Herbert for typing the manuscript. Finally, special thanks are expressed to NIST staff James F. Seiler and Nathaniel E. Waters who so carefully and ably prepared large amounts of materials for testing and conducted the many tests. James seiler is also acknowledged for his ingenuity and efforts in designing test apparatus, preparing instrumentation for the large test program; and for recording the data. 
1. "Evaluation of Materials for Port-Attack Pavement Repair," C.I. Rone and A.I. Sullivan III, CEEDO-TR-78-16, Civil and Environmental Engineering Development office, Tyndall Air Force Base, FI., Sept. 1978 (Final Report for Period sept. 1976-Dec. 1977), Technical Report distributed by Defense Technical Information Center, Defense Logistics Agency, Cameron Station, Alexandria, VA.

2. "An Investigation Into the Use of Polymer-Concrete for Rapid Repair of Airfield Pavements," Michael T. McNerney, CEEDOTR-78-10, Civil and Environmental Engineering Development Office, Tyndall Air Force Base, FL., Jan. 1978 (Final Report for Period June 1977 - Dec. 1977), Technical Report distributed by Defense Technical Information Center, Defense Logistics Agency, Cemeron Station, Alexandria, VA.

3. "Improved Acrylic Systems for Rapid Runway Repair," U.S. Nandi, R.G. Sinclair, P.C. Behrer, J.P. Boyer, and M.J. Snyder ESI-TR-82-46, Engineering and Services Laboratory Air Force Engineering and Services Center, Tyndall Air Force Base, FL. May 1983 (Final Report June - Sept. 1982), Technical Report distributed by Defense Technical Information Center, Defense Logistics Agency, Cameron Station, Alexandria, VA.

4. "Water-Compatible Polymer Concrete Materials for Use in Rapid Repair Systems for Airport Runways,"T. Sugama, L.E. Kukachka, P. Brown, B. Koplik, and M. Reich, ESL-TR-82-35, Engineering and Services Laboratory Air Force Engineering and Services Center, Tyndall Air Force Base, FL. Aug. 1983 (Interim Report April 1981 - Sept. 1982), Technical Report distributed by Defense Technical Information Center, Defense Logistics Agency, Cameron Station, Alexandria, VA.

5. "Advanced Materials Development for Repair of Bomb Damaged Runways," ESL-TR-82-14, J.P. Boyer, C. Kistler, U. Nandi, A.S. Pfau, S. Rohleder, and M.J. Snyder (BCL); and A.S. Kubo (BMD), Engineering and Services Laboratory, Air Force Engineering and Services Center, Tyndall Air Force Base, FL. Jan. 1982 (Final Report June 1980 - Jan. 1982), Technical Report distributed by Defense Technical Information Center, Defense Logistics Agency, Cameron Station, Alexandria, VA.

6. "Methyl Methacrylate Polymer-Concrete for Bomb Damage Repair," ESL-TR-82-04, David W. Fowler, Donald R. Paul, B.F. McCullough, and Alvin H. Meyer, Engineering and Services Laboratory, Air Force Engineering and Services Center, Tyndall Air Force Base, FL., Aug. 1982 (Final Report June 19:80 - Sept. 1982), Technical Report distributed by Defense 
Technical Information Center, Defense Logistics Agency, Cameron station, Alexandria, VA.

7. "Laboratory Evaluation of Expendient Pavement Repair Materials," Raymond S. Rollings, CEEDO-TR-78-44, Civil Environmental Engineering Development Office, Tyndall Air Force Base, FL., June 1978 (Final Report for Period Jan. 1976 - June 1978), Technical Report distributed by Defense Technical Information Center, Defense Logistics Agency, Cameron Station, Alexandria, VA.

8. "Polymer Research in Rapid Runway Repair Materials," ESL-TR79-43, Manfred Luttinger, Charles W. Kistler, Jr., Henry M. Grotta, and Richard G. Sinclair, Engineering and services Laboratory, Air Force Engineering and Services Center, Tyndall Air Force Base, FL., Nov. 19798 (Final Report Jan. 1979 - Oct. 1979), Technical Report distributed by Defense. Technical Information Center, Defense Logistics Agency, Cameron station, Alexandria, VA.

9. "Methyl Methacrylate Polymer-Concrete for Bomb Damage Repair, Phase I," David W. Fowler, Donald R. Paul, B.F. McCullough, Alvin H. Meyer, ESL-TR-80-28, Engineering and Services Laboratory, Air Force Engineering and Services Center, Tyndall Air Force Base, FL., June 1980 (Interim Report March 1979 - May 1980), Technical Report distributed by Defense Technical Information Center, Defense Logistics Agency, Cameron station, Alexandria, VA.

10. "Advanced Water-Compatible Materials for Bomb Damage Repair," T. Sugama, L.E. Kukachka, D.W. Huszagh, S. Shteyngart, and N.R. Carciello, ESI-TR-84-03, Engineering and Services Laboratory, Air Force Engineering and Services Center, Tyndall Air Force Base, FL., July 1984 (Final Report June 1982 - Sept. 1983), Technical Report distributed by Defense Technical Information Center, Defense Logistics Agency, Cameron station, Alexandria, VA.

11. "Engineering Development and Testing of Advanced Materials and Methods for Bomb Damage Repair Part 1 of 3," C. Kistler, A.S. Kubo, D.I. Read, ESI-TR-84-01, Engineering and Services Laboratory, Air Force Engineering and Services center, Tyndall Air Force Base, FL., Jan. 1985 (Final Report May 1982 - Oct. 1983), Technical Report distributed by Defense Technical Information Center, Defense Logistics Agency, Cameron Station, Alexandria, VA.

12. "Engineering Development and Testing of Advanced Materials and Methods for Bomb Damage Repair Part 2 of 3," C. Kistler, A.S. Kubo, D.L. Read, ESL-TR-84-01, Engineering and Services Laboratory, Air Force Engineering and Services Center, Tyndall Air Force Base, FL., Jan. 1985 (Final Report May 
1982 - Oct. 1983), Technical Report distributed by Defense Technical Information Center, Defense Logistics Agency, Cameron Station, Alexandria, VA.

13. "Engineering Development and Testing of Advanced Materials and Methods for Bomb Damage Repair Part 3 of 3," C. Kistler, A.S. Kubo, D.I. Read, ESL-TR-84-01, Engineering and Services Laboratory, Air Force Engineering and Services Center, Tyndall Air Force Base, FL., Jan. 1985 (Final Report May 1982 - Oct. 1983), Technical Report distributed by Defense Technical Information Center, Defense Logistics Agency, Cameron Station, Alexandria, VA.

14. Espenson, J.H., Chemical Kinetics and Reaction Mechanisms, MCGraw-Hill, 1981.

15. Benson, S.W., Thermochemical Kinetics, John Wiley and Sons, 1968 .

16. Handbook of Chemistry and Physics, Chemical Rubber Company, New York.

17. Fluid Flow and Heat Transfer Handbook, General Electric Company, Schenectady, New York.

18. Fields, S.D. and ottino, J.M., "Mixing Effects During Polymerization by the Adiabatic Temperature Rise Technique," A.I.Ch.E. J, 33(1), 1987, pp. 157-160.

19. Levanspiel, 0., Chemical Reaction Engineering, 2nd Edition, John Wiley and Sons, 1972.

20. Cold Weather Concreting, ACI Committee 306 Report, American Concrete Institute Materials Journal, July-August 1988. 
Table 9, in the main body of this report, presents a summary of the model parameters used in the set time prediction model. Most of these parameters were determined in one of the three types of auxiliary tests: resin warming (parameters $C_{v A}, C_{v B}$, and $c_{v}$ ), water immersion tests (parameters $r, t_{a i r}, t_{a}$, and $U_{0}$ ), and kinetic tests (parameters $\Delta H^{\prime}, \mathrm{n}, \mathrm{E}_{0}, \mathrm{E}_{\mathrm{n}}, \mathrm{m}_{\mathrm{O}}, \omega_{\mathrm{O}}$, and $\alpha$ ). In this appendix, theory and procedures for determining these parameters are presented for each test method. A brief summary of the auxiliary experiments is also provided.

\section{A.1 Resin Warming Auxiliary Test Results}

\section{A.1.1 Experiments}

Resin specific heats can be found by comparing temperature-time data for warming resins to that of warming water under the same experimental conditions. Since the specific heat of water is known it acts as an experimental control. In the tests, three separate $1000 \mathrm{ml}$ polyethylene bottles with screw tops were individually filled with water, Resin $A$, and Resin B to the shoulder of the bottles. Each bottle was fitted with two thermocouples, whose lead wires passed through a thin hollow reinforced plastic tube into the center of the liquid. The tube was centered and supported by a stopper fitted into the neck of the bottle. The three bottles were initially sealed and stored 
at $35^{\circ} \mathrm{F}$ overnight. At the beginning of the experiment, they were placed in an environmental chamber at $90^{\circ} \mathrm{F}$. Data from the six thermocouples were taken every $4 \mathrm{~s}$ for the first $240 \mathrm{~s}$ and every $60 \mathrm{~s}$ thereafter. The duration of the run was $9000 \mathrm{~s}$. The data for the test are given in Table Al (end of Appendix). For each bottle, the average of the two adjacent thermocouple readings is reported.

\section{A.1.2 Theory}

An energy balance for this system yeilds:

$$
-M_{v} \frac{d T}{d t}=U_{0} A_{0}\left[T-T_{a i r}\right]
$$

whose solution is:

$$
Y=\frac{T_{\text {air }}-T}{T_{\text {air }}-T_{0}}=\exp \left[-\frac{U_{O} A_{0}}{M_{V}} t\right]
$$

In equations (A1) and (A2), $T$ is the temperature of the liquid, $T_{0}$ is its initial value and $\mathrm{T}_{\mathrm{air}}$ is the temperature of the air outside the bottle. $U_{0}$ is the overall heat transfer coefficient based on the outside area $A_{0} \cdot \quad Y$ is a dimensionless temperature which is computed at each time. Equation (A2) can be linearized to give:

$$
\ln Y=-v t
$$


where

$$
v=\frac{U_{0} A_{0}}{M C_{V}}
$$

\section{A.1.3 Results}

Equation (A3) predicts that a plot of In Y vs. $t$ should be linear with a slope of $v$. Figure Al shows such a plot for the three data sets. Because the bottles are exposed to air which, together with polyethylene, is a good insulator, the temperature of the resin is presumed to be independent of position after an initial period during which initial temperature gradients become flat. For the data collected this occurred at about $2000 \mathrm{~s}$. Accordingly, the data was analyzed with $t_{0}=2044 \mathrm{~s}$, with this time subtracted away from all subsequent data. The value of $T_{0}$ was taken as the temperature at to and the three Iines were statistically forced through the point $Y=1, t=t_{0}$. The value of Tair in equation (A2) was taken equal to the average recorded temperature of the environmental chamber $\left(92.7^{\circ} \mathrm{F}\right)$ during the time span used in the data analysis.

For the three lines shown in Figure $A 1$, the values of $v$ were found to be $1.150 \times 10^{-4} \mathrm{~s}^{-1}, 2.342 \times 10^{-4} \mathrm{~s}^{-1}$ and $2.085 \times 10^{-4} \mathrm{~s}^{-1}$, for the water, Resin A and Resin B, respectively.

In the analysis, $U_{0} A_{0}$, the product of the heat transfer coefficient and exposed surface area, is presumed constant. This is likely because of the experimental design: all three liquids 


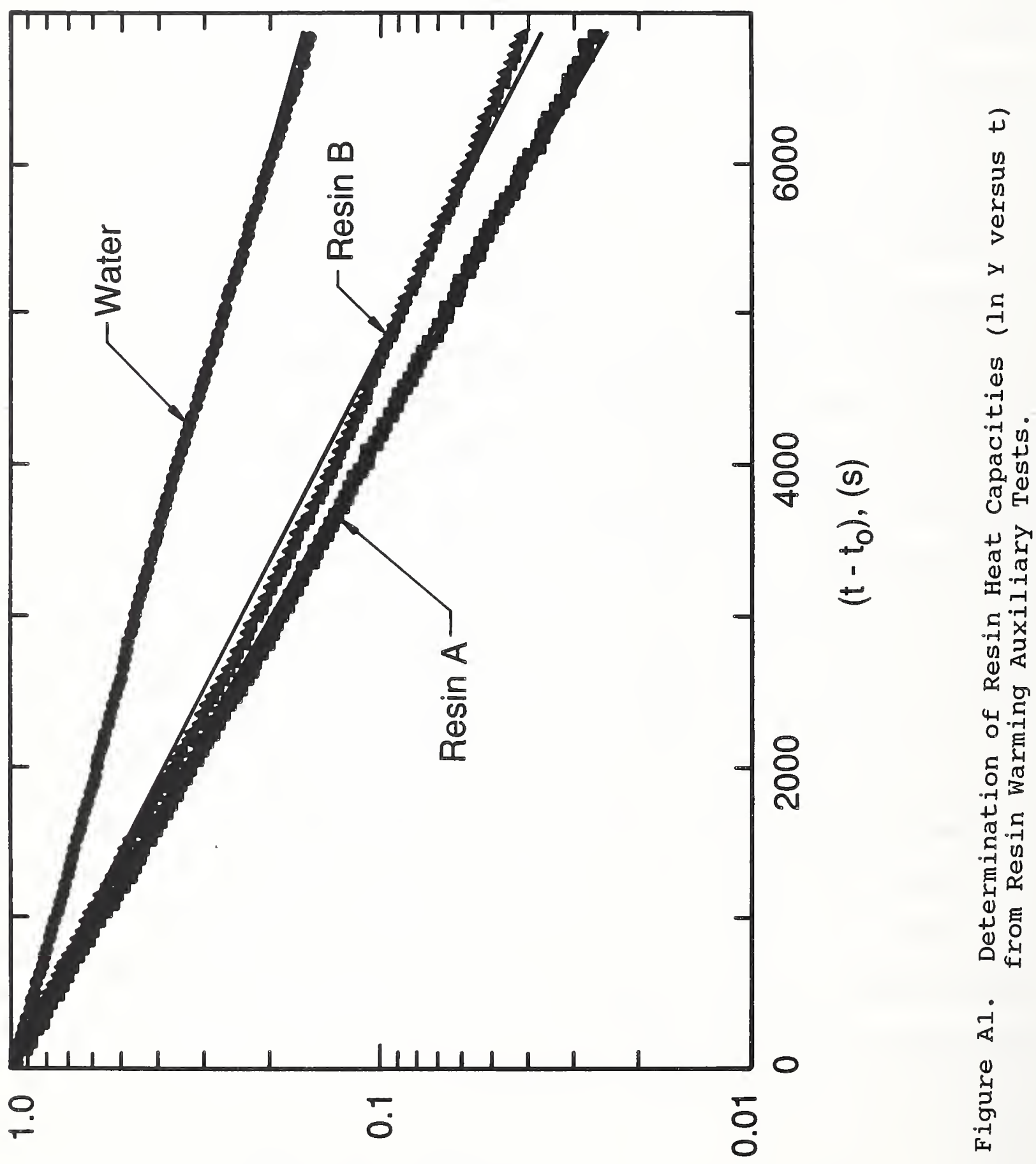


were exposed to the same environment at the same time. From the value of $\mathrm{v}$ for water, the mass of the water $(0.9566 \mathrm{~kg}$ ) and its specific heat at the average temperature $(4.181 \mathrm{~kJ} / \mathrm{kg} \cdot \mathrm{K})$, the value of $\mathrm{U}_{0} \mathrm{~A}_{0}$ was found to be $4.60 \times 10^{-4} \mathrm{~kJ} / \mathrm{K} \cdot \mathrm{s}$. For an exposed surface area of $4.81 \times 10^{-2} \mathrm{~m}^{2}$, this resulted in an overall heat transfer coefficient of $9.56 \times 10^{-2} \mathrm{~kJ} / \mathrm{kg} \mathrm{m} \mathrm{m}^{2} \mathrm{~s}$. This result is consistent with the magnitude of heat transfer coefficients reported for free convection from cooling and heating cylinders [17]. With $U_{O} A_{0}$ constant, the slopes of the lines for the two resins can be used to find their specific heats. This procedure predicted that $C_{V A}=1.846 \mathrm{~kJ} / \mathrm{kg} \cdot \mathrm{K}$ and $C_{V B}=1.669 \mathrm{~kJ} / \mathrm{kg} \cdot \mathrm{K}$. For the mass of Resin A and Resin B used in the set time tests (Table 9), the weighted composite specific heat for the mixed resin was of $\mathrm{C}_{\mathrm{v}}=1.748 \mathrm{~kJ} / \mathrm{kg} \cdot \mathrm{K}$. Using this value and the masses of aggregate and resin used in the regular tests, the value of m was calculated as 2.176 .

\section{A.2 Water Immersion Auxiliary Test Results}

\section{A.2.1 Experiment}

A test was conducted in the same bucket employed in the set time tests using the same grade and weight of aggregate. However, no resin was used. Instead, cold water was employed in a volume equal to the total volume of resin. The water was poured over the hot aggregate (within 10s) and temperatures were recorded as before, at mid-depth in the center, halfway between the center 
and the bucket wall, and at the bucket wall. Data for this test of water temperature versus time for the average of the three thermocouples are presented in Table A2. A plot of the data for the thermocouple halfway between the center and bucket wall is shown in Figure A2. This temperature was within a degree of the average value for times beyond $600 \mathrm{~s}$.

\section{A.2.2 Theory}

For this experiment, the energy balances for the water and the aggregate are given by equations (A3) and (A4), respectively:

$$
\begin{array}{ll}
-\frac{d T_{W}}{d t^{\prime}}=\frac{T_{w}-T_{\text {air }}}{r}+m\left(T_{w}-T_{a}\right) \quad \text { water } \\
-\frac{d T_{a}}{d t^{\prime}}=\left(T_{a}-T\right) & \text { aggregate }
\end{array}
$$

The initial temperatures of the water and aggregate are $\mathrm{T}_{\text {wo }}$ and Tao, respectively.

Equation (A3) can easily be obtained by setting the reaction term equal to zero in Equation 14, the energy balance for the resin, and letting $T=T_{W}$. In effect, the energy balance for the water is equal to that for the resin with the reaction term deleted. The aggregate energy balance (Equation A4) remains the same as Equation 15. An analytical solution of these equations is 
Table A2. Data for Water Immersion Auxiliary Tests $1 /$

\begin{tabular}{llllll} 
t(min) & $T_{W}\left({ }^{\circ} \mathrm{F}\right)$ & $t(\mathrm{~min})$ & $T_{\mathrm{W}}\left({ }^{\circ} \mathrm{F}\right)$ & t(min) & $T_{W}\left({ }^{\circ} \mathrm{F}\right)$ \\
\cline { 2 - 5 } 0.167 & & & & & 111.7 \\
0.233 & 47 & 230 & 96.0 & 580 & 112.2 \\
0.283 & 48.5 & 240 & 97.0 & 600 & 112.7 \\
0.35 & 50 & 250 & 98.0 & 620 & 113.2 \\
0.40 & 52.7 & 260 & 98.5 & 640 & 113.6 \\
0.45 & 53.5 & 270 & 99.0 & 660 & 114.0 \\
15 & 53.5 & 280 & 99.5 & 680 & 114.5 \\
25 & 74.8 & 290 & 100.0 & 700 & 114.7 \\
35 & 76.0 & 300 & 100.7 & 720 & 115.0 \\
45 & 77.2 & 310 & 101.2 & 740 & 115.3 \\
55 & 78.5 & 320 & 102.0 & 760 & 115.5 \\
80 & 79.5 & 330 & 102.5 & 780 & 116.0 \\
95 & 82.5 & 340 & 103.0 & 800 & 116.2 \\
105 & 84.0 & 350 & 103.5 & 820 & 116.5 \\
115 & 85.3 & 360 & 104.0 & 840 & 116.7 \\
125 & 86.3 & 370 & 104.5 & 860 & 117.0 \\
135 & 87.2 & 380 & 105.0 & 900 & 117.2 \\
145 & 88.0 & 400 & 105.8 & 930 & 117.5 \\
155 & 89.0 & 420 & 106.5 & 960 & 118.0 \\
165 & 90.0 & 440 & 107.5 & 1020 & 118.3 \\
180 & 90.7 & 460 & 108.0 & 1050 & 118.5 \\
190 & 92.0 & 480 & 108.8 & 1110 & 118.7 \\
200 & 93.0 & 500 & 109.7 & 1140 & 119.0 \\
210 & 93.7 & 520 & 110.3 & 1200 & 119.0 \\
220 & 94.5 & 540 & 110.6 & 1230 & 119.5 \\
& 95.3 & 560 & 111.2 & 1320 & 119.5
\end{tabular}

1) Initial water temperature $\left(\mathrm{T}_{\mathrm{WO}}\right)=36^{\circ} \mathrm{F}$

Initial aggregate temperature $\left(\mathrm{T}_{\mathrm{ao}}\right)=115^{\circ} \mathrm{F}$

Air temperature $\left(\mathrm{T}_{\text {air }}\right)=125^{\circ} \mathrm{F}$ 

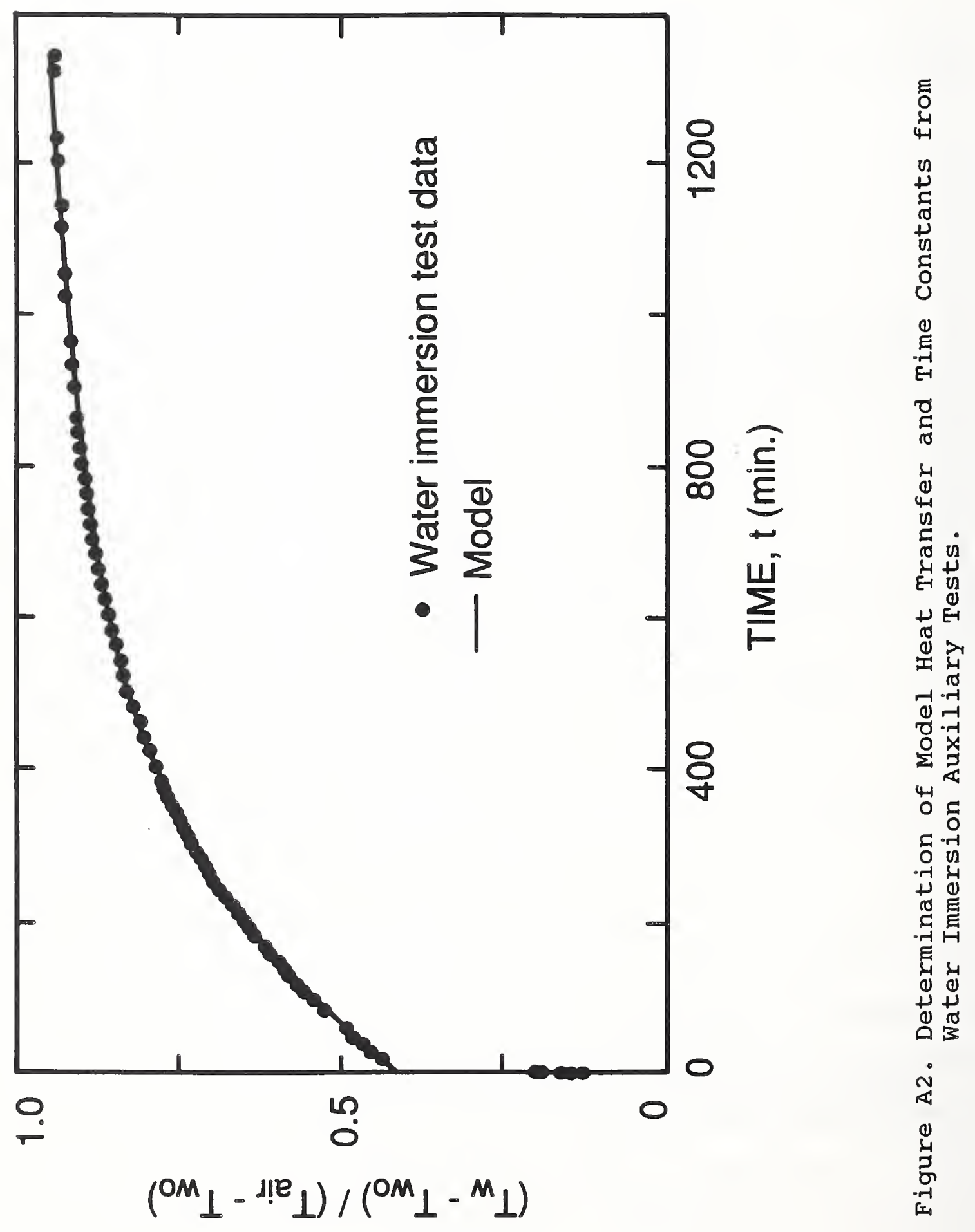
possible using the method of Laplace transforms. The solution is:

$$
\frac{T_{w}-T_{\text {air }}}{T_{\text {wo }}-T_{\text {air }}}=\frac{X}{2 b\left(1-w_{0}\right)}
$$

where

$$
x=\left\{\begin{array}{l}
{\left[r+\omega_{0}(1-a-b)-(a-b)\right] e^{-(a-b) t / t} \text { air }} \\
\left.-\left[r+\omega_{0}(1-a+b)-(a+b)\right] e^{-(a+b) t / t_{a i r}}\right\}
\end{array}\right\}
$$

with

$$
\begin{aligned}
& \omega_{0}=\frac{T_{\text {air }}-T_{a 0}}{T_{\text {wo }}-T_{a 0}} \\
& 2 a=(m+1) r+1, b=\sqrt{\left(\frac{m+1}{2}\right)^{2}+r^{2}\left(\frac{m-1}{2}\right) r+\frac{1}{4}} \\
& \text { and } \\
& \frac{T_{w}-T_{a}}{T_{\text {wo }}-T_{a 0}}=\frac{z}{2 b}
\end{aligned}
$$

where

$$
z=\left(-a+b+\omega_{0}\right) e^{-(a-b) t / t_{a i r}}-\left(a-b-\omega_{0}\right) e^{-(a+b) t / t} a i r
$$

At any time, $t$, the water temperature, $T_{W}$, can be found from equation (A5), while the aggregate temperature, $T_{a}$, can then be found from equation (A9).

$$
\text { A-9 }
$$




\section{A.2.3 Results}

Under the experimental conditions employed in the tests, the dimensionless temperature parameter $\omega_{0}$ was -0.1266 . To determine the values of $r$ and $t_{\text {air, }}$ a two-dimensional search was first made. A value of tair was assumed and, for each data point a reduced time, $t / t_{a i r}$, was calculated. $r$ was then varied until the sum of squares of the deviations was minimized. A new tair was then assumed and the procedure repeated to search for an ( $\left.r, t_{a i r}\right)$ pair which was a global minimum. However, no such minimum was found. It was not possible to find a finite value of $r$ which gave a realistic fit to the data. The problem stemmed from the fact that no data was collected between 30 and 200 s when most of the temperature change occurred. Also, during the first 30 , the three thermocouple gave widely different values so this data could not be analyzed by itself. It was noted, however, that all of the thermocouple readings collected at longer times (beyond 600s) were within two degrees of each other, indicating that temperature gradients within the system had equilibrated by then. At later times, it appeared the system was cooling as a whole, losing heat to the air. These facts indicated that $r$ should be large. Accordingly, the data was reanalyzed with the assumption that $r$ took on very large values. In effect, this reduced the analysis to a one-parameter search, finding the best value of tair. The fit is indicated by the solid curve in Figure A2, which gave $t_{\text {air }}=2.38 \times 10^{4} \mathrm{~s}(396 \mathrm{~min})$. This analysis still leaves the value of the aggregate time constant, $t_{a}$, undetermined, 
although it does indicate that it should be relatively small compared to tair.

\section{A.3 Kinetic Auxiliary Test Results}

The thermodynamic and kinetic parameters are those associated with the polymerization reaction. These include the modified heat of reaction, $\Delta H^{\prime}$, reaction order, $n$, activation energy, $E$, and the modified pre-exponential factor, B. All of these parameters are unknown and must be determined experimentally.

\section{A.3.1 Experiments}

Parameters were evaluated in independent experiments in which no aggregate was used and in which the reactor was insulated. For this purpose, experiments were conducted using beakers placed in insulated plastic buckets. A two-inch-thick foam polyurethane lid was fitted into the top of the bucket over the top of the beaker. Thermocouples which passed through the foam polyurethane and into the beaker measured three mid-depth temperatures: at the center of the beaker, halfway out, and near the wall. This matched the thermocouple arrangement in the set time tests conducted with aggregate. As in those tests, runs were conducted by first mixing catalyst with Resin $B$ and then mixing it with Resin A for 4 or 5 seconds. The mixture $(500 \mathrm{ml})$ which consisted of equal parts of Part $A$ and Part $B$ resins was then quickly poured into the beaker. The concentration of catalyst used was 
in the range employed in the set time tests. Resin temperatures were measured every 1 or 2 seconds. Because the beaker was insulated, measured temperatures were usually within a degree of one another. The average of the three temperatures was used in model calculations.

Table A3 summarizes the experimental conditions employed to determine the kinetics of reaction. Included are the catalyst concentration, C (expressed as a volume percent of Resin B $x$ 1000) and the initial resin temperature. As in the set time tests, equal volumes of the two resins were mixed, so that the relative proportions of the two resins were the same. Three temperatures were used: $40^{\circ}, 70^{\circ}$ and $90^{\circ} \mathrm{F}$. At each temperature, there were either five or seven catalyst levels, including runs made with no catalyst. Several replicate tests were made. The resin temperaturetime data'for all of the 21 runs made are given in Table A4 (end of Appendix) along with the experimental conditions and observed set times.

Table A3. Experimental Design for Determination of Kinetic Parameters

Initial Resin Temperature ${ }^{\circ} \mathrm{K}\left({ }^{\circ} \mathrm{F}\right)$ 278 295 305
Catalyst Concentration x 1000 c $\times 10^{3}$

$$
\begin{aligned}
& 0,0.3,0.4,0.7 \\
& 1.3,2.6,7.8 \\
& 0,0.3,0.4,0.7 \\
& 1.25,1.3,5.0 \\
& 0,0.3,0.4
\end{aligned}
$$$$
0.7,1.3
$$

Number of Experiments 


\section{A.3.2 Results}

A.3.2.1 Thermodynamic Parameter $(\Delta H)^{\prime}$

Because the system was well insulated in the auxiliary kinetic tests, the parameter $r$ can be set arbitrarily large in the resin energy balance. In addition, there is no term corresponding to heat loss into the aggregate. With these simplifications, the resin energy balance can be solved to give:

$$
T-T_{0}=T_{0}(\Delta H)^{P}
$$

This equation states mathematically that the adiabatic temperature rise in the insulated beaker will be directly proportional to resin conversion. In fact, the unknown dimensionless heat of reaction can be found from the final temperature, $T_{f}$, which is reached when $\mathrm{x}=1$ :

$$
(\Delta H)^{\prime}=\frac{T_{f}-T_{\circ}}{T_{O}}
$$

For each run the value of $(\Delta H)$ ' was calculated from equation (A12). Values of the set time, $t_{s}$, for each run are presented in Table A4. It was found that $(\Delta H)^{\prime}$ was independent of the initial temperature so that an average value of $(\Delta H)^{\prime}=0.3626$ could be used in the analysis. The average of $(\Delta H)^{\prime}=0.3626$ is the value 
reported in Table 9 and used in model predictions of set time performance.

The conversion, $x$, at any time, $t$, can conveniently be found as the fraction of the accomplished temperature change:

$$
x=\frac{T-T_{0}}{T_{f}-T_{0}}
$$

This is illustrated in Figure A3, where the conversion at any time is depicted as the ratio of the distances denoted by a and b.

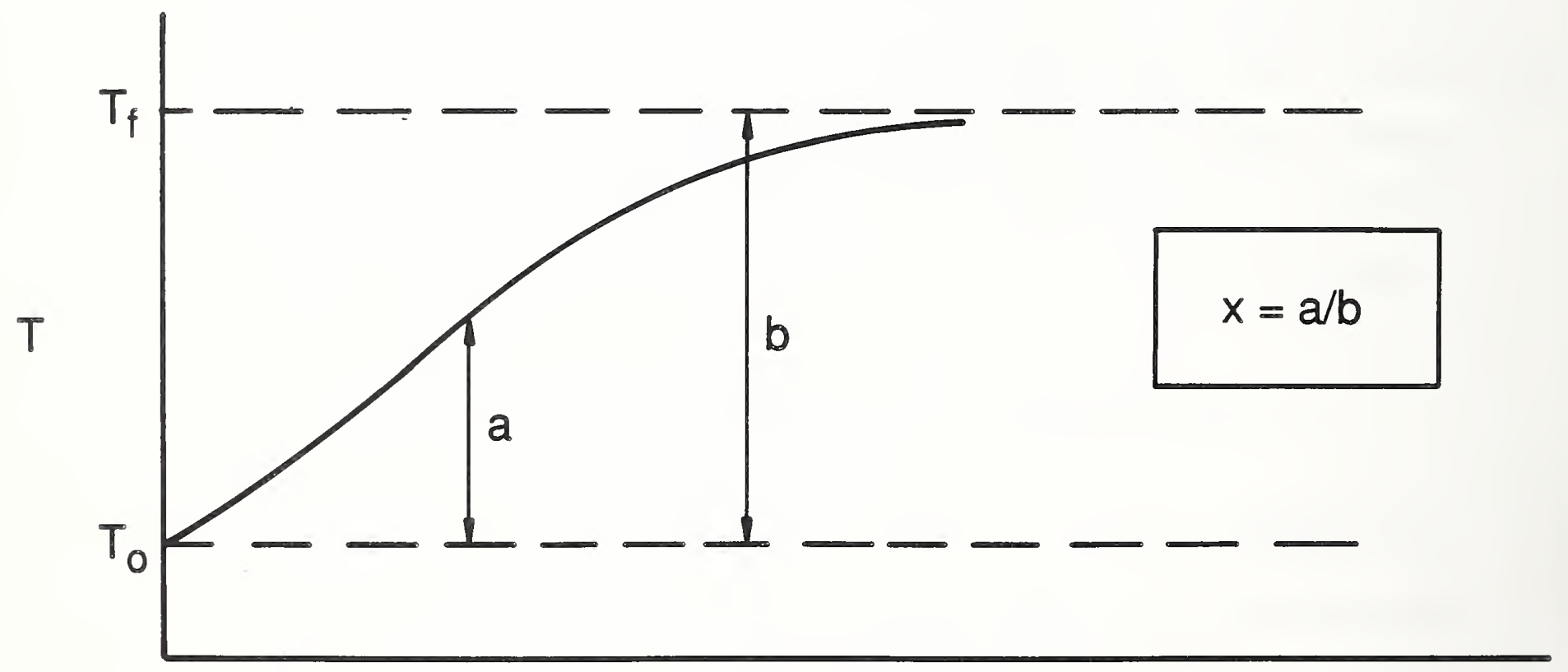

Figure A3. Determination of Conversion from Adiabatic Temperature-Time Profiles. 


\section{A.3.2.2 Kinetic Parameters - Analysis of Results}

Using equation (A13), the kinetic rate equation can be rearranged to give:

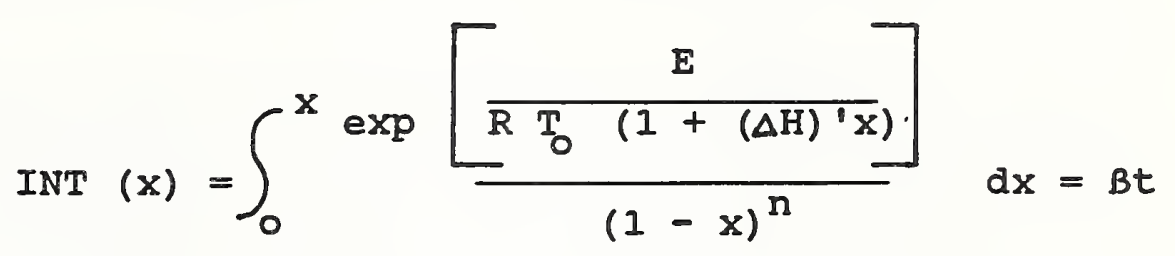

INT $(x)$ is the value of the defined intergral at any conversion $x$. In equation (A14) there are three unknowns, $\mathrm{n}$ the reaction order, E the activation energy, and $B$ the modified pre-exponential factor. Because of the integral it is not possible to solve directly for these parameters, and an iterative procedure must be used.

In the analysis ${ }^{1} \mathrm{E}$ was varied in increments of 200 from 1000 to $10,000 \mathrm{cal} / \mathrm{g}$ mol and $\mathrm{n}$ in increments of 0.5 from 0.5 to 3 . The $(x, t)$ data of Table $A 4$ was analyzed for each possible pair of $(E, n)$ values. Wtih $E$ and $n$ fixed, the value of $\operatorname{INT}(x)$ is determined by the integral in equation (A14). The value of $B$ was then found from the least squares slope of INT(x) vs. time. Since INT(x) vs $t$ is forced through the origin (INT(0) $=0$ at $t=0$ ) the statistics of zexo force was used. Using this procedure, $(E, n)$ pairs at each of the possible combinations were chosen. For each pair, the sum

IThis method is only possible for adiabatic systems where the temperatures can be written explicity as a function of conversion. When there is heat exchange to the surroundings or another phase present, the system is non-adiabatic, and solution by this method is not possible.

$$
\text { A- }-15
$$


of squares of the deviations $\left(s^{2}\right)$ between the theoretical and experimental temperature predictions was made. For almost all runs, one of these $(E, n)$ pairs had the lowest value of $s^{2}$. The pair then determined the best values of $E$ and $n$.

Figure A4 shows the fit obtained by this method for a run with $T_{0}$ $=71^{\circ} \mathrm{F}$ and $C=1.25 \times 10^{-3}$. The solid curve is the prediction of the model with $E=2000 \mathrm{cal} / \mathrm{g} \mathrm{mol} \mathrm{and} \mathrm{n}=1.5$. The analysis for all the runs showed that $n=1.5$ was by far the most common best value of reaction order. The best values of the activation energy, however, were not constant from run to run. They appeared to depend on both the initial resin temperature and the catalyst concentration. Accordingly, $n$ was fixed at 1.5 for all runs and the analysis was redone to adjust the best value of the activation energy $E$. In general, this changed the value of $E$ only slightly.

Table A5 presents the best values of $\mathrm{E}$ (cal/g mol) at each catalyst level $\mathrm{C}$ and initial temperature $\mathrm{T}_{0}$. The three replicate runs gave good reproducibility. The run at $c=5 \times 10^{-3}$ gave an inordinately low value of $\mathrm{E}$ and was not used in subsequent data analysis. The table shows, in general, that $\mathrm{E}$ decreases as $\mathrm{C}$ and $t_{0}$ increase. Lower activation energies at higher catalyst concentrations and higher initial temperatures are consistent with the function of the catalyst, which provides more sites where reaction can occur. Also lower activation energies raise reaction rates, accelerating set. 


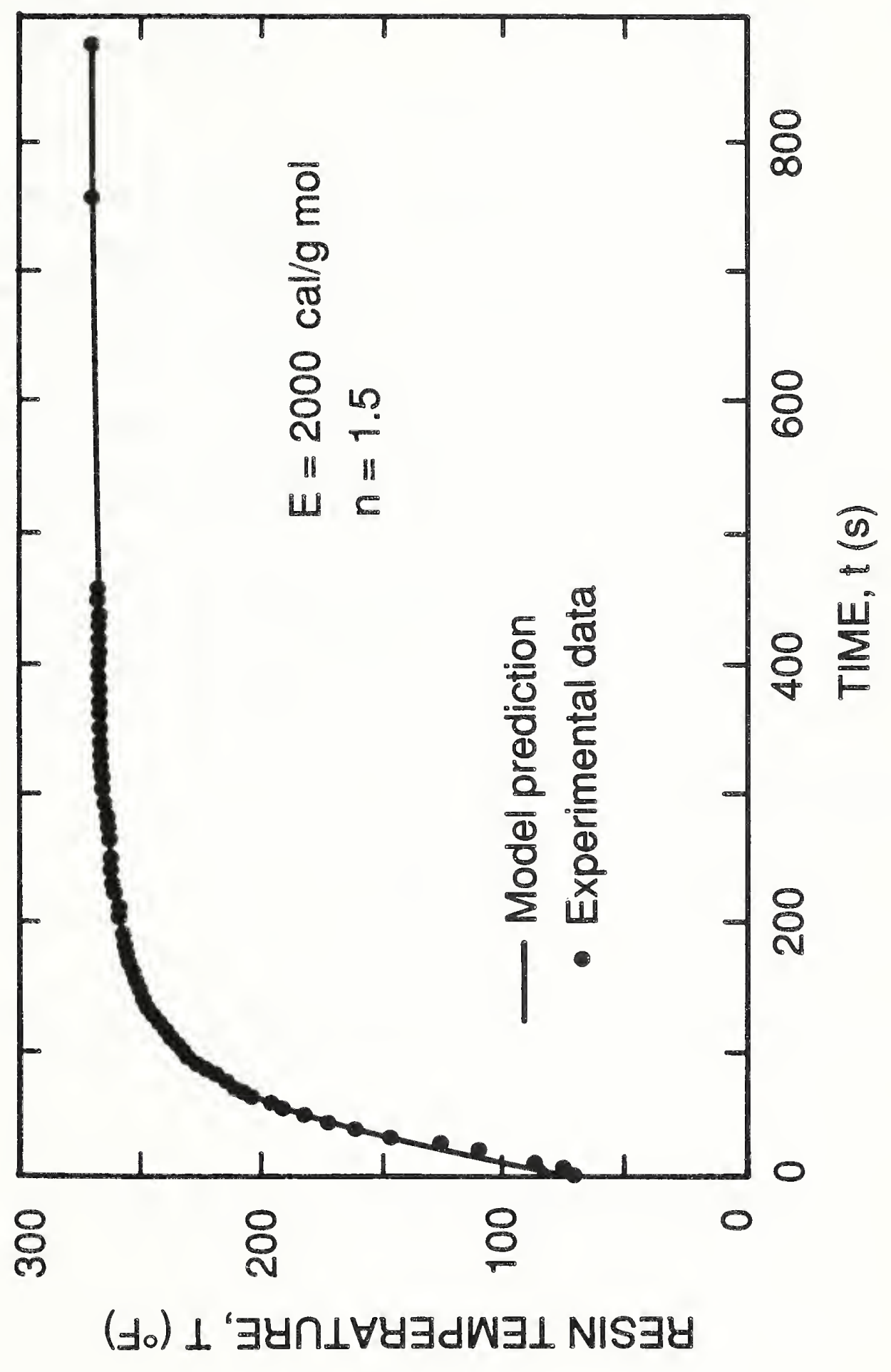

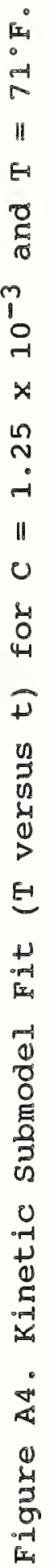
$A=17$ 
Table A5. Calculated Activation Energies E (cal/g mol)

Catalyst concentration $\times 1000$ $\left(\mathrm{C} \times 10^{3}\right)$
Activation Energy for Indicated Initial Resin Temperature, $\mathrm{T}_{\mathrm{O}}\left({ }^{\circ} \mathrm{F}\right)$

$\begin{array}{ccc}\underline{40} & \underline{71} & \underline{90} \\ 6600 & 7200 & 6600 \\ 5800 & 4300 & 4600 \\ 5600 & & \\ 5400 & 4900 & 2700 \\ 4600 & & \\ 5500 & 3050 & 1600 \\ 3200 & 2300^{+} & 1800 \\ 2100 & & \\ 2800 & -- & -- \\ -0 & 400 & -- \\ 2500 & -- & --\end{array}$

$\mp$ obtained for $\mathrm{C}=1.25 \times 10^{-3}$ 
It was found that a linear fit was obtained when the data of Table A5 was correlated with an equation of the form:

$$
\frac{1}{E}-\frac{1}{\bar{E}_{0}}=m^{\prime} C
$$

$E_{0}$ is the zero concentration activation energy (at $C=0$ ) and $\mathrm{m}$ is the slope of a plot of $\left(1 / \mathrm{E}-1 / \mathrm{E}_{0}\right)$ vs. C. The slope, $\mathrm{m}^{\prime}$, varies with the initial resin temperature. The best values obtained were $\mathrm{m}=8.30 \times 10^{-5}, 2.25 \times 10^{-4}$ and $3.79 \times 10^{-4} \mathrm{gmol} / \mathrm{cal}$ at $40^{\circ}, 71^{\circ}$ and $90^{\circ} \mathrm{F}$, respectively. The lines were all forced through $\mathrm{E}_{0}=6800$, the average of the $\mathrm{C}=0$ values in Table $\mathrm{A5}$.

The value of $\mathrm{m}^{\prime}$ itself was found to correlate well with $T_{0}$ when an Arrhenius type plot of $\log \mathrm{m}^{\prime}$ vs $1 / \mathrm{T}_{0}$ was made. The correlating equation is:

$$
\log \frac{m^{\prime}}{m_{0}^{\prime}}=\frac{-E_{m}}{2.3 R T_{0}}
$$

The best values of the intercept and activation energy were found to be:

$$
\mathrm{m}_{0}^{\prime}=1.54 \times 10^{3} \frac{\mathrm{g} \mathrm{mol}}{\mathrm{cal}} \text { and } \mathrm{E}_{\mathrm{m}}=9230 \frac{\mathrm{cal}}{\mathrm{gmol}}
$$


The sub-model corresponding to equations (A15) and (A16) can be shown to follow second order kinetics of the form:

$$
\frac{d E}{d c}=m^{\prime} c^{2}
$$

where

$$
m^{\prime}=m_{0}^{\prime} c^{-E m^{R T} 。}
$$

Table A6 presents the best values of the modified pre-exponential factor $B\left(s^{-1}\right)$ found at each catalyst level $C$ and initial temperature $\mathrm{T}_{0}$. The reported values are associated with the activation energies reported in Table A5. B was found to correlate well with the activation energy, regardless of the value of the activation energy or initial resin temperature. B can be found directly from the correlating equation:

$$
\log B / B_{O}=\alpha E
$$

To summarize, the overall submodel which predicts the activation energy, E, and modified pre-exponential factor, $B$, is given by equations (A15), (A16) and (A17). The values of $n$ and $(\Delta H)^{\prime}$ were fixed at 1.5 and 0.3626 , respectively. These equations and values were incorporated into the model in the kinetic rate law [Equation (16)] and reported in Table 9. Because of the additional uncertainty which use of these correlating equations introduces into the predictions of the model, backplots were made of temperature vs. time to see how well the submodel itself agreed 
Table A6. Calculated Modified Pre-Exponential Factors, B $\left(s^{-1}\right)$

Catalyst concentration $\times 1000$ $\left(C \times 10^{3}\right)$

$\left(\mathrm{C} \times 10^{3}\right)$

0

0.3

0.4

0.7

1.3

2.6

$7 \cdot 8$
Modified Pre-Exponential Factor for Indicated Initial Resin Temperature To- $\left({ }^{\circ} \mathrm{F}\right)$

$\underline{40}$

71

347

231

197

$7 \cdot 6$

17.7

53.9

$40.9 \quad 17.9$

1.13

82.8

1.82

0.26

2.45

$0.69^{+}$

0.62

1.88

2.27
$-$

$-\infty$
0.65

$-$

\footnotetext{
Fobtained for $\mathrm{C}=1.25$
}

with the experimental data. Reasonable predictions resulted at $40^{\circ} \mathrm{F}$ and $71^{\circ} \mathrm{F}$ with the poorest fit between the data and submodel predictions found at $90^{\circ} \mathrm{F}$ and the highest catalyst concentrations. 
Table Al. Data for Resin Warming Auxiliary Tests

\begin{tabular}{|c|c|c|c|c|}
\hline $\begin{array}{l}\text { Time } \\
\mathrm{s} \\
\end{array}$ & $\begin{array}{l}\text { Water Temp. } \\
\frac{(\circ \mathrm{F})}{}\end{array}$ & $\begin{array}{c}\text { Resin A Temp. } \\
\left({ }^{\circ} \mathrm{F}\right)\end{array}$ & $\begin{array}{l}\text { Resin B Temp. } \\
\left(^{\circ} \mathrm{F}\right)\end{array}$ & $\begin{array}{l}\text { Air Temp. } \\
\left({ }^{\circ} \mathrm{F}\right)\end{array}$ \\
\hline 0 & 35.00 & 35.60 & 35.35 & 88.0 \\
\hline 4 & 35.35 & 35.70 & 35.40 & 88.1 \\
\hline 8 & 35.40 & 35.80 & 35.40 & 88.3 \\
\hline 12 & 35.40 & 35.80 & 35.40 & 88.4 \\
\hline 16 & 35.45 & 35.80 & 35.40 & 88.5 \\
\hline 20 & 35.50 & 35.80 & 35.40 & 88.6 \\
\hline 24 & 35.45 & 35.80 & 35.40 & 88.8 \\
\hline 28 & 35.50 & 35.80 & 35.40 & 88.9 \\
\hline 32 & 35.50 & 35.80 & 35.40 & 88.9 \\
\hline 36 & 35.50 & 35.90 & 35.40 & 89.1 \\
\hline 40 & 35.50 & 35.90 & 35.45 & 89.4 \\
\hline 44 & 35.55 & 36.00 & 35.40 & 89.5 \\
\hline 48 & 35.60 & 36.00 & 35.40 & 89.6 \\
\hline 52 & 35.60 & 36.00 & 35.40 & 89.7 \\
\hline 57 & 35.60 & 36.00 & 35.45 & 89.7 \\
\hline 61 & 35.65 & 36.10 & 35.45 & 89.9 \\
\hline 65 & 35.70 & 36.15 & 35.45 & 89.9 \\
\hline 69 & 35.65 & 36.15 & 35.45 & 90.0 \\
\hline 73 & 35.65 & 36.20 & 35.45 & 90.1 \\
\hline 77 & 35.70 & 36.20 & 35.45 & 90.1 \\
\hline 81 & 35.75 & 36.25 & 35.45 & 90.2 \\
\hline 85 & 35.75 & 36.30 & 35.45 & 90.3 \\
\hline 89 & 35.80 & 36.35 & 35.50 & 90.4 \\
\hline 93 & 35.80 & 36.40 & 35.45 & 90.4 \\
\hline 97 & 35.80 & 36.40 & 35.55 & 90.5 \\
\hline 101 & 35.85 & 36.40 & 35.55 & 90.5 \\
\hline 105 & 35.85 & 36.50 & 35.55 & 90.5 \\
\hline 109 & 35.90 & 36.55 & 35.55 & 90.6 \\
\hline 114 & 35.90 & 36.60 & 35.55 & 90.6 \\
\hline 118 & 35.90 & 36.60 & 35.55 & 90.6 \\
\hline 122 & 35.95 & 36.65 & 35.55 & 90.6 \\
\hline 126 & 36.00 & 36.70 & 35.55 & 90.6 \\
\hline 130 & 36.00 & 36.75 & 35.55 & 90.7 \\
\hline 134 & 36.00 & 36.80 & 35.55 & 90.7 \\
\hline 138 & 36.05 & 36.80 & 35.60 & 90.7 \\
\hline 142 & 36.10 & 36.90 & 35.60 & 90.7 \\
\hline 146 & 36.10 & 36.90 & 35.55 & 90.7 \\
\hline 150 & 36.10 & 36.95 & 35.60 & 90.7 \\
\hline 154 & 36.10 & 37.05 & 35.65 & 90.8 \\
\hline 158 & 36.15 & 37.05 & 35.60 & 90.8 \\
\hline 162 & 36.20 & 37.10 & 35.65 & 90.8 \\
\hline 166 & 36.20 & 37.15 & 35.65 & 90.8 \\
\hline 171 & 36.25 & 37.15 & 35.60 & 90.8 \\
\hline 175 & 36.25 & 37.25 & 35.65 & 90.8 \\
\hline 179 & 36.30 & 37.25 & 35.65 & 90.8 \\
\hline
\end{tabular}


Table Al. Data for Resin Warming Auxiliary Tests (Continued)

\begin{tabular}{|c|c|c|c|c|}
\hline $\begin{array}{l}\text { Time } \\
\text { s }\end{array}$ & $\begin{array}{l}\text { Water Temp. } \\
\frac{(\circ \mathrm{F})}{}\end{array}$ & $\begin{array}{c}\text { Resin A Temp. } \\
\left({ }^{\circ} \mathrm{F}\right)\end{array}$ & $\begin{array}{c}\text { Resin B Temp. } \\
\left({ }^{\circ} \mathrm{F}\right)\end{array}$ & $\begin{array}{l}\text { Air Temp. } \\
\left({ }^{\circ} \mathrm{F}\right) \\
\end{array}$ \\
\hline $\begin{array}{l}183 \\
187 \\
191 \\
195 \\
199 \\
203 \\
207 \\
211 \\
215 \\
219 \\
224 \\
228 \\
232 \\
236 \\
240 \\
304 \\
364 \\
424 \\
484 \\
544 \\
604 \\
664 \\
724 \\
784 \\
844 \\
904 \\
964 \\
1024 \\
1084 \\
1144 \\
1204 \\
1264 \\
1324 \\
1384 \\
1444 \\
1504 \\
1564 \\
1624 \\
1684 \\
1744 \\
1804 \\
1864 \\
1924 \\
1984 \\
2044 \\
2104 \\
2164 \\
2224\end{array}$ & $\begin{array}{l}36.30 \\
36.30 \\
36.25 \\
36.40 \\
36.15 \\
36.40 \\
36.45 \\
36.45 \\
36.45 \\
36.50 \\
36.50 \\
36.55 \\
26.55 \\
36.55 \\
36.55 \\
36.75 \\
36.95 \\
37.20 \\
37.30 \\
37.40 \\
37.80 \\
38.95 \\
40.75 \\
41.60 \\
42.15 \\
42.60 \\
42.05 \\
43.30 \\
43.85 \\
44.30 \\
44.65 \\
45.05 \\
45.40 \\
45.80 \\
46.20 \\
46.60 \\
46.95 \\
47.30 \\
47.70 \\
48.00 \\
48.40 \\
49.10 \\
49.45 \\
49.75 \\
50.10 \\
50.40 \\
50.75 \\
51.10\end{array}$ & 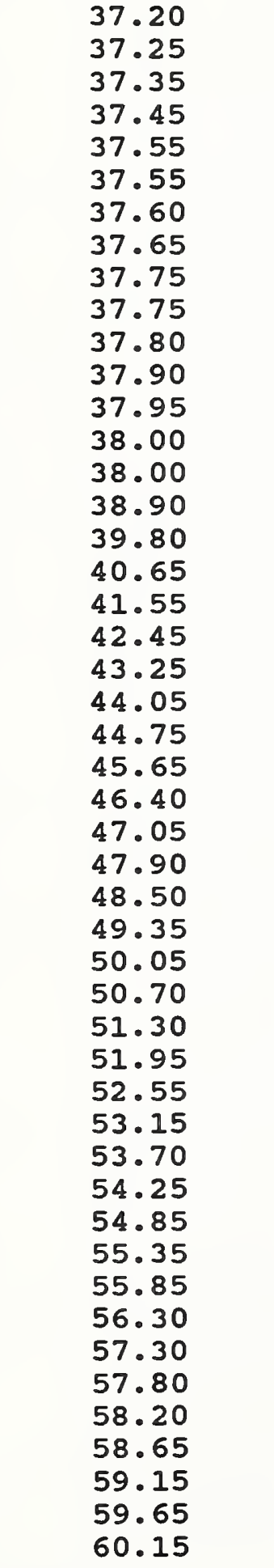 & $\begin{array}{l}35.60 \\
35.60 \\
35.60 \\
35.65 \\
35.65 \\
35.65 \\
35.70 \\
35.65 \\
35.65 \\
35.70 \\
35.70 \\
35.70 \\
35.75 \\
35.70 \\
35.70 \\
35.75 \\
35.90 \\
36.00 \\
36.10 \\
36.25 \\
36.40 \\
36.60 \\
36.75 \\
37.05 \\
37.30 \\
37.60 \\
37.85 \\
37.90 \\
38.50 \\
33.90 \\
39.20 \\
39.60 \\
40.05 \\
40.45 \\
40.90 \\
41.30 \\
41.80 \\
42.25 \\
42.70 \\
43.15 \\
53.65 \\
44.60 \\
45.15 \\
45.65 \\
46.20 \\
46.75 \\
47.75\end{array}$ & 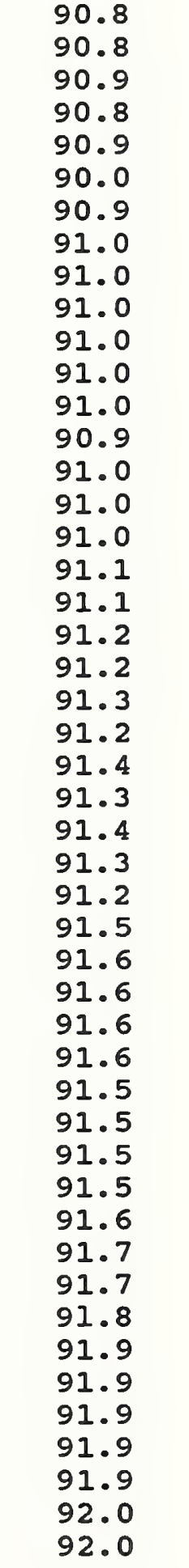 \\
\hline & & $A-23$ & & \\
\hline
\end{tabular}


Table A1. Data for Resin Warming Auxiliary Tests (Continued)

\begin{tabular}{|c|c|c|c|c|}
\hline $\begin{array}{l}\text { Time } \\
\text { s }\end{array}$ & $\begin{array}{l}\text { Water Temp. } \\
\frac{\left({ }^{\circ} \mathrm{F}\right)}{}\end{array}$ & $\begin{array}{c}\text { Resin A Temp. } \\
\left({ }^{\circ} \mathrm{F}\right)\end{array}$ & $\begin{array}{c}\text { Resin B Temp. } \\
\left({ }^{\circ} \mathrm{F}\right)\end{array}$ & $\begin{array}{l}\text { Air Temp. } \\
\left({ }^{\circ} \mathrm{F}\right)\end{array}$ \\
\hline $\begin{array}{l}2284 \\
2344 \\
2404 \\
2464 \\
2524 \\
2584 \\
2644 \\
2704 \\
2764 \\
2824 \\
2884 \\
2944 \\
3004 \\
3064 \\
3124 \\
3184 \\
3244 \\
3304 \\
3364 \\
3424 \\
3484 \\
3544 \\
3604 \\
3664 \\
3724 \\
3784 \\
3844 \\
3904 \\
3964 \\
4024 \\
4084 \\
4144 \\
4204 \\
4264 \\
4324 \\
4384 \\
4444 \\
4504 \\
4564 \\
4624 \\
4684 \\
4744 \\
4804 \\
4864 \\
4924 \\
4984 \\
5044 \\
5104\end{array}$ & $\begin{array}{l}51.40 \\
51.65 \\
52.00 \\
52.30 \\
52.60 \\
52.90 \\
53.15 \\
53.40 \\
53.70 \\
54.00 \\
54.20 \\
54.60 \\
54.80 \\
55.10 \\
55.40 \\
55.60 \\
55.90 \\
56.15 \\
56.35 \\
56.60 \\
56.80 \\
57.00 \\
57.20 \\
57.55 \\
57.80 \\
58.05 \\
58.20 \\
58.50 \\
58.65 \\
58.85 \\
59.05 \\
59.30 \\
59.50 \\
59.70 \\
59.60 \\
60.10 \\
60.30 \\
60.50 \\
60.70 \\
61.00 \\
61.10 \\
61.30 \\
61.50 \\
61.60 \\
61.85 \\
62.00 \\
62.20 \\
62.40\end{array}$ & $\begin{array}{l}60.65 \\
61.05 \\
61.55 \\
62.00 \\
62.45 \\
62.90 \\
63.35 \\
63.70 \\
64.15 \\
64.55 \\
64.95 \\
65.45 \\
65.85 \\
66.25 \\
66.60 \\
67.05 \\
67.45 \\
67.80 \\
68.15 \\
68.50 \\
68.80 \\
69.20 \\
69.45 \\
69.80 \\
70.15 \\
70.50 \\
70.80 \\
71.10 \\
71.40 \\
71.70 \\
71.95 \\
72.30 \\
72.60 \\
72.95 \\
73.20 \\
73.50 \\
73.75 \\
73.95 \\
74.20 \\
74.55 \\
74.80 \\
75.00 \\
75.25 \\
75.50 \\
75.80 \\
75.95 \\
76.25 \\
76.45\end{array}$ & $\begin{array}{l}48.20 \\
48.75 \\
49.30 \\
49.85 \\
50.40 \\
50.95 \\
51.55 \\
52.00 \\
52.55 \\
53.05 \\
53.55 \\
54.15 \\
54.60 \\
55.10 \\
55.60 \\
56.10 \\
56.65 \\
57.05 \\
57.65 \\
58.05 \\
58.45 \\
58.95 \\
59.45 \\
59.95 \\
60.35 \\
60.80 \\
61.25 \\
61.60 \\
62.00 \\
62.45 \\
62.85 \\
63.25 \\
63.70 \\
64.05 \\
64.50 \\
64.85 \\
65.25 \\
65.60 \\
65.95 \\
66.40 \\
66.70 \\
67.05 \\
67.35 \\
67.65 \\
68.05 \\
68.30 \\
68.65 \\
68.90\end{array}$ & $\begin{array}{l}92.1 \\
92.1 \\
92.1 \\
92.2 \\
92.2 \\
92.2 \\
92.1 \\
92.2 \\
92.1 \\
92.1 \\
92.2 \\
92.2 \\
92.3 \\
92.3 \\
92.4 \\
92.3 \\
92.2 \\
92.2 \\
92.1 \\
92.2 \\
92.3 \\
92.2 \\
92.3 \\
92.3 \\
92.2 \\
92.4 \\
92.4 \\
92.4 \\
92.5 \\
92.5 \\
92.5 \\
92.6 \\
92.5 \\
92.4 \\
92.4 \\
92.4 \\
92.5 \\
92.5 \\
92.5 \\
92.5 \\
92.7 \\
92.6 \\
92.7 \\
92.7 \\
92.7 \\
92.6 \\
92.8 \\
92.7\end{array}$ \\
\hline
\end{tabular}


Table A1. Data for Resin Warming Auxiliary Tests (Continued)

\begin{tabular}{|c|c|c|c|c|}
\hline $\begin{array}{c}\text { Time } \\
\mathrm{s} \\
\end{array}$ & $\begin{array}{l}\text { Water Temp. } \\
(\circ \mathrm{F})\end{array}$ & $\begin{array}{l}\text { Resin A Temp. } \\
\left({ }^{\circ} \mathrm{F}\right)\end{array}$ & $\begin{array}{c}\text { Resin B Temp. } \\
\left({ }^{\circ} \mathrm{F}\right)\end{array}$ & $\begin{array}{l}\text { Air Temp. } \\
(\circ \mathrm{F})\end{array}$ \\
\hline 5164 & 62.55 & 76.65 & 69.20 & 92.7 \\
\hline 5224 & 62.75 & 76.85 & 69.45 & 92.8 \\
\hline 5284 & 62.95 & 77.05 & 69.70 & 92.7 \\
\hline 5344 & 63.15 & 77.30 & 70.00 & 92.8 \\
\hline 5404 & 63.30 & 77.50 & 70.30 & 92.8 \\
\hline 5464 & 63.50 & 77.75 & 70.60 & 92.9 \\
\hline 5524 & 63.75 & 77.95 & 70.85 & 92.8 \\
\hline 5584 & 63.85 & 78.15 & 71.10 & 92.9 \\
\hline 5644 & 64.05 & 78.30 & 71.40 & 92.8 \\
\hline 5704 & 64.25 & 78.50 & 71.70 & 92.9 \\
\hline 5764 & 64.45 & 78.65 & 71.90 & 92.9 \\
\hline 5824 & 64.70 & 78.85 & 72.20 & 92.8 \\
\hline 5884 & 64.85 & 79.05 & 72.45 & 92.8 \\
\hline 5944 & 65.10 & 79.20 & 72.70 & 92.9 \\
\hline 6004 & 65.25 & 79.35 & 72.90 & 92.8 \\
\hline 6064 & 65.45 & 79.55 & 73.15 & 92.9 \\
\hline 6124 & 65.65 & 79.70 & 73.35 & 92.8 \\
\hline 6184 & 65.90 & 79.95 & 73.55 & 92.8 \\
\hline 6244 & 66.05 & 80.05 & 73.80 & 92.8 \\
\hline 6304 & 66.30 & 80.25 & 74.00 & 92.8 \\
\hline 6364 & 66.50 & 80.45 & 74.25 & 92.9 \\
\hline 6424 & 66.75 & 80.65 & 74.45 & 92.9 \\
\hline 6484 & 66.90 & 80.75 & 74.65 & 92.9 \\
\hline 6544 & 67.05 & 80.90 & 74.80 & 92.9 \\
\hline 6604 & 67.25 & 81.05 & 75.00 & 93.0 \\
\hline 6664 & 67.45 & 81.20 & 75.20 & 92.9 \\
\hline 6724 & 67.65 & 81.35 & 75.40 & 92.9 \\
\hline 6784 & 67.85 & 81.50 & 75.55 & 92.9 \\
\hline 6844 & 68.05 & 81.65 & 75.75 & 93.0 \\
\hline 6904 & 68.25 & 81.85 & 76.00 & 93.0 \\
\hline 6964 & 68.40 & 81.95 & 76.10 & 92.9 \\
\hline 7024 & 68.60 & 82.10 & 76.30 & 93.0 \\
\hline 7084 & 68.75 & 82.15 & 76.45 & 92.9 \\
\hline 7144 & 68.95 & 82.35 & 76.60 & 92.9 \\
\hline 7204 & 69.05 & 82.45 & 76.80 & 93.1 \\
\hline 7264 & 69.30 & 82.55 & 77.00 & 92.9 \\
\hline 7324 & 69.45 & 82.75 & 77.10 & 92.9 \\
\hline 7384 & 69.65 & 82.85 & 77.30 & 93.1 \\
\hline 7444 & 69.85 & 83.00 & 77.45 & 93.0 \\
\hline 7504 & 69.96 & 83.05 & 77.60 & 93.1 \\
\hline 7564 & 70.15 & 83.25 & 77.80 & 93.1 \\
\hline 7624 & 70.25 & 83.35 & 78.00 & 93.1 \\
\hline 7684 & 70.45 & 83.50 & 78.20 & 93.1 \\
\hline 7744 & 70.65 & 83.65 & 78.30 & 93.1 \\
\hline 7804 & 70.85 & 83.70 & 78.50 & 93.1 \\
\hline 7864 & 71.05 & 83.90 & 78.65 & 93.1 \\
\hline 7924 & 71.10 & 84.00 & $78.75^{\circ}$ & 93.1 \\
\hline 7984 & 71.25 & 84.05 & 78.90 & 93.2 \\
\hline
\end{tabular}


Table A1. Data for Resin Warming Auxiliary Tests (Continued)

\begin{tabular}{lcccc}
$\begin{array}{c}\text { Time } \\
\mathrm{S}\end{array}$ & $\begin{array}{c}\text { Water Temp. } \\
\left({ }^{\circ} \mathrm{F}\right)\end{array}$ & $\begin{array}{c}\text { Resin A Temp. } \\
\left({ }^{\circ} F\right)\end{array}$ & $\begin{array}{c}\text { Resin B Temp. } \\
\left({ }^{\circ} F\right)\end{array}$ & $\begin{array}{c}\text { Air Temp. } \\
\left(0^{\circ} F\right)\end{array}$ \\
\cline { 2 - 3 } 8044 & 71.45 & 84.15 & 79.05 & 93.2 \\
8104 & 71.65 & 84.30 & 79.20 & 93.1 \\
8164 & 71.80 & 84.50 & 79.40 & 93.2 \\
8224 & 72.00 & 84.60 & 79.50 & 93.2 \\
8284 & 72.15 & 84.65 & 79.65 & 93.2 \\
8344 & 72.30 & 84.70 & 79.75 & 93.2 \\
8404 & 72.45 & 84.85 & 79.95 & 93.3 \\
8464 & 72.60 & 85.00 & 80.10 & 93.3 \\
8524 & 72.75 & 85.10 & 80.20 & 93.3 \\
8584 & 72.95 & 85.15 & 80.35 & 93.1 \\
8644 & 73.10 & 85.25 & 80.45 & 93.2 \\
8704 & 73.30 & 85.35 & 80.60 & 93.3 \\
8764 & 73.35 & 85.45 & 80.75 & 93.3 \\
8824 & 73.55 & 85.50 & 80.85 & 93.2 \\
8884 & 73.70 & 85.65 & 80.95 & 93.3
\end{tabular}


Table A4. Resin Temperature Versus Time Data for Kinetic Auxiliary Tests

Run No. 1 Beaker Test

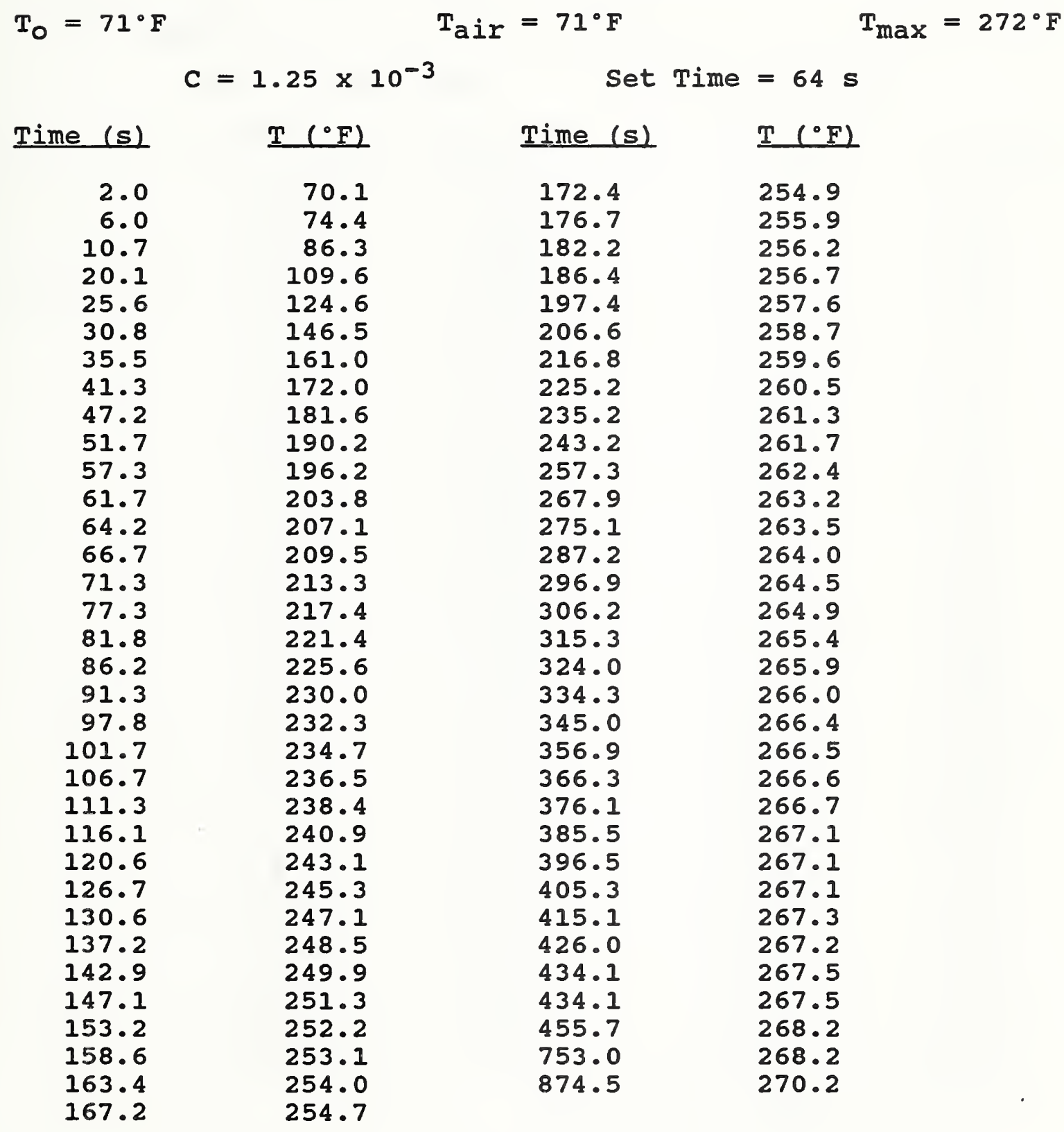


Table A4. Resin Temperature Versus Time Data for Kinetic Auxiliary Tests (Continued)

Run No. 2 Beaker Test

$T_{0}=70^{\circ} \mathrm{F}$

$$
\begin{array}{cc}
\mathrm{T}_{\text {air }}=71^{\circ} \mathrm{F} & \mathrm{T}_{\max }=261^{\circ} \mathrm{F} \\
\mathrm{C}=0.4 \times 10^{-3} & \text { Set } \mathrm{Time}=--\mathrm{s}
\end{array}
$$

Time (s)

$\underline{T(0 F)}$

70.2

0.4

11.2

16.0

20.8

25.6

29.6

33.9

38.0

43.0

47.8

53.9

62.0

67.0

70.9

76.0

82.1

86.3

90.2

95.9

101.7

106.4

112.4

116.9

122.8

126.7

131.2

136.8

142.0

146.7

151.8

157.4

162.0

167.5
78.5

85.2

91.1

99.0

110.7

118.2

127.0

138.1

149.4

157.8

169.1

176.3

183.9

192.2

199.5

203.0

207.5

212.4

216.2

218.9

222.4

225.7

228.4

230.9

233.9

235.4

236.9

238.4

240.4

241.0

242.2

243.4
Time (s)

171.7

175.8

180.3

184.8

189.9

195.4

201.8

206.3

211.2

217.0

223.9

226.6

232.1

237.0

240.9

245.7

257.6

266.7

275.8

285.8

295.6

305.6

315.9

325.5

332.0

390.4

442.3

460.9

521.3

580.9

642.4

772.0
$\underline{T}\left({ }^{\circ} \mathrm{F}\right)$

244.7

245.6

246.6

247.4

248.4

249.2

250.3

250.5

250.8

251.6

252.1

252.7

252.9

253.3

254.2

255.0

255.4

256.0

256.4

256.8

256.9

257.3

257.5

257.7

258.7

259.7

260.2

260.3

260.3

260.6

260.8

260.9 
Table A4. Resin Temperature versus Time Data for Kinetic Auxiliary Tests (Continued)

Run No. 3 Beaker Test

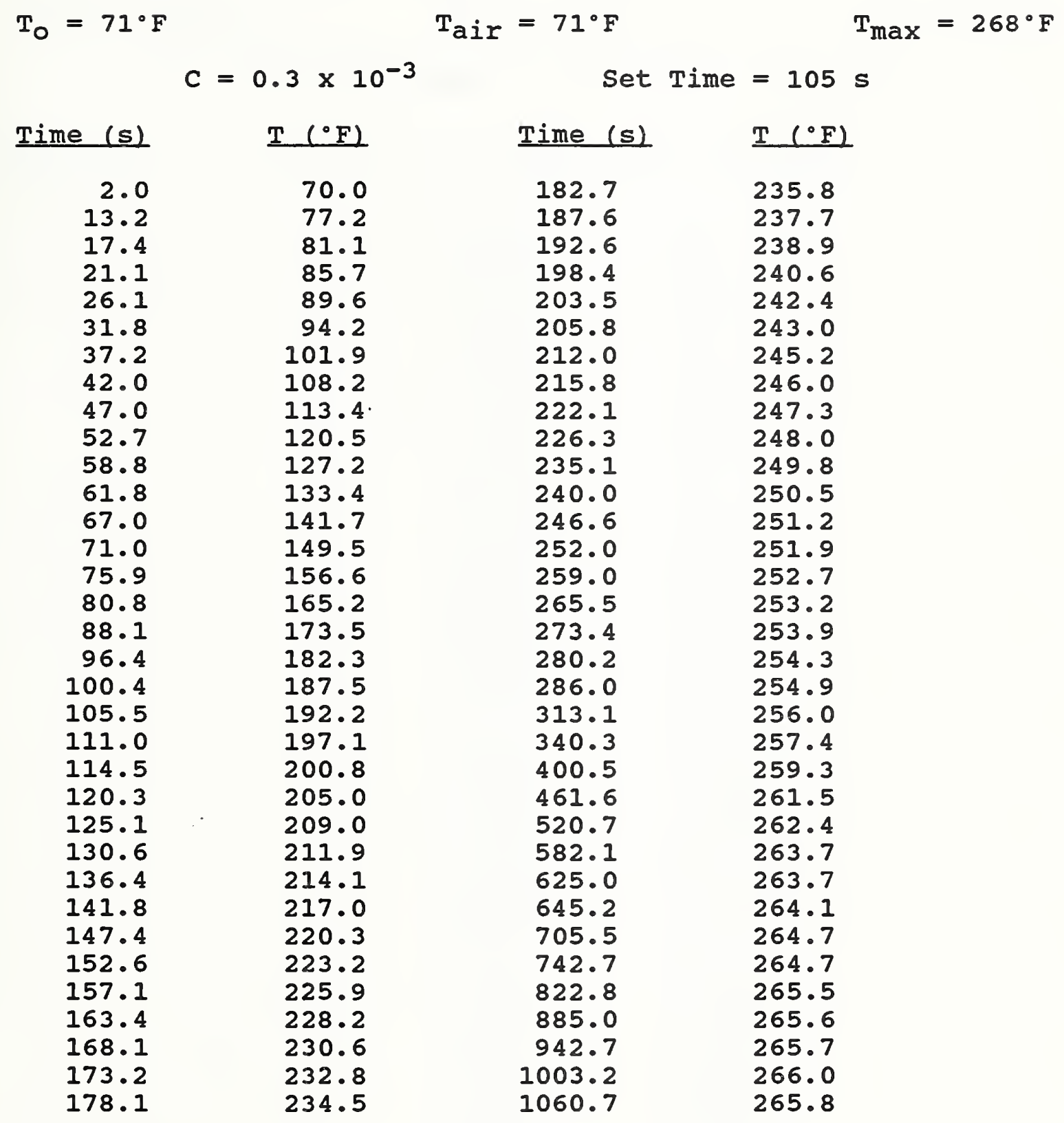


Table A4. Resin Temperature Versus Time Data for Kinetic Auxiliary Tests (Continued)

Run No. 4 Beaker Test

$$
\begin{gathered}
\mathrm{T}_{0}=71^{\circ} \mathrm{F} \quad \mathrm{T}_{\mathrm{air}}=71^{\circ} \mathrm{F} \quad \mathrm{T}_{\max }=269^{\circ} \mathrm{F} \\
\mathrm{C}=5.0 \times 10^{-3} \quad \text { Set } \mathrm{Time}=17 \mathrm{~s}
\end{gathered}
$$

Time (s)

1.4

6.8

11.0

16.1

21.9

31.9

37.8

42.2

48.3

54.3

57.9

63.4

68.1

72.5

76.9

82.5

87.3

92.7

98.4

102.5

107.5

111.3

121.0

132.5

140.9

153.7

162.4

172.1

182.3

193.2

203.5

267.3

285.4

323.7

386.3

445.0

505.4

565.3

625.4

686.0

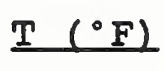

69.5

98.0

149.4

173.4

193.9

220.2

227.7

233.1

236.7

239.9

243.0

245.7

247.2

248.5

249.8

251.5

252.4

253.6

254.2

254.6

255.3

255.9

256.9

257.5

258.6

258.8

259.8

260.2

260.8

261.0

261.8

263.9

263.9

264.9

265.6

266.0

266.7

267.0

267.4

267.5 
Table A4. Resin Temperature Versus Time Data for Kinetic Auxiliary Tests (Continued)

Run No. 2A Beaker Test
$\mathrm{T}_{0}=90^{\circ} \mathrm{F}$
$\mathrm{T}_{\text {air }}=90^{\circ} \mathrm{F}$
$T_{\max }=282^{\circ} \mathrm{F}$
$c=0.0$
Set Time $=88 \mathrm{~s}$

Time (s)

0.9

6.9

10.7

14.6

19.1

24.6

29.6

35.3

39.8

44.6

51.4

54.1

58.7

62.9

67.5

72.5

76.9

82.8

86.2

91.0

94.4

99.5

103.7

108.5

112.3

117.2

112.1
$T\left(0^{\circ} \mathrm{F}\right)$

90.4

91.0

94.6

97.9

103.2

110.7

115.8

121.6

127.8

133.2

139.1

148.2

155.3

161.7

169.6

177.8

184.9

193.5

199.7

207.9

214.2

219.5

224.4

230.0

234.5

237.8

240.9
Time (s)

127.0

132.4

139.1

143.9

147.6

153.5

157.4

163.3

167.5

171.9

179.3

182.3

188.0

192.8

197.0

201.2

207.4

211.0

215.3

219.6

225.2

231.2

236.8

385.8

445.4

504.2
$\underline{T\left({ }^{\circ} \mathrm{F}\right)}$

244.0

247.4

251.2

253.2

255.6

258.0

259.2

261.1

263.1

264.4

266.1

266.7

268.1

269.3

270.3

271.3

272.5

272.6

273.7

274.6

275.1

276.0

276.5

281.0

281.4

281.5 
Table A4. Resin Temperature Versus Time Data for Kinetic Auxiliary Tests (Continued)

Run No. 3A Beaker Test

$\mathrm{T}_{\mathrm{O}}=90^{\circ} \mathrm{F}$

$$
\begin{array}{ccc}
\mathrm{T}_{\text {air }}=90^{\circ} \mathrm{F} & \mathrm{T}_{\max }=285^{\circ} \mathrm{F} \\
\mathrm{C}=0.7 \times 10^{-3} & \text { Set Time }=13 \mathrm{~s}
\end{array}
$$

$\underline{\mathrm{T}}\left({ }^{\circ} \mathrm{F}\right)$

1.9

3.9

6.0

10.6

13.7

18.2

23.1

29.2

33.9

37.4

43.6

49.6

53.0

58.1

63.6

68.1

79.4

82.3

87.0

93.2

96.8

101.8

106.8

110.8

116.1

121.1

125.5

130.8

135.6

143.2

148.6

158.2

166.8

178.1

187.5

195.8

255.7

319.8

381.1

438.7

504.4

564.1
Time (s)

90.5

121.4

172.7

194.9

209.7

220.7

230.8

238.0

245.0

250.3

254.4

257.7

259.6

262.3

263.6

266.5

269.7

270.3

271.4

272.6

273.1

274.0

274.7

275.3

275.9

275.8

276.6

277.0

277.5

277.8

278.2

278.8

279.2

279.5

280.0

280.1

281.7

282.1

282.8

283.0

283.4

283.8 
Table A4. Resin Temperature Versus Time Data for Kinetic Auxiliary Tests (Continued)

Run No. $4 \mathrm{~A} \quad$ Beaker Test
$\mathrm{T}_{\mathrm{O}}=90^{\circ} \mathrm{F}$
$\mathrm{T}_{\text {air }}=90^{\circ} \mathrm{F}$
$\mathrm{T}_{\max }=272^{\circ} \mathrm{F}$
$c=0.3 \times 10^{-3}$
Set Time $=57 \mathrm{~s}$

$\begin{array}{rr}\text { Time }(S) & T\left({ }^{\circ} F\right) \\ 1.2 & 90.4 \\ 9.9 & 100.5 \\ 13.8 & 109.4 \\ 18.1 & 116.8 \\ 23.8 & 128.6 \\ 28.4 & 137.5 \\ 33.2 & 149.1 \\ 38.0 & 158.5 \\ 40.9 & 170.0 \\ 48.2 & 179.3 \\ 52.5 & 188.0 \\ 57.4 & 195.6 \\ 62.1 & 201.7 \\ 65.5 & 207.9 \\ 70.6 & 213.6 \\ 74.6 & 218.0 \\ 80.2 & 221.8 \\ 82.8 & 226.2 \\ 88.8 & 229.7 \\ 92.9 & 234.4 \\ 99.0 & 237.8 \\ 102.4 & 240.2 \\ 108.2 & 243.1 \\ 112.5 & 244.6\end{array}$

\begin{tabular}{ll} 
Time (s) & $T\left({ }^{\circ} \mathrm{F}\right)$ \\
\hline 116.5 & 247.5 \\
120.8 & 249.3 \\
128.2 & 251.2 \\
131.1 & 253.3 \\
137.0 & 255.0 \\
142.0 & 256.1 \\
146.8 & 257.0 \\
152.7 & 257.9 \\
159.0 & 258.9 \\
164.7 & 259.8 \\
166.6 & 260.2 \\
171.5 & 261.1 \\
177.1 & 261.9 \\
182.4 & 262.6 \\
187.4 & 263.1 \\
193.1 & 263.6 \\
198.0 & 264.3 \\
201.2 & 264.8 \\
211.0 & 265.0 \\
220.6 & 265.0 \\
280.7 & 270.0 \\
339.7 & 271.4 \\
460.2 & 271.7 \\
519.6 & 271.7
\end{tabular}


Table A4. Resin Temperature Versus Time Data for Kinetic Auxiliary Tests (Continued)

Run No. IB Beaker Test

$$
\begin{gathered}
\mathrm{T}_{0}=40^{\circ} \mathrm{F} \\
\mathrm{C}=2.6 \times 10^{-3}
\end{gathered} \quad \begin{gathered}
\mathrm{T}_{\text {air }}=38^{\circ} \mathrm{F} \\
\text { Set } \mathrm{Time}=44 \mathrm{~s}
\end{gathered}
$$

Time (s)

0.7

6.7

11.0

16.8

22.4

26.5

31.2

37.1

41.9

47.7

54.1

59.9

65.1

69.5

75.2

80.2

83.9

89.3

94.7

99.6

104.6

108.7

114.1

119.0

123.6

129.2

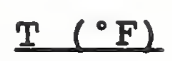

$$
40.4
$$

49.0

55.6

69.4

80.9

93.4

109.4

123.7

135.2

147.0

155.5

163.8

170.7

175.8

180.8

185.5

189.3

191.9

194.8

196.8

198.8

201. 0

203.0

205.0

206.7

208.3

\section{Time (s)}

137.0

142.0

149.9

153.6

159.7

164.6

170.8

176.1

179.5

185.6

188.7

193.7

198.4

205.5

215.6

221.5

232.7

252.3

260.0

318.9

376.7

437.0

497.4

554.1

617.1

737.3
$\underline{I}\left({ }^{\circ} \mathrm{F}\right)$

211.5

212.0

213.1

213.2

214.2

215.5

215.4

215.7

216.4

217.2

217.5

218.0

218.3

219.4

219.7

220.3

221.0

222.0

222.3

224.8

226.4

227.4

227.5

227.9

228.1

228.3 
Table A4. Resin Temperature Versus Time Data for Kinetic Auxiliary Tests (Continued)

Run No. 2B Beaker Test

$$
\mathrm{T}_{0}=40^{\circ} \mathrm{F}
$$

Time (s)

$-0.3$

9.5

19.1

28.6

40.5

50.1

61.6

71.0

80.2

90.4

99.7

118.9

129.6

138.8

150.8

161.3

170.7

181.6

190.4

200.1

210.6

220.5

230.3

238.5

250.0

261.0

272.4

282.0
T $(\cdot F)$

40.5

42.1

44.6

46.5

48.7

51.0

53.7

57.2

60.9

65.0

67.6

73.4

77.7

82.0

86.5

90.6

95.0

101.3

106.9

111.8

118.0

123.6

129.7

133.9

140.4

146.1

152.1

156.4
$\mathrm{T}_{\text {air }}=37^{\circ} \mathrm{F}$

$\mathrm{T}_{\max }=289^{\circ} \mathrm{F}$
Time (s)

292.1

302.0

312.5

323.4

331.3

339.8

349.9

360.3

371.2

382.0

391.2

401.5

411.6

422.6

432.4

442.1

448.4

512.3

570.8

632.5

692.2

751.3

812.1

869.5

930.2

990.0

1051.7
T $(\cdot F)$

162.4

167.3

171.9

176.0

180.2

183.3

187.3

190.3

193.4

195.0

197.3

199.2

201.4

203.4

204.9

207.2

207.6

214.4

217.6

220.1

222.0

223.6

224.3

224.6

225.3

225.7

225.8 
Table A4. Resin Temperature Versus Time Data for Kinetic Auxiliary Tests (Continued)

Run No. 3B Beaker Test

$$
\begin{gathered}
\mathrm{T}_{0}=40^{\circ} \mathrm{F} \quad \mathrm{T}_{\text {air }}=37^{\circ} \mathrm{F} \\
\mathrm{C}=7.8 \times 10^{-3} \quad \text { Set Time }=15 \mathrm{~s}
\end{gathered}
$$

\begin{tabular}{|c|c|}
\hline Time (s & $I\left({ }^{\circ} \mathrm{F}\right)$ \\
\hline-1.5 & 40.4 \\
\hline 3.9 & 47.2 \\
\hline 12.7 & 78.7 \\
\hline 18.0 & 125.0 \\
\hline 22.5 & 149.2 \\
\hline 28.6 & 167.8 \\
\hline 32.9 & 181.6 \\
\hline 39.4 & 194.9 \\
\hline 43.5 & 201.8 \\
\hline 49.3 & 207.2 \\
\hline 55.9 & 211.1 \\
\hline 61.1 & 214.0 \\
\hline 65.0 & 215.6 \\
\hline 71.7 & 218.7 \\
\hline 74.9 & 219.8 \\
\hline 80.3 & 221.2 \\
\hline 84.7 & 222.1 \\
\hline 89.9 & 224.1 \\
\hline 96.6 & 224.8 \\
\hline 99.3 & 225.8 \\
\hline 106.0 & 225.9 \\
\hline 109.0 & 227.1 \\
\hline 113.9 & 227.5 \\
\hline 120.2 & 228.1 \\
\hline 128.3 & 229.3 \\
\hline 138.7 & 229.7 \\
\hline 147.8 & 230.0 \\
\hline 161.0 & 231.2 \\
\hline 170.4 & 231.5 \\
\hline 181.4 & 232.0 \\
\hline 189.8 & 232.0 \\
\hline 200.0 & 232.2 \\
\hline 211.8 & 232.8 \\
\hline 217.8 & 232.5 \\
\hline 229.9 & 233.3 \\
\hline 239.8 & 233.1 \\
\hline 242.9 & 234.3 \\
\hline 304.3 & 234.6 \\
\hline 424.0 & 235.1 \\
\hline 483.3 & 235.1 \\
\hline 602.5 & 235.3 \\
\hline
\end{tabular}


Table A4. Resin Temperature Versus Time Data for Kinetic Auxiliary Tests (Continued)

Run No. 4B Beaker Test

$$
\begin{aligned}
& T_{0}=40^{\circ} \mathrm{F} \\
& \mathrm{T}_{\text {air }}=38^{\circ} \mathrm{F} \\
& \mathrm{T}_{\max }=235^{\circ} \mathrm{F} \\
& c=1.3 \times 10^{-3} \quad \text { Set } \text { Time }=60 \mathrm{~s}
\end{aligned}
$$

Time (s)

$-0.4$

5.3

12.3

15.5

20.9

26.5

29.8

36.3

41.0

47.9

52.2

58.0

64.4

69.1

75.1

78.8

84.2

90.2

94.3

98.5

105.6

110.1

114.2

118.6

124.4

129.2

132.3

138.4

143.1

148.2
$\underline{T}\left({ }^{\circ} \mathrm{F}\right)$

40.2

41.7

48.5

53.7

62.7

69.7

79.4

88.0

98.5

111.2

122.4

132.4

141.4

149.8

156.4

162.2

169.2

173.3

176.3

181.5

185.8

189.0

191.7

193.2

195.9

197.8

199.0

201.3

203.1

204.8
Time (s)

153.7

159.8

166.3

169.5

174.7

181.1

184.7

190.1

195.6

200.4

206.5

210.9

214.5

225.0

232.5

242.3

254.9

259.3

267.0

276.8

283.2

293.5

354.1

412.9

472.0

532.0

593.1

713.0

771.2

831.4
$\underline{T}(\cdot F)$

206.2

207.4

209.1

209.9

211.2

212.2

212.9

213.6

214.4

215.3

215.7

216.7

217.2

217.8

218.7

220.1

221.0

221.5

222.3

223.6

224.3

225.0

227.8

229.5

230.9

231.4

232.0

232.5

232.5

233.0 
Table A4. Resin Temperature Versus Time Data for Kinetic Auxiliary Tests (Continued)

Run No. IC Beaker Test

$$
\mathrm{T}_{0}=71^{\circ} \mathrm{F}
$$

$$
\begin{gathered}
\mathrm{T}_{\mathrm{air}}=71^{\circ} \mathrm{F} \quad \mathrm{T}_{\max }=255^{\circ} \mathrm{F} \\
\mathrm{C}=0.4 \times 10^{-3} \quad \text { Set Time }=78 \mathrm{~s}
\end{gathered}
$$

\begin{tabular}{|c|c|c|}
\hline Time (s) & $\underline{T(F)}$ & Time (s \\
\hline 0 & 72.7 & 71 \\
\hline 2 & 72.6 & 72 \\
\hline 4 & 72.5 & 74 \\
\hline 5 & 72.6 & 75 \\
\hline 7 & 74.3 & 77 \\
\hline 8 & 76.3 & 79 \\
\hline 10 & 78.3 & 80 \\
\hline 12 & 80.0 & 82 \\
\hline 13 & 82.2 & 84 \\
\hline 15 & 84.2 & 85 \\
\hline 16 & 86.4 & 87 \\
\hline 18 & 88.3 & 88 \\
\hline 20 & 90.4 & 90 \\
\hline 21 & 92.7 & 91 \\
\hline 23 & 94.9 & 93 \\
\hline 24 & 96.9 & 95 \\
\hline 26 & 99.2 & 96 \\
\hline 28 & 101.5 & 98 \\
\hline 29 & 104.0 & 99 \\
\hline 31 & 106.9 & 101 \\
\hline 32 & 108.9 & 103 \\
\hline 34 & 111.4 & 104 \\
\hline 36 & 113.9 & 106 \\
\hline 37 & 116.3 & 107 \\
\hline 39 & 119.0 & 109 \\
\hline 40 & 121.7 & 11.1 \\
\hline 42 & 124.5 & 112 \\
\hline 44 & 127.2 & 114 \\
\hline 45 & 130.0 & 115 \\
\hline 47 & 132.8 & 117 \\
\hline 48 & 135.7 & 119 \\
\hline 50 & 138.6 & 120 \\
\hline 52 & 141.4 & 122 \\
\hline 53 & 144.2 & 123 \\
\hline 55 & 147.0 & 125 \\
\hline 56 & 149.7 & 127 \\
\hline 58 & 152.4 & 128 \\
\hline 59 & 155.0 & 130 \\
\hline 61 & 157.7 & 131 \\
\hline 63 & 160.2 & 133 \\
\hline 64 & 162.7 & 135 \\
\hline 66 & 165.1 & 136 \\
\hline 68 & 167.4 & 138 \\
\hline & & \\
\hline
\end{tabular}

T (F)

172.0

173.9

175.9

177.8

179.7

181.5

183.3

185.0

186.6

188.3

189.8

191.4

192.9

194.4

195.8

197.2

198.5

199.9

201.2

202.4

203.7

204.8

206.0

207.1

208.2

209.4

210.4

211.4

212.4

213.4

214.4

215.4

216.3

217.2

218.0

218.9

219.8

220.6

221.4

222.2

222.9

223.7

224.5

225.2
Time (s) $\quad T$ (F)

141

143

144

146

147

149

151

152

154

155

157

159

160

162

163

165

167

168

170

171

173

174

176

178

179

181

183

184

186

187

189

190

192

194

195

197

198

200

202

203

205

206

208

210
225.9

226.5

227.2

227.8

228.4

229.0

229.6

230.2

230.8

231.3

231.9

232.4

232.9

233.4

233.9

234.4

234.9

235.3

235.8

236.2

236.7

237.1

237.5

237.9

238.3

238.6

239.0

239.4

239.8

240.1

240.4

240.8

241.1

241.5

241.8

242.0

242.4

242.7

242.9

243.2

243.5

243.7

244.0

244.2 
Table A4. Resin Temperature Versus Time Data for Kinetic Auxiliary Tests (Continued)

$$
T_{0}=71^{\circ} \mathrm{F}
$$

$$
\begin{aligned}
& \mathrm{T}_{\text {air }}=71^{\circ} \mathrm{F} \quad \mathrm{T}_{\max }=255^{\circ} \mathrm{F} \\
& c=0.4 \times 10^{-3} \\
& \text { Set } \text { Time }=78 \mathrm{~s}
\end{aligned}
$$

$\begin{array}{cccccc}\text { Time }(S) & T(F) & \text { Time }(S) & \text { T }(F) & \text { Time (S) } & \underline{T}(F) \\ 211 & 244.5 & 224 & 246.2 & 237 & 247.7 \\ 213 & 244.7 & 226 & 246.4 & 238 & 247.9 \\ 214 & 245.0 & 227 & 246.6 & 240 & 248.1 \\ 216 & 245.2 & 229 & 246.8 & 242 & 248.2 \\ 218 & 245.4 & 230 & 247.0 & 243 & 252.5 \\ 219 & 245.6 & 232 & 247.2 & 303 & 254.3 \\ 221 & 245.8 & 234 & 247.4 & 363 & 255.0 \\ 222 & 246.0 & 235 & 247.5 & & \end{array}$


Table A4. Resin Temperature Versus Time Data for Kinetic Auxiliary Tests (Continued)

Run No. $2 \mathrm{C}$ Beaker Test

$$
T_{0}=71^{\circ} \mathrm{F}
$$

\begin{tabular}{|c|c|}
\hline Time (s) & $T(F)$ \\
\hline 0 & 76.4 \\
\hline 5 & 77.5 \\
\hline 7 & 80.5 \\
\hline 8 & 83.0 \\
\hline 10 & 86.1 \\
\hline 11 & 89.1 \\
\hline 13 & 92.2 \\
\hline 15 & 94.7 \\
\hline 16 & 98.5 \\
\hline 18 & 102.0 \\
\hline 20 & 105.0 \\
\hline 21 & 108.4 \\
\hline 23 & 112.1 \\
\hline 24 & 116.2 \\
\hline 26 & 120.5 \\
\hline 27 & 124.5 \\
\hline 29 & 128.4 \\
\hline 31 & 132.5 \\
\hline 32 & 136.8 \\
\hline 34 & 141.1 \\
\hline 35 & 145.4 \\
\hline 37 & 149.6 \\
\hline 39 & 153.5 \\
\hline 40 & 157.2 \\
\hline 42 & 160.8 \\
\hline 43 & 163.9 \\
\hline 45 & 167.0 \\
\hline 47 & 169.9 \\
\hline 48 & 172.5 \\
\hline 50 & 175.0 \\
\hline 51 & 177.3 \\
\hline 53 & 179.6 \\
\hline 55 & 181.8 \\
\hline 56 & 183.9 \\
\hline 58 & 186.0 \\
\hline 59 & 187.9 \\
\hline 61 & 189.8 \\
\hline 63 & 191.6 \\
\hline 64 & 193.4 \\
\hline 66 & 195.1 \\
\hline 67 & 196.8 \\
\hline 69 & 198.4 \\
\hline 71 & 199.9 \\
\hline 72 & 201.5 \\
\hline
\end{tabular}

$$
\begin{aligned}
& \mathrm{T}_{\mathrm{air}}=71^{\circ} \mathrm{F} \\
& T_{\max }=264^{\circ} \mathrm{F} \\
& c=0.7 \times 10^{-3} \\
& \text { set } \text { Time }=55 \mathrm{~s}
\end{aligned}
$$

\begin{tabular}{|c|c|}
\hline Time (s) & $\underline{T}(\mathrm{~F})$ \\
\hline 74 & 203.0 \\
\hline 75 & 204.4 \\
\hline 77 & 205.8 \\
\hline 78 & 207.1 \\
\hline 80 & 208.4 \\
\hline 82 & 209.8 \\
\hline 83 & 211.1 \\
\hline 85 & 212.3 \\
\hline 86 & 213.5 \\
\hline 88 & 214.6 \\
\hline 90 & 215.8 \\
\hline 91 & 216.9 \\
\hline 93 & 218.0 \\
\hline 94 & 219.0 \\
\hline 96 & 220.1 \\
\hline 98 & 221.1 \\
\hline 99 & 222.1 \\
\hline 101 & 223.0 \\
\hline 102 & 224.0 \\
\hline 104 & $224 \cdot 9$ \\
\hline 106 & 225.7 \\
\hline 107 & 226.5 \\
\hline 109 & $227 \cdot 4$ \\
\hline 110 & 228.1 \\
\hline 112 & 228.9 \\
\hline 114 & 229.6 \\
\hline 115 & 230.4 \\
\hline 117 & 231.1 \\
\hline 118 & 231.8 \\
\hline 120 & 232.5 \\
\hline 122 & 233.1 \\
\hline 123 & 233.8 \\
\hline 125 & 234.4 \\
\hline 126 & 235.1 \\
\hline 128 & 235.6 \\
\hline 130 & 236.2 \\
\hline 131 & 236.8 \\
\hline 133 & 237.4 \\
\hline 134 & 237.9 \\
\hline 136 & 238.4 \\
\hline 138 & 238.9 \\
\hline 139 & 239.4 \\
\hline 141 & 239.9 \\
\hline 142 & 240.3 \\
\hline
\end{tabular}

Time (S) $\quad \underline{T(F)}$

144

145

147

149

150

152

154

155

157

158

160

161

163

165

166

168

169

171

173

174

176

177

179

181

182

184

185

187

189

190

192

193

195

197

198

200

201

203

205

206

208

209

211

213
240.8

241.3

241.7

2.42 .2

242.6

243.0

243.3

243.7

244.1

244.5

244.8

245. 1

245.5

245.8

246.1

246.4

246.7

247.0

247.3

247.6

247.9

248.1

248.4

248.6

248.9

249.1

249 : 4

249.6

249.8

250.0

250.2

250.5

250.7

250.9

251.1

251.2

251.4

251.6

251.8

252.1

252.2

252.4

252.5

252.7 
Table A4. Resin Temperature Versus Time Data for Kinetic Auxiliary Tests (Continued)

Run No. 2C Beaker Test

$$
\mathrm{T}_{\mathrm{o}}=71^{\circ} \mathrm{F} \quad \mathrm{T}_{\text {air }}=71^{\circ} \mathrm{F} \quad \mathrm{T}_{\max }=264^{\circ} \mathrm{F}
$$

$$
c=0.7 \times 10^{-3} \quad \text { set Time }=55 \mathrm{~s}
$$

Time (s) $\quad \underline{T}(\mathrm{~F})$

$\begin{array}{ll}214 & 252.9 \\ 216 & 253.0 \\ 217 & 253.2 \\ 219 & 253.3 \\ 221 & 253.5 \\ 222 & 253.7 \\ 224 & 253.8 \\ 225 & 253.9 \\ 227 & 254.0\end{array}$

Time (s)

228

230

232

233

235

237

238

240

241
$\mathrm{T}(\mathrm{F})$

254.2

254.3

254.5

254.6

254.7

254.8

255.0

255.1

255.2
Time (s) $\quad \underline{T}(\mathrm{~F})$

$243 \quad 258.6$

$303 \quad 260.6$

$363 \quad 261.9$

$423 \quad 262.8$

$483 \quad 263.4$

$543 \quad 263.9$

$603 \quad 264.1$

$663 \quad 264.3$ 
Table A4. Resin Temperature Versus Time Data for Kinetic Auxiliary Tests (Continued)

$$
\begin{aligned}
& \text { Run No. 3C Beaker Test } \\
& \mathrm{T}_{\mathrm{o}}=72^{\circ} \mathrm{F} \quad \mathrm{T}_{\text {air }}=73^{\circ} \mathrm{F} \quad \mathrm{T}_{\max }=268^{\circ} \mathrm{F} \\
& c=1.3 \times 10^{-3} \quad \text { Set } \text { Time }=32 \mathrm{~s}
\end{aligned}
$$

Time (s)

$\underline{T\left({ }^{\circ} F\right) \quad \text { Time }(s)}$

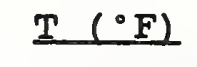

\section{Time (s)}

$\underline{T}\left({ }^{\circ} \mathrm{F}\right)$

0
1
3
4
6
8
9

11

12

14

16

17

19

20

22

24

25

27

28

30

32

33

35

36

38

39

41

43

44

46

47

49

51

52

54

55

57

59

60

62

63

65

67

68
74.6

74.4

75.3

79.0

83.4

87.6

92.7

97.6

103.3

108.5

114.7

121.7

128.2

135.1

142.0

148.7

254.9

160.0

164.4

168.6

172.3

175.7

178.9

181.9

184.7

187.5

190.0

192.5

194.8

197.0

199.1

201. 1

203.1

205.0

206.8

208.6

210.3

211.9

213.5

215.0

216.5

218.0

219.3

220.6
70

71

73

75

76

78

79

81

83

84

86

87

89

91

92

94

95

97

99

100

102

103

105

107

108

110

112

113

115

116

118

120

121

123

124

126

128

129

131

132

134

136

137

139
222.0

223.2

224.5

225.6

226.6

227.7

228.7

229.7

230.7

231.6

232.5

233.4

234.2

235.1

235.9

236.7

237.4

238.1

238.8

239.6

240.2

240.8

241.5

242.1

242.7

243.3

243.8

244.3

244.9

245.4

245.9

246.3

246.8

247.2

247.7

248 . 1

248.5

248.8

249.3

249.6

250.0

250.4

250.7

251.0
141

142

144

145

247

149

150

152

154

155

157

158

160

162

163

165

166

168

169

170

172

173

175

177

178

180

182

183

185

186

188

189

191

193

194

196

198

199

201

202

204

206

207

209
251.3

251.7

251.9

252.3

252.6

252.9

253.2

253.4

253.7

253.9

254.1

254.4

254.6

254.9

255.1

255.3

255.5

255.7

255.9

256.1

256.3

256.4

256.7

256.8

257.0

257.2

257.3

257.5

257.7

257.8

257.9

258.1

258.3

258.4

258.6

258.6

258.8

258.9

259.0

259.2

259.3

259.4

259.6

259.7 
Table A4. Resin Temperature Versus Time Data for Kinetic Auxiliary Tests (Continued)

$$
\begin{aligned}
& \text { Run No. 3C Beaker Test } \\
& \mathrm{T}_{\mathrm{o}}=72^{\circ} \mathrm{F} \quad \mathrm{T}_{\mathrm{air}}=73^{\circ} \mathrm{F} \quad \mathrm{T}_{\max }=268^{\circ} \mathrm{F} \\
& c=1.3 \times 10^{-3} \quad \text { Set } \text { Time }=32 \mathrm{~s}
\end{aligned}
$$

\begin{tabular}{|c|c|c|c|c|c|}
\hline Time (s) & $I\left({ }^{\circ} F\right)$ & Time (s) & $I\left({ }^{\circ} \mathrm{F}\right)$ & Time (s) & $\underline{T}\left({ }^{\circ} \mathrm{F}\right)$ \\
\hline 210 & 259.8 & 228 & 260.9 & 363 & 266.2 \\
\hline 212 & 259.9 & 230 & 261.0 & 423 & 266.8 \\
\hline 214 & 260.0 & 231 & 261.1 & 483 & 267.2 \\
\hline 215 & 260.1 & 233 & 261.2 & 543 & 267.5 \\
\hline 217 & 260.2 & 234 & 261.2 & 603 & 267.6 \\
\hline 218 & 260.3 & 236 & 261.3 & 663 & 267.6 \\
\hline 220 & 260.4 & 238 & 261.4 & 723 & 267.6 \\
\hline 222 & 260.5 & 239 & 261.5 & 783 & 267.5 \\
\hline 223 & 260.6 & 241 & 261.6 & 843 & 267.3 \\
\hline 225 & 260.7 & 243 & 263.9 & 903 & 266.9 \\
\hline 227 & 260.8 & 303 & 265.3 & 963 & 266.7 \\
\hline
\end{tabular}


Table A4. Resin Temperature Versus Time Data for Kinetic Auxiliary Tests (Continued)

$$
\begin{aligned}
& \text { Run No. ID Beaker Test } \\
& \mathrm{T}_{0}=41^{\circ} \mathrm{F} \quad \mathrm{T}_{\mathrm{air}}=40^{\circ} \mathrm{F} \quad \mathrm{T}_{\max }=234^{\circ} \mathrm{F} \\
& c=0.3 \times 10^{-3} \quad \text { Set Time }=205 \mathrm{~s}
\end{aligned}
$$

Time (s)

I $\left({ }^{\circ} \mathrm{F}\right)$ Time (s)

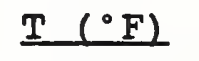

73.5

41.5

41.8

42.5

43.0

43.7

44.3

44.9

45.6

46.1

46.9

47.6

48.3

49.1

49.8

50.4

51.1

51.9 .

52.6

53.2

53.9

54.6

55.3

56.0

56.8

57.5

58.3

59.0

59.7

60.5

61.3

62.0

62.8

63.5

64.3

65.1

65.9

66.7

67.5

68.3

69.2

70.0

70.9

71.7

72.6
75

77

79

80

82

83

85

87

88

90

92

93

95

96

98

100

101

103

104

106

108

109

111

112

114

116

117

119

121

122

124

125

127

129

130

132

133

135

137

138

140

141

143

145

\section{4}

75.2

76.1

77.0

77.8

78.7

79.7

80.6

81.6

82.5

83.5

84.4

85.5

86.5

87.5

88.5

89.6

90.6

91.7

92.8

93.9

95.0

96.1

97.3

98.5

99.7

100.9

102.1

103.3

104.5

105.8

107.1

108.4

109.7

111.1

112.4

113.7

115.1

116.5

117.8

119.2

120.5

121.8
Time (s)

146

148

150

151

153

154

156

158

159

161

162

164

166

167

169

170

172

174

175

177

179

180

182

183

185

187

188

190

191

193

195

196

198

199

201

203

204

206

208

209

211

212

214

216
$\underline{P(\circ F)}$

123.1

124.4

125.7

127.0

128.2

129.6

130.9

132.1

133.4

134.7

136.0

137.2

138.5

139.7

140.9

142.1

143.3

144.4

145.6

146.6

147.8

148.9

150.0

151.1

152.2

153.3

154.3

155.4

15.6 .5

157.5

158.6

159.6

160.6

161.6

162.5

163.5

164.5

165.4

166.3

167.2

168.1

169.1

169.9

170.7 
Table A4. Resin Temperature Versus Time Data for Kinetic Auxiliary Tests (Continued)

$$
\begin{gathered}
\text { Run No. ID } \quad \text { Beaker Test } \\
\mathrm{T}_{0}=41^{\circ} \mathrm{F} \quad \mathrm{T}_{\mathrm{air}}=40^{\circ} \mathrm{F} \quad \mathrm{T}_{\max }=234^{\circ} \mathrm{F} \\
\mathrm{C}=0.3 \times 10^{-3} \quad \text { Set } \text { Time }=205 \mathrm{~s}
\end{gathered}
$$

\begin{tabular}{|c|c|c|c|c|c|}
\hline Time (s) & $\underline{\mathrm{T}\left({ }^{\circ} \mathrm{F}\right)}$ & Time (s) & $\underline{T}\left({ }^{\circ} F\right)$ & Time (s) & $T\left({ }^{\circ} \mathrm{F}\right)$ \\
\hline 217 & 171.5 & 241 & 182.3 & 266 & 191.1 \\
\hline 219 & 172.4 & 243 & 183.0 & 326 & 207.0 \\
\hline 221 & 173.1 & 245 & 183.6 & 386 & 216.7 \\
\hline 222 & 173.9 & 246 & 184.2 & 446 & 222.7 \\
\hline 224 & 174.6 & 248 & 184.9 & 506 & 226.4 \\
\hline 225 & 175.4 & 250 & 185.4 & 566 & 228.8 \\
\hline 227 & 176.1 & 251 & 186.0 & 626 & 230.5 \\
\hline 229 & 176.8 & 253 & 186.7 & 686 & 231.6 \\
\hline 230 & 177.5 & 254 & 187.2 & 746 & 232.4 \\
\hline 232 & 178.3 & 256 & 187.8 & 806 & 233.1 \\
\hline 233 & 179.0 & 258 & 188.4 & 866 & 233.4 \\
\hline 235 & 179.7 & 259 & 189.0 & 826 & 233.7 \\
\hline 237 & 180.3 & 261 & 189.5 & 866 & 233.9 \\
\hline 240 & 181.7 & 264 & 190.6 & & \\
\hline
\end{tabular}


Table A4. Resin Temperature Versus Time Data for Kinetic Auxiliary Tests (Continued)

Run No. 2D Beaker Test

$$
\begin{gathered}
\mathrm{T}_{0}=41^{\circ} \mathrm{F} \quad \mathrm{T}_{\mathrm{air}}=40^{\circ} \mathrm{F} \quad \mathrm{T}_{\max }=235^{\circ} \mathrm{F} \\
\mathrm{C}=0.4 \times 10^{-3} \quad \text { set } \mathrm{Time}=172 \mathrm{~s}
\end{gathered}
$$

Time (s)

$$
0
$$$$
4
$$$$
5
$$

70

$\underline{\mathrm{T}\left({ }^{\circ} \mathrm{F}\right) \quad \underline{\mathrm{Time}}(\mathrm{s})}$

42.5

42.5

41.5

41.9

42.5

43.2

44.1

44.9

45.7

46.5

47.7

48.6

49.2

49.9

50.8

51.6

52.6

53.5

54.3

55.2

56.0

56.8

57.8

58.6

59.5

60.3

61.2

62.1

63.1

64.0

64.9

65.8

66.8

67.7

68.7

69.7

70.7

71.7

72.7

73.8

74.7

75.7

76.8

77.9
71

73

75

76

78

79

81

83

84

86

87

89

91

92

94

96

97

99

100

102

104

105

107

108

110

112

113

115

116

118

120

121

123

125

126

128

129

131

133

134

136

137

139

141

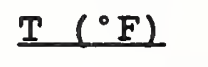

79.1

80.1

81.2

82.3

83.4

84.6

85.8

87.0

88.2

89.4

90.6

92.0

93.3

94.6

95.9

97.1

98.4

99.7

101.1

102.5

103.9

105.4

106.9

108.4

109.9

111.5

113.0

114.6

116.1

117.7

119.3

120.9

122.4

123.9

125.4

126.9

128.4

129.9

131.4

132.8

134.3

135.7

137.1

138.5
Time (s)

142

144

145

147

149

150

152

153

155

157

158

160

161

163

165

166

168

170

171

173

174

176

178

179

181

182

184

186

187

189

190

192

194

195

197

199

200

202

203

205

207

208

210

211
$\underline{\mathrm{T}}\left({ }^{\circ} \mathrm{F}\right)$

139.8

141.2

142.5

143.8

145.2

146.5

147.7

148.9

150.1

151.4

152.5

153.8

154.9

156.1

157.3

158.3

159.5

160.5

161.7

162.7

163.7

164.8

165.8

166.7

167.8

168.7

169.7

170.6

171.4

172.3

173.1

173.9

174.8

175.5

176.3

177.1

177.8

178.6

179.3

180.0

180.7

181.4

182.1

182.8 
Table A4. Resin Temperature Versus Time Data for Kinetic Auxiliary Tests (Continued)

Run No. 2D Beaker Test

$$
\begin{gathered}
\mathrm{T}_{0}=41^{\circ} \mathrm{F} \quad \mathrm{T}_{\text {air }}=40^{\circ} \mathrm{F} \quad \mathrm{T}_{\max }=235^{\circ} \mathrm{F} \\
\mathrm{C}=0.4 \times 10^{-3} \quad \text { Set } \mathrm{Time}=172 \mathrm{~s}
\end{gathered}
$$

$\begin{array}{llllll}\text { Time(s) } & \text { T }\left({ }^{\circ} F\right) & \text { Time(s) } & \underline{T}\left(^{\circ} F\right) & \text { Time(s) } & \underline{T}\left(^{\circ} F\right) \\ 213 & 183.4 & 231 & 190.3 & 366 & 219.4 \\ 215 & 184.1 & 232 & 190.8 & 426 & 224.9 \\ 216 & 184.8 & 234 & 191.4 & 486 & 228.2 \\ 218 & 185.4 & 236 & 191.9 & 546 & 230.4 \\ 219 & 186.0 & 237 & 192.5 & 606 & 231.9 \\ 221 & 186.7 & 239 & 193.0 & 666 & 232.9 \\ 223 & 187.3 & 240 & 193.5 & 726 & 233.6 \\ 224 & 187.9 & 242 & 194.1 & 786 & 234.1 \\ 226 & 188.5 & 244 & 194.6 & 846 & 234.4 \\ 228 & 189.1 & 245 & 195.1 & 906 & 234.6 \\ 229 & 189.7 & 306 & 210.3 & & \end{array}$


Table A4. Resin Tempeature Versus Time Data for Kinetic Auxiliary Tests (Continued)

$$
\begin{aligned}
& \text { Run No. 3D Beaker Test } \\
& \mathrm{T}_{\mathrm{o}}=41^{\circ} \mathrm{F} \quad \mathrm{T}_{\mathrm{air}}=40^{\circ} \mathrm{F} \quad \mathrm{T}_{\max }=214^{\circ} \mathrm{F} \\
& c=0.7 \times 10^{-3} \quad \text { set } \text { Time }=108 \mathrm{~s}
\end{aligned}
$$

Time (s)

T $\left({ }^{\circ} \mathrm{F}\right) \quad$ Time(s)

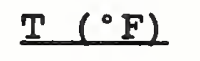

114.1

43.4

44.2

46.2

47.3

48.5

49.7

50.9

52.2

53.5

54.8

56.1

57.5

58.8

60.1

61.4

68.9

64.3

65.7

67.0

68.4

69.9

71.3

72.9

74.4

75.9

77.4

78.9

80.5

82.1

83.7

85.3

87.1

88.9

90.9

92.8

94.7

96.7

98.8

100.9

102.9

105.1

107.3

109.6

111.8
77

79

80

82

84

85

87

88

90

92

93

95

96

98

100

101

103

105

106

108

109

111

113

114

116

117

119

121

122

124

126

127

129

130

132

134

135

137

138

140

142

143

145

147
116.5

118.9

121.2

123.5

125.8

128.0

130.3

132.4

134.6

136.7

138.7

140.4

142.0

143.6

145.1

146.7

148.2

149.7

151.2

152.7

154.1

155.4

156.7

158.0

159.3

160.5

161.8

162.9

164.1

165.2

166.3

167.4

168.4

169.4

170.4

171.2

172.1

173.0

173.9

174.7

175.5

176.3

177.1
Time (s)

148

150

151

153

155

156

158

159

161

163

164

166

167

169

171

172

174

176

177

179

180

182

184

185

187

189

190

192

193

195

197

198

200

201

203

205

206

208

209

211

213

214

216

218
177.8

178.6

179.3

180.0

180.7

181.4

182.1

182.7

183.3

183.9

184.4

185.0

185.6

186.2

186.6

187.2

187.7

188.2

188.7

189.2

189.7

190.3

190.8

191.2

191.7

192.1

192.6

193.0

193.5

194.0

194.3

194.9

195.2

195.6

196.1

196.4

196.8

197.2

197.6

197.9

198.3

198.6

199.0

199.2 
Table A4. Resin Temperature Versus Time Data for Kinetic Auxiliary Tests (Continued)

Run No. 3D Beaker Test

$$
\begin{array}{r}
\mathrm{T}_{0}=41^{\circ} \mathrm{F} \quad \mathrm{T}_{\text {air }}=40^{\circ} \mathrm{F} \quad \mathrm{T}_{\max }=214^{\circ} \mathrm{F} \\
\mathrm{C}=0.7 \times 10^{-3} \quad \text { Set } \mathrm{Time}=108 \mathrm{~s}
\end{array}
$$

$\operatorname{Time}(\mathbf{s})$

\begin{tabular}{cc}
$T\left({ }^{\circ} \mathrm{F}\right)$ & Time $(\mathrm{S})$ \\
\hline & \\
199.6 & 231 \\
199.9 & 232 \\
200.2 & 234 \\
200.6 & 235 \\
200.9 & 237 \\
201.2 & 239 \\
201.5 & 240
\end{tabular}

$\mathrm{T}\left({ }^{\circ} \mathrm{F}\right)$

Time(s) $\quad \underline{T}\left({ }^{\circ} F\right)$

219

221.

222

224

226

227

229

201.5

201.8

202.0

202.3

202.5

202.9

203.1

203.4
242

243

245

305

365

425
203.7

203.9

204.2

210.4

213.0

213.7 
Table A4. Resin Temperature Versus Time Data for Kinetic Auxiliary Tests (Continued)

$$
\begin{aligned}
& \text { Run No. 4D Beaker Test } \\
& \mathrm{T}_{\mathrm{o}}=41^{\circ} \mathrm{F} \quad \mathrm{T}_{\mathrm{air}}=40^{\circ} \mathrm{F} \quad \mathrm{T}_{\max }=236^{\circ} \mathrm{F} \\
& c=0.3 \times 10^{-3} \quad \text { set } \text { Time }=194 \mathrm{~s}
\end{aligned}
$$

\begin{tabular}{|c|c|c|c|c|c|}
\hline Time (s) & $T\left({ }^{\circ} F\right)$ & Time (s) & $I\left({ }^{\circ} \mathrm{F}\right)$ & Time (s) & $I\left({ }^{\circ} \mathrm{F}\right)$ \\
\hline 3 & 43.2 & 79 & 82.9 & 150 & 140.4 \\
\hline 5 & 43.4 & 81 & 83.9 & 152 & 141.8 \\
\hline 7 & 44.0 & 82 & 85.0 & 153 & 143.1 \\
\hline 13 & 46.8 & 84 & 86.1 & 155 & 144.4 \\
\hline 15 & 47.6 & 86 & 87.2 & 157 & 145.6 \\
\hline 16 & 48.4 & 87 & 88.3 & 158 & 147.0 \\
\hline 18 & 49.1 & 89 & 89.5 & 160 & 142.2 \\
\hline 19 & 49.8 & 90 & 90.6 & 162 & 149.4 \\
\hline 21 & 50.5 & 92 & 91.7 & 163 & 150.8 \\
\hline 23 & 51.3 & 94 & 92.9 & 165 & 151.9 \\
\hline 24 & 52.1 & 95 & 94.2 & 166 & 153.1 \\
\hline 26 & 52.9 & 97 & 95.4 & 168 & 154.3 \\
\hline 27 & 53.7 & 98 & 96.6 & 170 & 155.5 \\
\hline 29 & 54.6 & 100 & 97.8 & 171 & 156.7 \\
\hline 31 & 55.3 & 102 & 99.1 & 173 & 157.9 \\
\hline 32 & 56.2 & 103 & 100.4 & 174 & 159.0 \\
\hline 34 & 57.0 & 105 & 101.7 & 176 & 160.1 \\
\hline 36 & 57.8 & 107 & 103.0 & 178 & 161.2 \\
\hline 37 & 58.7 & 108 & 104.3 & 179 & 162.3 \\
\hline 39 & 59.5 & 110 & 105.7 & 181 & 163.4 \\
\hline 40 & 60.3 & 111 & 107.1 & 183 & 164.4 \\
\hline 42 & 61.2 & 113 & 108.4 & 184 & 165.5 \\
\hline 44 & 62.0 & 115 & 109.9 & 186 & 166.5 \\
\hline 45 & 62.9 & 116 & 111.2 & 187 & 167.5 \\
\hline 47 & 63.8 & 118 & 112.6 & 189 & 168.5 \\
\hline 48 & 64.6 & 120 & 114.1 & 191 & 169.5 \\
\hline 50 & 65.6 & 121 & 115.5 & 192 & 170.4 \\
\hline 52 & 66.4 & 123 & 117.0 & 194 & 171.3 \\
\hline 53 & 67.3 & 124 & 118.4 & 195 & 172.2 \\
\hline 55 & 68.2 & 126 & 119.9 & 197 & 173.1 \\
\hline 57 & 69.1 & 128 & 121.3 & 199 & 173.9 \\
\hline 58 & 70.1 & 129 & 122.7 & 200 & 174.8 \\
\hline 60 & 71.0 & 131 & 124.0 & 202 & 175.6 \\
\hline 61 & 72.0 & 132 & 125.4 & 204 & 176.4 \\
\hline 63 & 72.9 & 134 & 126.8 & 205 & 177.2 \\
\hline 65 & 73.9 & 136 & 128.2 & 207 & 178.0 \\
\hline 66 & 74.9 & 137 & 129.6 & 208 & 178.7 \\
\hline 68 & 75.8 & 139 & 131.0 & 210 & 179.5 \\
\hline 69 & 76.8 & 140 & 132.4 & 212 & 180.3 \\
\hline 71 & 77.7 & 142 & 133.7 & 213 & 181.1 \\
\hline $7 \overline{3}$ & 78.7 & 144 & 135.1 & 215 & 181.8 \\
\hline 74 & 79.7 & 145 & 136.4 & 217 & 182.4 \\
\hline 76 & 80.8 & 147 & 137.7 & 218 & 183.2 \\
\hline 78 & 81.8 & 149 & 139.1 & 220 & 183.8 \\
\hline
\end{tabular}


Table A4. Resin Temperature Versus Time Data for Kinetic Auxiliary Tests (Continued)

$$
\begin{array}{r}
\text { Run No. 4D } \quad \text { Beaker Test } \\
\mathrm{T}_{0}=41^{\circ} \mathrm{F} \quad \mathrm{T}_{\mathrm{air}}=40^{\circ} \mathrm{F} \quad \mathrm{T}_{\max }=236^{\circ} \mathrm{F} \\
\mathrm{C}=0.3 \times 10^{-3} \quad \text { Set } \text { Time }=194 \mathrm{~s}
\end{array}
$$

Time(s)

221

223

225

226

228

229

231

233

234
I. $(\cdot F)$ Time(s)

184.6

185.2

185.9

186.5

187.2

187.8

188.4

189.0

189.6

\section{6}

238

239

241

242

244

246

306

366
I ( $P$ F) Time(s)

190.2

190.8

191.4

192.0

192.5

193.1

193.7

209.8

219.4
426

486

546

606

666

726

786

846

906

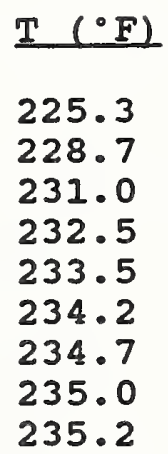

225.3

228.7

231.0

232.5

233.5

234.2

234.7

235.2

$A-51$ 
Table A4. Resin Temperature Versus Time Data for Kinetic Auxiliary Tests (Continued)

$$
\begin{gathered}
\text { Run No. } 1 \mathrm{E} \quad \text { Beaker Test } \\
\mathrm{T}_{0}=91^{\circ} \mathrm{F} \quad \mathrm{T}_{\mathrm{air}}=90^{\circ} \mathrm{F} \quad \mathrm{T}_{\max }=286^{\circ} \mathrm{F} \\
\mathrm{C}=0.4 \times 10^{-3} \quad \text { Set } \mathrm{Time}=45 \mathrm{~s}
\end{gathered}
$$

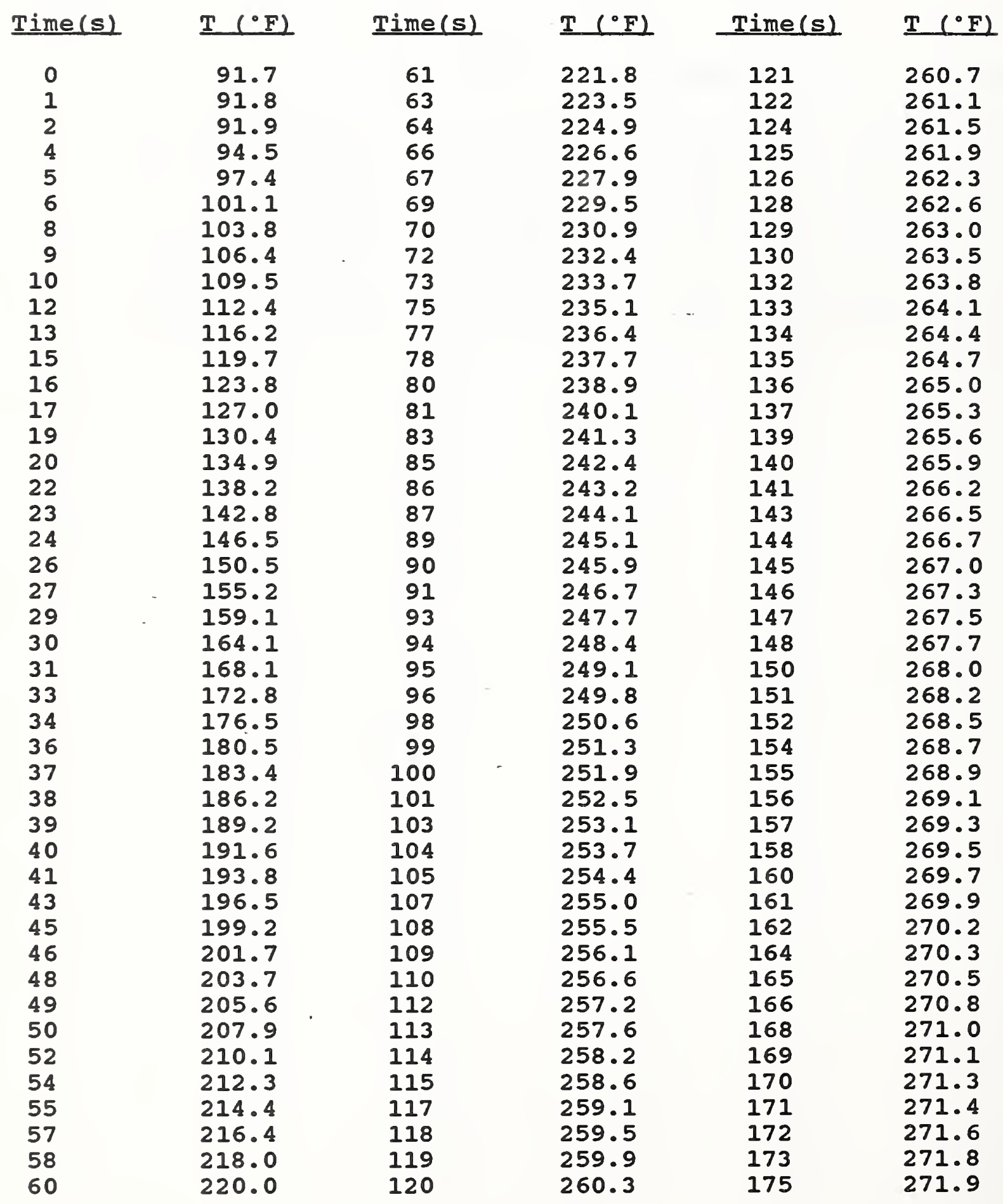


Table A4. Resin Temperature Versus Time Data for Kinetic Auxiliary Tests (Continued)

$$
\begin{gathered}
\text { Run No. IE } \quad \text { Beaker Test } \\
\mathrm{T}_{0}=91^{\circ} \mathrm{F} \quad \mathrm{T}_{\mathrm{air}}=90^{\circ} \mathrm{F} \quad \mathrm{T}_{\max }=286^{\circ} \mathrm{F} \\
\mathrm{C}=0.4 \times 10^{-3} \quad \text { Set } \text { Time }=45 \mathrm{~s}
\end{gathered}
$$

\begin{tabular}{|c|c|c|c|c|c|}
\hline $\operatorname{Time}(\mathrm{s})$ & $T\left({ }^{\circ} \mathrm{F}\right)$ & $\operatorname{Time}(\mathrm{s})$ & $T\left({ }^{\circ} \mathrm{F}\right)$ & Time (s) & $I\left({ }^{\circ} F\right)$ \\
\hline 176 & 272.1 & 201 & 274.8 & 227 & 276.9 \\
\hline 177 & 272.2 & 202 & 274.9 & 228 & 277.0 \\
\hline 178 & 272.4 & 204 & 275.1 & 230 & 277.1 \\
\hline 179 & 272.5 & 205 & 275.1 & 231 & 277.2 \\
\hline 180 & 272.7 & 206 & 275.3 & 232 & 277.2 \\
\hline 182 & 272.8 & 207 & 275.4 & 233 & 277.3 \\
\hline 183 & 273.0 & 209 & 275.5 & 234 & 277.4 \\
\hline 184 & 273.1 & 210 & 275.6 & 236 & 277.5 \\
\hline 186 & 273.3 & 211 & 275.7 & 237 & 277.6 \\
\hline 187 & 273.4 & 212 & 275.8 & 238 & 277.7 \\
\hline 188 & 273.5 & 214 & 276.0 & 240 & 277.8 \\
\hline 190 & 273.7 & 215 & 276.0 & 301 & 280.5 \\
\hline 191 & 273.8 & 216 & 276.1 & 361 & $282 \cdot 2$ \\
\hline 192 & 273.9 & 218 & 276.2 & 421 & 283.4 \\
\hline 193 & 274.1 & 219 & 276.3 & 481 & 284.2 \\
\hline 194 & 274.2 & 220 & 276.4 & 541 & 284.8 \\
\hline 195 & 274.3 & 222 & 276.5 & 601 & 285.2 \\
\hline 197 & 274.4 & 223 & 276.6 & 661 & 285.4 \\
\hline 198 & 274.6 & 224 & 276.7 & 721 & 285.6 \\
\hline 200 & 274.7 & 226 & 276.8 & & \\
\hline
\end{tabular}


Table A4. Resin Temperature Versus Time Data for Kinetic Auxiliary Tests (Continued)

$$
\begin{gathered}
\text { Run No. } 2 \mathrm{E} \quad \text { B ker Test } \\
\mathrm{T}_{0}=91^{\circ} \mathrm{F} \quad \mathrm{T}_{\mathrm{air}}=90^{\circ} \mathrm{F} \quad \mathrm{T}_{\max }=292^{\circ} \mathrm{F} \\
\mathrm{C}=0.7 \times 10^{-3} \quad \text { Set } \mathrm{Time}=27 \mathrm{~s}
\end{gathered}
$$

\begin{tabular}{|c|c|c|c|c|c|}
\hline Time (s) & $\underline{I}\left({ }^{\circ} F\right)$ & $\operatorname{Time}(s)$ & $I\left({ }^{\circ} F\right)$ & Time (s) & $\underline{T}\left({ }^{\circ} \mathrm{F}\right)$ \\
\hline 0 & 92.6 & 51 & 222.2 & 102 & 261.0 \\
\hline 1 & 92.3 & 52 & 223.6 & 103 & 261.5 \\
\hline 2 & 94.1 & 53 & 225.1 & 104 & 262.0 \\
\hline 4 & 97.4 & 54 & 226.4 & 106 & 262.5 \\
\hline 5 & 100.5 & 56 & 227.7 & 107 & 263.0 \\
\hline 6 & 104.9 & 57 & 229.0 & 108 & 263.4 \\
\hline 7 & 107.7 & 58 & 230.2 & 109 & 263.9 \\
\hline 8 & 111.0 & 59 & 231.5 & 110 & 264.3 \\
\hline 9 & 114.4 & 60 & 232.6 & 111 & 264.7 \\
\hline 10 & 118.7 & 61 & 233.8 & 112 & 265.1 \\
\hline 12 & $122 \cdot 3$ & 63 & 234.9 & 114 & 265.5 \\
\hline 13 & 125.5 & 64 & 236.0 & 115 & 265.8 \\
\hline 14 & 129.2 & 65 & 237.1 & 116 & 266.2 \\
\hline 15 & 133.8 & 66 & 238.1 & 117 & 266.6 \\
\hline 16 & 138.0 & 67 & 239.2 & 118 & 266.9 \\
\hline 17 & 143.4 & 68 & 240.2 & 119 & 267.3 \\
\hline 19 & 148.5 & 70 & 241.2 & 121 & 267.6 \\
\hline 20 & 153.8 & 71 & 242.1 & 122 & 268.0 \\
\hline 21 & 158.6 & 72 & 243.1 & 123 & 268.3 \\
\hline 22 & 163.4 & 73 & 244.0 & 124 & 268.6 \\
\hline 23 & 168.0 & 74 & 244.9 & 125 & 268.9 \\
\hline 24 & 172.0 & 75 & 245.7 & 126 & 269.2 \\
\hline 26 & 175.7 & 77 & 246.6 & 128 & 269.5 \\
\hline 27 & 179.0 & 78 & 247.5 & 129 & 269.8 \\
\hline 28 & 182.0 & 79 & 248.2 & 130 & 270.1 \\
\hline 29 & 184.9 & 80 & 249.1 & 131 & 270.4 \\
\hline 30 & 187.5 & 81 & 249.8 & 132 & 270.6 \\
\hline 31 & 190.1 & 82 & 250.6 & 133 & 270.9 \\
\hline 32 & 192.5 & 83 & 251.3 & 135 & 271.2 \\
\hline 34 & 194.9 & 85 & 252.1 & 136 & 271.4 \\
\hline 35 & 197.1 & 86 & 252.8 & 137 & 271.7 \\
\hline 36 & 199.3 & 87 & 253.5 & 138 & 271.9 \\
\hline 37 & 201.4 & 88 & 254.2 & 139 & 272.2 \\
\hline 38 & 203.4 & 89 & 254.8 & 140 & 272.4 \\
\hline 39 & 205.3 & 90 & 255.5 & 141 & 272.6 \\
\hline 41 & 207.2 & 92 & 256.1 & 143 & 272.9 \\
\hline 42 & 209.0 & 93 & 256.7 & 144 & 273.1 \\
\hline 43 & 210.8 & 94 & 257.3 & 145 & 273.3 \\
\hline 44 & 212.6 & 95 & 257.8 & 146 & 273.5 \\
\hline 45 & 214.2 & 96 & 258.4 & 147 & 273.8 \\
\hline 46 & 215.9 & 97 & 259.0 & 148 & 274.0 \\
\hline 48 & 217.6 & 99 & 259.5 & 150 & 274.2 \\
\hline 49 & 219.1 & 100 & 260.0 & 151 & 174.4 \\
\hline 50 & 220.7 & 101 & 260.5 & 152 & 274.6 \\
\hline
\end{tabular}


Table A4. Resin Temperature Versus Time Data for Kinetic Auxiliary Tests (Continued)

Run No. 2E Beaker Test

$$
\begin{gathered}
\mathrm{T}_{0}=91^{\circ} \mathrm{F} \quad \mathrm{T}_{\text {air }}=90^{\circ} \mathrm{F} \quad \mathrm{T}_{\max }=292^{\circ} \mathrm{F} \\
\mathrm{C}=0.7 \times 10^{-3} \quad \text { Set } \mathrm{Time}=27 \mathrm{~s}
\end{gathered}
$$

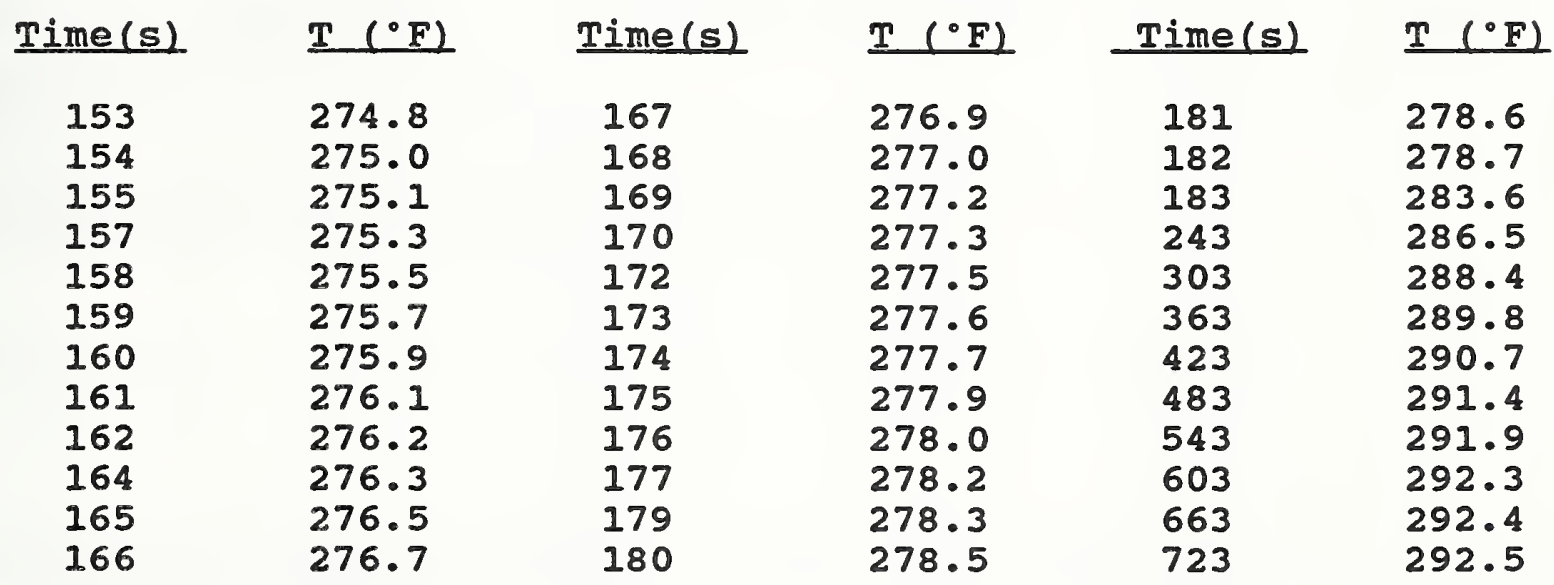

$$
A-55
$$


Table A4. Resin Temperature Versus Time Data for Kinetic Auxiliary Tests (Continued)

Run No. 3E Beaker Test

$$
\begin{array}{cc}
\mathrm{T}_{0}=91^{\circ} \mathrm{F} \quad \mathrm{T}_{\text {air }}=90^{\circ} \mathrm{F} & \mathrm{T}_{\max }=271^{\circ} \mathrm{F} \\
\mathrm{C}=1.3 \times 10^{-3} & \text { Set } \mathrm{Time}=21 \mathrm{~s}
\end{array}
$$

\begin{tabular}{|c|c|c|c|c|c|}
\hline Time (s) & $T\left({ }^{\circ} F\right)$ & Time (s) & $T\left({ }^{\circ} \mathrm{F}\right)$ & Time (s) & $\mathrm{T}\left({ }^{\circ} \mathrm{F}\right)$ \\
\hline 0 & 91.7 & 43 & 225.0 & 85 & 255.4 \\
\hline 1 & 94.6 & 44 & 226.2 & 86 & 255.9 \\
\hline 2 & 99.6 & 45 & 227.5 & 87 & 256.3 \\
\hline 3 & 105.7 & 46 & 228.7 & 88 & 256.7 \\
\hline 4 & 111.6 & 47 & 229.9 & 89 & 257.1 \\
\hline 6 & 118.5 & 48 & 230.9 & 90 & 257.6 \\
\hline 7 & 124.8 & 50 & 232.2 & 91 & 258.0 \\
\hline 8 & 131.2 & 51 & 233.2 & 93 & 258.3 \\
\hline 9 & 138.8 & 52 & 234.3 & 94 & 258.7 \\
\hline 10 & 144.9 & 53 & 235.3 & 95 & 259.1 \\
\hline 11 & 151.6 & 54 & 236.3 & 96 & 259.4 \\
\hline 12 & 159.3 & 55 & 237.3 & 97 & 259.8 \\
\hline 14 & 166.6 & 56 & 238.3 & 98 & 260.1 \\
\hline 15 & 173.6 & 57 & 239.2 & 100 & 260.4 \\
\hline 16 & 177.9 & 58 & 240.1 & 101 & 260.7 \\
\hline 17 & 182.5 & 59 & 241.0 & 102 & 261.0 \\
\hline 18 & 186.3 & 60 & 241.9 & 103 & 261.3 \\
\hline 19 & 189.1 & 61 & 242.7 & 104 & 261.6 \\
\hline 21 & 191.4 & 62 & 243.6 & 105 & 261.9 \\
\hline 22 & 193.7 & 64 & 244.3 & 107 & 262.1 \\
\hline 23 & 195.9 & 65 & 245.1 & 108 & 262.4 \\
\hline 24 & 198.0 & 66 & 245.9 & 109 & 262.6 \\
\hline 25 & 200.1 & 67 & 246.6 & 110 & 262.9 \\
\hline 26 & 202.1 & 68 & 247.3 & 111 & 263.1 \\
\hline 28 & 204.0 & 69 & 248.0 & 112 & 263.3 \\
\hline 29 & 205.9 & 71 & 248.7 & 114 & 263.6 \\
\hline 30 & 207.7 & 72 & 249.3 & 115 & 263.8 \\
\hline 31 & 209.5 & 73 & 249.9 & 116 & 264.0 \\
\hline 32 & 211.3 & 74 & 205.6 & 117 & 264.2 \\
\hline 33 & 212.9 & 75 & 251.2 & 118 & 264.4 \\
\hline 35 & 214.6 & 76 & 251.8 & 119 & 264.6 \\
\hline 36 & 216.1 & 78 & 252.4 & 120 & 264.8 \\
\hline 37 & 217.7 & 79 & 252.9 & 182 & 269.9 \\
\hline 38 & 219.2 & 80 & 253.5 & 242 & 271.0 \\
\hline 39 & 220.7 & 81 & 253.9 & 302 & 271.0 \\
\hline 40 & 222.2 & 82 & 254.5 & 362 & 271.6 \\
\hline 41 & 223.6 & 83 & 255.0 & & \\
\hline
\end{tabular}


NIST-114A

(REV. 3-89)
U.S. DEPARTMENT OF COMMERCE NATIONAL INSTITUTE OF STANDARDS AND TECHNOLOGY

\section{BIBLIOGRAPHIC DATA SHEET}

1. PUEUCATION OR REPORT MUMBER

NISTIR $89-4026$

2. PERFORMIMO ORGANIZATION AEPORT MUMBER

3. PUBLCATION DATE

SEPTEMBER 1989

4. TITLE AHD SUETTIE

Set Time Control Studies of Polymer Concrete

5. AUTHOR(S)

Robert G. Mathey and James Pommersheim

6. PERFOAMINO ORQANIZATION (IF JOINT OR OTHER THAN NIST, SEE INSTAUCTIONS) U.S. DEPARTMEMT OF COMMERCE

MATTONAL INSTITUTE OF STANDARDS AND TECHNOLOQY

CarTHERSEUNG, MD 20899

7. CONTRACT/ORANT MUMBER

8. TYPE OF REPORT AND PERIOD COVERED

9. SPONSORINO ORQAMIZATION NAME AND COMPLETE ADDRESS (STREET, CITY, STATE, ZIP)

Air Force Engineering and Services Center

Tyndall Air Force Base, FL 32403-8001

10. SUPPLEMENTAAY NOTES

DOCUMEMT DESCRIBES A COMPUTER PROGRAM; SF-185, FIPS SOFTWARE SURMARY, IS ATTACMED.

11. AESTRACT (A 200-WORD OR LESS FACTUAL SUMMARY OF MOST SIGNIFICANT IMFORMATION. IF DOCUMENT INCLUDES A SIGHIFICANT BIBLOORAPHY OR LTERATURE SURVE. MENTION IT HERE.I

Set time data were obtained for polymer concrete made with a proprietary polyurethane resin for a wide range of aggregate and resin temperatures. Catalyst concentrations were adjusted so that setting occurred within a required time range. The effects of the presence of water and ice on set time were also studied. Set time data were also obtained from pilot tests using another polyurethane and catalyst for various aggregate and resin temperatures and moisture conditions. Considerably more catalyst was required in the pilot tests to obtain comparable set times. The impact of temperature variations on flexural strength was investigated. The flexural strength and failure mechanism at early ages depended on the temperature of aggregate and resin at the time of casting the polymer concrete.

A model for the prediction of set time of polymer concrete was developed based upon thermodynamic and kinetic principles. The model parameters were determined experimentally from auxiliary laboratory tests conducted separately from the set time tests. Reasonable agreement was found between the model and the data from the set time tests since observed set times and resin temperatures generally agreed with those predicted by the model. Using the model, a series of design charts were prepared which can be used to predict set time when catalyst concentration and inttial aggregate and resin temperatures are given, or to determine the catalyst concentration needed to assure set time corresponding to specified aggregate and resin temperatures.

12. KEY WORDS (6 TO 12 ENTRIES; ALPHABETICAL ORDER; CAPITALIZE ONLY PROPER MAMES; AND SEPARATE KEY WORDS QY SEMICOLONS)

aggregate; flexural strength; heat transfer; model; peak exotherm; polymer concrete; polyurethane; rapid repair; set time; set time prediction model

13. AVALABIUTY

\section{UNUMTED}

FON OFFICLAL DISTRIBUTION. DO NOT RELEASE TO MATIONAL TECHNICAL INFORMATION SERVICE (NTIS).

ORDER FMOM SUPERINTENDENT OF DOCUMENTS, U.S. GOVERNMENT PRINTING OFFICE, WASMINGTON, DC 20402.

ORDER FROM MATIONAL TECHMICAL INFORMATION SERVICE (MTIS), SPRIMGFIED, VA 22161.
14. NUMEER OF PRINTED PACES

$$
194
$$

15. PRICE

A09 

